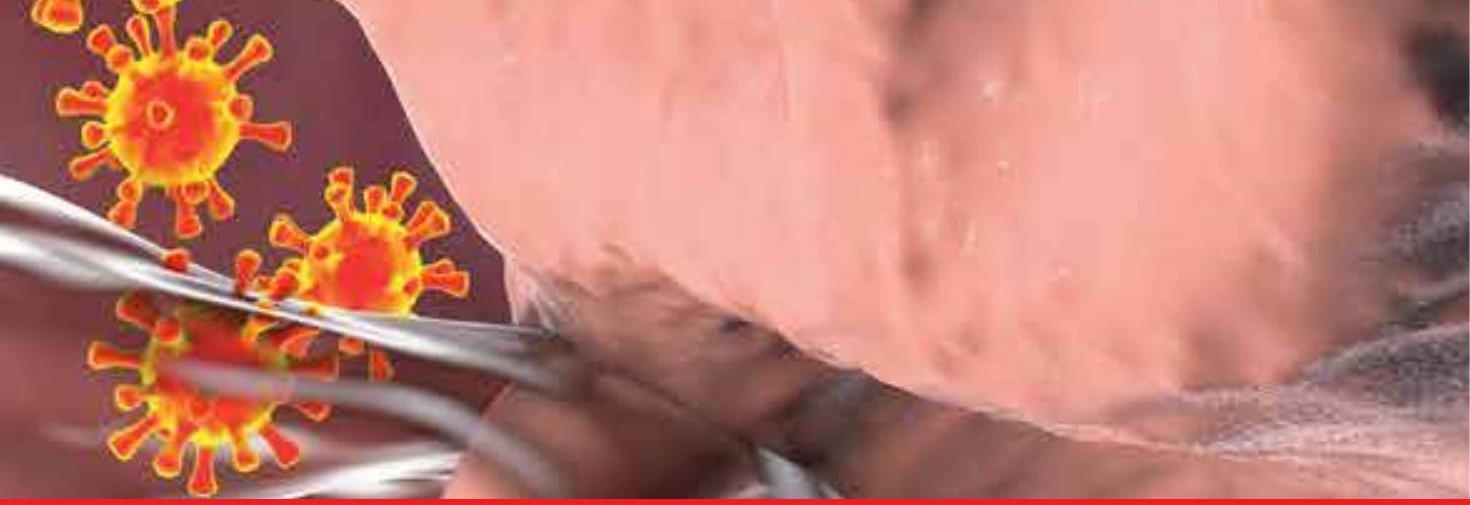

\title{
IntechOpen
}

\section{Male Reproductive Health}

Edited by Wei Wu, Francesco Ziglioli

and Umberto Maestroni
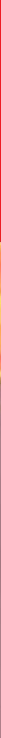



\section{Male Reproductive Health}

Edited by Wei Wu,

Francesco Ziglioli and Umberto Maestroni 

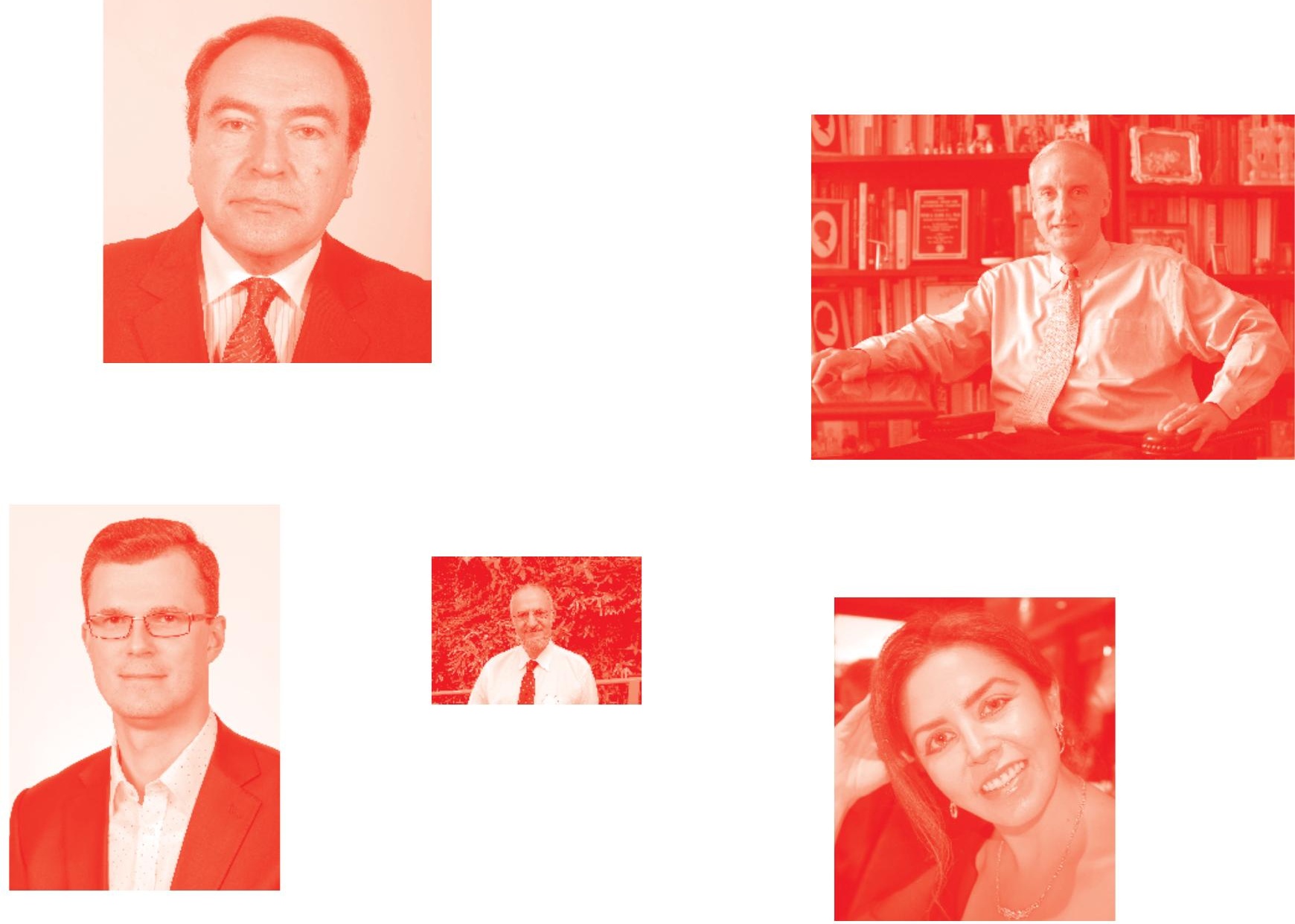

Supporting open minds since 2005
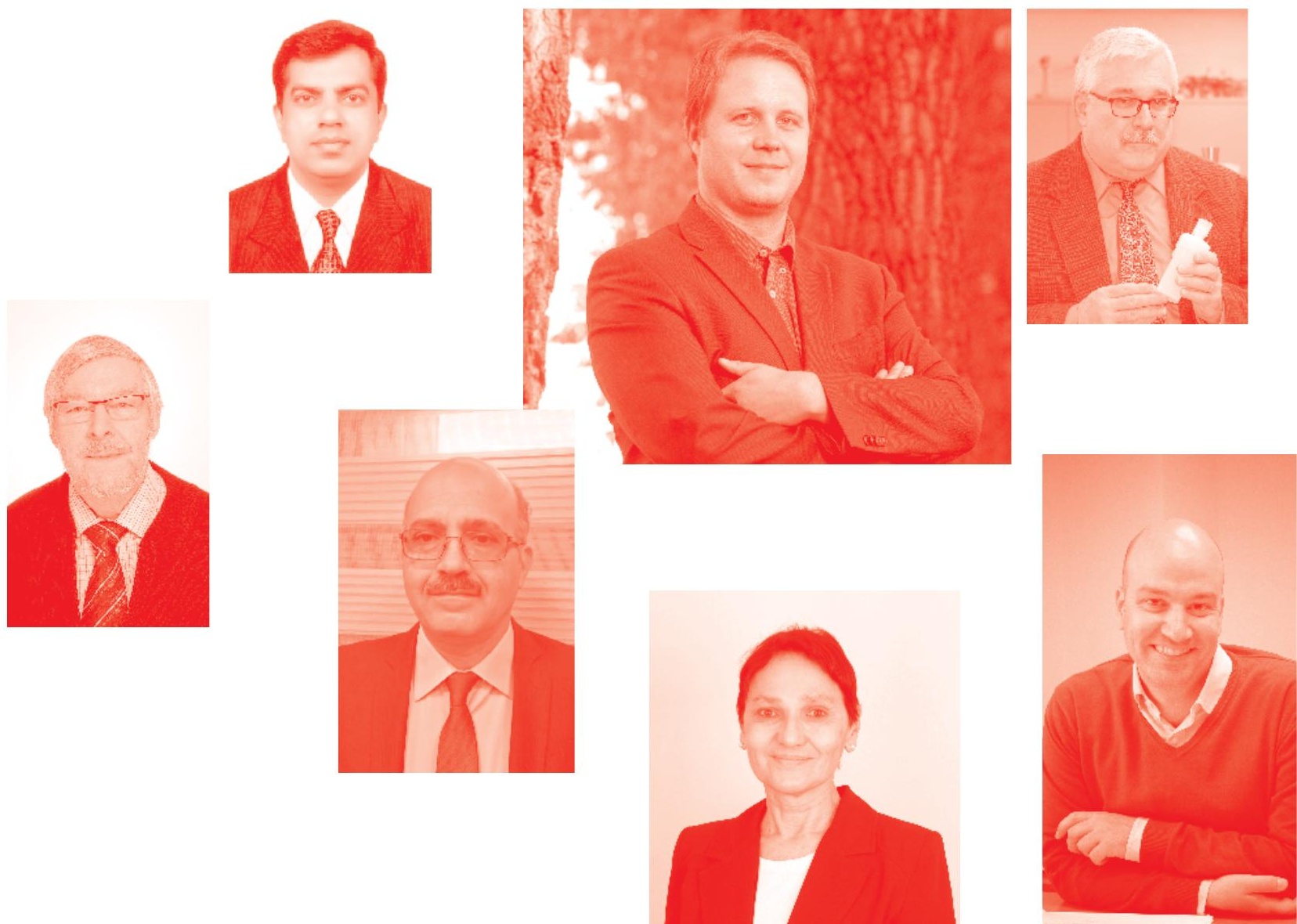
Male Reproductive Health

http: //dx. doi.org/10.5772/intechopen. 77761

Edited by Wei Wu, Francesco Ziglioli and Umberto Maestroni

\section{Contributors}

Nguyen Thi Trang, Vu Thi Huyen, Rajalakshmi Manikkam, Indu Sabapathy, Andrea Benelli, Chiara Vaccaro, Sonia Guzzo, Virginia Varca, Andrea Gregori, Mauro Luis Barbosa Júnior, Ericka Kirsthine Valentin, Karoline Camargo Bragante, Marta Dąbrowska-Bender, Robert Słoniewski, Anna Staniszewska, Serife Zehra Altunkurek, Daishu Han, Fei Wang, Ilyas Kairgaliyev, Amin Tamadone, Ulanbek Zhan-Byrbekuly, Arezoo Khoradmehr, Michal Jeseta, Jan Nevoral, Maria Teresa Herdeiro, Margarida Fardilha, Magda Henriques, Susana Loureiro, Nicola Zampieri, Federica Bianchi, Simone Patanè, Elettra Vestri, Francesco Camoglio, Roger Hart, Jenni Pontre

( ) The Editor(s) and the Author(s) 2020

The rights of the editor(s) and the author(s) have been asserted in accordance with the Copyright, Designs and Patents Act 1988. All rights to the book as a whole are reserved by INTECHOPEN LIMITED. The book as a whole (compilation) cannot be reproduced, distributed or used for commercial or non-commercial purposes without INTECHOPEN LIMITED's written permission. Enquiries concerning the use of the book should be directed to INTECHOPEN LIMITED rights and permissions department (permissions@intechopen.com).

Violations are liable to prosecution under the governing Copyright Law .

\section{(cc) BY}

Individual chapters of this publication are distributed under the terms of the Creative Commons Attribution 3.๑ Unported License which permits commercial use, distribution and reproduction of the individual chapters, provided the original author(s) and source publication are appropriately acknowledged. If so indicated, certain images may not be included under the Creative Commons license. In such cases users will need to obtain permission from the license holder to reproduce the material. More details and guidelines concerning content reuse and adaptation can be found at http : //www . intechopen . com/copyright-policy . html .

\section{Notice}

Statements and opinions expressed in the chapters are these of the individual contributors and not necessarily those of the editors or publisher. No responsibility is accepted for the accuracy of information contained in the published chapters. The publisher assumes no responsibility for any damage or injury to persons or property arising out of the use of any materials, instructions, methods or ideas contained in the book.

First published in London, United Kingdom, 2020 by IntechOpen IntechOpen is the global imprint of INTECHOPEN LIMITED, registered in England and Wales, registration number: 11086078 , 7th floor, 10 Lower Thames Street, London,

EC3R 6AF, United Kingdom

Printed in Croatia

British Library Cataloguing-in-Publication Data

A catalogue record for this book is available from the British Library

Additional hard and PDF copies can be obtained from orders@intechopen.com

Male Reproductive Health

Edited by Wei Wu, Francesco Ziglioli and Umberto Maestroni

p. cm.

Print ISBN 978-1-78985-647-7

Online ISBN 978-1-78985-648-4

eBook (PDF) ISBN 978-1-78923-805-1 


\section{We are IntechOpen, \\ the world's leading publisher of Open Access books}

\section{Built by scientists, for scientists}

\section{$4,600+$}

Open access books available

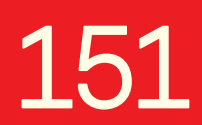

Countries delivered to

\section{$120,000+$}

International authors and editors

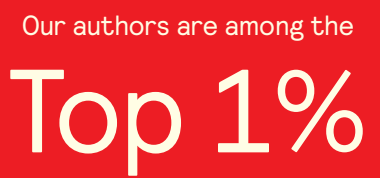

most cited scientists

Contributors from top 500 universities
$135 \mathrm{M}+$

Downloads
$12.2 \%$

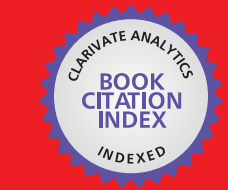

WEB OF SCIENCE ${ }^{\text {M }}$

Selection of our books indexed in the Book Citation Index in Web of Science ${ }^{\mathrm{TM}}$ Core Collection (BKCI)

\section{Interested in publishing with us? \\ Contact book.department@intechopen.com}

Numbers displayed above are based on latest data collected.

For more information visit www.intechopen.com 



\section{Meet the editors}

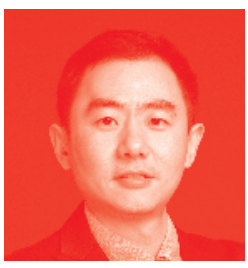

Dr. Wei Wu is an associate professor and associate department chair in the Department of Toxicology at Nanjing Medical University, China. He was a guest researcher at the NIEHS between 2017 and 2018. He has authored 70 peer-reviewed papers in international journals such as Environment International, EBioMedicine, Clinical Epigenetics, and Human Reproduction. He has edited two books and collaborated on eight books, 13 patents, and the organization of three international conferences. He is a reviewer of 71 journals. He serves as the editor-in-chief of International Journal of Sexual Health and Reproductive Health Care, executive editor of Annals of Molecular and Genetic Medicine, and editor of many other journals, including Scientific Reports and Journal of Experimental and Clinical Toxicology.

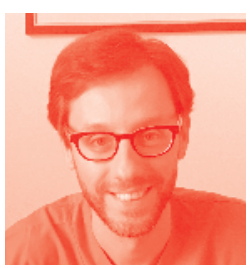

Francesco Ziglioli graduated at the University of Pavia (Italy) in 2006 and completed his residency in urology in 2012 at the University-Hospital of Parma (Italy). After a job experience as a urologist in the United Kingdom, he attended a fellowship in laparoscopy and robotic surgery at the Saint-Augustin Clinic in Bordeaux (France) in 2016. He works as a urologist at the Department of Urology at the University-Hospital of Parma. He is a Fellow of the European Board of Urology. He is a member of the editorial board of three international journals and has published mainly in the field of prostate and kidney cancer.

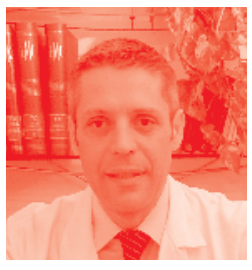

Umberto Maestroni graduated at the University of Bologna (Italy) in 1996 and completed his residency in general surgery at the University of Ferrara (Italy) in 2001 and in urology at the University of Parma (Italy) in 2007. He has been a rotating resident at the Department of Surgery, Division of Endoscopic Surgery at the Cedars-Sinai Medical Center in Los Angeles (1999). He is the Director of the Department of Urology at the University-Hospital of Parma (Italy). He is a member of the editorial board of three international journals and has published mainly in the field of prostate cancer and other urologic diseases and treatments. 



\section{Contents}

Preface

Section 1

Male Infertility Risk Factors and Therapy

Chapter 1

The Early Life Influences on Male Reproductive Health

by Jennifer Pontré and Roger Hart

Chapter 2

The Role of Endocrine-Disrupting Chemicals in Male Fertility Decline by Magda Carvalho Henriques, Susana Loureiro, Margarida Fardilha and Maria Teresa Herdeiro

Chapter 3

Endocrine Disruptors: Very Low Doses with Genuinely High Impacts on Male Reproduction

by Michal Ješeta and Jan Nevoral

Chapter 4

Infertility Worldwide: The Lack of Global Pediatric Andrologists and Prevention

by Zampieri Nicola, Bianchi Federica, Patanè Simone, Vestri Elettra and Camoglio Francesco Saverio

Chapter 5

Sertoli Cell Phagocytosis: An Essential Event for Spermatogenesis by Fei Wang and Daishu Han

Chapter 6

Polymorphism of Xenobiotic Detoxification Genes and Male Infertility by Nguyen Thi Trang and Vu Thi Huyen

Mesenchymal Stem Cell Therapy of Male Infertility by Amin Tamadon, Ulanbek Zhan-byrbekuly, Ilyas Kairgaliyev and Arezoo Khoradmehr 
Section 2

Testicular Cancer and Prostate Cancer

Chapter 8

Testicular Cancer and the Importance of Early Diagnosis

by Serife Zehra Altunkurek

Chapter 9

The Role of MRI-TRUS Fusion Biopsy in the Diagnosis of Clinical

Significant Prostate Cancer (CsPca)

by Benelli Andrea, Vaccaro Chiara, Guzzo Sonia, Varca Virginia

and Gregori Andrea

Chapter 10

The Pelvic Health Physical Therapy and the Prostatectomy

by Mauro Luis Barbosa Junior, Ericka Kirsthine Valentin

and Karoline Camargo Bragante

Chapter 11

Combinatorial Drug Therapy with Phytochemicals as Adjuvants in

Prostate Cancer Management

by Rajalakshmi Manikkam and Indu Sabapathy

Chapter 12

Sexual and Psychoemotional Disorders in Male Patients Treated for Prostate Carcinoma

by Marta Dąbrowska-Bender, Robert Stoniewski, Urszula Religioni, Anna Stoniewska, Anna Staniszewska, Karolina Jabtkowska-Górecka, Magdalena Milewska, Adrianna Sobol and Anna Kupiecka 


\section{Preface}

Male reproductive health is an important area affecting men's overall health and well-being. Over the last few decades, there has been increasing concern regarding human male reproductive health. Estimates report that about one in three males suffers from andrological diseases. Infertility is a worldwide problem that affects approximately $15 \%$ of married couples. Half of these cases can be traced to male partners. Several risk factors have been identified that may have a negative impact on men's reproduction health, such as endocrine-disrupting chemicals. There is also evidence that endocrine-disrupting chemical exposure has multigenerational and transgenerational effects on reproductive disease. Infertile men are at an elevated risk of cancer development later in life, primarily genitourinary malignancies such as testicular and prostate cancer. This book will focus on male reproductive health, from the aspects of semen quality, male infertility, testicular cancer, and prostate cancer, and their detection, diagnosis, treatment, and prevention.

Section 1 discusses male infertility risk factors and therapy. The seven chapters of this section cover the potential early life causes of male infertility, effects of endocrine-disrupting chemicals in the male reproductive system and the decline of male fertility, evidence for the developmental programming of male reproductive maturation and function, mechanisms of Sertoli cell phagocytosis in spermatogenesis, polymorphism of xenobiotic detoxification genes and male infertility, and mesenchymal stem cell therapy of male infertility.

Section 2 discusses testicular cancer and prostate cancer. The five chapters in this section cover testicular cancer and its early diagnosis, the role of MRI-TRUS fusion biopsy in the diagnosis of clinically significant prostate cancer, pelvic health physical therapy and prostate cancer, combinatorial drug therapy with phytochemicals as adjuvants in prostate cancer management, and sexual and psychoemotional disorders in male patients treated for prostate carcinoma.

Many individuals have made this book a reality. Its completion would not have been possible without the efforts of numerous contributors. I would like to thank Ms. Dolores Kuzelj and Ms. Andrea Koric at IntechOpen for their strong support from inception to completion of this book. I would also like to acknowledge my coeditors and coauthors for their efforts.

Wei Wu

Department of Toxicology, School of Public Health, Nanjing Medical University, 
Francesco Ziglioli and Umberto Maestroni

Department of Urology,

University-Hospital of Parma,

Parma, Italy 
Section 1

Male Infertility Risk Factors and Therapy 



\title{
Chapter 1
}

\section{The Early Life Influences on Male Reproductive Health}

\author{
Jennifer Pontré and Roger Hart
}

\begin{abstract}
Increasing concern exists regarding male reproductive health worldwide. This is due to the appearance of medical reports outlining apparent adverse trends, such as a worldwide decline in total fertility rate, and an increase in testicular disorders such as testicular cancer, cryptorchidism -in parallel with a probable decline in semen quality. This is of particular concern as there is evidence to suggest that a poor sperm count is potentially associated with overall lifelong morbidity and mortality, and is effectively a predictor of lifelong health risk. This chapter examines the evidence for this decline and its potential early life causes, from in-utero exposures to childhood development.
\end{abstract}

Keywords: male reproduction health, sperm, testosterone, in-utero, phthalate, BPA

\section{Introduction}

Between 1986 and 1993, British physician and epidemiologist David Barker published a series of articles in the Lancet, proposing his hypothesis of the foetal origins of adult health and disease [1-3]. In these publications, he argued that adverse alterations in the developmental early life environment in utero, had potential to induce and initiate phenotypic and adaptive changes affecting an individual's responses to their later life environment, which might prove maladaptive when the early and late environments were markedly different $[4,5]$. Barker's specific foetal concerns were inadequate nutrition, [6] intrauterine growth retardation, low birth weight and premature birth and their causal relationship to the origins of hypertension, coronary heart disease and non-insulin-dependent diabetes, in later life [7]. However there is now growing evidence to suggest that this 'developmental programming' and the foetal environment, which includes placental function, maternal metabolism, exposures and lifestyle factors (including maternal smoking), may influence additional systems including reproductive health and development in both males and females [5, 8].

Increasing concern exists regarding male reproductive health worldwide due to the appearance of medical reports outlining apparent adverse trends, in the context of a worldwide decline in total fertility rate (Figure 1) $[9,10]$. This includes an increase in the incidence of the proposed 'testicular dysgenesis syndrome' [10] which encompasses a constellation of testicular disorders including testicular cancer, [11,12] cryptorchidism and hypospadias [13]. This is in parallel with population-based evidence to suggest declining semen quality, [14] alterations in serum testosterone levels and a change in the timing of onset of male puberty [9]. Worryingly, one comprehensive review of the literature proposed that semen quality had declined by 52.4\% between 1973 and 2011 among unselected men from Western countries [14]. Another recent report, published 


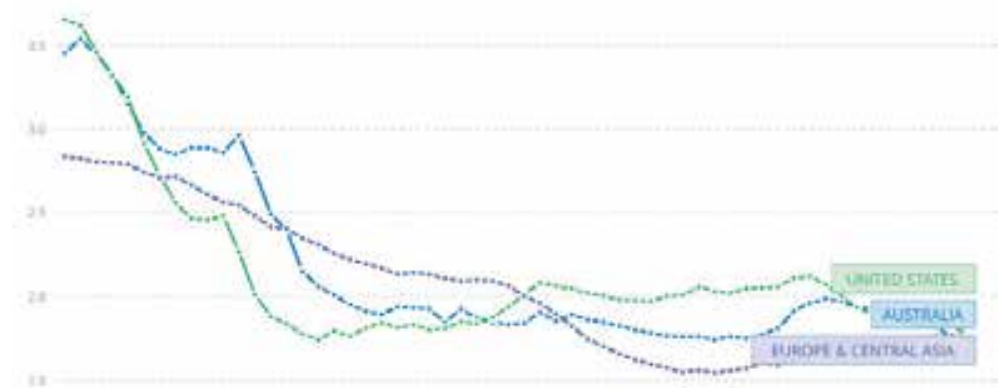

$1960-2017$

Figure 1.

Total fertility rates for Australia, United States, Europe and Central Asia 1960-2017. Reprinted with permission from the World Bank: www.worldbank.org.

in 2015, found that a high proportion of healthy, unselected 20-year-old Caucasian men displayed suboptimal semen quality which did not meet the lower limit of World Health Organization reference ranges for sperm concentration, motility and morphology values [15]. These findings were echoed by a further Swiss study published in 2019 where over $60 \%$ of participants displayed suboptimal median sperm concentration [12]. Sperm count is of obvious importance in fertility and reproduction, however recent studies have now demonstrated that poor sperm count is potentially associated with overall lifelong morbidity and mortality, and is effectively a 'canary in the mine' marker for lifelong health risk [14, 16-18]. To elicit a greater understanding of the early life influences on these important, early determinants of male reproduction and health are therefore of great importance.

In this chapter, we present and discuss the evidence for the developmental programming of male reproductive maturation and function.

\section{Male reproductive development}

Male reproductive development has a long time to maturation, with onset in the embryo and completion in puberty. The critical and narrow prenatal window for the normal differentiation and growth of male reproductive tissue during which testosterone and its potent metabolite dihydrotestosterone, (DHT) masculinise the male foetus is estimated to be around 8-14 weeks of gestation [19-21]. The formation of the indifferent bipotential gonad occurs between the fourth and sixth weeks of foetal life, and male reproductive development subsequently begins when the SRY gene, encoding a 'testis-determining factor' on the Y chromosome stimulates the development of the primitive sex cords to form the medullary cords. Sertoli cells appear, and in the eighth week, Leydig cells appear and commence production of testosterone. In the presence of this testosterone, the mesonephric ducts develop to form the primary male genital ducts. They give rise to the efferent ductules, epididymis, vas deferens and seminal vesicles, whilst the paramesonephric ducts degenerate. Meanwhile, in the presence of DHT, the male external genitalia differentiate as the genital tubercle elongates to become the phallus and the urethral folds close over, forming the penile urethra. 
The hypothalamic-pituitary-gonadal axis is active in the mid-gestational foetus, but silenced towards the end of gestation. This restraint is removed at birth, leading to reactivation of the axis and an increase in serum gonadotropin concentrations, often labelled the 'mini-puberty' [22, 23]. Testosterone concentration rises to a peak at age 1-3 months, but then falls in conjunction with the falling luteinising hormone (LH) concentration [22]. Prenatal and postnatal activation of the hypothalamicpituitary-gonadal axis is associated with penile and testicular growth and testicular descent, and is therefore regarded as important for the development of male genitalia. These concentrations then gradually decrease towards age 6 months when there is an active inhibition of gonadotrophin-releasing hormone ( $\mathrm{GnRH})$ secretion, which persists throughout childhood, [22, 24] and the hypothalamic-pituitarygonadal axis remains quiescent until puberty.

\section{Male pubertal development}

Male puberty marks the transitional period during which the infantile boy attains adult reproductive capacity with usual age of onset around 11.5 years.

Pubertal development of secondary sexual characteristics is initiated, at least in part, by a sustained increase in pulsatile release of $\mathrm{GnRH}$ from the hypothalamus. There is testicular growth as the seminiferous tubules are stimulated by folliclestimulating hormone (FSH), and once their volume exceeds 3-4 ml pubertal onset is confirmed. Leydig cells, stimulated by $\mathrm{LH}$, produce testosterone which influences penile growth and pubic hair development. Spermatogenesis occurs under the regulation of multiple endocrine and local factors [9]. Although the exact mechanisms underlying the commencement of puberty in both males and females is unclear, there is evidence for influence of a multitude of factors including genetic, environmental factors, body composition, physical fitness, nutritional and socioeconomic status, ethnicity, residence and exposure to endocrine disrupters [25]. Other important stimulatory and inhibitory pathways involving glutamate kisspeptin and the $\mathrm{G}$ protein-coupled receptor GPR54 exist [26, 27].

In essence, the increase of pulsatile $\mathrm{GnRH}$ secretion at puberty represents the cumulative effect of highly complex and intricate hypothalamic interactions that are markedly influenced by genetic factors and environmental signals [26]. An advancement in the timing of puberty has been reported worldwide over the past two decades [28]. The timing of puberty has important public health ramifications because it is related to a number of health outcomes [29]. Early puberty is potentially associated with increased risk of testicular cancer, as well as adolescent alcohol abuse, smoking, drug use, early sexual debut, sexually transmitted infections, aggressive behaviour and poor academic performance $[15,30]$. These observations urge further study of the onset of puberty as a possible sensitive and early marker of the interactions between environmental conditions and genetic susceptibility that can influence physiological and pathological processes [25].

\section{Potential influences of male reproductive development and pubertal development}

\subsection{Placental malfunction and antenatal factors}

Impaired placental malfunction, which has the potential to disrupt foetal androgen production, has been theorised to affect male reproductive development, and a definite link between impaired foetal growth and reproductive function has been 
established. Consequences on gonadal differentiation, sexual organ development, onset of puberty, gamete quality, hormonal status and fertility have been observed $[31,32]$. Several studies have described an association between foetal growth restriction and an increased risk of male reproductive health problems, including hypospadias, cryptorchidism and testicular cancer $[13,33,34]$. In addition, twin or triplet pregnancy and preterm birth have also been shown to be associated with non-gestational-related impaired reproductive development [35]. One study demonstrated an inverse relationship between the incidence of cryptorchidism, and decreasing gestational age at birth, suggesting that premature delivery is important in view of the timing of testicular descent in foetal life [36]. A strong association between low birth weight and hypospadias has been demonstrated [37, 38].

Increasing birth weight in males has also been shown to be positively correlated with adult serum testosterone levels, however no effect on other reproductive hormone levels has been shown [39]. Adult men born with lower birth weights have, in another study, been shown to display features of hypogonadism, with reduced testicular size, lower testosterone levels and higher LH values, than controls born with appropriate weights [39]. Male children with early onset of their pubertal growth spurt are more likely to have been born underweight [40]. In a cohort of Australian men followed from birth, men born with gestational appropriate birth weights were significantly less likely to be grouped in the lowest quartile for their total motile sperm counts. Those men who were born preterm demonstrated reduced serum testosterone levels in adulthood, suggesting an adverse influence of growth restraint and prematurity on later life testicular function [41]. A prospective Danish birth cohort study of more than 2500 live born males found statistically significant associations between cryptorchidism and low birth weight, prematurity, being small for gestational age, substantial vaginal bleeding in pregnancy and breech presentation, which is in accordance with other studies [42].

\subsection{Maternal medical complications of pregnancy}

Abnormal maternal glucose metabolism in pregnancy may be associated with an increased risk of genital malformation for the male offspring [8, 43]. In women with gestational diabetes, the risk of delivering a male infant with cryptorchidism is increased by a factor of four compared to women without diabetes [43]. It is postulated that early growth delay of the foetus in the first trimester might play a role. This early failure of normal growth has been demonstrated even in children of diabetic mothers who are ultimately born large for gestational age [44]. The evidence is conflicting however, as no association between gestational diabetes and cryptorchidism was found in another registry-based study from Israel [45]. Maternal hypertension during pregnancy and preeclampsia are associated with hypospadias and other genital malformations, $[37,46]$ suggesting that placental insufficiency may play an important role in male foetal genital development.

\subsection{Maternal undernutrition}

The 5 month Dutch Winter Hunger Famine in 1944 gave rise to the suggestion that maternal nutrient restriction may play a role in determination of subsequent pathologic outcomes $[47,48]$. This relationship has been demonstrated in several animal models [49-51]. Whilst the exact mechanism is unknown, it is theorised that maternal nutrient restriction might reprogram the development of the pituitary-adrenal axis, alter the male pituitary response to $\mathrm{GnRH}$, lead to excess glucocorticoid exposure and thus exert an adverse effect on gonadal development and function [49]. This may vary according to the timing and magnitude of the 
undernutrition. More studies in both humans and animals are required to further explore the effect of maternal undernutrition during the critical programming window in the foetus [50].

\subsection{Maternal obesity}

The prevalence of overweight and obese individuals in their reproductive years is increasing worldwide, and there is an established link between obesity and reduced fecundity in men and women [52]. Maternal obesity (and potentially paternal obesity around the time of conception) creates an adverse intrauterine environment for the developing foetus, and may have a detrimental reprogramming effect on offspring $[52,53]$. Maternal obesity may alter the molecular composition of gametes, leading to epigenetic changes which impair the developmental trajectory of the resultant embryo and of future generations [32]. In male rats, maternal obesity during pregnancy and lactation has been shown to increase testicular and sperm oxidative stress leading to premature ageing of reproductive capacity [54]. In humans, one epidemiologic study reported a detrimental influence of high maternal body mass index (BMI) on the semen quality and plasma concentration of inhibin B of male offspring, [31, 52] a finding confirmed by other studies [52]. The exact processes through which maternal nutrition or maternal environment affect reproductive function in the offspring remain unclear, and may be due to an alteration of oestrogen exposure with the hormonal control of the development of the male foetal urogenital organs. Epigenetic modifications are also a clear link [31].

\subsection{Maternal smoking}

Exposure to cigarette smoking in utero has consistently been shown to negatively impact on male reproductive development, and in fact maternal smoking exposure during pregnancy may have a stronger effect on subsequent spermatogenesis than a man's own smoking in later life [8]. Reductions in median sperm output and total motile sperm are evident, and substantial [41]. One Danish cross-sectional study showed maternal smoking during pregnancy to be associated with earlier onset of puberty, lower final adult height, higher BMI, reduced testicular volume, lower total sperm count, reduced spermatogenesis-related hormones (inhibin-B and FSH) and higher free testosterone [55]. Likewise, a study of 1770 young men from the general population in Denmark, Norway, Finland, Lithuania and Estonia reported that maternal smoking during pregnancy was associated with a $20 \%$ reduction in sperm concentration $[8,56]$.

The effect of prenatal exposure to maternal cigarette smoke has been evaluated in another study where human gonadal cell numbers were examined by histopathological analysis following first trimester termination of pregnancy. A significant reduction in the number of germ cells and somatic cells in embryonic male (and female) gonads and the effect was dose dependent in heavy smokers [57].

\subsection{Maternal gestational stress}

Maternal exposure to stress in pregnancy has been shown to be a significant determinant of male reproductive development later in life. One prospective longitudinal cohort study examined this association in almost 650 males at 20 years of age. Maternal gestational stress, measured by exposure to stressful life events in early gestation was associated with lower total sperm counts, reduced number of progressive motile sperm and lower morning serum testosterone concentration. There was no effect of stressful events in late pregnancy (beyond 18 weeks' 
gestation), in keeping with the proposed early foetal masculinisation programming window [19]. This is in keeping with animal models reported previously [58]. It is unclear as to the mechanism of impact, however it is theorised that alterations in cortisol levels within the critical window of programming and development of the male reproductive organs may be responsible [59].

\subsection{Maternal serum oestrogens}

A relationship between increasing incidence of disorders of development of the male reproductive tract, declining sperm counts and exposure to exogenous oestrogen in utero has been postulated for many years [53]. Animal studies have previously shown that exposure to exogenous oestrogens $[60,61]$ and environmental xenoestrogens $[61,62]$ can damage testicular function, however concern that ubiquitous and increasing global oestrogen pollution may have effect on testicular function have so far been unconfirmed by the lack of alteration in domestic animal sperm production over the past century $[41,63]$. Hence this view does have its detractors [64]. The first study to formally examine the association of maternal oestrogen exposure on male reproductive development was a longitudinal cohort study of almost 400 adult males. It found that sperm output in adulthood was inversely correlated with cord serum oestradiol and oestrone [41]. Furthermore it has been reported that oestrogenic chemical exposure can also cause cryptorchidism [9]. It has been suggested that endogenous oestrogens may inhibit the hypothalamicpituitary-gonadal axis via steroid negative feedback to reduce $\mathrm{LH}$ secretion, which may lead to a reduction in intra-testicular testosterone during the crucial window of development and programming in the male foetus [41]. A vegetarian diet with iron supplementation in pregnant women has been associated with a higher risk of hypospadias, perhaps due to greater exposure to phytoestrogens [37, 65].

\subsection{Growth and adiposity in childhood and adolescence}

Following the conclusion of the gestational period, growth and adiposity in childhood and adolescence are also important determinants of future male reproductive health. It is possible that normal growth and BMI through childhood and adolescence are associated with better adult testicular function [41]. Optimal body mass index trajectory through childhood and adolescence is associated with larger testicular volume and higher serum inhibin B and testosterone in adulthood. Rapid weight gain between birth and 24 months of age is associated with earlier onset of puberty [40]. Rapid early life weight gain has been linked to elevated insulin-like growth factor I concentrations and insulin resistance, elevated adrenal androgen concentrations, exaggerated adrenarche, obesity and consequently to concentrations of hormones such as leptin. These could all promote the activity of the $\mathrm{GnRH}$ pulse generator, thereby influencing the timing of puberty $[40,66]$. It is unclear whether it is the predisposition to metabolic disorder that leads to later adverse testicular function or vice versa. However, it is probable that adverse dietary patterns exacerbate the problem, as adopting a Western dietary pattern in adolescence is well known to be linked with poor metabolic health, [67] but it is also associated with reductions in sperm concentration and serum DHT in young men [68].

Consistent height above the 50th percentile for age through childhood is associated with larger adult mean testicular volume [41]. In addition, adolescents with features of metabolic disorder at 17 years, or insulin resistance at 20 years of age, have been shown to have impaired testicular function and altered hormone levels compared to those without metabolic disorder. One study showed that men with features of metabolic risk evident at age 17 years of age had lower concentrations 
of serum testosterone and inhibin B compared with those considered at low risk of metabolic disorder. Furthermore men with ultrasound evidence of non-alcoholic fatty liver disease (NAFLD) had reduced total sperm output, testosterone and inhibin B compared to men without NAFLD, when assessed at 20 years of age [69]. In analysing the data higher concentrations of systemic inflammatory markers were associated with an apparent gonadotoxic influence; with reductions in sperm output, seminal volume, sperm concentration, serum inhibin $\mathrm{B}$, with increases in serum LH and FSH. Whereas, a higher concentration of systemic C-reactive protein had an apparent central negative influence on serum FSH and LH secretion inducing a central hypogonadal state with reductions in serum testosterone and seminal volume [59].

\subsection{Oestrogenic endocrine disruptors: bisphenol A and phthalate exposure}

A large number of ubiquitous anti-androgenic endocrine disruptors exist in increasing volumes within the environment. These chemicals interfere with the synthesis, secretion, transport, binding, action or elimination of hormones with potential adverse effects on male reproductive health. Endocrine-disrupting chemicals have been shown in animal models to decrease spermatogenic capacity and increase incidence of male infertility. In rats, exposure to anti-androgenic chemicals during the masculinisation programming window resulted in cryptorchidism, hypospadias, micropenis, short anogenital distance (a surrogate marker of androgen activity) and reduced sperm count $[8,20]$. It is postulated that exposure to endocrine disruptors during the initiation of male reproductive tract development may interfere with the normal hormonal signalling and formation of male reproductive organs [70]. Of note, oestrogenic and anti-androgenic compounds are well established to induce hypospadias in humans and mice [37, 38].

Bisphenol A (BPA) has been used extensively for decades in the manufacture of polycarbonates, epoxy resins and plastics [71]. Unconjugated BPA binds to oestrogen receptors producing weak oestrogenic activity. Anti-androgenic effects are also seen. Free BPA is metabolised by the liver of the mother and foetus, and even at low environmental levels can transfer across the human placenta [72]. BPA studies on experimental animals show that effects are generally more detrimental during in utero exposure, a critical developmental stage for the embryo [73]. In vivo studies on rats showed a relationship between BPA exposure and inhibition of testicular steroidogenesis, hypogonadotropic hypogonadism, decreased sperm count and proliferation of mammary tissue [74-77].

In human studies, there is conflicting evidence for the reproductive effects of BPA. Concurrent BPA exposure has been shown to be associated with decreased sperm concentration and total sperm count, [78] increase in sperm DNA damage, [79]altered serum reproductive hormone levels and reduced semen quality [80]. However, the influences with regard to antenatal maternal BPA exposure are less evident, as a recent longitudinal cohort study of 700 healthy men evaluated stored maternal antenatal serum from a birth cohort and related total maternal BPA concentrations (as a surrogate of foetal exposure) to mature male reproductive function [71]. Whilst a small positive correlation between maternal serum BPA level and sperm concentration and motility was present, no other associations of maternal serum BPA with testicular function were observed [81]. In another review of concurrent adult exposure, whilst evidence of a link was noted in five of six included studies, no consistent relationships or trends could be observed across all studies [82].

Phthalates are another group of environmentally pervasive industrial endocrinedisrupting chemicals, some of which are potent anti-androgens, [83] which are 
suspected to interfere with developmental androgen action [84]. In rats, prenatal exposure to several phthalates elicits a syndrome of genital dysmorphology in males, including incomplete testicular descent, smaller testis weight and penile size, alterations to the vas deferens and epididymis, and most notably, shortened anogenital distance [85]. Animal studies demonstrating adverse effects of phthalate exposure on semen quality, preceded those showing the same effect in humans [86]. Critical to the induction of these effects is a marked reduction in foetal testicular testosterone production at the critical window for the development of the reproductive tract normally under androgen control [85]. In infants exposed in-utero to higher concentrations of maternal phthalates there are reports of a reduction in the anogenital distance, a reproducible marker of prenatal androgenisation [83, 87]. In human adult males, the data suggests equally concerning effects, with antenatal maternal serum phthalate levels showing negative associations with testicular volume, total serum testosterone and serum FSH concentration [84]. However, it is important to state that it is more customary in the scientific literature to report urine concentrations of phthalates rather than serum. In addition to in-utero exposures, phthalate levels in breast milk have been linked to an increased LH to free testosterone ratio in male offspring at 3 months of age, suggesting testicular impairment may occur postnatally during lactation and breast feeding [9]. However, no definite association has been made between breastmilk phthalates and cryptorchidism $[88,89]$. Later in adulthood, adult exposure to environmental phthalates has been linked with reductions in semen parameters in men seeking paternity [90].

Endocrine-disrupting chemicals clearly present potential for significant impact on male reproductive health related to early exposures, however further research is necessary to clarify their risk, as there are a myriad of chemicals within the environment with endocrine-disrupting properties. Their effects may be synergistic, [91] non-dose dependent and the influence of each chemical may vary according to an individual's genetic susceptibility [92].

\subsection{Multigenerational and transgenerational environmental effects}

There is increasing evidence to suggest that early life perturbations due to various exposures are able to exert a direct effect on the human epigenome, both in utero and in adulthood. Both multigenerational and transgenerational effects of certain environmental or lifestyle exposures are possible due to epigenetic dysregulation and inheritance in germ cells $[62,93]$. These epigenetic effects include DNA methylation, histone post-translational modifications and non-coding RNAs [93]. As shown in Figure 2, these two phenomena differ depending on whether the affected generation had direct exposure to the original endocrine disruptor or not. If a pregnant mother (designated as the filial or F0) is exposed to an adverse stimulus, her child (F1) may be affected as a consequence of direct exposure to the same stimulus in utero. Because the germ cells of the F1 offspring are developing throughout gestation, their children (F2) are also directly exposed. Effects seen in the F2 generation are therefore multigenerational. In contrast, effects observed in the F3 generation that had no direct exposure would be transgenerational [93].

Numerous exposures described above, including endocrine disrupters and other lifestyle-related factors such as smoking, diet and stress may affect the male reproductive health of future generations. DNA methylation is perhaps the best known mechanism of epigenetic gene modification, and a direct effect of some environmental factors on DNA methylation has been demonstrated in experimental studies in animal models [9]. In a rat model, gestational exposure to endocrine disruptors led to heritable effects in second and third generation offspring, [94] including decreased spermatogenic capacity and increased incidence of male infertility [95]. 


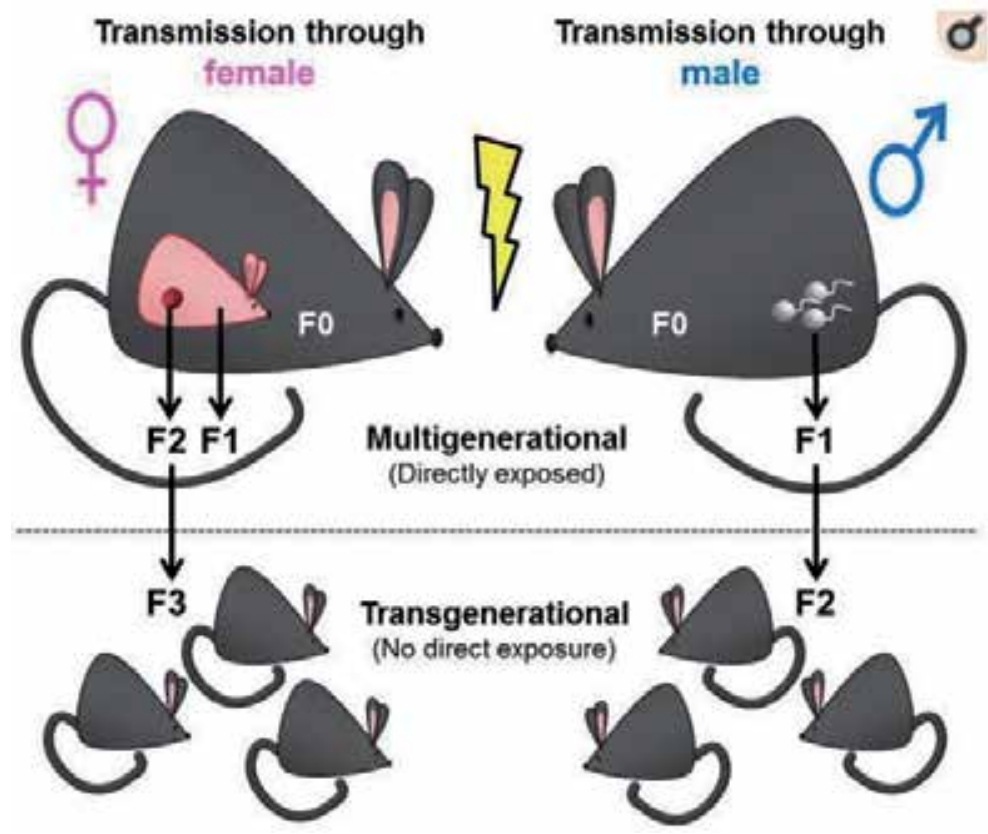

Figure 2.

Multigenerational and transgenerational effects. Reprinted with permission from Elsevier. (C) Xin et al. [93].

Although no human data exist to attest to this, this exciting and evolving area of research requires further work to validate findings.

\section{Conclusion}

There is a growing body of clear and compelling evidence for the early life origins of male reproductive health (Figure 3). Considering the central role the

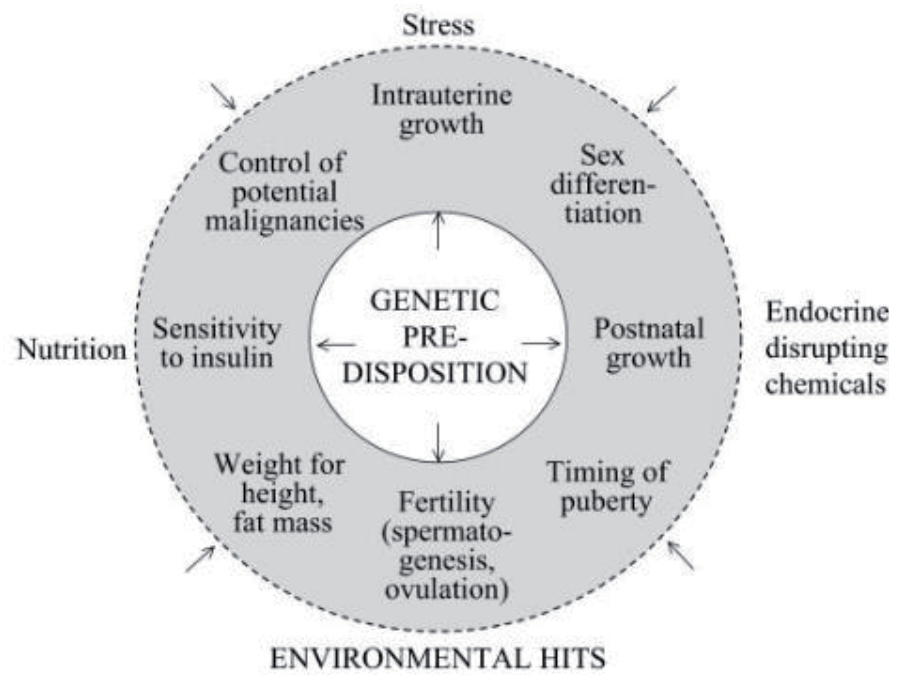

Figure 3.

Early determinants of male reproductive health. Reprinted with permission from Oxford university press. (C) Parent et al. [25]. 
reproductive hormones have in male sex differentiation, it is more than reasonable to suspect the involvement of factors that affect the production and the action of androgens during crucial windows of foetal development. However, although this developmental programming begins in utero, there is further convincing evidence for the effect of additional postnatal influences in early and later life. The specific mechanisms through which these associations exert their effect are as yet poorly understood. Disorders of male reproduction are clearly on the rise worldwide, and this escalation is predicted to only increase exponentially given the current obesity epidemic and the increasing impact of humans on the environment. Therefore, given the significant disease burden expected to result from declining male reproductive health, attention to further research and public health policy in this area is of the utmost importance. In addition, given the evidence for a significant number of maternal exposures and behaviours, public health measures and education focusing on maternal health are of obvious importance.

\section{Conflict of interest}

Professor Roger Hart is a shareholder in Western IVF and has received educational sponsorship from Merck, MSD, Ferring pharmaceuticals and Bayer.

\section{Author details}

Jennifer Pontré (1,2 $^{2}$ nd Roger Hart ${ }^{1,2,3,4 *}$

1 King Edward Memorial Hospital, Perth, Western Australia, Australia

2 Fertility Specialists of Western Australia, Bethesda Hospital, Claremont, Western Australia, Australia

3 Fertility Specialists South, Applecross, Western Australia, Australia

4 Division of Obstetrics and Gynaecology, King Edward Memorial Hospital, University of Western Australia, Perth, Western Australia, Australia

*Address all correspondence to: roger.hart@uwa.ed.au

IntechOpen

(C) 2019 The Author(s). Licensee IntechOpen. This chapter is distributed under the terms of the Creative Commons Attribution License (http://creativecommons.org/licenses/ by/3.0), which permits unrestricted use, distribution, and reproduction in any medium, provided the original work is properly cited. (cc) BY 


\section{References}

[1] Barker DJ, Gluckman PD, Godfrey KM, Harding JE, Owens JA, Robinson JS. Fetal nutrition and cardiovascular disease in adult life. Lancet. 1993;341(8850):938-941

[2] Barker DJ, Osmond C. Infant mortality, childhood nutrition, and ischaemic heart disease in England and Wales. Lancet. 1986;1(8489):1077-1081

[3] Barker DJ, Winter PD, Osmond C, Margetts B, Simmonds SJ. Weight in infancy and death from ischaemic heart disease. Lancet. 1989;2(8663):577-580

[4] Hanson MA, Gluckman PD. Developmental origins of health and disease: New insights. Basic \& Clinical Pharmacology \& Toxicology.

2008;102(2):90-93

[5] Sloboda DM, Hickey M, Hart R. Reproduction in females: The role of the early life environment. Human Reproduction Update. 2011;17(2):210-227

[6] Almond D, Currie J. Killing me softly: The fetal origins hypothesis. Journal of Economic Perspectives. 2011;25(3):153-172

[7] Last JMA. Dictionary of Public Health. United Kingdom: Oxford University Press; 2007

[8] Juul A, Almstrup K, Andersson AM, Jensen TK, Jorgensen N, Main KM, et al. Possible fetal determinants of male infertility. Nature Reviews. Endocrinology. 2014;10(9):553-562

[9] Skakkebaek NE, Rajpert-De Meyts E, Buck Louis GM, Toppari J, Andersson AM, Eisenberg ML, et al. Male reproductive disorders and fertility trends: Influences of environment and genetic susceptibility. Physiological Reviews. 2016;96(1):55-97

[10] Skakkebaek NE, Rajpert-De Meyts E, Main KM. Testicular dysgenesis syndrome: An increasingly common developmental disorder with environmental aspects. Human Reproduction. 2001;16(5):972-978

[11] Nigam M, Aschebrook-Kilfoy B, Shikanov S, Eggener S. Increasing incidence of testicular cancer in the United States and Europe between 1992 and 2009. World Journal of Urology. 2015;33(5):623-631

[12] Rahban R, Priskorn L, Senn A, Stettler E, Galli F, Vargas J, et al. Semen quality of young men in Switzerland: A nationwide cross-sectional populationbased study. Andrology. 2019;7(5):1-9

[13] VirtanenHE,ToppariJ.Epidemiology and pathogenesis of cryptorchidism. Human Reproduction Update. 2008;14(1):49-58

[14] Levine H, Jørgensen $N$, Martino-Andrade A, Mendiola J, Weksler-Derri D, Mindlis I, et al. Temporal trends in sperm count: A systematic review and meta-regression analysis. Human Reproduction Update. 2017;23(6):646-659

[15] Hart RJ, Doherty DA, McLachlan RI, Walls ML, Keelan JA, Dickinson JE, et al. Testicular function in a birth cohort of young men. Human Reproduction. 2015;30(12):2713-2724

[16] Jensen TK, Jacobsen R, Christensen K, Nielsen NC, Bostofte E. Good semen quality and life expectancy: A cohort study of 43,277 men. American Journal of Epidemiology. 2009;170(5):559-565

[17] Latif T, Kold Jensen T, Mehlsen J, Holmboe SA, Brinth L, Pors K, et al. Semen quality as a predictor of subsequent morbidity: A Danish cohort study of 4,712 men with longterm follow-up. American Journal of Epidemiology. 2017;186(8):910-917 
[18] Eisenberg ML, Li S, Behr B, Cullen MR, Galusha D, Lamb DJ, et al. Semen quality, infertility and mortality in the USA. Human Reproduction. 2014;29(7):1567-1574

[19] Bräuner EV, Hansen ÅM, Doherty DA, Dickinson JE, Handelsman DJ, Hickey M, et al. The association between in-utero exposure to stressful life events during pregnancy and male reproductive function in a cohort of 20-year-old offspring: The Raine study. Human Reproduction. 2019;34(7):1345-1355

[20] Welsh M, Saunders PT, Fisken M, Scott HM, Hutchison GR, Smith LB, et al. Identification in rats of a programming window for reproductive tract masculinization, disruption of which leads to hypospadias and cryptorchidism. The Journal of Clinical Investigation. 2008;118:1479-1490

[21] Sharpe RM. Environmental/ lifestyle effects on spermatogenesis. Philosophical Transactions of the Royal Society, B: Biological Sciences. 2010;365:1697-1712

[22] Abreu AP, Kaiser UB. Pubertal development and regulation. The Lancet Diabetes \& Endocrinology. 2016;4(3):254-264

[23] Johannsen TH, Main KM, Ljubicic ML, Jensen TK, Andersen HR, Andersen MS, et al. Sex differences in reproductive hormones during mini-puberty in infants with Normal and disordered sex development. The Journal of Clinical Endocrinology and Metabolism. 2018;103(8):3028-3037

[24] Kuiri-Hanninen T, Sankilampi U, Dunkel L. Activation of the hypothalamic-pituitary-gonadal axis in infancy: Minipuberty. Hormone Research in Pædiatrics. 2014;82(2):73-80

[25] Parent AS, Teilmann G, Juul A, Skakkebaek NE, Toppari J,
Bourguignon JP. The timing of normal puberty and the age limits of sexual precocity: Variations around the world, secular trends, and changes after migration. Endocrine Reviews. 2003;24(5):668-693

[26] Burt Solorzano CM, McCartney CR. Obesity and the pubertal transition in girls and boys. Reproduction. 2010;140(3):399-410

[27] Roa J, Aguilar E, Dieguez C, Pinilla L, Tena-Sempere M. New frontiers in kisspeptin/GPR54 physiology as fundamental gatekeepers of reproductive function. Frontiers in Neuroendocrinology. 2008;29(1): 48-69

\section{[28] NHANES III. NHANES III}

Reference Manuals and Reports (CD-ROM). Analytic and Reporting Guidelines: The Third National Health and Nutrition Examination Survey (1988-94). Hyattsville, MD: National Center for Health Statistics, Centers for Disease Control and Prevention; 1997

[29] Golub MS, Collman GW, Foster PM, Kimmel CA, Rajpert-De Meyts E, Reiter EO, et al. Public health implications of altered puberty timing. Pediatrics. 2008;121(Suppl 3):S218-S230

[30] Downing J, Bellis MA. Early pubertal onset and its relationship with sexual risk taking, substance use and anti-social behaviour: A preliminary cross-sectional study. BMC Public Health. 2009;9:446

[31] Dupont CCA, Junien C, Mandon-Pépin B, Levy R, Chavatte-PalmerP.Maternalenvironment and the reproductive function of the offspring. Theriogenology. 2012;78(7):1405-1414

[32] Lane M, Zander-Fox DL, Robker RL, McPherson NO. Peri-conception parental obesity, reproductive health, and transgenerational impacts. Trends 
in Endocrinology and Metabolism. 2015;26(2):84-90

[33] Main KM, Jensen RB, Asklund C, Hoi-Hansen CE, Skakkebaek NE. Low birth weight and male reproductive function. Hormone Research. 2006;65(Suppl 3):116-122

[34] NordenvallAS, FrisenL,NordenstromA, Lichtenstein P, Nordenskjold A. Population based nationwide study of hypospadias in Sweden, 1973 to 2009: Incidence and risk factors. The Journal of Urology. 2014;191(3):783-789

[35] van Rooij IA, van der Zanden LF, Brouwers MM, Knoers NV, Feitz WF, Roeleveld N. Risk factors for different phenotypes of hypospadias: Results from a Dutch case-control study. BJU International. 2013;112(1):121-128

[36] Preiksa RT, Zilaitiene B, Matulevicius V, Skakkebaek NE, Petersen JH, Jorgensen N, et al. Higher than expected prevalence of congenital cryptorchidism in Lithuania: A study of 1204 boys at birth and 1 year follow-up. Human Reproduction. 2005;20(7):1928-1932

[37] Bouty A, Ayers KL, Pask A, Heloury Y, Sinclair AH. The genetic and environmental factors underlying hypospadias. Sexual Development. 2015;9:239-259

[38] Giordano F, Abballe A, De Felip E, di Domenico A, Ferro F, Grammatico P, et al. Maternal exposures to endocrine disrupting chemicals and hypospadias in offspring. Birth Defects Research Part A: Clinical and Molecular Teratology. 2010;88(4):241-250

[39] Vanbillemont G, Lapauw B, Bogaert V, De Naeyer H, De Bacquer D, Ruige J, et al. Birth weight in relation to sex steroid status and body composition in young healthy male siblings. The Journal of Clinical Endocrinology and Metabolism. 2010;95:1587-1594
[40] Karaolis-Danckert N, Buyken AE, Sonntag A, Kroke A. Birth and early life influences on the timing of puberty onset: Results from the DONALD (DOrtmund nutritional and anthropometric longitudinally designed) study. The American Journal of Clinical Nutrition. 2009;90:1559-1565

[41] Hart RJ, Doherty DA, Keelan JA, McLachlan R, Skakkebaek NE, Norman RJ, et al. Early life events predict adult testicular function; data derived from the Western Australian (Raine) birth cohort. The Journal of Clinical Endocrinology and Metabolism. 2016;101(9):3333-3344

[42] Damgaard IN, Jensen TK, Groups, T.N.C.S, Petersen JH, Skakkebæk NE, Toppari J, et al. Risk factors for congenital cryptorchidism in a prospective birth cohort study. PLoS One. 2008;3:e3051

[43] Virtanen HE, Tapanainen AE, Kaleva MM, Suomi AM, Main KM, Skakkebaek NE, et al. Mild gestational diabetes as a risk factor for congenital cryptorchidism. The Journal of Clinical Endocrinology and Metabolism. 2006;91(12):4862-4865

[44] Pedersen JF, Molsted-Pedersen L. Early fetal growth delay detected by ultrasound marks increased risk of congenital malformation in diabetic pregnancy. British Medical Journal. 1981;283(6286):269-271

[45] TrabertB, Chodick G, ShalevV, SellaT, LongneckerMP,McGlynnKA.Gestational diabetes and the risk of cryptorchidism and hypospadias. Epidemiology. 2014;25(1):152-153

[46] van der Zanden LF, van Rooij IA, Feitz WF, Franke B, Knoers NV, Roeleveld N. Aetiology of hypospadias: A systematic review of genes and environment. Human Reproduction Update. 2012;18(3):260-283 
[47] Ravelli AC, van Der Meulen JH, Osmond C, Barker DJ, Bleker OP. Obesity at the age of $50 \mathrm{y}$ in men and women exposed to famine prenatally. The American Journal of Clinical Nutrition. 1999;70(5):811-816

[48] Roseboom TJ, van der Meulen JH, van Montfrans GA, Ravelli AC, Osmond C, Barker DJ, et al. Maternal nutrition during gestation and blood pressure in later life. Journal of Hypertension. 2001;19(1):29-34

[49] Edwards LJ, McMillen IC. Impact of maternal undernutrition during the periconceptional period, fetal number, and fetal sex on the development of the hypothalamo-pituitary adrenal axis in sheep during late gestation. Biology of Reproduction. 2002;66:1562-1569

[50] Rae MT, Kyle CE, Miller DW, Hammond AJ, Brooks AN, Rhind SM. The effects of undernutrition, in utero, on reproductive function in adult male and female sheep. Animal Reproduction Science. 2002;72(1-2):63-71

[51] Lea RG, Andrade LP, Rae MT, Hannah LT, Kyle CE, Murray JF, et al. Effects of maternal undernutrition during early pregnancy on apoptosis regulators in the ovine fetal ovary. Reproduction. 2006;131(1):113

[52] Ramlau-Hansen $\mathrm{CH}$, Nohr EA, Thulstrup AM, Bonde JP, Storgaard L, Olsen J. Is maternal obesity related to semen quality in the male offspring? A pilot study. Human Reproduction. 2007;22(10):2758-2762

[53] Sharpe RM, Skakkebaek NE. Are oestrogens involved in falling sperm counts and disorders of the male reproductive tract? Lancet. 1993;341(8857):1392-1395

[54] Rodriguez-Gonzalez GL, Vega CC, Boeck L, Vazquez M, Bautista CJ, Reyes-Castro LA, et al. Maternal obesity and overnutrition increase oxidative stress in male rat offspring reproductive system and decrease fertility. International Journal of Obesity. 2015;39(4):549-556

[55] Ravnborg TL, Jensen TK, Andersson AM, Toppari J, Skakkebaek NE, Jorgensen N. Prenatal and adult exposures to smoking are associated with adverse effects on reproductive hormones, semen quality, final height and body mass index. Human Reproduction. 2011;26(5):1000-1011

[56] Jensen TK, Jorgensen N, Punab M, Haugen TB, Suominen J, Zilaitiene B, et al. Association of in utero exposure to maternal smoking with reduced semen quality and testis size in adulthood: A cross-sectional study of 1,770 young men from the general population in five European countries. American Journal of Epidemiology. 2004;159(1):49-58

[57] Mamsen LS, Lutterodt MC, Andersen EW, Skouby SO, Sorensen KP, Andersen CY, et al. Cigarette smoking during early pregnancy reduces the number of embryonic germ and somatic cells. Human Reproduction. 2010;25(11):2755-2761

[58] Crump CJ, Chevins PF. Prenatal stress reduces fertility of male offspring in mice, without affecting their adult testosterone levels. Hormones and Behavior. 1989;23(3):333-343

[59] Barrett ES, Swan SH. Stress and androgen activity during fetal development. Endocrinology. 2015;156(10):3435-3441

[60] Atanassova NN, Walker M, McKinnell C, Fisher JS, Sharpe RM. Evidence that androgens and oestrogens, as well as folliclestimulating hormone, can alter Sertoli cell number in the neonatal rat. Journal of Endocrinology. 2005;184(1):107-117 
[61] Sharpe RM, Rivas A,

Walker M, McKinnell C, Fisher JS.

Effect of neonatal treatment of rats with potent or weak (environmental) oestrogens, or with a GnRH antagonist, on Leydig cell development and function through puberty into adulthood. International Journal of Andrology. 2003;26(1):26-36

[62] Toppari J, Larsen JC, Christiansen P, Giwercman A, Grandjean P, Guillette LJ Jr, et al. Male reproductive health and environmental xenoestrogens. Environmental Health Perspectives. 1996;104(Suppl 4):741-803

[63] Setchell BP. Sperm counts in semen of farm animals 1932-1995. International Journal of Andrology. 1997;20(4):209-214

[64] Handelsman DJ. Estrogens and falling sperm counts. Reproduction, Fertility, and Development. 2001;13(4):317-324

[65] North K, Golding J. A maternal vegetarian diet in pregnancy is associated with hypospadias. The ALSPAC study team. Avon longitudinal study of pregnancy and childhood. BJU International. 2000;85(1):107-113

[66] Dunger DB, Ahmed ML, Ong KK. Early and late weight gain and the timing of puberty. Molecular and Cellular Endocrinology.

2006;254-255:140-145

[67] Ambrosini GL, Emmett PM, Northstone K, Jebb SA. Tracking a dietary pattern associated with increased adiposity in childhood and adolescence. Obesity. 2014;22(2):458-465

[68] Ognjenovic M, Ambrosini GL, Malacova E, Doherty DA, Oddy WH, Handelsman DJ, et al. Associations between major dietary patterns and testicular function in a populationbased cohort of young men: Results from the Western Australian pregnancy cohort (Raine) study. Andrology. 2019;7(3):273-280

[69] Hart RJ, Doherty DA, Mori TA, Adams LA, Huang RC, Minaee N, et al. Features of the metabolic syndrome in late adolescence are associated with impaired testicular function at 20 years of age. Human Reproduction. 2019;34(3):389-402

[70] Guerrero-Bosagna CM, Skinner MK. Epigenetic transgenerational effects of endocrine disruptors on male reproduction. Seminars in Reproductive Medicine. 2009;27(5):403-408

[71] vom Saal FS, Akingbemi BT, Belcher SM, Birnbaum LS, Crain DA, Eriksen M, et al. Chapel Hill bisphenol A expert panel consensus statement: Integration of mechanisms, effects in animals and potential to impact human health at current levels of exposure. Reproductive Toxicology. 2007;24(2):131-138

[72] Balakrishnan B, Henare K, Thorstensen EB, Ponnampalam AP, Mitchell MD. Transfer of bisphenol A across the human placenta. American Journal of Obstetrics and Gynecology. 2010;202(4):393.e1-393.e7

[73] Manfo F, Jubendradass R, Nantia E, Moundipa P, Mathur P. Adverse effects of bisphenol A on male reproductive function BT. Reviews of Environmental Contamination and Toxicology. 2014;228:57-82. DOI: 10.1007/978-3-319-01619-1_3

[74] Cariati F, D’Uonno N, Borrillo F, Iervolino S, Galdiero G, Tomaiuolo R. Bisphenol a: An emerging threat to male fertility. Reproductive Biology and Endocrinology. 2019;17:6

[75] Vom Saal FS. Triennial reproduction symposium: Environmental programming of reproduction during 
fetal life: Effects of intrauterine position and the endocrine disrupting chemical bisphenol A. Journal of Animal Science. 2016;94:2722-2736

[76] Wisniewski P, Romano RM, Kizys MM, Oliveira KC, Kasamatsu T, Giannocco G, et al. Adult exposure to bisphenol A (BPA) in Wistar rats reduces sperm quality with disruption of the hypothalamic-pituitary-testicular axis. Toxicology. 2015;329:1-9

[77] Hass U, Christiansen S, Boberg J, Rasmussen MG, Mandrup K, Axelstad M. Low-dose effect of developmental bisphenol A exposure on sperm count and behaviour in rats. Andrology. 2016;4(4):594-607

[78] Li DK, Zhou Z, Miao M, He Y, Wang J, Ferber J, et al. Urine bisphenol-A (BPA) level in relation to semen quality. Fertility and Sterility. 2011;95(2):625-630.e1-4

[79] Meeker JD, Ehrlich S, Toth TL, Wright DL, Calafat AM, Trisini AT, et al. Semen quality and sperm DNA damage in relation to urinary bisphenol A among men from an infertility clinic. Reproductive Toxicology. 2010;30(4):532-539

[80] Lassen TH, Frederiksen H, Jensen TK, Petersen JH, Joensen UN, Main KM, et al. Urinary bisphenol A levels in young men: Association with reproductive hormones and semen quality. Environmental Health Perspectives. 2014;122(5):478-484

[81] Hart RJ, Doherty DA, Keelan JA, Minaee NS, Thorstensen EB, Dickinson JE, et al. The impact of antenatal bisphenol A exposure on male reproductive function at 20-22 years of age. Reproductive Biomedicine Online. 2018;36(3):340-347

[82] Minguez-Alarcon L, Hauser R, Gaskins AJ. Effects of bisphenol A on male and couple reproductive health: A review. Fertility and Sterility. 2016;106(4):864-870

[83] Swan SH, Sathyanarayana S, Barrett ES, Janssen S, Liu F, Nguyen RH, et al. First trimester phthalate exposure and anogenital distance in newborns. Human Reproduction. 2015;30(4):963-972

[84] Hart RJ, Frederiksen H, Doherty DA, Keelan JA, Skakkebaek NE, Minaee NS, et al. The possible impact of antenatal exposure to ubiquitous phthalates upon male reproductive function at 20 years of age. Frontiers in Endocrinology. 2018;9:288

[85] Foster PM. Disruption of reproductive development in male rat offspring following in utero exposure to phthalate esters. International Journal of Andrology. 2006;29(1):140-147; discussion 81-5

[86] Wang YX, You L, Zeng Q, Sun Y, Huang YH, Wang C, et al. Phthalate exposure and human semen quality: Results from an infertility clinic in China. Environmental Research.

2015;142:1-9

[87] Swan SH, Main KM, Liu F, Stewart SL, Kruse RL, Calafat AM, et al. Decrease in anogenital distance among male infants with prenatal phthalate exposure. Environmental Health Perspectives. 2005;113(8):1056-1061

[88] Krysiak-Baltyn K, Toppari J, Skakkebaek NE, Jensen TS, Virtanen HE, Schramm KW, et al. Association between chemical pattern in breast milk and congenital cryptorchidism: Modelling of complex human exposures. International Journal of Andrology. 2012;35(3):294-302

[89] Brucker-Davis F, Wagner-Mahler K, Delattre I, Ducot B, Ferrari P, Bongain A, et al. Cryptorchidism at birth in Nice area (France) is associated 
with higher prenatal exposure to PCBs and DDE, as assessed by colostrum concentrations. Human Reproduction. 2008;23(8):1708-1718

[90] Smarr MM, Kannan K, Sun L, Honda M, Wang W, Karthikraj R, et al. Preconception seminal plasma concentrations of endocrine disrupting chemicals in relation to semen quality parameters among male partners planning for pregnancy. Environmental Research. 2018;167:78-86

[91] Bonde JP, Flachs EM, Rimborg S, Glazer CH, Giwercman A, Ramlau-Hansen $\mathrm{CH}$, et al. The epidemiologic evidence linking prenatal and postnatal exposure to endocrine disrupting chemicals with male reproductive disorders: A systematic review and meta-analysis. Human Reproduction Update. 2016;23(1):104-125

[92] Joensen UN, Jorgensen N, Thyssen JP, Szecsi PB, Stender S, Petersen JH, et al. Urinary excretion of phenols, parabens and benzophenones in young men: Associations to reproductive hormones and semen quality are modified by mutations in the Filaggrin gene. Environment International. 2018;121(Pt 1):365-374

[93] Xin F, Susiarjo M, Bartolomei MS. Multigenerational and transgenerational effects of endocrine disrupting chemicals: A role for altered epigenetic regulation? Seminars in Cell \& Developmental Biology. 2015;43:66-75

[94] Blaze J, Roth TL. Evidence from clinical and animal model studies of the long-term and transgenerational impact of stress on DNA methylation. Seminars in Cell \& Developmental Biology. 2015;43:76-84

[95] Anway MD, Cupp AS, Uzumcu M, Skinner MK. Epigenetic transgenerational actions of endocrine disruptors and male fertility. Science. 2005;308(5727):1466-1469 



\title{
The Role of Endocrine-Disrupting Chemicals in Male Fertility Decline
}

\author{
Magda Carvalho Henriques, Susana Loureiro, \\ Margarida Fardilha and Maria Teresa Herdeiro
}

\begin{abstract}
Endocrine-disrupting chemicals (EDCs) are exogenous compounds with natural or anthropogenic origin omnipresent in the environment. These compounds disrupt endocrine function through interaction with hormone receptor or alteration of hormone synthesis. Humans are environmentally exposed to EDCs through the air, water, food and occupation. During the last decades, there has been a concern that exposure to EDCs may contribute to an impairment of human reproductive function. EDCs affect male fertility at multiple levels, from sperm production and quality to the morphology and histology of the male reproductive system. It has been proposed that exposure to EDCs may contribute to an impairment of sperm motility, concentration, volume and morphology and an increase in the sperm DNA damage. Moreover, EDCs exert reproductive toxicity inducing structural damage on the testis vasculature and blood-testis barrier and cytotoxicity on Sertoli and Leydig cells. This chapter will explore the effects of EDCs in male reproductive system and in the decline of male fertility.
\end{abstract}

Keywords: endocrine-disrupting chemicals, male infertility, lifestyle, environmental pollutants, body burden

\section{Introduction}

Endocrine-disrupting chemicals (EDCs) are exogenous substances or mixtures of chemicals that can disrupt male and female endocrine function through the interaction with hormone receptors. They lead to alterations in hormone action, synthesis, transport and metabolic processes [1]. Several compounds such as dioxins, plastic contaminants (e.g., bisphenols (BP)), triclosan (TCS), pesticides and herbicides (e.g., diphenyl-dichloro-trichloroethane (DDT)), metals and others are known EDCs [2].

Humans may be exposed to EDCs due to contamination of water and food chain, inhalation of contaminated house dust and through occupational exposure [2]. Although, in some westernized countries the use of certain EDCs has been banned, there are cases that human exposure to these chemicals is inevitable. Thus, during the past decades, human exposure to EDCs has received increased attention, and particular focus has been given to the harmful effects of EDCs to the male reproductive system. Evidences suggest that EDCs may have significant adverse 
effects on human health and are contributing to the trends in occurrence of male reproductive health problems and the decline in male fertility [3]. According to the literature, male reproductive decline may result from a combination of morphological, functional and molecular alterations in the reproductive organs, often due to exposure to EDCs. Most studies are focused either on the evaluation of basic seminal parameters or reproductive outcomes, but there are evidences that EDCs may impact at the level of the reproductive and endocrine systems. For example, there are evidences that TCS has a tendency to bioaccumulate in the epididymis [4]. Bisphenol A (BPA) has been reported to have both estrogenic and antiandrogenic effects [5-7]. It has been also negatively associated with sperm quality [8-10]. Toxicological studies showed that BPA caused adverse reproductive outcomes, namely, decreased epididymal weight, daily sperm production and testosterone $(\mathrm{T})$ levels in rodents [11-13]. Recently, our group performed a systematic review regarding the effect of exposure to mercury $(\mathrm{Hg})$ on human fertility [14]. Results revealed that higher levels of $\mathrm{Hg}$ in blood and hair were associated with male subfertility or infertility status.

This chapter summarizes the effects of male exposure to EDCs on markers of male fertility. The agents discussed here, which include TCS, BPA, metals (such as cadmium (Cd) and $\mathrm{Hg}$ ), polychlorinated biphenyls (PCBs) and others were chosen based on their human exposure prevalence and adverse effects on human reproductive health.

\section{EDCs induce reproductive system toxicity: ultrastructural, cellular and molecular changes}

The male reproductive system is composed by two testes, a system of genital ducts, the accessory glands (seminal vesicles, prostate, Cowper and Littre glands) and the penis [15]. Testes, the male sexual glands, are ovoid organs localized outside the abdominal cavity within the scrotum. This localization maintains the temperature at $2-4^{\circ} \mathrm{C}$ lower than the body temperature, optimal for the testes function. Testes are surrounded by two different layers of protective tissue, the tunica albuginea and the tunica vaginalis. The testicular parenchyma is composed of one to three seminiferous tubules, the functional unit of the testis, and of interstitial tissue surrounding the tubules that contain the Leydig cells (LC), which are responsible for the production of $\mathrm{T}$ in the presence of luteinizing hormone ( $\mathrm{LH}$ ) (Figure 1) [16]. The seminiferous tubules are composed of male germ cells (spermatogonia, spermatocytes and spermatids) and Sertoli cells (SC). SC are involved in the mechanical support and nutrition of germ cells, regulation of male germ cell proliferation and differentiation, phagocytosis, steroid hormone synthesis and metabolism and maintenance of the integrity of seminiferous epithelium. The male reproductive system is responsible for the production of spermatozoa, for the synthesis and secretion of male sex hormones and for the delivery of male gametes into the female reproductive tract. The process of spermatogenesis is highly regulated by the hypothalamic-pituitary-gonadal (HPG) axis.

Evidences suggest that the normal morphology and function of the male reproductive system are affected by several factors including environmental pollutants (Figure 1) (e.g., EDCs). In addition to altered testicular morphology and dysfunction, exposure to EDCs also increased the incidence of testicular pathologies. For instance, exposure to phthalates was associated with the development of testicular cancer, cryptorchidism and hypospadias [17]. This section discusses the current knowledge on reproductive system EDC toxicity in humans and other animals. 


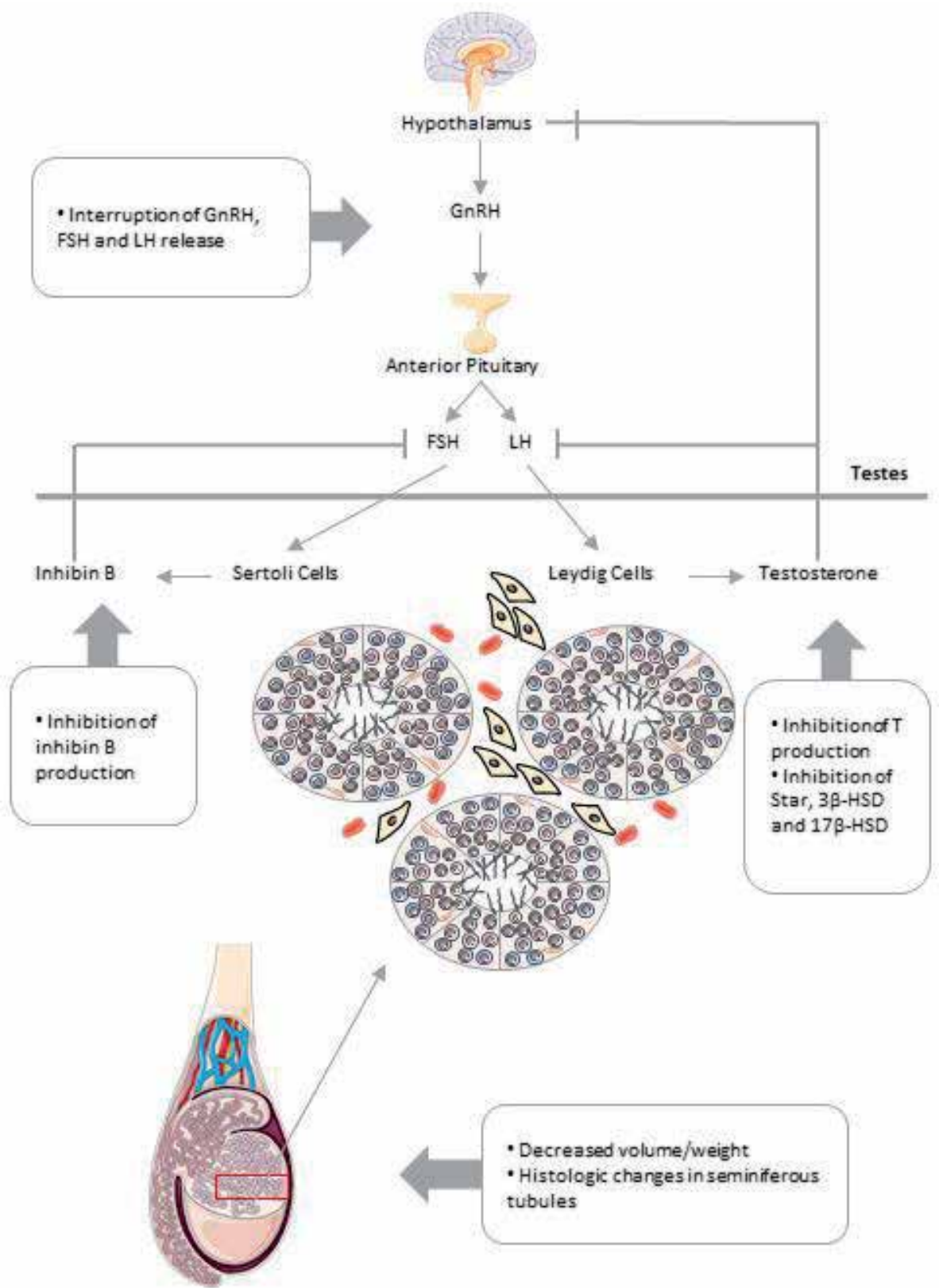

Figure 1.

Schematic representation of the effects of EDCs on HPG axis and testicular morphology.

\subsection{Changes in volume/weight of reproductive organs}

The volume/weight of the male reproductive organs is an important indicator of the integrity of this system. Several animal studies showed a significant decrease in the weight of the testes and sex accessory tissues in animals exposed to EDCs [4, 18-23]. For instance, male rats treated with 10 and $20 \mathrm{mg} /$ (kg day) of TCS revealed a significant decrease in the weight of the testes, epididymis, ventral prostate, vas deferens and seminal vesicles [18]. However, an administration of $5 \mathrm{mg} /$ ( $\mathrm{kg}$ day) of TCS did not cause significant change in the testes and sex accessory tissues [18]. Recently, Lan et al. [4] showed that the absolute 
weights of testes and epididymis of rats treated with 10,50 or $200 \mathrm{mg} / \mathrm{kg}$ of TCS were not significantly affected.

Rodents were exposed to BPA by the oral route or subcutaneous injections $[24,25]$. A dose of $2 \mathrm{ng} / \mathrm{g}$ body weight induced a decrease in epididymal weight and an increase in prostate weight. Bisphenol S (BPS), considered a safe substitute for BPA, has chemical similarities with BPA and may act as an EDC. Thus, a recent work compared the effects of BPA and BPS on the morphology and physiology of the ventral prostate of adult gerbils [26]. Animals treated with BPA and BPS showed no alterations in prostate weight. Regarding histopathology, BPS-treated animals showed intense prostatic hyperplasia; increased relative frequency of epithelium, muscular stroma and non-muscular stroma; and decreased luminal compartment, and BPA-treated animals showed increased occurrence of hyperplastic growth. But, in general the authors found that BPS promoted more structural and histopathological changes than BPA.

Exposure to metals also induced effects on testes size. A dose of $5 \mathrm{mg} / \mathrm{kg}$ body weight of cadmium chloride $\left(\mathrm{CdCl}_{2}\right)$ administered to rats by oral gavage caused a significant decrease in testes and epididymis weight [19]. Moreover, $\mathrm{Hg}$ and zinc (Zn) significantly decreased the absolute and relative testicular weights in murine, with $\mathrm{Hg}$ producing the highest reduction in weight [27]. Similar results were obtained by Narayana et al. [22] and Geng et al. [23] that showed a decrease in the weights of reproductive organs of rats exposed to pesticides.

Rats exposed to phthalates demonstrated reduced testicular weights and histologic changes in the seminiferous tubules [20, 21]. Moreover, rats exposed to phthalates during the prenatal period developed reproductive anomalies, namely, smaller testes and penis size [28].

Human studies related to the effects of exposure to EDCs on testicular volume/ weight are limited but in accordance with animal studies. For instance, in a study in Croatian men, no occupational exposures were exposed to metals, and blood Cd was negatively correlated with testes size, suggesting that this metal exerts toxicity on human testes [29].

\subsection{Alterations in testicular morphology}

Experimental studies showed that exposure to EDCs had adverse effects on testes, resulting in testicular damage at structural and consequently functional level. Male rats treated with $20 \mathrm{mg}$ /(kg day) of TCS exhibited several histopathological malformations in the testes and sex accessory tissues [18]. Lumen of vas deferens from the treated rats exhibited the presence of stereocilia detached from the epithelium and the presence of eosinophilic bodies. Moreover, the stereocilia were found to be thin, few or absent in the epithelium of TCS-treated rats. Rats treated with a high dose of TCS $(200 \mathrm{mg} / \mathrm{kg})$ showed changes in the cauda epididymis and in the testis compared with the control group [4]. In the cauda epididymis, the alterations included vacuolated and exfoliated epithelial cells. Moreover, these authors identified the absence of sperm tails in the seminiferous tubules in the TCS-treated groups.

Mice exposed to BPA showed the formation of morphologically multinucleated giant cells in testicular seminiferous tubules [30], disruption of the blood-testis barrier (BTB) and impaired spermatogenesis [31, 32]. Similar results were obtained by other study using pesticides that induced severe degenerative changes in seminiferous tubules [23]. Metals, such as $\mathrm{Cd}$ and $\mathrm{Hg}$, also induced structural alterations in the testis structure, including damage in the vascular endothelium and in the BTB integrity and necrosis and disintegration of spermatocytes [27, 33]. In general, these animal studies showed that EDCs induced changes in testicular morphology, which may be a reason for the decline of male fertility. For instance, damage in epididymis 
compromise the transport of testicular sperm out of the testis, the acquisition of progressive spermatozoa motility and the sperm storage. Moreover, damage at SC and LC levels compromise the structure of the BTB and seminiferous tubules.

\subsection{Testicular dysfunction due to EDC exposure}

The two main functions of the testes are spermatogenesis (exocrine function) and steroidogenesis (endocrine function). In normal conditions the gonadotrophinreleasing hormone $(\mathrm{GnRH})$ is secreted by the hypothalamus, stimulating the synthesis of $\mathrm{LH}$ and the follicle-stimulating hormone (FSH) [34]. LH is recognized by $\mathrm{LH}$ receptors in LC stimulating T biosynthesis (steroidogenesis). FSH is recognized by FSH receptors in SC having an important role in spermatozoa production (spermatogenesis). Several studies showed that these functions are affected by exposure to EDCs (Figure 1) [10, 18, 35-39]. Prenatal exposure to EDCs was associated with testicular anomalies later in life, which includes reduced semen volume and quality, increased incidence of cryptorchidism and hypospadias and increased incidence of testicular cancer [40]. EDCs reduced SC number and impaired LC development, inducing testicular anomalies at morphological and functional level [39]. This section presents the studies that assessed the relationship between animal and human exposure to EDCs and testicular dysfunction, including alterations in reproductive hormone levels.

Evidences from animal studies suggest that TCS reduces the production of $\mathrm{T}$ in LC and disturbs the function of major steroidogenic enzymes [41, 42]. Male rats treated with TCS or pesticides showed a significant decrease in the levels of serum LH, FSH, cholesterol, pregnenolone and T compared to control [18, 23]. Regarding human studies, a case-control study showed that urinary levels of phthalates and TCS were negatively associated with inhibin B and positively with LH [39]. Additionally, an inverse association was found between urinary levels of phthalates or BPA and testosterone and estradiol $\left(\mathrm{E}_{2}\right)[38,39]$. Similar results were obtained by Meeker et al. [35] that showed an inverse association between BPA concentrations in urine and serum levels of inhibin $B$ and $E_{2}: T$ ratio in men recruited through an infertility clinic. Moreover, a positive association between BPA concentrations in urine and FSH and FSH:inhibin B ratio was found. Hanoaka et al. [36] did not found an association between exposure to BPA and free T and LH concentrations in men. However, a significant decrease in FSH concentrations was found in the BPA exposed men. Urinary levels of BPA were not associated with sperm quality in fertile men but were associated with markers of androgenic action [37]. A significant inverse association was found between urinary levels of BPA and free androgen index (FAI) levels and the FAI:LH ratio. Further, a significant positive association between BPA and sex hormone-binding globulin (SHBG) was found in fertile men. Recently, Lassen et al. [10] examined associations between urinary BPA concentration and reproductive hormones in young men from the general population. The authors found positive associations between urinary BPA concentrations and T, $\mathrm{E}_{2}, \mathrm{LH}$ and free T levels. BPA and BPS induced significant changes in T and estradiol [26].

Meeker et al. [38] demonstrated that exposure to phthalates may be associated with altered male endocrine function. Urinary concentrations of some phthalates were inversely associated with $\mathrm{T}, \mathrm{E}_{2}$ and FAI.

Metals, namely, $\mathrm{Cd}$, also affect the development of the male reproductive system and testis function. Mice prenatal exposed to Cd showed defects on the development of gonads, depletion of germ cells and impairment of spermatozoa maturation [43]. $\mathrm{Cd}$ also induces testicular dysfunction, which results of the functional impairment of SC and LC. Regarding human studies, the effect of Cd exposure to male endocrine function was assessed by several authors (as reviewed by de Angelis et al. [33]). 
The results obtained are controversial; some authors found that $\mathrm{Cd}$ concentrations were positively correlated with $\mathrm{FSH}, \mathrm{T}, \mathrm{E}_{2}, \mathrm{LH}$ and inhibin B and negatively correlated with prolactin $[29,44]$. However, other authors did not find significant correlations between $\mathrm{Cd}$ concentrations and serum hormone levels [45, 46]. In general, these results suggest that exposure to EDCs may be associated with alterations in circulating hormone levels in men. Additionally, Yang et al. [47] showed that levels of GnRH and LH were significantly higher in occupationally manganese (Mn)exposed group compared with the non-exposed men. The levels of T were lower in the exposed group. However, this study demonstrated that there was no association between exposure to $\mathrm{Mn}$ and $\mathrm{E}_{2}$ and $\mathrm{FSH}$ and prolactin levels.

\subsection{Molecular effects of EDCs}

The effects of EDCs on the morphology and function of the male reproductive system may be attributed to the interactions of these chemicals with several molecules. Male rats treated with $20 \mathrm{mg}$ / (kg day) of TCS showed a significant reduction in the testicular levels of mRNA for cholesterol side-chain cleavage enzyme (Cyp11a1), 25-hydroxyvitamin D-1 alpha hydroxylase (Cyp27b1), 3 $\beta$-hydroxysteroid dehydrogenase (Hsd3b1), 17 $\beta$-hydroxysteroid dehydrogenase (Hsd17b6), steroidogenic acute regulatory protein (Star) and androgen receptor $(A r)$ as compared to control [18]. Moreover, the authors found that there was a decreased localization of StAR protein in testicular LC as determined by immunolocalization indicating a reduced expression of this protein in animals treated with TCS as compared to control. These results could be correlated to the reduction in LC number.

In vitro studies investigated the effect of BPA on steroidogenesis $[48,49]$. The authors found that BPA inhibited the production of testosterone in a concentrationdependent manner over the course of the $24 \mathrm{~h}$ incubation [48]. Moreover, the concentrations of $E_{2}$ were greater in the presence of BPA. The decrease in the concentrations of $\mathrm{T}$ is related with the inhibition of activities of some enzymes, such as $3 \beta$-hydroxysteroid dehydrogenase (HSD3B1) and $17 \alpha$-hydroxylase (CYP17A). However, the activity of aromatase was not altered by BPA treatment. More recently, additional results in MA-10 Leydig cell line showed that BPA affects steroidogenic genes, for instance, induces the upregulation of CYP11A1 and CYP19 genes [49]. Moreover, the authors found that BPA treatment induced the phosphorylation levels of c-Jun and the levels of protein expression of SF-1, suggesting that the JNK/c-Jun pathway may be involved in BPA toxicity. Similar results were observed in an animal study [49].

The testes from male Sprague-Dawley rats treated with $\mathrm{CdCl}_{2}$ showed a significant increase in the activities of aspartate aminotransferase (AST) and alanine aminotransferase (ALT) [19]. Geng et al. [23] found that pesticides altered the testicular protein expression of B-cell lymphoma 2 (Bcl-2) and Bcl-2-associated $\mathrm{X}$ protein (Bax). Moreover, these authors showed that the activities of testicular enzymes including acyl carrier protein (ACP), lactate dehydrogenase (LDH) and gamma-glutamyltransferase $(\gamma-\mathrm{GT})$ were significantly altered by exposure to pesticides.

\section{Spermatozoa}

Sperm motility, together with concentration and morphology, is considered as one of the important predictors of male fertility in vivo. Declining human sperm quality has been demonstrated in several recent studies. Age, lifestyle, environmental pollutants and nutritional factors can affect semen quality [14, 50-52]. 
The present section focuses on studies of environmental exposure to EDCs and male reproductive function, as measured by declines in semen quality parameters or increased sperm DNA damage/fragmentation.

\subsection{Effects of EDCs on sperm production, morphology, motility and velocity}

Several studies have been published regarding the association of exposure to phenols and human semen quality [53-55]. A case-control study was conducted to evaluate the association between exposure to phenols and idiopathic male infertility [55]. For that, the authors recruited idiopathic infertile men and fertile controls and measured urinary levels of BPA, benzophenone-3, pentachlorophenol, TCS, 4-tertoctylphenol (4-t-OP), 4-n-octylphenol (4-n-OP) and 4-n-nonylphenol (4-n-NP) and semen parameters. The authors found that exposure to 4- $t$-OP, 4-n-OP and 4-n$\mathrm{NP}$ was associated with idiopathic male infertility, and exposure to 4- $t$-OP and 4- $n$ NP was also associated with abnormal semen quality parameters. However, in this study the authors did not find more relationships between exposure to other phenols and idiopathic male infertility. In another study, urinary BPA concentrations were associated with declines in sperm concentration, motility and morphology [53]. An increasing urine BPA level was associated with lower semen concentration, lower total sperm count, lower sperm vitality and lower sperm motility [54]. Moreover, the authors demonstrated a dose-response relationship between increasing urine BPA level and reduction in semen quality. Lassen et al. [10] also found an inverse association between BPA concentrations and progressive motility, but in this study, BPA excretion was not associated with semen volume, sperm concentration, total sperm count or percentage morphologically normal forms. However, some authors did not find any association between urinary BPA concentrations and some semen parameters, such as semen volume or sperm morphology $[8,54]$.

TCS has been shown to decrease sperm density probably due to reduced testicular spermatogenesis [18]. A reduced sperm density was observed in the lumina of epididymal tubule from the treated rats. Rats treated with high doses of TCS (50 and $200 \mathrm{mg} / \mathrm{kg}$ ) showed a significant decrease in the daily sperm production and an increase in the percentage of sperm abnormalities, which included elevated ratios of abnormal sperm head and tails [4]. Zhu et al. [56] performed a cross-sectional study to evaluate the association between exposure to TCS measured by urinary TCS concentration and semen quality in humans. The authors found an association between urinary TCS concentrations and poor semen quality parameters; namely, the authors found an inverse association between urinary TCS concentrations and percentage of sperm motility, sperm count, sperm concentration and percentage of normal morphology, suggesting that environmental exposure to TCS may have impact on semen quality.

Regarding exposure to PCBs, several studies showed an inverse association between exposure to PCB 153 and sperm motility, while relationships with sperm concentration or total sperm count were inconsistent [57-59]. Additionally, Hauser et al. [60] found an inverse dose-response relationship between PCB 138 and sperm concentration, motility and morphology.

The correlation between exposure to metals and adverse consequences for human and animal fertility is not completely established. Several studies determined the effects of exposure to metals on male gametes. In vitro studies, using bovine sperm, determined the effect of direct exposure to $\mathrm{Hg}$ on male gametes [61, 62]. Arabi et al. [61] showed that exposure to $\mathrm{Hg}(50,100,200$, and $300 \mu \mathrm{mol} / \mathrm{l})$ induced LPO (lipid peroxidation), decreased the glutathione (GSH) content and decreased the percentage of viable spermatozoa. Additionally, a more recent study showed that bovine sperm exposed to $\mathrm{Hg}$ at $8 \mathrm{nM}$ and $8 \mu \mathrm{M}$ have less motility and have impaired sperm 
membrane integrity, increasing levels of reactive oxygen species (ROS) and LPO and decreasing the antioxidant activity and diminished fertility ability [62]. Regarding human fertility, in a cross-sectional study, participants with high blood $\mathrm{Hg}$ level had lower sperm with a normal morphology [63]. Cd is another male reproductive toxicant that exerts effects even at low levels of exposure by several mechanisms [64]. In vitro studies on human spermatozoa obtained through ejaculation allow to evaluate the effect of Cd treatment in semen parameters $[65,66]$. Cd decreased sperm motility and sperm viability and induced detrimental effects on spermatozoa metabolism by inhibition of the activity of glycogen phosphorylase, glucose-6-phosphatase, fructose-1,6-diphosphatase, glucose-6-phosphate isomerase, amylase, $\mathrm{Mg}^{2+}-$ dependent ATPase and lactic and succinic acid dehydrogenases. As reviewed by de Angelis et al. [33], significant negative correlations were found between Cd levels and semen parameters, including total sperm count, concentration, motility and morphology. Results from a meta-analysis indicate that men with low fertility had higher semen $\mathrm{Pb}$ and $\mathrm{Cd}$ levels and lower semen $\mathrm{Zn}$ levels [67]. Sperm motility was significantly decreased in men occupationally exposed to Mn [47].

Occupational exposure to pesticides increased the risk of morphological abnormalities in sperm in addition with a decline in sperm count and a decreased percentage of viable spermatozoa. For instance, the exposure to pesticides reduced the seminal volume, sperm motility and concentration and increased the seminal $\mathrm{pH}$ and the abnormal sperm head morphology [68-70]. A study showed that young Swedish men exposed to phthalates presented a decrease in progressive sperm motility [71]. Additionally, levels of urinary phthalates and insecticides were also associated with lower sperm concentration, lower motility and increased percentage of sperm with abnormal morphology [72-75]. These results confirmed the results obtained by in vitro and in vivo studies $[76,77]$.

\subsection{Sperm DNA damage}

Sperm DNA integrity is essential for the correct transmission of genetic information [78]. Damage at sperm DNA level may result in male infertility. Sperm DNA damage is caused by oxidative stress that causes impairment in the sperm membrane [79]. It is well-known that some EDCs may induce oxidative stress and decrease the cellular levels of GSH and protein-sulfhydryl groups. Preclinical studies with male rats showed that exposure to BPA was associated with a significant increase in sperm DNA damage [80]. A statistically significant positive association between urinary concentrations of parabens and BPA and sperm DNA damage was found in male partners of subfertile couples $[53,81]$. Contrary results were obtained by Goldstone et al. [8] that found a negative relationship between BPA and DNA fragmentations.

Additionally, other EDCs such as heavy metals (e.g., $\mathrm{Hg}$ ), PCBs and insecticides induce sperm DNA damage [59, 61, 73, 75, 82-84]. Urinary levels of $\mathrm{Hg}$ and nickel in infertile men were associated with increasing trends for tail length, and the levels of Mn were associated with increasing trend for tail distributed moment [82]. The adverse effects of phthalates on sperm DNA were assessed by several studies among infertile men $[75,84]$. Urinary concentrations of phthalate metabolites were associated with sperm DNA damage. These studies suggest that environmental and occupational exposure to EDCs may be associated with increased sperm DNA damage.

\section{Conclusions}

The results yielded in this chapter showed that both environmental and occupational exposures to EDCs affect male reproductive function at multiple levels. 
In human populations, the majority of studies point toward an association between exposure to EDCs and male reproduction system disorders, such as infertility, testicular cancer, poor sperm quality and/or function. Exposure to EDCs was associated with declined semen quality, increased sperm DNA damage, alterations in testis morphology and endocrine function. However, there are studies exploring the effect of EDCs on male reproductive health including semen quality, reproductive hormones and male fertility that produced inconsistent results probably due to small-sized study populations and lack of control for potential confounding variables. These contrary results highlight the need to discuss and investigate the effect of environmental pollutants in the male reproductive health. Moreover, the identification of the sequence of events and mechanisms might be important to better understand the effect of exposure to EDCs on male reproductive system and their contribution to male fertility decline.

\section{Acknowledgements}

Thanks are due to the support of iBiMED (UID/BIM/04501/2013, UID/ BIM/04501/2019 and POCI-01-0145-FEDER-007628), CESAM (UID/ AMB/50017/2019 and POCI-01-0145-FEDER-007638) and FCT/MEC through national funds. We are also thankful to FCT of the Portuguese Ministry of Science and Higher Education by an individual grant to M.C.H. (SFRH/BD/131846/2017).

\section{Conflict of interest}

The authors declare no conflicts of interest.

$\begin{array}{ll}\text { Abbreviations } \\ \text { ACP } & \text { acyl carrier protein } \\ \text { ALT } & \text { alanine aminotransferase } \\ \text { AR } & \text { androgen receptor } \\ \text { AST } & \text { aspartate aminotransferase } \\ \text { Bax } & \text { Bcl-2-associated X protein } \\ \text { Bcl-2 } & \text { B-cell lymphoma 2 } \\ \text { BP } & \text { bisphenols } \\ \text { BPA } & \text { bisphenol A } \\ \text { BPS } & \text { bisphenol S } \\ \text { BTB } & \text { blood-testis barrier } \\ \text { Cd } & \text { cadmium } \\ \text { CdCl } & \text { cadmium chloride } \\ \text { DDT } & \text { diphenyl-dichloro-trichloroethane } \\ \text { E } 2 & \text { estradiol } \\ \text { EDCs } & \text { endocrine-disrupting chemicals } \\ \text { FAI } & \text { free androgen index } \\ \text { FSH } & \text { follicle-stimulating hormone } \\ \text { GnRH } & \text { gonadotropin-releasing hormone } \\ \text { GSH } & \text { glutathione } \\ \text { Hg } & \text { mercury } \\ \text { LC } & \text { Leydig cells } \\ \text { LDH } & \text { lactate dehydrogenase } \\ & \end{array}$




$\begin{array}{ll}\text { LH } & \text { luteinizing hormone } \\ \text { Mn } & \text { manganese } \\ \text { PCBs } & \text { polychlorinated biphenyls } \\ \text { ROS } & \text { reactive oxygen species } \\ \text { SC } & \text { Sertoli cells } \\ \text { SHBG } & \text { sex hormone-binding globulin } \\ \text { StAR } & \text { steroidogenic acute regulatory protein } \\ \text { T } & \text { testosterone } \\ \text { TCS } & \text { triclosan } \\ \text { Zn } & \text { zinc } \\ \gamma-G T & \text { gamma-glutamyltransferase }\end{array}$

\section{Author details}

Magda Carvalho Henriques ${ }^{1,2}$, Susana Loureiro ${ }^{2}$, Margarida Fardilha ${ }^{1 \dagger}$ and Maria Teresa Herdeiro ${ }^{1 * \dagger}$

1 Department of Medical Sciences, Institute of Biomedicine (iBiMED), University of Aveiro, Aveiro, Portugal

2 Department of Biology, Centro de Estudos do Ambiente e do MAR (CESAM), University of Aveiro, Aveiro, Portugal

*Address all correspondence to: teresaherdeiro@ua.pt

$\uparrow$ These authors contributed equally for this chapter.

\section{IntechOpen}

(C) 2019 The Author(s). Licensee IntechOpen. This chapter is distributed under the terms of the Creative Commons Attribution License (http://creativecommons.org/licenses/ by/3.0), which permits unrestricted use, distribution, and reproduction in any medium, provided the original work is properly cited. (cc) BY 


\section{References}

[1] Gore AC, Chappell VA, Fenton SE, Flaws JA, Nadal A, Prins GS, et al. EDC-2: The Endocrine Society's second scientific statement on endocrinedisrupting chemicals. Endocrine Reviews. 2015;36(6):E1-E150

[2] Frye C, Bo E, Calamandrei G, Calzà L, Dessì-Fulgheri F, Fernández M, et al. Endocrine disrupters: A review of some sources, effects, and mechanisms of actions on behaviour and neuroendocrine systems. Journal of Neuroendocrinology. 2012;24:144-159

[3] Meeker JD. Exposure to environmental endocrine disrupting compounds and men's health. Maturitas. 2010;66(3):236-241

[4] Lan Z, Hyung Kim T, Shun Bi K, Hui Chen X, Sik KH. Triclosan exhibits a tendency to accumulate in the epididymis and shows sperm toxicity in male Sprague-dawley rats. Environmental Toxicology. 2015;30(1):83-91. DOI: $10.1002 /$ tox.21897

[5] Wetherill YB, Akingbemi BT, Kanno J, McLachlan JA, Nadal A, Sonnenschein $\mathrm{C}$, et al. In vitro molecular mechanisms of bisphenol A action. Reproductive Toxicology. 2007;24(2):178-198

[6] Lee HJ, Chattopadhyay S, Gong E-Y, Ahn RS, Lee K. Antiandrogenic effects of bisphenol $A$ and nonylphenol on the function of androgen receptor. Toxicological Sciences. 2003;75(1):40-46

[7] Akingbemi BT, Sottas CM, Koulova AI, Klinefelter GR, Hardy MP. Inhibition of testicular steroidogenesis by the xenoestrogen bisphenol A is associated with reduced pituitary luteinizing hormone secretion and decreased steroidogenic enzyme gene expression in rat Leydig cells. Endocrinology. 2004;145(2):592-603
[8] Goldstone AE, Chen Z, Perry MJ, Kannan K, Louis GMB. Urinary bisphenol a and semen quality, the LIFE study. Reproductive Toxicology. 2015;51:7-13

[9] Knez J, Kranvogl R, Breznik BP, Vončina E, Vlaisavljević V. Are urinary bisphenol a levels in men related to semen quality and embryo development after medically assisted reproduction? Fertility and Sterility. 2014;101(1):215221.e5

[10] Lassen TH, Frederiksen H, Jensen TK, Petersen JH, Joensen UN, Main KM, et al. Urinary bisphenol a levels in young men: Association with reproductive hormones and semen quality. Environmental Health Perspectives. 2014;122(5):478-484

[11] Herath CB, Jin W, Watanabe G, Arai K, Suzuki AK, Taya K. Adverse effects of environmental toxicants, octylphenol and bisphenol a, on male reproductive functions in pubertal rats. Endocrine. 2004;25(2):163-172

[12] Salian S, Doshi T, Vanage G. Perinatal exposure of rats to bisphenol A affects the fertility of male offspring. Life Sciences. 2009;85(21-22):742-752

[13] Salian S, Doshi T, Vanage G. Neonatal exposure of male rats to bisphenol A impairs fertility and expression of sertoli cell junctional proteins in the testis. Toxicology. 2009;265(1-2):56-67

[14] Henriques MC, Loureiro S, Fardilha M, Herdeiro MT. Exposure to mercury and human reproductive health: A systematic review. Reproductive Toxicology. 2019 Apr;85:93-103

[15] Netter FH. Atlas of Human Anatomy. 6th ed. Philadelphia: Elsevier; 2014 
[16] Ilacqua A, Francomano D, Aversa

A. The physiology of the testis. In: Belfiore A, LeRoith D, editors. Principles of Endocrinology and Hormone Action. Cham, Switzerland: Springer; 2018. pp. 455-491. DOI: 10.1007/978-3-319-44675-2_17

[17] Nordkap L, Joensen UN, Blomberg Jensen M, Jørgensen N. Regional differences and temporal trends in male reproductive health disorders: Semen quality may be a sensitive marker of environmental exposures. Molecular and Cellular Endocrinology. 2012;355:221-230

[18] Kumar V, Chakraborty A, Kural MR, Roy P. Alteration of testicular steroidogenesis and histopathology of reproductive system in male rats treated with triclosan. Reproductive Toxicology. 2009;27(2):177-185

[19] El-Demerdash FM, Yousef MI, Kedwany FS, Baghdadi HH. Cadmiuminduced changes in lipid peroxidation, blood hematology, biochemical parameters and semen quality of male rats: Protective role of vitamin $E$ and $\beta$-carotene. Food and Chemical Toxicology. 2004;42(10):1563-1571

[20] Gangolli SD. Testicular effects of phthalate esters. Environmental Health Perspectives. 1982;45:77-84. DOI: 10.1289/ehp. 824577

[21] Wolf C, Lambright C, Mann P, Price M, Cooper RL, Ostby J, et al. Administration of potentially antiandrogenic pesticides (procymidone, linuron, iprodione, chlozolinate, $\mathrm{p}, \mathrm{p}^{\prime}$-DDE, and ketoconazole) and toxic substances (dibutyl- and diethylhexyl phthalate, PCB 169, and ethane dimethane sulphonate) during sexual difference. Toxicology and Industrial Health. 1999;15(1-2):94-118. DOI: 10.1177/074823379901500109

[22] Narayana K, Prashanthi N, Nayanatara A, Kumar HHC, Abhilash K,
Bairy KL. Neonatal methyl parathion exposure affects the growth and functions of the male reproductive system in the adult rat. Folia Morphologica. 2006;65(1):26-33

[23] Geng X, Shao H, Zhang Z, Ng JC, Peng C. Malathion-induced testicular toxicity is associated with spermatogenic apoptosis and alterations in testicular enzymes and hormone levels in male Wistar rats. Environmental Toxicology and Pharmacology. 2015;39(2):659-667

[24] Richter CA, Birnbaum LS, Farabollini F, Newbold RR, Rubin $B S$, Talsness CE, et al. In vivo effects of bisphenol A in laboratory rodent studies. Reproductive Toxicology.

2007;24(2):199-224

[25] Vom Saal FS, Cooke PS, Buchanan DL, Palanza P, Thayer KA, Nagel SC, et al. A physiologically based approach to the study of bisphenol a and other estrogenic chemicals on the size of reproductive organs, daily sperm production, and behavior. Toxicology and Industrial Health. 1998;14(1-2):239260. DOI: $10.1177 / 074823379801400115$

[26] Silva JPA, Ramos JG, Campos MS, da Silva LD, de Azevedo Brito PV, Mendes EP, et al. Bisphenol-S promotes endocrine-disrupting effects similar to those promoted by bisphenol-A in the prostate of adult gerbils. Reproductive Toxicology. 2019;85:83-92

[27] Orisakwe OE, Afonne OJ, Nwobodo E, Asomugha L, Dioka CE. Low-dose mercury induces testicular damage protected by zinc in mice. European Journal of Obstetrics, Gynecology, and Reproductive Biology. 2001;95(1):92-96

[28] Foster PMD, Gray E, Leffers H, Skakkebæk NE. Disruption of reproductive development in male rat offspring following in utero exposure to phthalate esters. International Journal 
of Andrology. 2006;29(1):140-147. DOI: 10.1111/j.1365-2605.2005.00563.x

[29] Jurasović J, Cvitković P, Pizent A, Čolak B, Telišman S. Semen quality and reproductive endocrine function with regard to blood cadmium in Croatian male subjects. Biometals. 2004;17(6):735-743. DOI: $10.1007 /$ s10534-004-1689-7

[30] Takao T, Nanamiya W, Nagano I, Asaba K, Kawabata K, Hashimoto K. Exposure with the environmental estrogen bisphenol a disrupts the male reproductive tract in young mice. Life Sciences. 1999;65(22):2351-2357

[31] Cheng CY, Wong EWP, Lie PPY, Li MWM, Su L, Siu ER, et al. Environmental toxicants and male reproductive function. Spermatogenesis. 2011;1(1):2-13. DOI: 10.4161/spmg.1.1.13971

[32] Su L, Mruk DD, Cheng CY. Drug transporters, the blood-testis barrier and spermatogenesis. The Journal of Endocrinology. 2010;208(3):207-223. DOI: $10.1677 / J O E-10-0363$

[33] de Angelis C, Galdiero M, Pivonello C, Salzano C, Gianfrilli D, Piscitelli $\mathrm{P}$, et al. The environment and male reproduction: The effect of cadmium exposure on reproductive functions and its implication in fertility. Reproductive Toxicology. 2017;73:105-127

[34] Corradi PF, Corradi RB, Greene LW. Physiology of the hypothalamic pituitary gonadal axis in the male. The Urologic Clinics of North America. 2016;43(2):151-162

[35] Meeker JD, Calafat AM, Hauser R. Urinary bisphenol a concentrations in relation to serum thyroid and reproductive hormone levels in men from an infertility clinic. Environmental Science \& Technology. 2010;44(4):1458-1463. DOI: 10.1021/ es 9028292
[36] Hanaoka T, Kawamura N, Hara K, Tsugane S. Urinary bisphenol A and plasma hormone concentrations in male workers exposed to bisphenol A diglycidyl ether and mixed organic solvents. Occupational and Environmental Medicine. 2002;59(9):625-628

[37] Mendiola J, Jørgensen N, Andersson A-M, Calafat AM, Ye X, Redmon JB, et al. Are environmental levels of bisphenol A associated with reproductive function in fertile men? Environmental Health Perspectives. 2010;118(9):1286-1291. DOI: 10.1289/ehp.1002037

[38] Meeker JD, Calafat AM, Hauser R. Urinary metabolites of di(2-ethylhexyl) phthalate are associated with decreased steroid hormone levels in adult men. Journal of Andrology. 2009;30(3):287-297

[39] Den Hond E, Tournaye H, De Sutter P, Ombelet W, Baeyens W, Covaci A, et al. Human exposure to endocrine disrupting chemicals and fertility: A case-control study in male subfertility patients. Environment International. 2015;84:154-160

[40] Sharpe RM, Skakkebaek NE. Are oestrogens involved in falling sperm counts and disorders of the male reproductive tract? Lancet. 1993;341(8857):1392-1395

[41] Forgacs AL, Ding Q, Jaremba RG, Huhtaniemi IT, Rahman NA, Zacharewski TR. BLTK1 murine leydig cells: A novel steroidogenic model for evaluating the effects of reproductive and developmental toxicants. Toxicological Sciences. 2012;127(2):391402. DOI: $10.1093 /$ toxsci/kfs121

[42] Kumar V, Balomajumder C, Roy P. Disruption of LH-induced testosterone biosynthesis in testicular Leydig cells by triclosan: Probable mechanism of action. Toxicology. 2008;250(2-3):124-131 
[43] Tam PPL, Liu WK. Gonadal development and fertility of mice treated prenatally with cadmium during the early organogenesis stages. Teratology. 1985;32(3):453-462. DOI: 10.1002/tera.1420320314

[44] Akinloye O, Arowojolu AO, Shittu OB, Anetor JI. Cadmium toxicity: A possible cause of male infertility in Nigeria. Reproductive Biology. 2006;6(1):17-30

[45] Zeng X, Jin T, Buchet JP, Jiang X, Kong Q, Ye T, et al. Impact of cadmium exposure on male sex hormones: A population-based study in China. Environmental Research. 2004;96(3):338-344

[46] Mendiola J, Moreno JM, Roca M, Vergara-Juárez N, Martínez-García MJ, García-Sánchez A, et al. Relationships between heavy metal concentrations in three different body fluids and male reproductive parameters: A pilot study. Environmental Health. 2011;10(1):6

[47] Yang H, Wang J, Yang X, Wu F, Qi Z, $\mathrm{Xu} \mathrm{B}$, et al. Occupational manganese exposure, reproductive hormones, and semen quality in male workers: A cross-sectional study. Toxicology and Industrial Health. 2019;35(1):53-62

[48] Zhang X, Chang H, Wiseman S, He Y, Higley E, Jones $\mathrm{P}$, et al. Bisphenol A disrupts steroidogenesis in human H295R cells. Toxicological Sciences. 2011;121(2):320-327

[49] Lan H-C, Wu K-Y, Lin I-W, Yang Z-J, Chang A-A, Hu M-C. Bisphenol A disrupts steroidogenesis and induces a sex hormone imbalance through c-Jun phosphorylation in Leydig cells. Chemosphere. 2017;185:237-246

[50] Mínguez-Alarcón L, Afeiche MC, Williams PL, Arvizu M, Tanrikut C, Amarasiriwardena CJ, et al., Earth Study Team. Hair mercury ( $\mathrm{Hg}$ ) levels, fish consumption and semen parameters among men attending a fertility center. International Journal of Hygiene and Environmental Health. 2018;221(2):174-182

[51] Ilacqua A, Izzo G, Pietro EG, Baldari C, Aversa A. Lifestyle and fertility: The influence of stress and quality of life on male fertility. Reproductive Biology and Endocrinology. 2018;16(1):115. DOI: 10.1186/s12958-018-0436-9

[52] Silva JV, Cruz D, Gomes M, Correia BR, Freitas MJ, Sousa L, et al. Study on the short-term effects of increased alcohol and cigarette consumption in healthy young men's seminal quality. Scientific Reports. 2017;7(1):45457

[53] Meeker JD, Ehrlich S, Toth TL, Wright DL, Calafat AM, Trisini AT, et al. Semen quality and sperm DNA damage in relation to urinary bisphenol A among men from an infertility clinic. Reproductive Toxicology. 2010;30(4):532-539

[54] Li D-K, Zhou Z, Miao M, He Y, Wang J, Ferber J, et al. Urine bisphenol-A (BPA) level in relation to semen quality. Fertility and Sterility. 2011;95(2):625-630.e4

[55] Chen M, Tang R, Fu G, Xu B, Zhu P, Qiao S, et al. Association of exposure to phenols and idiopathic male infertility. Journal of Hazardous Materials. 2013;250-251:115-121

[56] Zhu W, Zhang H, Tong C, Xie C, Fan G, Zhao S, et al. Environmental exposure to triclosan and semen quality. International Journal of Environmental Research and Public Health. 2016;13(2):224

[57] Richthoff J, Rylander L, Jönsson BAG, Akesson H, Hagmar L, NilssonEhle P, et al. Serum levels of $2,2^{\prime}, 4,4^{\prime}, 5,5^{\prime}$-hexachlorobiphenyl (CB-153) in relation to markers of 
reproductive function in young males from the general Swedish population. Environmental Health Perspectives. 2003;111(4):409-413. DOI: 10.1289/ ehp.5767

[58] Rignell-Hydbom A, Rylander L, Giwercman A, Jönsson BAG, NilssonEhle P, Hagmar L. Exposure to CB-153 and $\mathrm{p}, \mathrm{p}^{\prime}-\mathrm{DDE}$ and male reproductive function. Human Reproduction. 2004;19(9):2066-2075

[59] Rignell-Hydbom A, Rylander L, Giwercman A, Jönsson BAG, Lindh C, Eleuteri P, et al. Exposure to PCBs and p,p'-DDE and human sperm chromatin integrity. Environmental Health Perspectives. 2005;113(2):175-179

[60] Hauser R, Chen Z, Pothier L, Ryan L, Altshul L. The relationship between human semen parameters and environmental exposure to polychlorinated biphenyls and p,p'-DDE. Environmental Health Perspectives. 2003;111(12):1505-1511

[61] Arabi M. Bull spermatozoa under mercury stress.

Reproduction in Domestic Animals. 2005;40(5):454-459

[62] Silva EFSJD, Missio D, Martinez CS, Vassallo DV, Peçanha FM, Leivas FG, et al. Mercury at environmental relevant levels affects spermatozoa function and fertility capacity in bovine sperm. Journal of Toxicology and Environmental Health, Part A. Current Issues. 2019;82(4):268-278

[63] Ai C-E, Li C-J, Tsou M-C, Chen J-L, Hsi H-C, Chien L-C. Blood and seminal plasma mercury levels and predatory fish intake in relation to low semen quality. Environmental Science and Pollution Research. 2019;26(19):19425-19433

[64] Thompson J, Bannigan J. Cadmium: Toxic effects on the reproductive system and the embryo. Reproductive Toxicology. 2008;25(3):304-315

[65] Pant N, Pant AB, Chaturvedi PK, Shukla M, Mathur N, Gupta YK, et al. Semen quality of environmentally exposed human population: The toxicological consequence. Environmental Science and Pollution Research. 2013;20(11):8274-8281. DOI: 10.1007/s11356-013-1813-8

[66] Kanwar U, Chadha S, Batla A, Sanyal SN, Sandhu R. Effect of selected metal ions on the motility and carbohydrate metabolism of ejaculated human spermatozoa. Indian Journal of Physiology and Pharmacology. 1988;32(3):195-201

[67] Sun J, Yu G, Zhang Y, Liu X, Du C, Wang L, et al. Heavy metal level in human semen with different fertility: A meta-analysis. Biological Trace Element Research. 2017;176(1):27-36

[68] Yucra S, Rubio J, Gasco M, Gonzales C, Steenland K, Gonzales GF. Semen quality and reproductive sex hormone levels in peruvian pesticide sprayers. International Journal of Occupational and Environmental Health. 2006;12(4):355-361. DOI: 10.1179/oeh.2006.12.4.355

[69] Lifeng T, Shoulin W, Junmin J, Xuezhao S, Yannan L, Qianli W, et al. Effects of fenvalerate exposure on semen quality among occupational workers. Contraception. 2006;73(1):92-96

[70] Hossain F, Ali O, D’Souza UJA, Naing DKS. Effects of pesticide use on semen quality among farmers in rural areas of Sabah, Malaysia. Journal of Occupational Health. 2010;52(6):353-360

[71] Axelsson J, Rylander L, RignellHydbom A, Jönsson BAG, Lindh CH, Giwercman A. Phthalate exposure and reproductive parameters in 
young men from the general Swedish population. Environment International. 2015;85:54-60

[72] Duty SM, Silva MJ, Barr DB, Brock JW, Ryan L, Chen Z, et al. Phthalate exposure and human parameters. Epidemiology.

2003;14(3):269-277

[73] Meeker JD, Barr DB, Hauser R. Human semen quality and sperm DNA damage in relation to urinary metabolites of pyrethroid insecticides. Human Reproduction. 2008;23(8):1932-1940. DOI: $10.1093 /$ humrep/den 242

[74] Duty SM, Calafat AM, Silva MJ, Brock JW, Ryan L, Chen Z, et al. The relationship between environmental exposure to phthalates and computeraided sperm analysis motion parameters. Journal of Andrology. 2004;25(2):293-302

[75] Duty SM, Silva MJ, Barr DB, Brock JW, Ryan L, Chen Z, et al. Phthalate exposure and human semen parameters. Epidemiology. 2003;14(3):269-277

[76] Pant N, Pant A, Shukla M, Mathur N, Gupta Y, Saxena D. Environmental and experimental exposure of phthalate esters: The toxicological consequence on human sperm. Human \& Experimental Toxicology. 2011;30(6):507-514. DOI: $10.1177 / 0960327110374205$

[77] Barakat R, Lin P-CP, Rattan S, Brehm E, Canisso IF, Abosalum ME, et al. Prenatal exposure to DEHP induces premature reproductive senescence in male mice. Toxicological Sciences. 2017;156(1):96-108. DOI: 10.1093/toxsci/kfw248

[78] Agarwal A. Role of sperm chromatin abnormalities and DNA damage in male infertility. Human Reproduction Update. 2003;9(4):331-345. DOI: 10.1093/

humupd/dmg027
[79] Wright C, Milne S, Leeson H. Sperm DNA damage caused by oxidative stress: Modifiable clinical, lifestyle and nutritional factors in male infertility. Reproductive Biomedicine Online. 2014;28(6):684-703

[80] Tiwari D, Vanage G. Mutagenic effect of bisphenol a on adult rat male germ cells and their fertility. Reproductive Toxicology. 2013;40:60-68

[81] Meeker JD, Yang T, Ye X, Calafat AM, Hauser R. Urinary concentrations of parabens and serum hormone levels, semen quality parameters, and sperm DNA damage. Environmental Health Perspectives. 2011;119(2):252-257

[82] Zhou Y, Fu XM, He DL, Zou XM, Wu CQ, Guo WZ, et al. Evaluation of urinary metal concentrations and sperm DNA damage in infertile men from an infertility clinic. Environmental Toxicology and Pharmacology. 2016;45:68-73. DOI: 10.1016/j. etap.2016.05.020

[83] Rignell-Hydbom A, Axmon A, Lundh T, Jönsson BA, Tiido T, Spano M. Dietary exposure to methyl mercury and PCB and the associations with semen parameters among Swedish fishermen. Environmental Health. 2007;6(1):14. DOI: 10.1186/1476-069X-6-14

[84] Hauser R, Meeker JD, Singh NP, Silva MJ, Ryan L, Duty S, et al. DNA damage in human sperm is related to urinary levels of phthalate monoester and oxidative metabolites. Human Reproduction. 2007;22(3):688-695 


\title{
Endocrine Disruptors: Very Low Doses with Genuinely High Impacts on Male Reproduction
}

\author{
Michal Ješeta and Jan Nevoral
}

\begin{abstract}
Endocrine disruptors (EDs) are chemical substances that affect physiological processes in the body via hormonal regulation. They are often detected in food, plastic water bottles, cosmetics, and many other daily need items. Thereafter, EDs are detected in many bodily fluids, pointing out the real exposure to even very low doses. Permanent and long-term utilization of EDs has harmful effects on male reproductive health mainly due to interference with sex hormone synthesis and mechanism of action. However, with decreasing dosage of EDs, the possibilities of unpredictable modes of action arise. In addition to various molecular actions of individual EDs, the interference of individual ones represents another dimension of the ED issue. This review provides an overview of the EDs and their possible impact on reproductive health in males, with focus on sperm quality with the mighty potential of epigenetic transmission to further generations. The "posttranslational" effect of EDs in really low doses in real exposure routes is stigmatized in this review, being strongly considered as creeping molecular action of individual EDs as well as amplifications of their copresence in the environment.
\end{abstract}

Keywords: endocrine disruptor, bisphenol, regretable substitution, posttranslational modification

\section{Introduction}

Maturation of sperm cells (spermatogenesis) is a continuous process starting in puberty. The process is stimulated by follicle-stimulating hormone (FSH) and luteinizing hormone ( $\mathrm{LH})$. Until the onset of puberty, spermatogonia are quiescent and their quantity does not change significantly. After sexual maturity is reached, an expressive activation of mitochondrial activity and the process of spermatogenesis begin, leading to the formation of spermatids. They are then transformed into spermatozoa by the spermiohistogenesis process, when a round spermatid changes into a sperm cell with a tail, middle section, and head. However, whole spermatogenesis, including gonadal ridge colonization and differentiation of primordial germ cells (PGCs), followed by further development, begins during early embryogenesis. In light of this fact, there are several exposure windows when environmental noxi can hit spermatogenesis along the entire process.

Considering the transmission of extraneous agents, the hemotesticular barrier (HTB) represents the morphological division of the seminiferous tubulus into two 
compartments: basal and adluminal. The barrier is crucial for full functionality of germinal epithelium, as well as for the elimination of negative impacts of environmental pollutants. Physiologically, this strict division ensures free paracellular movement of substances among the compartments, such as water, nutrients, electrolytes, hormones, and paracrine factors. HTB provides protection of the emerging sperm cells from autoimmune damage by antibodies to sperm cells produced if the barrier was impaired, and the immune system would be in contact with spermatozoa during puberty when the body has already reached immunocompetence. Therefore, the cross talk of the immune system and HTB is potentially another sensitive target to a pollutant impact.

There is a basal compartment in close proximity to the basal membrane. This segment contains vessels and nerves, and spermatogenesis is initiated here. Spermatogonia and spermatocytes up to the proleptotene stage are present here. This segment is necessary for nutrition. The spermatogonia are subsequently transported through tight intercellular junctions to the adluminal compartment which is a place of spermatogenesis completion and subsequent metamorphosis of spermatids to spermatozoa. Both compartments are demarcated by the blood-testis barrier (BTB). Vessels and nerves are no longer present in this segment, and the nutrition of the germinal epithelium cells is covered by the Sertoli cells. The impact of various doses and concentrations of EDs on the male reproductive system can affect the functions of this barrier. The differentiation and development of the male reproductive system depends on elementary estrogen/ androgen ratio, and the antagonistic and agonistic effects of EDs often disrupt their balance. The development of testicular tissue is crucial for further development of the entire reproductive system, as the endocrine activity of testicles determines overall masculinization of the body. Any disruption in the development of the testicles can therefore impair the overall masculinization process and sperm production.

Sperm concentration in men decreases worldwide, and spermiogram parameters deteriorate mainly in the Western world population [1]. Among others, huge amounts of endocrine disruptors (EDs) in our environment can cause this state. This final manifestation of the noxious effect of EDs has an unknown background, such as dose, kinds of EDs, interactions, and crosstalk of individual EDs and/or the timing of the exposure. Therefore, biomonitoring data represents significant input for experimental designing, leading to the description of molecular action in simulated conditions. Based on the newest findings, the record of the biological impact of individual EDs is an ongoing research issue leading to indicating the found compounds as endocrine disruptors.

Many cases of impaired sexual development due to the effects of EDs are also known from the animal kingdom. For example, reduction of penile length was observed in crocodiles living in waters contaminated with EDs [2]. EDs can significantly influence not only the process of spermatogenesis but also the development of testicular tissue. It has been documented that increased exposition of pregnant mice to BPA caused alterations of organelles, that is, mitochondria and lysosomes, in Sertoli and Leydig cells, respectively. These alterations led to maturation disorders in spermatocytes and androgen synthesis inhibition [3].

\section{Spermatogenesis, epigenetics, biochemical status of spermatozoa, and implications for male reproduction}

The creation of the spermatozoon leads to the terminally differentiated cell with an extremely high level of chromatin methylation and silencing. The final shape of the spermatozoon, often species-specific, requires many morphological and biochemical changes, in particular, dynamic remodelation of the chromatin [4]. 
Protamination, histone-protamine exchange in elongating spermatids, represents a drastic, expressible change of sperm chromatin [5]. A tight protamine-derived DNA package protects sperm chromatin against damage and, interestingly, even the ratio of protamines PRM1 (sperm protamine P1) and PRM2 (sperm protamine P2) is decisive about sperm quality [6]. In accordance with the tight chromatin package, DNA is strongly methylated, and, therefore, general chromatin silencing is required for sperm stability [7, 8]. Protamination represents a tool for the protection of paternal gene imprinting [9]. Temporal protamine-packaged sperm DNA undergoes a second exchange of chromatin proteins after fertilization, and then maternal histones are incorporated into the paternal pronucleus. Both protaminehistone transition events, first and second in testicular seminiferous tubuli and fertilized oocyte, respectively, are obviously sensitive to environmental influences and represent susceptible exposure windows [10,11].

Although most core histone is substituted by protamines, a residual speciesspecific amount of histones resists in the sperm head. In addition to DNA methylome, epigenetic hallmarks of mature spermatozoa include the epigenetic code of residual histones, based on many posttranslational modifications (PTMs) of individual amino acids $[12,13]$. These chromatin-repressive histone marks positively correlate with DNA methylome and accompany imprinted genes. Moreover, the sperm histone code shows an exact physiological role in fertilization and early embryonic development [14]. The histone code establishment is highly orchestrated [15] and, therefore, enforces spermatid sensitivity to exposure to environmental pollutants.

Following comprehensive demethylation of parental chromatin after fertilization, the total erasure of the methylation pattern, including gene imprinting on paternal and maternal alleles, is needed for the re-establishment of gene imprinting adequate to the paternal pattern in the sperm cell. This erasure comes early after gonadal ridge colonization, and primordial germ cells (PGCs) occur, at human embryonic days E32 and E10.5 in mice [16]. The recurrent "writing" of the epigenetic pattern into imprinted loci occurs in the late prenatal period when the spermatogonia are formed. This period between erased PGCs and remethylated spermatozoa represents a highly sensitive and quite extensive exposure window, when the epigenetic status can be changed by environmental factors during embryonic development in utero. There is another dynamic chromatin demethylation, many years later, when sperm chromatin remodeling occurs when paternal and maternal pronuclei are developed in the early zygote. This methylation erasure is not complete and excludes parent-of-origin methylation, that is, erasure-resistant loci, such as IAPs, LINEs, and transposon-related loci. Taken together, the transgenerational and intergenerational inheritances of epigenetic shifts (i.e., non-genomic or nonMendelian inheritance) are based on these two exposure windows, when epigenetic erasure, including gene imprinting in PGCs and imprinted gene-excluding erasure, occur, respectively [17]. The renewal of gene imprinting between PGCs and mature gamete is another power of transgenerational epigenetic inheritance [18]. The dynamics of the epigenetic code is subjected to a well-tuned orchestra of "erasures" (TET oxygenases, histone deacetylases, and demethylases) and "writers" (DNA methyltransferases, histone methyl transferases, and acetyl transferases) (reviewed in [19]). It is assumed that, via EDs, they change the epigenetic code through these upstream factors (the possible methods of exposure are summarized in Figure 1).

Doubtless, a properly established epigenetic code plays an extremely important role, in particular in imprinted genes in epimutation-prone gametes. The epigenetic code of the spermatozoon is highly protected by the protamination, determining the stability of the genome and gene imprinting. Otherwise, epigenetic disorders arise: Prader-Willi syndrome, Angelman syndrome, or Silver-Russell syndrome. Moreover, residual histones bring the epigenetic information via histone PTMs. 


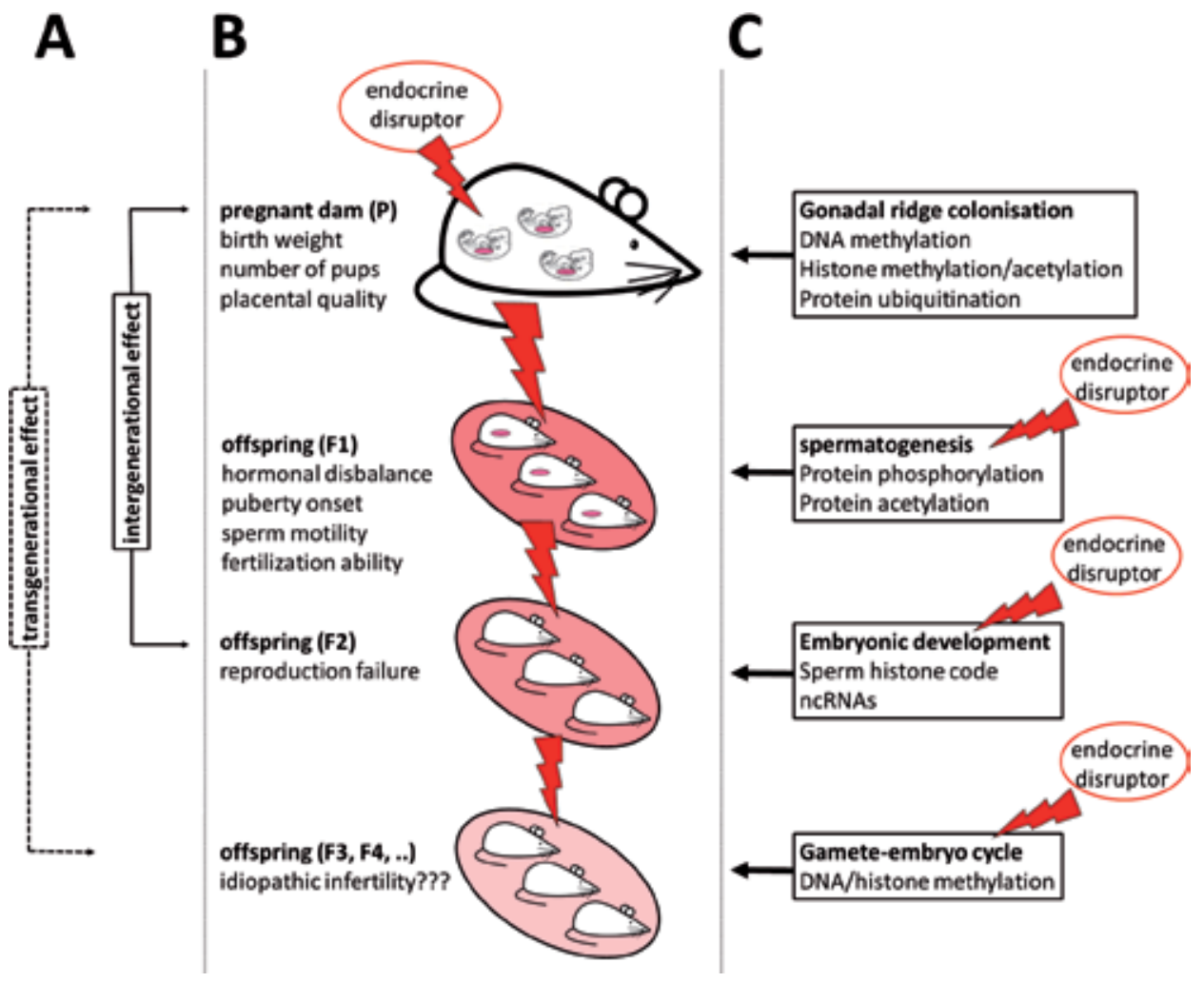

Figure 1.

Endocrine disruptors induce non-genomic inheritance through posttranslational modifications (PTMs) of various epigenetic factors. (A) Environmentally impacted posttranslational modifications of proteins incoming into intergenerational and transgenerational effects. (B) Endocrine disruptors are able to affect developing gonads through transplacental transmission in utero. Gonad activity is changed and hormonal levels, puberty onset, and sperm quality are affected. Sperm quality contributes to embryonic development and can influence the health of an offspring, and, therefore, the intergenerational transmission of the ED effect to $F_{2}$ generation is obvious. Gene imprinting and epigenetic erasure are assumed to be the tools of this effect. The epigenetic code of erasure-resistant loci is possibly affected by $E D$, and the transgenerational effect appears. Nonspecific symptoms accompany these epigenetic faults, and many disorders are classified as idiopathic. (C) From the molecular point of view, inadequate changes in DNA and chromatin proteins, including PTMs of core histones and/or $R N A$ polymerases, are responsible for the epigenetic record and gene manifestation, and ED becomes potentially dangerous for these protein modifications through "posttranslational" effect. Obviously, male reproduction is endangered through several exposure windows during gamete formation, including epigenetic code erasure and re-establishment. Therefore, in addition to direct modification of chromatin, responsible "erasures" and "writers" (responsible for de-differentiation and gene imprinting, respectively) undergo regulation via PTMs when the EDs' effect is considered.

Obviously, in addition to the genetic information, the sperm head carries a package of epigenetic notice, very sensitive to the disruption through its establishment throughout the spermatogenesis.

In addition to the establishment of epigenetic code of sperm histones, achievement of other PTMs of regulating proteins is required. Frequently, the loss of a PTM leads to protein activity lacking, sometimes leading to fatal clinical manifestations, for example, the inability of PARKIN1 S-sulfhydration of cysteine followed by sporadic Parkinson's disease [20]. During post-ejaculation the sperm changes, such as capacitation and acrosomal reaction; there are many PTMs of key proteins necessary for the achievement of fertilization ability. Therefore, protein kinase A (PKA)-driven phosphorylation of Arg-X-X-(Ser/Thr) motifs is required, as the result of upstream regulation by soluble adenylyl cyclase and cAMP production [21]. However, acetylation of $\varepsilon$-amino group of lysine residues arises as regulatory tool for 
PKA, and, accordingly, the hyperacetylation of sperm proteins is needed for sperm capacitation [22], essential for sperm hyperactivation in female reproductive tract. Versatile role of protein acetylation is obvious, including aforementioned residual histones as well as protein kinases. Taken together, the impact of endocrine disruptors on histone PTMs [23, 24] as well as sperm phosphorylation [25-27] has been described, and, therefore, the modifications of proteins (protein PTMs) become the likely manner in which disruptors (EDs) work in their real doses.

\section{Endocrine disruptors: mode of action and nonlinear effect}

There are many shared features of EDs, such as spatiotemporal omnipresence, exposure to very low doses, and, therefore, often a nontoxic effect [28]. Nevertheless, the affection of hormonal balance represents a major sign of them, giving the name to endocrine disruptors [29]. Indeed, there is an increasing number of observations of exposure to EDs, across all age, race, profession, lifestyle, and health status categories [30]. These findings are in accordance with the ubiquity of EDs through the presence in daily need items.

\begin{tabular}{|c|c|c|c|}
\hline Compound & Phenotype of filial generation & Species & Reference \\
\hline Antibiotics (Geneticin) & $\begin{array}{l}\text { Up-/downregulation of genes } \\
\text { responsible for basic metabolism, } \\
\text { cell cycle, stress response, and } \\
\text { development }\end{array}$ & $\begin{array}{l}\text { Drosophila } \\
\text { melanogaster }\end{array}$ & {$[108]$} \\
\hline Atrazine & $\begin{array}{l}\text { Reproduction, altered transcriptome } \\
\text { responsible for steroidogenesis, and } \\
\text { DNA methylation }\end{array}$ & $\begin{array}{l}\text { Medaka (Oryzias } \\
\text { latipes) }\end{array}$ & [109] \\
\hline $\begin{array}{l}\text { Benzylisoquinoline } \\
\text { alkaloids }\end{array}$ & Reduction of lipid accumulation & $\begin{array}{l}\text { Caenorhabditis } \\
\text { elegans }\end{array}$ & [110] \\
\hline $\mathrm{BPA}$ & $\begin{array}{l}\text { Affected neurogenesis and damaged } \\
\text { social interactions }\end{array}$ & Mouse (C57BL/6 J) & [111] \\
\hline DDT & Pathology of gonads, obesity & $\begin{array}{l}\text { Rat (Sprague } \\
\text { Dawley) }\end{array}$ & {$[112]$} \\
\hline Dioxin & Testicular tissue abnormalities & $\begin{array}{l}\text { Zebrafish (Danio } \\
\text { rerio) }\end{array}$ & {$[113]$} \\
\hline $\begin{array}{l}\text { Di(2-ethylhexyl)phthalate } \\
\text { (DEHP) }\end{array}$ & Reproduction failure & Mouse (CD-1) & {$[114]$} \\
\hline Glyphosate & $\begin{array}{l}\text { Obesity, prostate, and ovary diseases; } \\
\text { kidney failure; birth abnormalities }\end{array}$ & $\begin{array}{l}\text { Rat (Sprague } \\
\text { Dawley) }\end{array}$ & {$[115]$} \\
\hline Methoxychlor & Obesity, ovary, and kidney diseases & $\begin{array}{l}\text { Rat (Sprague } \\
\text { Dawley) }\end{array}$ & {$[116]$} \\
\hline Vinclozolin & $\begin{array}{l}\text { Alterations transcriptome with } \\
\text { disease susceptibility of gonads, } \\
\text { ancestry glands, mamma, and kidney }\end{array}$ & $\begin{array}{l}\text { Rat (Sprague } \\
\text { Dawley) }\end{array}$ & {$[117]$} \\
\hline
\end{tabular}

Representative studies are included, testing different compounds (in toxic and sub-toxic doses) on various biomodels, mostly exposed during the establishment of germ cells and gonad maturation. These exposures lead to changed phenotype of filial generation through the epimutation of germ cells. In addition to pregnant exposure, PTMs of epigenetic factors and/or histone code represent a molecular tool of endocrine disruptor-inherited impact along generations, even though the exposure is during adulthood. Although direct human evidence is lacking, there are several indications of the effect of transmission of endocrine disruptors in very low doses, on further generations due to PTM-driven epimutations [106, 107].

Table 1.

Overview of recent knowledge of environmental inheritance of endocrine disruptor effects. 
The "family" of EDs is wide and still growing, as is our awareness of their biological impact. Therefore, EDs include polybrominated diphenyl ethers, phthalates, polyethylene terephthalate (PET), bisphenols, and others (Table 1). Hence, flame retardants in electronic devices, perfumes, plastic bottles, and polycarbonates, respectively, are the most usual source of EDs. Surprisingly, some daily need items, such as paper bags, cans, receipts, and dental sealants, include bisphenols, although they seem to be free of any endocrine disruptors. Even strict elimination and usage control of pesticides are not able to exclude the endocrine-disrupting effect through contamination of food with residua of some of them, for example, glyphosate [31], atrazine [32], and imidacloprid [33]. Because EDs are so widespread, humans are exposed to them via different routes: oral intake with food and beverages and transdermal exposure and/or inhalation. Some specific routes of exposure are derived from the uniqueness of the stage of ontogenesis, such as transplacental in utero exposure during pregnancy, followed by translactational exposure when a baby is nursed.

Most EDs are released into the environment in a very low amount, and, therefore, the human intake is appropriately much smaller. This is the result of the legacy action of responsible authorities (European Food Safety Authority, EFSA; Food and Drug Administration, FDA), which has established the limits of intakes (tolerable daily intake, TDI) for many ED compounds. However, extremely low doses have been recognized as having a biological effect. In the light of this fact, the earlier
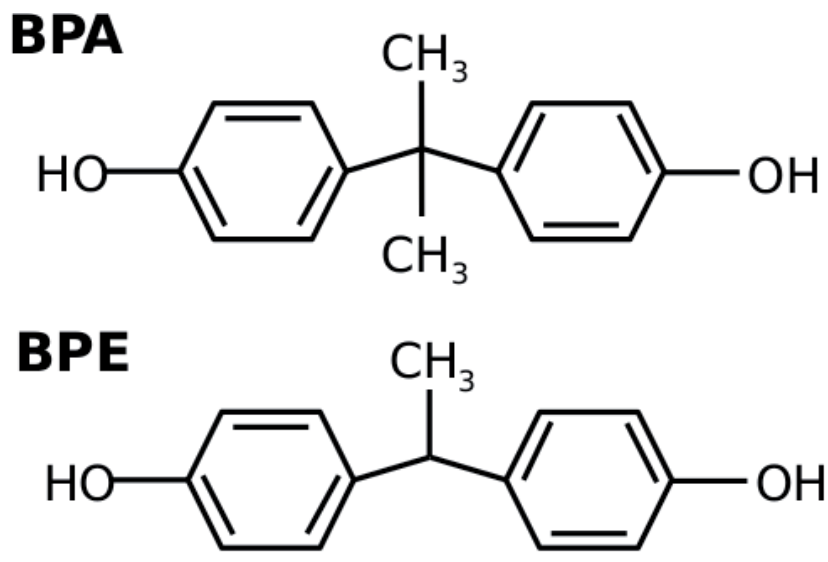

\section{BPF}

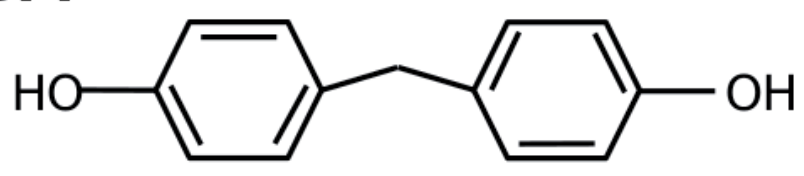

\section{BPS}

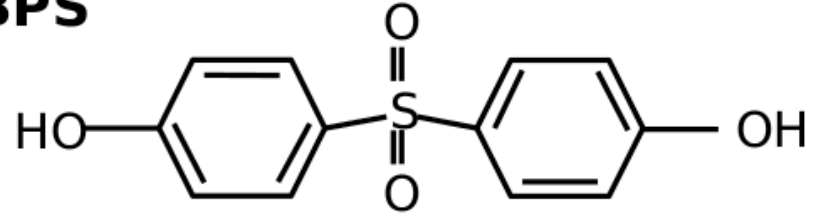

Figure 2.

Molecular structure of BPA and its alternatives. BPA, bisphenol A (2,2-Bis(4-hydroxyphenyl)propane); BPE, bisphenol E (4-(1-(4-hydroxyphenyl)ethyl)phenol); BPF, bisphenol S (4,4'-dihydroxydiphenylmethane); BPS, bisphenol S (4,4'-sulfonylbisphenol). 
accepted quantities of no-observed-adverse-effect level (NOAEL) and lowestobserved-adverse-effect level (LOAEL) lose importance. Interestingly, lower doses show often more deleterious effect than the higher ones, pointing out the nonlinear effect [29]. The response of the cell, tissue, or an organism on the dose is in a nonmonotonic (i.e., U-shape) curve [34]. It was difficult to accept this phenomenon, but recently we consider it to be one of the features of EDs [35-37].

After many substances were described to be an ED, elimination or total restriction followed. Therefore, several compounds have been introduced as a substitution. $n$-Hexane and alternative bisphenols (BPS, BPF, and BPAF) have become widespread, such as alternatives to dichloromethane and bisphenol A (BPA), respectively, although the unambiguous safety of these substitutions has not been proved (chemical structure of selected bisphenols is presented in Figure 2). For instance, BPA usage has been banned in children's toys and baby bottles, and, in addition to these, BPA-free products were introduced based on the consumer preferences [30]. However, BPS to BPA exchange has taken place, although "endocrine" safety has not been elucidated. In this point of view, we can denote it to be a regrettable substitution, and comprehensive testing of these alternative compounds is required.

\section{The impact of EDs on male reproductive health}

According to a range of studies, the effect of EDs is significant mainly during the development of the male reproductive system. The cocktail effect of multiple substances in low concentrations with similar action target has been described many times. Particularly trans-uterine exposition during embryonic development is critical, when testicular dysgenesis syndrome can develop [38]. There is a presumption that it is caused by impaired function of Leydig cells and testosterone production [39]. For initiation of prostate development and masculinization of the sex ducts, the presence and correct ratio of steroid hormones is necessary. Nevertheless, EDs often act as inhibitors of 5-alpha reductase enzyme that is necessary for the conversion of androgens to testosterone and inhibitors of aromatase necessary for androgens aromatization to estrogens [40].

\subsection{Effect on gonads and accessory glands}

Cryptorchidism: This is a serious developmental disorder which may be also caused by exposition of the fetus to EDs in utero and subsequent feeding with breast milk with a high concentration of EDs [41].

Hypospadias: It has been documented that utilization of EDs in the form of medication for pregnant women led to various disorders of testicular development [42].

Testicular cancer: The half-life of the EDs with lipophilic character is up to 30 years. It has been observed that mothers of adult men with testicular cancer had high levels of polychlorinated biphenyls (PCBs) in the blood, which led to the conclusions that the ability of PCBs to accumulate in the body makes their presence one of the factors contributing to development of this type of cancer [43]. Considering the half-life of many toxins, for example, PCBs, we can assume that these toxins will achieve their endocrine-disrupting effect as their real amount in the environment decreases, while their toxic effects are not taken into account anymore.

Prostate hyperplasia: It has been described in rats that exposition of males to low doses of estrogens and xenoestrogens led to prostate hyperplasia. These results support concerns that, in today's plastic era, this phenomenon will also manifest 
in adult men [44]. Moreover, in 2017, it was documented that doses of BPA equivalent to doses potentially present in the environment caused increased growth of prostate cells [45].

\subsection{Effect on spermatogenesis}

Sperm concentration in ejaculates of men has been decreasing for a long time, mainly in Western world populations (the USA, Europe, Australia, and New Zealand) [1]. This long-term process has been observed since the 1970s. The situation might be caused by environmental changes, primarily by the increased occurrence of various EDs [46]. It is generally acknowledged that the process of sperm production is significantly reduced by FSH and $\mathrm{LH}$, while alterations on this level may cause impairment of spermatogenesis to infertility [47].

\subsection{Effect on cells of germinal epithelium}

It is known that EDs are capable of influencing the offspring in utero through transplacental transmission and via breast milk and that they cause disorders that can be transferred epigenetically to further generations. In certain periods of fetal development, testicles are estrogen-sensitive, and their excessive exposure to this hormone can result in complete arrest of steroidogenesis. EDs with an estrogenic character can interfere with the correct functioning of the reproductive system.

During spermatogenesis, spermatogonia are transformed to spermatozoa when a round spermatid changes into a sperm cell with tail, middle piece, and sperm head. For this process, Sertoli cells play a key role as they form the functional blood-testis barrier (BTB) with very tight junctions. This barrier is dynamic and demarcates the basal compartment and adluminal compartment of seminiferous tubules. The barrier is necessary to prevent damaging of sperm cells by the immune system, since contact of blood and mature sperm cells leads to the production of antibodies to spermatozoa. These antibodies can then enter the seminal plasma and damage sperm cells. The principle of the hemotesticular barrier are very tight junctions between the Sertoli cells which divide the structure of seminiferous tubules into basal and adluminal compartments.

\subsection{Disruption of the blood-testis barrier (BTB)}

Effects on the hemotesticular barrier can significantly affect spermatogenesis and can have an impact on embryonic development of testicular tissue. The division contributes to unlimited capillary supply of nutrients, hormones, and other biomolecules which are needed for mitotic renewal of spermatogonia, their proliferation, and differentiation. However, the other developmental stages must not come into contact with blood. If this barrier did not exist or was damaged, antibodies to sperm cells would be produced, which could ultimately result in male infertility [48].

BTB and effect of EDs: Detachment of both compartments is ensured by tight intercellular junctions of adjacent Sertoli cells. These are very tight connections represented mainly by tight junction, adherens junction, desmosome, and gap junction types. The riskiest period is when spermatocyte at the proleptotene stage passes through the barrier, which needs to undergo structural changes. It is this particular period when the effect of substances such as the endocrine disruptors is most significant.

It is known that the level of free BPA in blood plasma decreases the concentrations of occludin, $\mathrm{N}$-cadherin, and connexin 43, which are proteins that 
significantly contribute to the production and regeneration of tight junctions. Decreased levels of these proteins affect the function of BTB [49].

Taken together, a very low dose of EDs seems to have the most deleterious impact. There are obviously different modes of action of EDs, and, all the more so, the molecular targets of EDs are the center of interest of the current studies describing disruptors.

\section{Molecular mechanism of EDs in extremely low doses}

The toxic effects of many compounds are well-known and described, and the amount of published findings is still growing by thousands of papers each year. In general, genotoxicity and carcinogenesis [50], oxidative stress induction [51], and DNA damage and cell senescence [52-54] are known impacts of several toxic compounds. However, sub-toxic effects of toxic compounds (pesticides and drugs) described earlier as well as seemingly safe compounds (alternative bisphenols) represent a serious risk for human public health. For this reason, there are many biomonitoring initiatives, followed by legislation and the development of nextgeneration plastics.

In accordance with toxin elimination during the last decades, people in developed countries have been recently exposed to rather sub-toxic doses in trace amounts. This effect is known as endocrine disrupting, affecting the body in other ways than toxins, that is, genomic, non-genomic, and epigenetic modes of action. While the genomic effect is similar to toxin action, the non-genomic effect is the closest to endocrine disruption; the mimicking of the presence of a hormone, targeting of hormonal signaling, and/or misregulation of hormone production and expression of receptors are known mechanisms of endocrine-disrupting effects [55-57]. Hormonal disbalance impacts the hypothalamus-pituitary-gonadal axis [58], with possible clinical manifestations: changed anogenital distance, morphological changes of sex determinations, and earlier puberty onset [59]. However, the tested doses are very high, whereas, on the contrary, very low doses correspond to the real exposure, often leading to small differences on the level of tissue and cell, without any demonstration of clinical aspects. Although changes in hormonal balance are well-known [60, 61], EDs are even capable of affecting hormonal action directly in a cell without a shift in hormonal profile. Therefore, the estrogen-like and estrogenic effects of BPA have been described in germ [62], ovarian [63], and testicular cells $[64,65]$. Frequently, the G-protein-coupled estrogen receptor is a target of the estrogen-like effect of BPA $[65,66]$, as well as alternative bisphenols [67]. Transcription and subcellular distribution of estrogen receptors ER $\alpha$ and ER $\beta$ and aromatase, an enzyme converting adro- to estrogens, are changed in bisphenol S-exposed oocytes [68]. These non-genomic alterations are accompanied by cytoskeleton abnormalities. In particular, the meiotic spindle is extremely sensitive [69] and, indeed, affected in mammalian oocytes exposed to bisphenols $[68,70,71]$, leading to increased incidence of aneuploidy [72].

The comparable effect of EDs is known during spermatogenesis: BPA is capable of affecting meiotic division and chromosome segregation, increasing the incidence of aneuploidy-derived disorders [73]. In addition, the molecular mechanism of BPA consists in impacting several signal pathways and results in the change of protein kinase A activity and protein tyrosine phosphorylation, ATP generation, and oxidative stress-related enzymes (i.e., peroxiredoxin-5, glutathione peroxidase 4, succinate dehydrogenase), crucial for sperm motility and ability of oocyte fertilization [26, 27, 74]. Dose-response association of BPA and motility parameters of human sperm has been observed [75]. Interestingly, some EDs have shown a 
stronger negative impact on Y-chromosome-bearing spermatozoa, and the sex ratio of offsprings can be changed [76, 77].

Many non-genomic methods of ED action lead to inappropriate epigenetic changes of DNA and core histones. Although the sequence of nucleotide remains unaffected, the changes of genome-wide methylation status, as well as silencing or enhancing the individual loci, follow the exposure of EDs. These epimutations result in changed transcriptional activity of the genome with many negative impacts, such as failure of scavenging of reactive oxygen species, DNA damage repair, and/or inadequate mitochondrial biogenesis. These cellular changes lead to clinical manifestations, most of which are diagnosed as “idiopathic." Obviously, exposure to EDs causes obesity [78], type 2 diabetes [79], metabolic disorders, and infertility [80].

While the exposure of somatic cells creates health problems for exposed individuals, influence on gametes leads to an intergenerational effect when the burden is transduced to the next generation of daughters and sons [81]. Indeed, the exposure to bisphenols impairs genome-wide DNA methylation, as well as histone code in oocytes $[71,82]$, followed by changes in the imprinting of genes in the embryo and placenta [83]. In spermatozoa, DNA methylation [84] is potentially affected by environmental pollutants, leading to aberrant gene imprinting $[85,86]$. It can be assumed that the sperm histone code is sensitive to endocrine disruptors, with effect similar to estrogens, as well as to the involvement of estrogen receptors in histone code establishment [15]. Moreover, the negative role of environmental pollutants in the influence on noncoding RNAs in spermatozoa, another tool of epigenetic regulation [87] with ability to drive epigenetic inheritance [88], is wellknown [89, 90].

The exposure in utero and transplacental transmission of an ED affect DNA demethylation in developing PGCs and result in transgenerational inheritance of this burden. Accordingly, the exposure of pregnant rat females to fungicide vinclozolin [91] or DDT [92] leads to modified epigenome, that is, DNA methylome, histone retention in sperm, and ncRNAs. Translactational exposure, another way of indirect influence with environmental agents, is a reason of changes of male reproduction after lactating female mice were exposed to BPA [93]. Moreover, this type of exposure to bisphenols creates a risk of changed nursing behavior and also affects the mammary glands of mothers [94].

Whereas endocrine-disrupting hypothesis is assumed for very low doses of EDs, there is a relevant phenomenon of interactions of individual EDs. The comprehensive work of T. Pollock and his colleagues produced valuable results, describing cross talk of common EDs. The combined presence of bisphenols is considered to be deleterious [95] as well as the simultaneous presence of triclosan, a soap compound $[96,97]$. Degradation of bisphenol is inhibited under other ED exposure, and, obviously, the co-exposure achieves various modes on how to affect the body [98]. In addition to human and mammalian models, there is evidence of interaction of xenobiotics and pesticide residua [99], as well as synergistic interactions of organophosphates and pyrethroids [100], potentially leading to the collapse of honey bee colonies [101]. In contrast to synergic effects leading to the increase of the deleterious impact, competition of some pollutants is known, and, surprisingly, a reverse effect of the synergic activity of pollutants has been described, where one pollutant protects cells against damage caused by another pollutant [102]. The molecular action of interacting pollutants remains to be unexplained in mammalian models, and there is obvious need for further study. Also the results of these studies will influence public health protection. 


\section{Perspectives}

The aforementioned routes of exposure to EDs, including their interactions, obviously lead to different systemic response as the result of molecular action in tissues and cells. The molecular mode of action seems to be the key for the elimination of EDs' negative effect on the body. Based on already described manifestations of EDs in higher and lower doses, two dose-dependent modes of action are recognized: toxic effect and endocrine disruption. It seems that the current issue of EDs is in extremely low doses without clinical manifestations, leading to "idiopathic" infertility, metabolic syndrome, and other failures with nonspecific symptoms. Moreover, intergenerational and transgenerational inheritances occur because of the change of the epigenetic code of germ cells. The posttranslational modifications of crucial proteins, particularly regulating epigenetic factors, seem to be a common feature of these very low doses. In accordance with this, we can mark this effect to be "posttranslational." The possible contribution of posttranslational modifications of key proteins is indicated in Figure 1.

There is an obvious direct impact of EDs on male reproduction due to oral, respiratory, and/or transdermal exposure. Thereafter, both the gonads and accessory glands are affected, leading to the failure of male reproduction, often diagnosed as idiopathic. On the spermatozoon level, direct protein targeting is assumed, including cytosolic proteins as well as sperm histone code. Even protamine PTMs are considered to have a biological role, and, in accordance with the abovementioned importance of acetylated lysines, protamine acetylation seems to be most potent for sperm quality. The impact on DNA and chromatin proteins (i.e., histones and protamines) represent hazardous mode of inter- and transgenerational transmission of ED-driven epigenome.

In addition to the direct impact of EDs, indirect impact is also observed. The exposure of EDs during pregnancy and prenatal life represents the most dangerous exposure method when the germline is affected during gene imprinting erasure and re-imprinting in developing spermatozoa [85] and oocytes [103]. This exposure window allows an ED to affect the health of a generation of grandchildren through transgenerational inheritance $[104,105]$. Epigenetic transmission to further generations involves various modifications, such as DNA and histone methylation, histone acetylation, and other PTMs of core histones, as well as epigenetic writers and erasures, translational factors, and others. Obviously, PTMs actually drive the phenomenon of the epigenetic inheritance, and the molecular impact of individual EDs is still unknown, as is their interaction (Table 1).

There is a strong need for further study focused on the ED-modulated epigenetic code and its manifestation in the body. In accordance with our "posttranslational" hypothesis of ED action, comprehensive screening of the most crucial PTMs should be taken into account in an assessment of individual EDs. Taken together, biomonitoring has an extremely significant role in the fight against EDs, as does the subsequent testing of EDs in the ascertained doses. Simulation of real exposures to individual EDs and their interactions are appropriate, using both in vitro and in vivo experimental assessments. Finally, advanced screening methods capable of identifying PTMs are needed for qualified recognition of an ED as harmful/harmless.

\section{Acknowledgements}

The study of endocrine disruptors is supported by the Czech Health Research Council (NV18-01-00544); H2020 (Human Biomonitoring Initiative HBM4EU); 
MH CZ-DRO (FNBr, 65269705), project MSMT LTC18059; COST action CellFit CA16119; the Charles University Research Fund (Progres Q39); and the National Sustainability Program I (NPU I) Nr. LO1503 provided by the Ministry of Education, Youth and Sports of the Czech Republic (MEYS CR); project No. SVV 02690 awarded by MEYS CR; and project No. CZ.02.1.01/0.0/0.0/16_019/0000787 "Fighting Infectious Diseases," awarded by MEYS CR and financed by the European Regional Development Fund. We would like to thank Ms. Iveta Zimova, Mr. Vaclav Rucka, and all graduate and pregraduate students for their kind help with the experimental work.

\section{Conflict of interest}

The authors declare no conflict of interest.

\section{Author details}

Michal Ješeta ${ }^{1 *}$ and Jan Nevoral ${ }^{2,3}$

1 Department of Obstetrics and Gynecology, University Hospital and Masaryk University, Brno, Czech Republic

2 Biomedical Center, Faculty of Medicine in Pilsen, Charles University, Czech Republic

3 Department of Histology and Embryology, Faculty of Medicine in Pilsen, Charles University, Czech Republic

*Address all correspondence to: jeseta@gmail.com

\section{IntechOpen}

(C) 2019 The Author(s). Licensee IntechOpen. This chapter is distributed under the terms of the Creative Commons Attribution License (http://creativecommons.org/licenses/ by/3.0), which permits unrestricted use, distribution, and reproduction in any medium, provided the original work is properly cited. (cc) BY 


\section{References}

[1] Levine H, Jørgensen N, MartinoAndrade A, Mendiola J, Weksler-Derri D, Mindlis I, et al. Temporal trends in sperm count: A systematic review and meta-regression analysis. Human Reproduction Update. 2017;23:646-659. DOI: $10.1093 / \mathrm{humupd} / \mathrm{dmx} 022$

[2] McLachlan JA, Simpson E, Martin M. Endocrine disrupters and female reproductive health. Best Practice \& Research. Clinical Endocrinology \& Metabolism. 2006;20:63-75. DOI: 10.1016/j.beem.2005.09.009

[3] Liu X-L, Chen X-Y, Wang Z-C, Shen T, Zhao H. Effects of exposure to bisphenol A during pregnancy and lactation on the testicular morphology and caspase- 3 protein expression of ICR pups. Biomed Reports. 2013;1:420-424. DOI: 10.3892/br.2013.79

[4] Rathke C, Baarends WM, Awe S, Renkawitz-Pohl R. Chromatin dynamics during spermiogenesis. Biochimica et Biophysica Acta, Gene Regulatory Mechanisms. 2014;1839:155-168. DOI: 10.1016/j.bbagrm.2013.08.004

[5] Oliva R. Protamines and male infertility. Human Reproduction Update. 2006;12:417-435. DOI: 10.1093/ humupd/dml009

[6] Carrell DT, Emery BR, Hammoud S. Altered protamine expression and diminished spermatogenesis: What is the link? Human Reproduction Update. 2007;13:313-327. DOI: 10.1093/humupd/ dml057

[7] Nanassy L, Carrell DT. Analysis of the methylation pattern of six gene promoters in sperm of men with abnormal protamination. Asian Journal of Andrology. 2011;13:342-346. DOI: 10.1038/aja.2010.160

[8] Rahiminia T, Yazd EF, Fesahat F, Moein MR, Mirjalili AM, Talebi AR.
Sperm chromatin and DNA integrity, methyltransferase mRNA levels, and global DNA methylation in oligoasthenoteratozoospermia. Clinical and Experimental Reproductive Medicine. 2018;45:17-24. DOI: 10.5653/ cerm.2018.45.1.17

[9] Carrell DT, Emery BR, Hammoud S. The aetiology of sperm protamine abnormalities and their potential impact on the sperm epigenome. International Journal of Andrology. 2008;31:537-545. DOI: 10.1111/j.1365-2605.2008.00872.x

[10] Zatecka E, Castillo J, Elzeinova F, Kubatova A, Ded L, Peknicova J, et al. The effect of tetrabromobisphenol A on protamine content and DNA integrity in mouse spermatozoa. Andrology. 2014;2:910-917. DOI: 10.1111/j.2047-2927.2014.00257.x

[11] Ankolkar M, Deshpande SS, Balasinor NH. Systemic hormonal modulation induces sperm nucleosomal imbalance in rat spermatozoa.

Andrologia. 2018;50:e13060. DOI: 10.1111/and.13060

[12] Brunner AM, Nanni P, Mansuy IM. Epigenetic marking of sperm by post-translational modification of histones and protamines. Epigenetics \& Chromatin. 2014;7:2. DOI:

10.1186/1756-8935-7-2

[13] Luense LJ, Wang X, Schon SB, Weller AH, Lin Shiao E, Bryant JM, et al. Comprehensive analysis of histone post-translational modifications in mouse and human male germ cells. Epigenetics \& Chromatin. 2016;9:24. DOI: $10.1186 / \mathrm{s} 13072-016-0072-6$

[14] Schon SB, Luense LJ, Wang X, Bartolomei MS, Coutifaris C, Garcia BA, et al. Histone modification signatures in human sperm distinguish clinical abnormalities. Journal of Assisted Reproduction and Genetics. 
2019;36:267-275. DOI: $10.1007 /$ s10815-018-1354-7

[15] Dumasia K, Kumar A, Deshpande $\mathrm{S}$, Balasinor NH. Estrogen, through estrogen receptor 1 , regulates histone modifications and chromatin remodeling during spermatogenesis in adult rats. Epigenetics. 2017;12:953-963. DOI: 10.1080/15592294.2017.1382786

[16] Lucas-Herald AK, Bashamboo A. Gonadal Development. Endocrine Development. 2014;27:1-16. DOI: $10.1159 / 000363608$

[17] Sales VM, Ferguson-Smith AC, Patti M-E. Epigenetic mechanisms of transmission of metabolic disease across generations. Cell Metabolism. 2017;25:559-571. DOI: 10.1016/j. cmet.2017.02.016

[18] Iqbal K, Tran DA, Li AX, Warden C, Bai AY, Singh P, et al. Deleterious effects of endocrine disruptors are corrected in the mammalian germline by epigenome reprogramming. Genome Biology. 2015;16:59. DOI: 10.1186/ s13059-015-0619-z

[19] Zeng Y, Chen T. DNA methylation reprogramming during mammalian development. Genes (Basel). 2019;10:257. DOI: 10.3390/ genes10040257

[20] Vandiver MS, Paul BD, Xu R, Karuppagounder S, Rao F, Snowman AM, et al. Sulfhydration mediates neuroprotective actions of parkin. Nature Communications. 2013;4:1626. DOI: $10.1038 /$ ncomms2623

[21] O'Flaherty C. Phosphorylation of the arginine-X-X-(serine/threonine) motif in human sperm proteins during capacitation: Modulation and protein kinase a dependency. Molecular Human Reproduction. 2004;10:355-363. DOI: 10.1093/molehr/gah046
[22] Ritagliati C, Luque GM, Stival C, Baro Graf C, Buffone MG, Krapf D. Lysine acetylation modulates mouse sperm capacitation. Scientific

Reports. 2018;8:13334. DOI: 10.1038/ s41598-018-31557-5

[23] Men Y, Zhao Y, Zhang P, Zhang H, Gao Y, Liu J, et al. Gestational exposure to low dose Zearalenone disrupting offspring spermatogenesis might Be through epigenetic modifications. Basic \& Clinical Pharmacology \& Toxicology. 2019:1-12. DOI: 10.1111/bcpt.13243

[24] González-Rojo S, Lombó M, Fernández-Díez C, Herráez MP. Male exposure to bisphenol A impairs spermatogenesis and triggers histone hyperacetylation in zebrafish testes. Environmental Pollution. 2019;248:368379. DOI: 10.1016/j.envpol.2019.01.127

[25] Xie F, Chen X, Weng S, Xia T, Sun X, Luo T, et al. Effects of two environmental endocrine disruptors di-n-butyl phthalate (DBP) and monon-butyl phthalate (MBP) on human sperm functions in vitro. Reproductive Toxicology. 2019;83:1-7. DOI: 10.1016/j. reprotox.2018.10.011

[26] Rahman MS, Kwon WS, Karmakar PC, Yoon SJ, Ryu BY, Pang MG. Gestational exposure to bisphenol A affects the function and proteome profile of F1 spermatozoa in adult mice. Environmental Health Perspectives. 2017;125:238-245. DOI: 10.1289/ EHP378

[27] Rahman MS, Kwon W-S, Lee J-S, Yoon S-J, Ryu B-Y, Pang M-G. Bisphenol-a affects male fertility via fertility-related proteins in spermatozoa. Scientific Reports. 2015;5:9169. DOI: 10.1038/srep09169

[28] Žalmanová T, Hošková K, Nevoral J, Prokešová Š, Zámostná K, Kott T, et al. Bisphenol S instead of bisphenol A: A story of reproductive disruption by regretable substitution-A review. Czech 
Journal of Animal Science. 2016;61. DOI: $10.17221 / 81 / 2015-C J A S$

[29] Vandenberg LN, Colborn T, Hayes TB, Heindel JJ, Jacobs DR, Lee D-H, et al. Hormones and endocrinedisrupting chemicals: Low-dose effects and nonmonotonic dose responses. Endocrine Reviews. 2012;33:378-455. DOI: 10.1210/er.2011-1050

[30] Scherer LD, Maynard A, Dolinoy DC, Fagerlin A, Zikmund-Fisher BJ. The psychology of "regrettable substitutions": Examining consumer judgements of bisphenol A and its alternatives. Health, Risk \& Society. 2014;16:649-666. DOI: $10.1080 / 13698575.2014 .969687$

[31] Nardi J, Moras PB, Koeppe C, Dallegrave E, Leal MB, Rossato-Grando LG. Prepubertal subchronic exposure to soy milk and glyphosate leads to endocrine disruption. Food and Chemical Toxicology. 2017;100:247-252. DOI: 10.1016/j.fct.2016.12.030

[32] Fang Y, Ni C, Dong Y, Li H, Wu S, Li X, et al. In utero exposure to atrazine disrupts rat fetal testis development. Frontiers in Pharmacology. 2018;9:1391. DOI: 10.3389/fphar.2018.01391

[33] Mesnage R, Biserni M, Genkova D, Wesolowski L, Antoniou MN. Evaluation of neonicotinoid insecticides for oestrogenic, thyroidogenic and adipogenic activity reveals imidacloprid causes lipid accumulation. Journal of Applied Toxicology. 2018;38:1483-1491. DOI: $10.1002 /$ jat.3651

[34] Lagarde F, Beausoleil C, Belcher SM, Belzunces LP, Emond C, Guerbet M, et al. Non-monotonic dose-response relationships and endocrine disruptors: A qualitative method of assessment. Environmental Health. 2015;14:13. DOI: 10.1186/1476-069X-14-13

[35] Molina A, Abril N, Morales-Prieto N, Monterde J, Ayala N, Lora A, et al.
Hypothalamic-pituitary-ovarian axis perturbation in the basis of bisphenol A (BPA) reproductive toxicity in female zebrafish (Danio rerio). Ecotoxicology and Environmental Safety. 2018;156:116-124. DOI: 10.1016/j. ecoenv.2018.03.029

[36] Oudir M, Chader H, Bouzid B, Bendisari K, Latreche B, Boudalia S, et al. Male rat exposure to low dose of di(2-ethylhexyl) phthalate during prepubertal, pubertal and post-pubertal periods: Impact on sperm count, gonad histology and testosterone secretion. Reproductive Toxicology. 2018;75:33-39. DOI: 10.1016/j.reprotox.2017.11.004

[37] Ramos C, Ladeira C, Zeferino S, Dias A, Faria I, Cristovam E, et al. Cytotoxic and genotoxic effects of environmental relevant concentrations of bisphenol A and interactions with doxorubicin. Mutation Research/ Genetic Toxicology and Environmental Mutagenesis. 2019;838:28-36. DOI: 10.1016/j.mrgentox.2018.11.009

[38] Lymperi S, Giwercman A. Endocrine disruptors and testicular function. Metabolism. 2018;86:79-90. DOI: 10.1016/j.metabol.2018.03.022

[39] Eladak S, Grisin T, Moison D, Guerquin M-J, N'Tumba-Byn T, PozziGaudin S, et al. A new chapter in the bisphenol A story: Bisphenol S and bisphenol $\mathrm{F}$ are not safe alternatives to this compound. Fertility and Sterility. 2015;103:11-21. DOI: 10.1016/j. fertnstert.2014.11.005

[40] Sweeney MF, Hasan N, Soto AM, Sonnenschein C. Environmental endocrine disruptors: Effects on the human male reproductive system. Reviews in Endocrine \& Metabolic Disorders. 2015;16:341-357. DOI: 10.1007/s11154-016-9337-4

[41] Brucker-Davis F, Wagner-Mahler K, Delattre I, Ducot B, Ferrari P, Bongain A, et al. Cryptorchidism at birth in Nice 
area (France) is associated with higher prenatal exposure to PCBs and DDE, as assessed by colostrum concentrations. Human Reproduction. 2008;23:17081718. DOI: $10.1093 /$ humrep/den186

[42] Toppari J, Virtanen HE, Main KM, Skakkebaek NE. Cryptorchidism and hypospadias as a sign of testicular dysgenesis syndrome (TDS):

Environmental connection. Birth Defects Research. Part A, Clinical and Molecular Teratology. 2010;88:910-919. DOI: $10.1002 /$ bdra.20707

[43] Hardell L, van Bavel B, Lindström G, Carlberg M, Dreifaldt AC, Wijkström $\mathrm{H}$, et al. Increased concentrations of polychlorinated biphenyls, hexachlorobenzene, and chlordanes in mothers of men with testicular cancer. Environmental Health Perspectives. 2003;111:930-934. DOI: 10.1289/ ehp.5816

[44] Taylor JA, Richter CA, Ruhlen RL, vom Saal FS. Estrogenic environmental chemicals and drugs: Mechanisms for effects on the developing male urogenital system. The Journal of Steroid Biochemistry and Molecular Biology. 2011;127:83-95. DOI: 10.1016/j. jsbmb.2011.07.005

[45] Huang D, Wu J, Su X, Yan H, Sun Z. Effects of low dose of bisphenol A on the proliferation and mechanism of primary cultured prostate epithelial cells in rodents. Oncology Letters. 2017;14:2635-2642. DOI: 10.3892/ ol.2017.6469

[46] Le Moal J, Rolland M, Goria S, Wagner V, De Crouy-Chanel P, Rigou A, et al. Semen quality trends in French regions are consistent with a global change in environmental exposure. Reproduction. 2014;147:567-574. DOI: 10.1530/REP-13-0499

[47] Bretveld R, Brouwers M, Ebisch I, Roeleveld N. Influence of pesticides on male fertility. Scandinavian Journal of Work, Environment \& Health. 2007;33:13-28

[48] Cheng CY, Mruk DD. The bloodtestis barrier and its implications for male contraception. Pharmacological Reviews. 2012;64:16-64. DOI: 10.1124/ pr.110.002790

[49] Li MWM, Mruk DD, Lee WM, Cheng CY. Disruption of the bloodtestis barrier integrity by bisphenol $A$ in vitro: Is this a suitable model for studying blood-testis barrier dynamics? The International Journal of Biochemistry \& Cell Biology. 2009;41:2302-2314. DOI: 10.1016/j. biocel.2009.05.016

[50] Harada T, Takeda M, Kojima S, Tomiyama N. Toxicity and carcinogenicity of dichlorodiphenyltrichloroethane (DDT). Toxicology Research. 2016;32:21-33. DOI: $10.5487 /$ TR.2016.32.1.021

[51] Buha A, Antonijević B, Milovanović V, Janković S, Bulat Z, Matović V. Polychlorinated biphenyls as oxidative stress inducers in liver of subacutely exposed rats: Implication for dosedependence toxicity and benchmark dose concept. Environmental Research. 2015;136:309-317. DOI: 10.1016/j. envres.2014.11.005

[52] Angelé-Martínez C, Goodman C, Brumaghim J. Metal-mediated DNA damage and cell death: Mechanisms, detection methods, and cellular consequences. Metallomics. 2014;6:1358-1381. DOI: 10.1039/ c4mt00057a

[53] Kašuba V, Milić M, Rozgaj R, Kopjar N, Mladinić M, Žunec S, et al. Effects of low doses of glyphosate on DNA damage, cell proliferation and oxidative stress in the HepG2 cell line. Environmental Science and Pollution Research. 2017;24:19267-19281. DOI: 10.1007/s11356-017-9438-y 
[54] Møller P, Wils RS, Jensen

DM, Andersen MHG, Roursgaard

M. Telomere dynamics and cellular senescence: An emerging field in environmental and occupational toxicology. Critical Reviews in Toxicology. 2018;48:761-788. DOI: $10.1080 / 10408444.2018 .1538201$

[55] Goyal HO, Braden TD, Williams CS, Williams JW. Estrogen-induced developmental disorders of the rat penis involve both Estrogen receptor (ESR)and androgen receptor (AR)-mediated Pathways1. Biology of Reproduction. 2009;81:507-516. DOI: 10.1095/

biolreprod.108.071951

[56] Cotter KA, Yershov A, Novillo A, Callard GV. Multiple structurally distinct $\mathrm{ER} \alpha \mathrm{mRNA}$ variants in zebrafish are differentially expressed by tissue type, stage of development and estrogen exposure. General and Comparative Endocrinology. 2013;194:217-229. DOI: $10.1016 / j$. ygcen.2013.09.014

[57] Sheng Z, Wang C, Ren F, Liu Y, Zhu B. Molecular mechanism of endocrine-disruptive effects induced by bisphenol A: The role of transmembrane G-protein estrogen receptor 1 and integrin $\alpha v \beta 3$. Journal of Environmental Sciences. 2019;75:1-13. DOI: 10.1016/j. jes.2018.05.002

[58] Bellingham M, Fowler PA, Amezaga MR, Rhind SM, Cotinot C, MandonPepin B, et al. Exposure to a complex cocktail of environmental endocrinedisrupting compounds disturbs the Kisspeptin/GPR54 system in ovine hypothalamus and pituitary gland. Environmental Health Perspectives. 2009;117:1556-1562. DOI: 10.1289/ ehp.0900699

[59] Howdeshell KL, Hotchkiss AK, Thayer KA, Vandenbergh JG, vom Saal FS. Exposure to bisphenol A advances puberty. Nature. 1999;401:763-764. DOI: $10.1038 / 44517$
[60] Pollock T, Greville LJ, Tang B, deCatanzaro D. Triclosan elevates estradiol levels in serum and tissues of cycling and peri-implantation female mice. Reproductive Toxicology. 2016;65:394-401. DOI: 10.1016/j. reprotox.2016.09.004

[61] Pollock T, Weaver RE, Ghasemi R, deCatanzaro D. Butyl paraben and propyl paraben modulate bisphenol A and estradiol concentrations in female and male mice. Toxicology and Applied Pharmacology. 2017;325:18-24. DOI: 10.1016/j.taap.2017.04.001

[62] Karmakar PC, Kang H-G, Kim Y-H, Jung S-E, Rahman MS, Lee H-S, et al. Bisphenol A affects on the functional properties and proteome of testicular germ cells and spermatogonial stem cells in vitro culture model. Scientific Reports. 2017;7:11858. DOI: 10.1038/ s41598-017-12195-9

[63] Shi X-Y, Wang Z, Liu L, Feng L-M, $\mathrm{Li} N$, Liu S, et al. Low concentrations of bisphenol A promote human ovarian cancer cell proliferation and glycolysisbased metabolism through the estrogen receptor- $\alpha$ pathway. Chemosphere. 2017;185:361-367. DOI: 10.1016/j. chemosphere.2017.07.027

[64] Wang H, Ding Z, Shi Q-M, Ge X, Wang H-X, Li M-X, et al. Antiandrogenic mechanisms of Bisphenol A involve androgen receptor signaling pathway. Toxicology. 2017;387:10-16. DOI: 10.1016/j.tox.2017.06.007

[65] Ge L-C, Chen Z-J, Liu H-Y, Zhang K-S, Liu H, Huang H-B, et al. Involvement of activating ERK1/2 through $\mathrm{G}$ protein coupled receptor 30 and estrogen receptor $\alpha / \beta$ in low doses of bisphenol A promoting growth of Sertoli TM4 cells. Toxicology Letters. 2014;226:81-89. DOI: 10.1016/j. toxlet.2014.01.035

[66] Fitzgerald AC, Peyton C, Dong J, Thomas P. Bisphenol A and related 
alkylphenols exert nongenomic estrogenic actions through a $G$ proteincoupled Estrogen receptor 1 (Gper)/ epidermal growth factor receptor (Egfr) pathway to inhibit meiotic maturation of Zebrafish Oocytes1. Biology of Reproduction. 2015;93:135. DOI: 10.1095/biolreprod.115.132316

[67] Cao L-Y, Ren X-M, Li C-H, Zhang J, Qin W-P, Yang Y, et al. Bisphenol AF and bisphenol $B$ exert higher estrogenic effects than bisphenol A via $G$ proteincoupled estrogen receptor pathway. Environmental Science \& Technology. 2017;51:11423-11430. DOI: 10.1021/acs. est.7b03336.

[68] Žalmanová T, Hošková K, Nevoral J, Adámková K, Kott T, Šulc M, et al. Bisphenol S negatively affects the meotic maturation of pig oocytes. Scientific Reports. 2017;7:485. DOI: 10.1038/s41598-017-00570-5

[69] Holubcová Z, Blayney M, Elder K, Schuh M. Human oocytes. Error-prone chromosome-mediated spindle assembly favors chromosome segregation defects in human oocytes. Science. 2015;348:1143-1147. DOI: 10.1126/science.aaa9529

[70] Campen KA, Kucharczyk KM, Bogin B, Ehrlich JM, Combelles $\mathrm{CMH}$. Spindle abnormalities and chromosome misalignment in bovine oocytes after exposure to low doses of bisphenol A or bisphenol S. Human Reproduction. 2018;33:895-904. DOI: 10.1093/humrep/dey050

[71] Nevoral J, Kolinko Y, Moravec J, Žalmanová T, Hošková K, Prokešová Š, et al. Long-term exposure to very low doses of bisphenol S affects female reproduction. Reproduction. 2018;156:47-57. DOI: 10.1530/

REP-18-0092

[72] Hunt PA, Koehler KE, Susiarjo M, Hodges CA, Ilagan A, Voigt RC, et al. Bisphenol A exposure causes meiotic aneuploidy in the female mouse.

Current Biology. 2003;13:546-553

[73] Mandrioli D, Belpoggi F, Silbergeld EK, Perry MJ. Aneuploidy: A common and early evidence-based biomarker for carcinogens and reproductive toxicants. Environmental Health. 2016;15:97. DOI: 10.1186/s12940-016-0180-6

[74] Rahman MS, Kwon W-S, Ryu D-Y, Khatun A, Karmakar PC, Ryu B-Y, et al. Functional and proteomic alterations of F1 capacitated spermatozoa of adult mice following gestational exposure to bisphenol A. Journal of Proteome Research. 2018;17:524-535. DOI: 10.1021/acs.jproteome.7b00668

[75] Ji H, Miao M, Liang H, Shi H, Ruan D, Li Y, et al. Exposure of environmental Bisphenol A in relation to routine sperm parameters and sperm movement characteristics among fertile men. Scientific Reports. 2018;8:17548. DOI: $10.1038 / \mathrm{s} 41598-018-35787-5$

[76] You Y-A, Mohamed EA, Rahman MS, Kwon W-S, Song W-H, Ryu B-Y, et al. 2,3,7,8-Tetrachlorodibenzop-dioxin can alter the sex ratio of embryos with decreased viability of Y spermatozoa in mice. Reproductive Toxicology. 2018;77:130-136. DOI: 10.1016/j.reprotox.2018.02.011

[77] Song W-H, Mohamed EA, Pang W-K, Kang K-H, Ryu D-Y, Rahman MS, et al. Effect of endocrine disruptors on the ratio of $\mathrm{X}$ and $\mathrm{Y}$ chromosomebearing live spermatozoa. Reproductive Toxicology. 2018;82:10-17. DOI: 10.1016/j.reprotox.2018.09.002

[78] Darbre PD. Endocrine disruptors and obesity. Current Obesity Reports. 2017;6:18-27. DOI: 10.1007/ s13679-017-0240-4

[79] Song Y, Chou EL, Baecker A, You N-CY, Song Y, Sun Q, et al. Endocrine-disrupting chemicals, risk of type 2 diabetes, and diabetes-related 
metabolic traits: A systematic review and meta-analysis. Journal of Diabetes. 2016;8:516-532. DOI: $10.1111 / 1753-0407.12325$

[80] Rutkowska AZ, DiamantiKandarakis E. Polycystic ovary syndrome and environmental toxins. Fertility and Sterility. 2016;106:948-958. DOI: 10.1016/j.fertnstert.2016.08.031

[81] Pietryk EW, Clement K, Elnagheeb M, Kuster R, Kilpatrick K, Love MI, et al. Intergenerational response to the endocrine disruptor vinclozolin is influenced by maternal genotype and crossing scheme. Reproductive Toxicology. 2018;78:9-19. DOI: 10.1016/j. reprotox.2018.03.005

[82] Wang T, Han J, Duan X, Xiong B, Cui X-S, Kim N-H, et al. The toxic effects and possible mechanisms of Bisphenol A on oocyte maturation of porcine in vitro. Oncotarget. 2016;7:32554-32565. DOI: 10.18632/ oncotarget.8689

[83] Susiarjo M, Sasson I, Mesaros C, Bartolomei MS. Bisphenol A exposure disrupts genomic imprinting in the mouse. PLoS Genetics. 2013;9:e1003401. DOI: 10.1371/journal.pgen.1003401

[84] Lu Z, Ma Y, Gao L, Li Y, Li Q, Qiang $M$. Urine mercury levels correlate with DNA methylation of imprinting gene H19 in the sperm of reproductive-aged men. PLoS One. 2018;13:e0196314. DOI: 10.1371/journal.pone.0196314

[85] Doshi T, D’souza C, Vanage G. Aberrant DNA methylation at Igf2-H19 imprinting control region in spermatozoa upon neonatal exposure to bisphenol $\mathrm{A}$ and its association with post implantation loss. Molecular Biology Reports. 2013;40:4747-4757. DOI: 10.1007/s11033-013-2571-x

[86] Zhang X-F, Zhang L-J, Feng Y-N, Chen B, Feng Y-M, Liang G-J, et al. Bisphenol A exposure modifies DNA methylation of imprint genes in mouse fetal germ cells. Molecular Biology Reports. 2012;39:8621-8628. DOI: 10.1007/s11033-012-1716-7

[87] Reza AMMT, Choi Y-J, Han SG, Song H, Park C, Hong K, et al. Roles of microRNAs in mammalian reproduction: From the commitment of germ cells to peri-implantation embryos. Biological Reviews of the Cambridge Philosophical Society. 2019;94:415-438. DOI: 10.1111/ brv.12459

[88] Rodgers AB, Morgan CP, Leu NA, Bale TL. Transgenerational epigenetic programming via sperm microRNA recapitulates effects of paternal stress. Proceedings of the National Academy of Sciences. 2015;112:13699-13704. DOI: 10.1073/pnas.1508347112

[89] Brieño-Enríquez MA, García-López J, Cárdenas DB, Guibert S, Cleroux E, Děd L, et al. Exposure to endocrine disruptor induces Transgenerational epigenetic deregulation of MicroRNAs in primordial germ cells. PLoS One. 2015;10:e0124296. DOI: 10.1371/journal. pone.0124296

[90] Horan TS, Marre A, Hassold T, Lawson C, Hunt PA. Germline and reproductive tract effects intensify in male mice with successive generations of estrogenic exposure. PLoS Genetics. 2017;13:e1006885. DOI: 10.1371/journal. pgen.1006885

[91] Ben Maamar M, Sadler-Riggleman I, Beck D, Skinner MK. Epigenetic Transgenerational inheritance of altered sperm histone retention sites. Scientific Reports. 2018;8. DOI: 10.1038/ s41598-018-23612-y

[92] Skinner MK, Ben Maamar M, Sadler-Riggleman I, Beck D, Nilsson E, McBirney M, et al. Alterations in sperm DNA methylation, non-coding RNA and histone retention associate with DDTinduced epigenetic transgenerational 
inheritance of disease. Epigenetics \& Chromatin. 2018;11:8. DOI: 10.1186/ s13072-018-0178-0

[93] Kalb AC, Kalb AL, Cardoso TF, Fernandes CG, Corcini CD, Junior ASV, et al. Maternal transfer of bisphenol A during nursing causes sperm impairment in male offspring. Archives of Environmental Contamination and Toxicology. 2016;70:793-801. DOI: 10.1007/s00244-015-0199-7

[94] LaPlante CD, Catanese MC, Bansal $\mathrm{R}$, Vandenberg LN. Bisphenol S alters the lactating mammary gland and nursing Behaviors in mice exposed during pregnancy and lactation. Endocrinology. 2017;158:3448-3461. DOI: 10.1210/en.2017-00437

[95] Pollock T, Greville LJ, Weaver RE, Radenovic M, deCatanzaro D. Bisphenol S modulates concentrations of bisphenol A and oestradiol in female and male mice. Xenobiotica. 2019;49:540-548. DOI: 10.1080/00498254.2018.1480818

[96] Pollock T, Mantella L, Reali $\mathrm{V}$, deCatanzaro D. Influence of Tetrabromobisphenol A, with or without concurrent triclosan, upon bisphenol A and estradiol concentrations in mice. Environmental Health Perspectives. 2017;125:087014. DOI: 10.1289/EHP1329

[97] Pollock T, Tang B, deCatanzaro D. Triclosan exacerbates the presence of 14C-bisphenol A in tissues of female and male mice. Toxicology and Applied Pharmacology. 2014;278:116-123. DOI: 10.1016/j.taap.2014.04.017

[98] Pollock T, Weaver RE, Ghasemi R, deCatanzaro D. A mixture of five endocrine-disrupting chemicals modulates concentrations of bisphenol A and estradiol in mice. Chemosphere. 2018;193:321-328. DOI: 10.1016/j. chemosphere.2017.11.030
[99] Hawthorne DJ, Dively GP. Killing them with kindness? In-hive medications may inhibit xenobiotic efflux transporters and endanger honey bees. PLoS One. 2011;6:e26796. DOI: 10.1371/journal.pone.0026796

[100] Johnson RM, Pollock HS, Berenbaum MR. Synergistic interactions between in-hive miticides in Apis mellifera. Journal of Economic Entomology. 2009;102:474-479. DOI: 10.1603/029.102.0202

[101] vanEngelsdorp D, Evans JD, Saegerman C, Mullin C, Haubruge E, Nguyen BK, et al. Colony collapse disorder: A descriptive study. PLoS One. 2009;4:e6481. DOI: 10.1371/journal. pone. 0006481

[102] Lee G-A, Choi K-C, Hwang K-A. Treatment with phytoestrogens reversed triclosan and bisphenol A-induced anti-apoptosis in breast cancer cells. Biomolecules \& Therapeutics (Seoul). 2018;26:503-511. DOI: $10.4062 /$ biomolther.2017.160

[103] Trapphoff T, Heiligentag M, El Hajj N, Haaf T, Eichenlaub-Ritter U. Chronic exposure to a low concentration of bisphenol A during follicle culture affects the epigenetic status of germinal vesicles and metaphase II oocytes. Fertility and Sterility. 2013;100:1758-1767.e1. DOI: 10.1016/j. fertnstert.2013.08.021

[104] Skinner MK. Endocrine disruptor induction of epigenetic transgenerational inheritance of disease. Molecular and Cellular Endocrinology. 2014;398:4-12. DOI: 10.1016/j. mce.2014.07.019

[105] Brehm E, Flaws JA.

Transgenerational effects of endocrine disrupting chemicals on male and female reproduction. Endocrinology. 2019. DOI: $10.1210 /$ en.2019-00034

[106] Latchney SE, Fields AM, Susiarjo M. Linking inter-individual variability 
to endocrine disruptors: Insights for epigenetic inheritance. Mammalian Genome. 2018;29(1-2):141-152. DOI: $10.1007 / \mathrm{s} 00335-017-9729-0$

[107] Wei Y, Schatten H, Sun Q-Y. Environmental epigenetic inheritance through gametes and implications for human reproduction. Human Reproduction Update. 2015;21:194-208. DOI: 10.1093/humupd/dmu061

[108] Stern S, Snir O, Mizrachi E, Galili M, Zaltsman I, Soen Y. Reduction in maternal Polycomb levels contributes to transgenerational inheritance of a response to toxic stress in flies. The Journal of Physiology. 2014;592:23432355. DOI: 10.1113/jphysiol.2014.271445

[109] Cleary JA, Tillitt DE, vom Saal FS, Nicks DK, Claunch RA, Bhandari RK. Atrazine induced transgenerational reproductive effects in medaka (Oryzias latipes). Environmental Pollution. 2019;251:639-650. DOI: 10.1016/j. envpol.2019.05.013

[110] Chow Y-L, Sato F.

Transgenerational lipid-reducing activity of benzylisoquinoline alkaloids in Caenorhabditis elegans. Genes to Cells. 2019;24:70-81. DOI: 10.1111/gtc.12657

[111] Wolstenholme JT, Drobná Z, Henriksen AD, Goldsby JA, Stevenson $\mathrm{R}$, Irvin JW, et al. Transgenerational bisphenol A causes deficits in social recognition and alters post-synaptic density genes in mice. Endocrinology. 2019. DOI: $10.1210 /$ en.2019-00196

[112] King SE, McBirney M, Beck D, Sadler-Riggleman I, Nilsson E, Skinner MK. Sperm epimutation biomarkers of obesity and pathologies following DDT induced epigenetic transgenerational inheritance of disease. Environmental Epigenetics. 2019;5:dvz008. DOI: 10.1093/eep/dvz008

[113] Baker BB, Yee JS, Meyer DN, Yang D, Baker TR. Histological and Transcriptomic changes in male Zebrafish testes due to early life exposure to low level 2,3,7,8-Tetrachlorodibenzo- $p$-dioxin. Zebrafish. 2016;13:413-423. DOI: 10.1089/zeb.2016.1275

[114] Pocar P, Fiandanese N, Berrini A, Secchi C, Borromeo V. Maternal exposure to di(2-ethylhexyl)phthalate (DEHP) promotes the transgenerational inheritance of adult-onset reproductive dysfunctions through the female germline in mice. Toxicology and Applied Pharmacology. 2017;322:113121. DOI: 10.1016/j.taap.2017.03.008

[115] Kubsad D, Nilsson EE, King SE, Sadler-Riggleman I, Beck D, Skinner MK. Assessment of glyphosate induced epigenetic transgenerational inheritance of pathologies and sperm epimutations: generational toxicology. Scientific Reports. 2019;9:6372. DOI: 10.1038/ s41598-019-42860-0

[116] Manikkam M, Haque MM, Guerrero-Bosagna C, Nilsson EE, Skinner MK. Pesticide methoxychlor promotes the epigenetic transgenerational inheritance of adult-onset disease through the female germline. PLoS One. 2014;9:e102091. DOI: 10.1371/journal.pone.0102091

[117] Skinner MK, Nilsson E, SadlerRiggleman I, Beck D, Ben Maamar M, McCarrey JR. Transgenerational sperm DNA methylation epimutation developmental origins following ancestral vinclozolin exposure. Epigenetics. 2019;14:721-739. DOI: 10.1080/15592294.2019.1614417 



\title{
Infertility Worldwide: The Lack of Global Pediatric Andrologists and Prevention
}

\author{
Zampieri Nicola, Bianchi Federica, Patanè Simone, \\ Vestri Elettra and Camoglio Francesco Saverio
}

\begin{abstract}
Andrology is the medical specialty dealing with men's health and reproductive system, including the genital, hormonal, reproductive, sexual, as well as psychological aspects, from birth to adulthood. Regular andrological checkups are essential both to reveal possible problems and to receive thorough advice and information so as to ensure that sexual and reproductive functions are well preserved. Estimates report that about one in three males suffers from andrological diseases, their rates varying according to the age: $27-30 \%$ of pediatric male subjects have reproductive and/or sexual conditions. In adulthood, $40 \%$ of men are affected by andrological diseases, in particular infertility and sexual problems. We studied medical literature about infertility, its prevention, and its treatment; our outcomes were to evaluate the role of research to prevent infertility especially in pediatric and adolescent age. The analysis of the data shows that in absolute numbers, the conditions directly associated with infertility are less studied than the treatment with medically assisted procreation. This research is intended as a warning to the countries worldwide: all those involved in the pediatric treatment area should be stimulated to act toward this goal, and each country should bear the responsibility of promoting and financing andrological screening campaigns.
\end{abstract}

Keywords: infertility, varicocele, pediatric, adolescence, undescended testes, medical-assisted reproduction

\section{Introduction}

Andrology is the medical specialty dealing with men's health and reproductive system, this including the genital, hormonal, reproductive, sexual, as well as psychological aspects, from birth to adulthood. Regular andrological checkups are essential both to reveal possible problems and to receive thorough advice and information as to ensure that sexual and reproductive functions are well preserved.

Estimates report that about one in three males suffers from andrological diseases, their rates varying according to the age: $27-30 \%$ of pediatric male subjects have reproductive and/or sexual conditions, especially cryptorchidism, varicocele, hypogonadism, congenital anomalies of the genitourinary tract, and sexually transmitted diseases. In adulthood, $40 \%$ of men are affected by andrological diseases, in 
particular infertility and sexual problems. The main surgically correctable diseases to prevent hypofertility are varicocele $(30 \%)$ and undescended testes $(<5 \%)[1-3]$.

The origin of many of the andrological conditions appearing during adulthood is to be traced before the age of 18 and sometimes even during gestation. The male gonad is extremely sensitive to external events even during gestation and soon after childbirth up until puberty. The andrological evaluation of pediatric patients is therefore extremely important for the early diagnosis of genital anomalies such as penile alterations or abnormal positions of the testis; early evaluation is helpful also to search for risk factors in terms of male general and sexual health.

Andrology greatly trusts primary prevention to reduce the incidence of andrological diseases and conditions. Clinical studies and primary prevention interventions in andrology should be focused on the most vulnerable crucial phases of male gonad development that can be affected by a variety of external agents.

The preservation of the genital and sexual health of young people also means protecting their fertility, a very important action within the broader scope of the interventions aimed at reducing the drop in the birthrate affecting modern society. Despite few exceptions, the prevention and early diagnosis of the andrological conditions have been neglected worldwide for too long. This has favored an increase in the incidence and prevalence of diseases that are otherwise easy to prevent and treat if diagnosed early.

The data collected during screening procedures in young males show that $<5 \%$ receive an andrological examination before the age of 20. Female patients of the same age adhere to gynecological screening tests with decidedly higher rates. A real "gender discrimination" about prevention [4].

This leads to an increase in undiagnosed andrological diseases that remain so until adulthood when the treatment becomes more complex for the patient and more expensive for the national healthcare system.

Therefore, it is necessary to promote awareness on this social issue: undergoing regular and well-timed andrological checkups is essential for the early diagnosis of andrological conditions as well as for the general health of men's sexual and genital functions.

This point in mind, in order to safeguard the reproductive and sexual health of young men, the synergic approach involving pediatricians, general practitioners, doctors at family planning clinics, and andrologists for the adults plays a key role together with the implementation of territorial networks integrating the know-how and expertise of all these health professionals.

This is especially true in the extremely vulnerable period of life generally ranging from 11 to 18 years of age, when young male patients experience the transition to adult life and maturity from the reproductive and sexual point of view.

All this can be achieved also increasing the social awareness on the matter via systematic information and education of the population thanks to campaigns and primary prevention interventions. To this end, research and study of andrological diseases in the pediatric-adolescent patients are crucial, especially research, whose main aim is to anticipate the treatment of all those conditions that can alter the fertility potential of men.

These are the grounds for this study, which compares good clinical practices worldwide for the preservation of male fertility in young patients by comparing the results with the evidence from the scientific research carried out on the treatment of male infertility.

In the last 40 years, the number of spermatozoa in the semen of male patients of childbearing potential has decreased by more than a half [5].

Incorrect lifestyles, pollution, and poor prevention are the main causes of a dramatical drop in the male fertility rates. According to the latest international 
reports, the rate of male infertility among the couples who seek advice from specialized centers to bear a child is $30-35 \%$, and age is not the only liable factor; correctable causes include varicocele, which accounts for $30-35 \%$ of cases, and evidence of previous untreated or poorly followed cryptorchidism (5\%) [5-7].

Medically assisted procreation is suggested as one solution to the human and social problem of sterility. But, as reported by many authors, can assisted procreation be considered as a suitable therapy?

In many countries, assisted procreation is funded from public health insurance. Without this coverage, it would be used much less frequently. What is then more important? The treatment of sterility or the increase in the birthrate? The answer to this question is manifold.

One of the reports by the International Committee for Monitoring Assisted Reproductive Technology (ICMART) re-established that over 1 million ART cycles were performed worldwide in 2002, with a progressive increase compared to the previous years. The progressive increase shows how research and clinical medicine are drastically moving away from the real investigation of infertility [6-8].

The costs associated with the ART can be divided into direct and indirect costs; the direct costs, which vary according to the mother's age, are those necessary to "guarantee" a pregnancy, from the medically assisted treatment to childbirth. The indirect costs include the costs directly related to childbirth, to a possibly premature birth, to twin pregnancies, to the management of any complications, and to the management of chronic diseases of the newborn child and of the mother as well [7-9].

Obviously, the average direct cost of each procedure is calculated by dividing the total number of procedures performed per year by the number of live births. These costs are country-related, with variations of up to tenfold values; direct ART treatment costs show considerable variations among countries, with the USA standing out as the most expensive and Northern European countries and Japan as the least expensive countries. For example, reports show that the costs per live birth are similar for ages $24(€ 17,000)$ and $33(€ 18,500)$, after which they begin to increase, with the cost per live birth reaching $€ 54,000$ at age 42 .

Indirect costs, especially when associated with multiple gestations, vary from country to country: in 2004 such costs ranged between $€ 24,377$ for a singleton pregnancy and $€ 35,042$ for a twin pregnancy up to 27 days after birth [6-9].

The first international report on the results of assisted medical procreation (AMP) was published in Paris in 1991 on the occasion of the 7th World IVF Congress. From a scientific point of view, the role of international reports is to monitor the number of procedures as well as to study the efficacy of the treatments indicated.

Every year the procedure registers are updated. The recorded data show a constant increase in these procedures with a steady increase in live births. The latest data, published in 2018 and referring to 2011, show that approximately 1.6 million procedures were performed with approximately 400,000 births worldwide. These figures allow to calculate the costs per year for the national healthcare systems [7-9].

\section{Literature searching}

This research was performed by taking into consideration two aspects separately: infertility and pediatric andrological diseases associated with infertility. Browsing the most important engines for scientific research (PubMed, Scopus, Google Scholar), several keywords were considered: infertility, male, semen, 
adolescent, varicocele, undescended testes, cryptorchidism, hormone, and assisted medical procreation (Table 1).

We searched with association like: adolescent and infertility; varicocele and semen, etc.

A number of papers and number of the most important associations are explained in the table.

Some considerations are essential: the literature regarding medically assisted procreation should be considered only from 1990 onward, and, from a strictly epidemiological point of view, also for varicocele some distinctions should be made. Varicocele seems to have a clear phenotypic trend, for which it is possible that in some countries the prevalence of the disease is lower than in others, justifying a paucity of literature on this topic. However, when comparing the origin of scientific publications on pediatric varicocele and cryptorchidism, Europe and North America cover about $70 \%$ of the overall publications worldwide, reaching $80 \%$ of the published literature about infertility and assisted medical procreation. Asia and Africa, on the contrary, show poor preventive research while favoring the research on assisted medical procreation.

The analysis of the data offers some interesting insights:

1. Most of the literature on the topics of this research was published after the year 2000 , with the two maximum rates of 84 and $79 \%$ for medically assisted procreation. This can be reasonably associated with the widespread use of the procedures after the 1990s. If such figures are correlated to the other percentages found, they also show how the focus of scientific research has slanted toward the treatment of infertility rather than its prevention.

2. In absolute numbers, the conditions directly associated with infertility are less studied than the treatment with medically assisted procreation.

\begin{tabular}{|c|c|c|c|c|}
\hline Group & Key & Total & $>2000 \%$ of paper & $\begin{array}{c}\text { Statistical } \\
\text { comparison per group }\end{array}$ \\
\hline 1 & Infertility-male & 46103 & $26296(57 \%)$ & 1/2: $\mathrm{p}<0.05$ \\
\hline 2 & Varicocele & 5292 & $2788(52 \%)$ & 1/3: $p<0.05$ \\
\hline 3 & $\begin{array}{l}\text { Undescended } \\
\text { testes }\end{array}$ & 10245 & $4250(41 \%)$ & 1/3: $p<0.05$ \\
\hline 4 & $\begin{array}{l}\text { Assisted } \\
\text { reproduction }\end{array}$ & 25399 & 20309 (79\%) & 1/4: $p<0.05$ \\
\hline 5 & $\begin{array}{l}\text { V-adolescence/ } \\
\text { pediatric age }\end{array}$ & $\begin{array}{l}1396147 \text { (real pediatric- } \\
\text { adolescent age-range with } \\
\text { follow-up) }\end{array}$ & $776(55 \%)$ & $2 / 5: p<0.05$ \\
\hline 6 & Infertility-U & 1195 & $676(56 \%)$ & 6/3: $p<0.05$ \\
\hline 7 & Infertility-semen & 11289 & $6556(58 \%)$ & $1 / 7: p>0.05$ \\
\hline 8 & $\begin{array}{l}\text { Assisted medical } \\
\text { procreation }\end{array}$ & 6701 & $5635(84 \%)$ & 1/8: $\mathrm{p}<0.05$ \\
\hline 9 & Infertility-VAR & 2429 & $1349(55 \%)$ & 1/9: $\mathrm{p}<0.05$ \\
\hline \multicolumn{5}{|c|}{$\begin{array}{l}\text { Statistical analysis: Statistical analysis was performed using the student } t \text {-test. Significance value was set at p }<0.0 \\
\text { Associations: varicocele and pediatric age/adolescence; infertility and undescended testes; infertility and varicocele; } \\
\text { statistical comparison between groups: chi-square test comparing number of total paper published and paper } \\
\text { published after } 2000 \text { per each -group and sub groups. }\end{array}$} \\
\hline
\end{tabular}

Table 1.

Data from the research: number of papers published per disease and with multiple associations. 
3. A comparison between varicocele and cryptorchidism, namely, the two main male infertility diseases, shows that although varicocele is the first treatable cause of infertility, it is not as much investigated as cryptorchidism, accounting for $<5 \%$ of the curable causes of infertility. From a purely numerical point of view, cryptorchidism is studied more than varicocele, with varicocele being more investigated after the year 2000. This means that longterm studies on varicocele have been done only in the last 20 years.

4. A comparison between group 1 (infertility and male), which is the most represented in terms of number of publications pre- and post-2000, and all the other subgroups points out that the "infertility and semen" subgroup is the only comparable group within the main scope of the survey. This indicates that most of the studies on male infertility do not investigate the causes leading to these conditions, because they focus only on their effects

5. The correlation between infertility and varicocele offers some insights: while in numerical terms, there is little investigation of varicocele in association with infertility, which is one of its effects; more is studied about its treatment (surgical treatment, percutaneous treatment, etc.). It is important to report that since 2000 , only 147 papers focused on pediatric-adolescent varicocele and its management with a long time follow-up ( $>3$ years).

\section{Pediatric varicocele}

\subsection{Focus about pediatric varicocele: the first infertility-related and treatable andrological disease}

About this specific topic, where varicocele is the first treatable cause of infertility in adulthood, we found that a total of 625 articles was published since 2000, matching the mentioned criteria; after our selection only 147 articles resulted providing innovative topics in the pediatric range. As a first consideration, we can state that most publications concentrate in Europe, Asia, and North America (the USA being by far the most represented in North America). The percentage of pediatric works is $\mathbf{2 7 . 0 \%}$ being above average in Europe and North and South America. Asia has a considerable number of published articles even though the percentage of pediatric ones is far below average. Africa and Oceania have, respectively, 2 and 1 pediatric articles.

Then we analyzed the main topic and secondary topics of the selected articles. Prevalence of different categories in each continent was summarized, and the main subjects for Europe are surgical technique, videolaparoscopy, and diagnosis; for North America, surgical technique, diagnosis, and endocrinology; and for Asia, video laparoscopy, endocrinology, and screening.

South America includes 10 articles discussing mainly about fertility and semen analysis, being the only region in which this topic appears to be central. Africa had only two publications in the pediatric field, centered on diagnosis and nonoperative treatment. The only pediatric publication published in Oceania was centered on video laparoscopy.

Overall prevalence of topics in the discussed articles was considered as well, and we found that in North America and Asia follow-up prevails as a concomitant topic in many articles, together with complications and relapses. Another topic strongly represented in these regions is endocrinology. On the other side, Europe maintains topics that mainly represented surgical technique and videolaparoscopy, accounting 
for about $50 \%$ of all topics, and then diagnosis is still present, showing little difference between main topic and all mentioned topics in the publications.

Eventually, a study of the topics and their prevalence over years was performed to see the trend of interest. A significant trend in publications could not be evinced, neither overall nor for single continent. Publication numbers by year underwent cyclic changes over the last 20 years with a peak in 2008 including 16 publications about pediatric varicocele.

A natural comment to the number of publication is the fact that pediatric articles, focusing on pure research, account for $<1$ third of overall articles about varicocele. This could be due to the fact that historically varicocele is considered as an adult pathology; thus not enough interest is found in its pediatric side. Different series of studies report a higher prevalence of varicocele in adult population than in pediatric one. However it must be taken into account the lack, in almost all countries, of pediatric screening programs for varicocele that could give a strong bias about the exact prevalence of the pathology in pediatric population. Moreover the study of varicocele related to infertility is considered more imminent in adult life, when looking for paternity that during adolescence when study of future fertility may seem premature. In fact many studies on varicocele are performed retrospectively when the patient in adult life has not the possibility to become father (see table).

Concerning the major topics of the publications, in the most represented continents, the first interest of research is surgical technique, may it be traditional surgery or videolaparoscopy technique. We can also see that in the first three majorly represented topics and figures either screening or diagnosis this reflects an attention of research to detection and treatment rather than to follow-up or prevention of infertility. Other topics were only minimally represented. It must be stated that healthcare organization of each single country may influence the topics and publications: in fact screening would not be so represented in countries with private healthcare or, on the other hand, countries with increased population density would feel less important the problem of infertility. The prevalence of varicocele according to the literature remains constant in different ethnic groups; thus, differences in publication do not reflect a difference of entity of the disease but rather a different contribution to publications.

In South America the research group for the published articles is the same, and the works represent mainly an evolution of the same study focusing on semen analysis, metabolomics, infertility pathophysiology, and endocrinology.

The three most prevalent topics in North America and Asia underline an attention to study the evolution of the pathology in time even after treatment and to evaluate if the outcomes of surgical treatment meet the standards for good practice. Articles discussing endocrinology often evaluate testicular volume at diagnosis and follow catch-up growth after surgery, trying to give an indication of the best timing to prevent infertility. On the other side, the spectrum of topics in Europe reflects poor attention to prevention of infertility and follow-up after surgery.

Of particular interest is that there is no increasing trend during the years despite an increase in the trend of publications about overall causes of infertility and medically assisted procreation. In fact in delivering a PubMed research, it appears that publications about MAP are more than 30 times higher than those about varicocele.

We must report the fact that Asia appears abundantly below average, but a strong bias is given that the fact that many publications from China were in original language [10-17].

The same applies to the correlation between undescended testes and infertility if compared to the studies on cryptorchidism alone. Both associations between infertility and disease show a progressive percentage increase in the total number of studies. 


\section{Final considerations}

This research is intended as a warning to the countries worldwide: when talking about fertility, it is right to give a couple the chance to access medically assisted procreation; consequently, scientific studies to improve its outcomes are reasonable. International reports are therefore necessary and should foster research with increasing outcomes. More space should also be given to investigate and prevent male fertility diseases starting from the pediatric age, especially when they might impair the patient's future fertile potential [18].

All those involved in the pediatric treatment area should be stimulated to act toward this goal, and each country should bear the responsibility of promoting and financing andrological screening campaigns. At the international level, there are still few opportunities, in terms of funds and staff, for the adolescents to receive andrological counseling. This is then the bottom line: Is medically assisted procreation the cure to one or more diseases, or is it the answer to the lack of a social support network?

When talking about couple infertility, male causes account for about 35-40\%, among these, varicocele figures as the first [19].

Thus collective interest, research efforts, and healthcare funding aim to study couple infertility at the time of inability of procreation, correction of varicocele in adult age, and medically assisted procreation. This choice is taken despite the increased risk of chronic irreversible damage of treating varicocele and other pediatric andrological diseases in adult age and despite the costs and risks of MAP with the additional risk of failure of medically assisted procreation.

In conclusion, the research effort and the capital invested in prevention of infertility are not balanced with respect to efforts and investments relied into medical assisted procreation.

\section{Conflict of interest}

The authors declare no conflict of interest.

\section{Acronyms and abbreviations}

AMP Assisted medical procreation

ART Assisted reproductive technology 


\section{Author details}

Zampieri Nicola*, Bianchi Federica, Patanè Simone, Vestri Elettra and Camoglio Francesco Saverio

Woman and Child Hospital, Azienda Ospedaliera Universitaria Integrata, Department of Surgery, Dentistry, Paediatrics and Gynaecology, Paediatric Fertility Lab, University of Verona, Verona, Italy

*Address all correspondence to: dr.zampieri@libero.it

\section{IntechOpen}

(C) 2019 The Author(s). Licensee IntechOpen. This chapter is distributed under the terms of the Creative Commons Attribution License (http://creativecommons.org/licenses/ by/3.0), which permits unrestricted use, distribution, and reproduction in any medium, provided the original work is properly cited. (cc) BY 


\section{References}

[1] Abaci A et al. Epidemiology, classification and management of undescended testis: Does medication have value in its treatment? Journal of Clinical Research in Pediatric Endocrinology. 2013;5:65-72

[2] Datta J, Palmer MJ, Tanton C, et al. Prevalence of infertility and help seeking among 15,000 women and men. Human Reproduction. 2016;31: 2108-2118

[3] Agarwal A, Mulgund A, Hamada A, Chyatte MR. A unique view on male infertility around the globe.

Reproductive Biology and

Endocrinology. 2015;13:37-46

[4] Kaya Y, Kizillkaya Beji N, Aydin Y, Hassa $\mathrm{H}$. The effect of health-promoting lifestyle education on the treatment of unexplained female infertility.

European Journal of Obstetrics, Gynecology, and Reproductive Biology. 2016;207:109-114

[5] Jensen CFS, Khan O, Nagras ZG, Sønksen J, Fode M, Østergren PB, et al. Male infertility problems of patients with strict sperm morphology between $5-14 \%$ may be missed with the current WHO guidelines. Scandinavian Journal of Urology. 2019;3:1-5

[6] Adamson GD, de Mouzon J, Chambers GM, Zegers-Hochschild F, Mansour R, et al. International committee for monitoring assisted reproductive technology: World report on assisted reproductive technology, 2011. Fertility and Sterility. 2018;110: 1067-1080

[7] Cohen J. The future of international registries for assisted reproductive technologies. Fertility and Sterility. 2001;76:871-873

[8] van Heesch MM, van Asselt $A D$, Evers JL, van der Hoeven MA,
Dumoulin JC, van Beijsterveldt CE, et al. Cost-effectiveness of embryo transfer strategies: A decision analytic model using long-term costs and consequences of singletons and multiples born as a consequence of IVF. Human

Reproduction. 2016;31(11):2527-2540

[9] Connolly MP, Hoorens S, Chambers GM, ESHRE Reproduction and Society Task Force. The costs and consequences of assisted reproductive technology: An economic perspective. Human Reproduction Update. 2010; 16(6):603-613

[10] Jacobson DL, Johnson EK. Varicoceles in the pediatric and adolescent population: Threat to future fertility? Fertility and Sterility. 2017; 108:370

[11] Gorelick JI, Goldstein M. Loss of fertility in men with varicocele. Fertility and Sterility. 1993;59:613

[12] Tulloch WS. Varicocele in subfertility; results of treatment. British Medical Journal. 1955;2:356

[13] Levinger U, Gornish M, Gat Y, et al. Is varicocele prevalence increasing with age? Andrologia. 2007;39:77

[14] Canales BK, Zapzalka DM, Ercole CJ, et al. Prevalence and effect of varicoceles in an elderly population.

Urology. 2005;66:627

[15] Alcalay J, Kedem R, Kornbrot B, et al. The ethnic distribution of varicocele. Military Medicine. 1986;151:327

[16] The influence of varicocele on parameters of fertility in a large group of men presenting to infertility clinics. World Health Organization. Fertility and Sterility. 1992;57:1289

[17] Jensen CFS, Khan O, Nagras ZG, et al. Male infertility problems of 
patients with strict sperm morphology between $5-14 \%$ may be missed with the current WHO guidelines. Scandinavian Journal of Urology. 2019 Jan;3:1

[18] Zampieri N, Cervellione RM. Varicocele in adolescents: A 6-year longitudinal and follow-up observational study. Journal of Urology. 2008;180(4 Suppl):1653-1656

[19] Zampieri N, Bosaro L, Costantini C, Zaffagnini S, Zampieri G. Relationship between testicular sperm extraction and varicocelectomy in patients with varicocele and non-obstructive azoospermia. Urology. 2013;82(1):74-77 


\title{
Sertoli Cell Phagocytosis: An Essential Event for Spermatogenesis
}

\author{
Fei Wang and Daishu Han
}

\begin{abstract}
During spermatogenesis, most male germ cells undergo apoptosis, and the cytoplasmic portions of the elongating spermatids are shed as residual bodies (RB). Both apoptotic germ cells (AGC) and RB must be phagocytosed by Sertoli cells, which are essential to maintain testicular homeostasis for normal spermatogenesis. The phagocytosis of AGC and RB by Sertoli cells confers various meanings, including elimination of apoptotic components, removal of autoantigens, and the recycle of degenerated substrates as an energy source. Sertoli cell phagocytosis can be regulated by various mechanisms. The impairment of Sertoli cell phagocytosis may disrupt tissue homeostasis in the testis, thereby impairing to testicular function and spermatogenesis. This chapter discusses the mechanisms underlying phagocytic removal of AGC and RB by Sertoli cells and the consequences of this biological event for spermatogenesis and male fertility.
\end{abstract}

Keywords: Sertoli cell, phagocytosis, spermatogenesis, apoptosis, male fertility

\section{Introduction}

Mammalian spermatogenesis is a cell-organized differentiation process of male germ cells in the testis. This process includes spermatogonium mitosis, spermatocyte meiosis, and spermatid morphogenesis. Throughout spermatogenesis, Sertoli cells tightly embrace differentiating germ cells in the seminiferous epithelium and create a microenvironment essential for germ cell differentiation. In addition to physical support, Sertoli cells provide nutrition for developing germ cells and take up apoptotic components. During spermatogenesis, most of male germ cells undergo apoptosis, and those that finalize differentiation process will shed their most cytoplasmic components as residual bodies (RB). Apoptotic germ cells (AGC) and RB must be timely eliminated by Sertoli cells via phagocytosis.

The phagocytic elimination of AGC and RB by Sertoli cells has been proposed to contribute to spermatogenesis in several ways: (1) reducing space competition for enormous male germ cells to finalize differentiation process, (2) preventing noxious cellular contents that may be released by necrosis of apoptotic germ cells, (3) removing autoantigens that may induce an autoimmune response, and (4) recycling of AGC and RB as an energy source for Sertoli cells.

Various mechanisms are involved in the regulation of Sertoli cell phagocytosis of $\mathrm{AGC}$ and RB. The interaction of class B scavenger receptor type I (SR-BI) expressed 
on phagocytes and phosphatidylserine (PS) exposed on apoptotic cell surfaces is a universal mechanism by which phagocytes engulf apoptotic cells [1]. This mechanism is also involved in the regulation of the phagocytosis of AGC and RB by Sertoli cells [2]. Tyro3, Axl, and Mer (TAM) tyrosine kinase receptors and their functional common ligand, growth arrest specific gene 6 (Gas6), are also essential for optimal phagocytosis of AGC by Sertoli cells. Several other genes that regulate Sertoli cell phagocytosis of AGC have been recognized. The mechanisms underlying phagocytic removal of AGC by Sertoli cells are the main focus of this article.

Impairment of Sertoli cell phagocytosis is associated with pathogenesis and dysfunction of the testis, thus impairing male fertility. The inhibition of Sertoli cell phagocytic ability disrupts spermatogenesis [3]. Gene mutation that impairs Sertoli cell phagocytosis may lead to autoimmune orchitis and male infertility [4]. The pathogenic conditions due to impaired Sertoli cell phagocytosis are mentioned in the text.

\section{Germ cell apoptosis and Sertoli cell phagocytosis}

The mammalian testis consists of two distinct compartments: the seminiferous tubules and the interstitial spaces among the tubules (Figure 1). The two major functions of the testis include spermatogenesis, occurring within the seminiferous epithelium, and steroidogenesis by Leydig cells that are in the interstitial spaces.

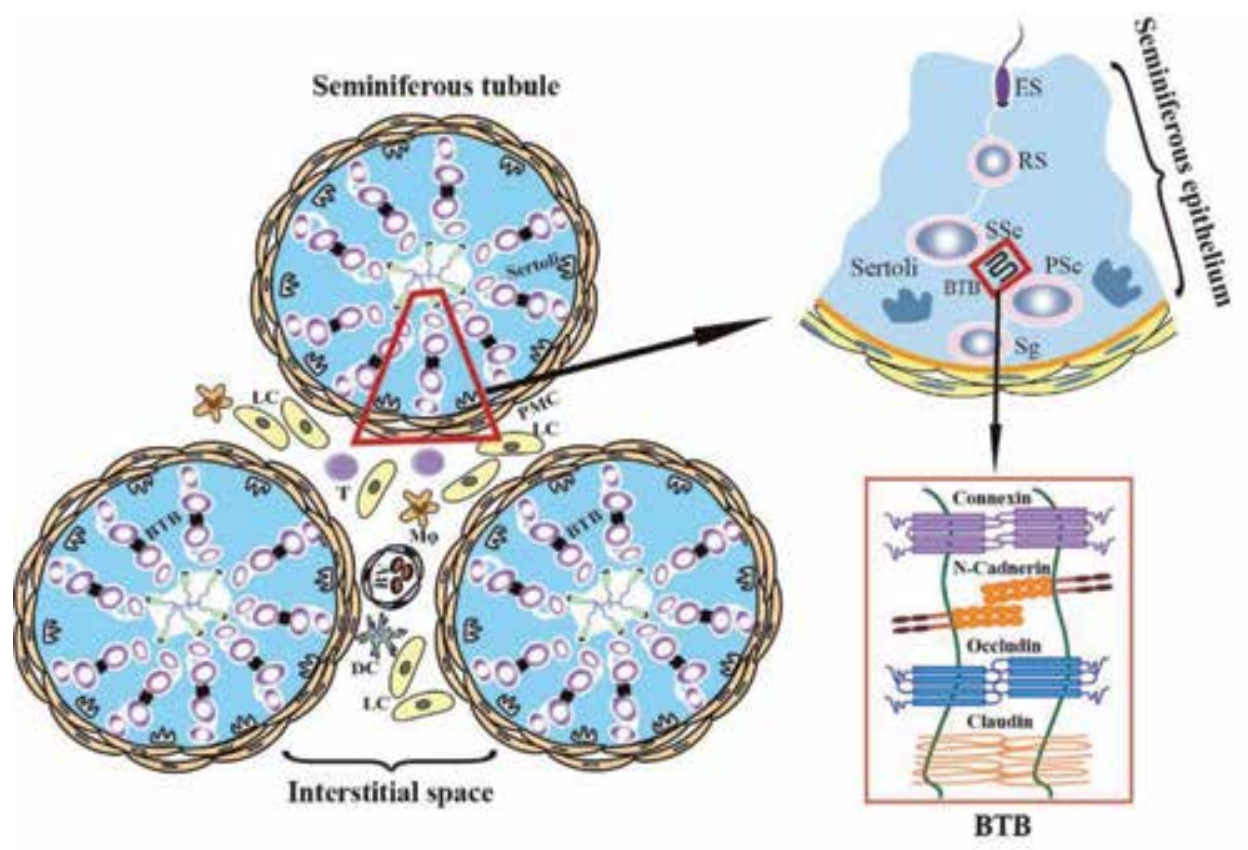

Figure 1.

Human testicular schematic of histological structure and cellular constituents. The testis consists of two separate regions, namely, seminiferous tubules and interstitial spaces (left panels). The seminiferous tubules are composed of multiple layers of peritubular myoid cells (PMC) that constitute a tubular wall and Sertoli cells embracing different stages of male germ cells to form the seminiferous epithelium where spermatogenesis is fulfilled (right upper panel). The seminiferous epithelium is divided into two compartments, namely, the basal compartments and adluminal compartments, by the BTB that is formed by various junctions (right low panel) between two adjacent Sertoli cells, near the basal side. Different stages of developing germ cells, including spermatogonia $(S g)$, primary spermatocytes (PSc), secondary spermatocytes (SSc), round spermatids (RS), and elongated spermatids (ES), are localized on the seminiferous epithelium from the basal compartments to adluminal compartments. The interstitial spaces are composed of various cell types, the majority of which are Leydig cells (LC), but also macrophages $(M \varphi)$, as well as minor dendritic cells $(D C)$ and Tymphocytes $(T)$. 
The seminiferous tubules possess a special microenvironment essential for spermatogenesis, which is composed of columnar Sertoli cells tightly encompassing developing germ cells. The blood-testis barrier (BTB) that is formed by two adjacent Sertoli cells near the basal side of the tubules is critical for maintaining the tissue homeostasis and immune microenvironment for normal germ cell development. During spermatogenesis, more than $75 \%$ germ cells have been estimated to undergo apoptosis [5, 6]. Apoptosis can occur at any stage of germ cells. Male germ cell survival and apoptosis are highly regulated by endocrine hormones [7]. In particular, follicle-stimulating hormone (FSH) produced by the pituitary and testosterone synthesized in Leydig cells is essential for healthy spermatogenesis. Low level of FSH increases germ cell apoptosis. The administration of testosterone in vivo inhibits germ cell apoptosis. Both FSH and testosterone could not act on germ cells because these cells do not express the receptors of two hormones. By contrast, FSH and testosterone can regulate the functions of Sertoli cells that express the hormonal receptors. Therefore, FSH and testosterone indirectly regulate germ cell apoptosis via Sertoli cells. The cascade of caspase activation is involved in the initiation of germ cell apoptosis [8]. Caspase 2 activation initiates the caspase cascade, in which $\mathrm{BAX}$ is involved in the cleavage of caspases.

Like other apoptotic cells, the translocation of phosphatidylserine (PS) to the surface of the cellular membrane is a characterization of male germ cell apoptosis [9]. The PS on the surface of apoptotic cells can be recognized by SR-BI and engulfed by phagocytes. At the final stage of germ cell development, most of the cytoplasm portions of spermatozoa are shed as RB before spermatozoa release to the lumen of the seminiferous tubules. However, immunohistochemical staining only detects a limited number of AGC. The RB are also rarely observed by histological analysis. These phenomena are assumed due to the rapid removal of apoptotic cells and RB through phagocytosis, a common way for engulfing apoptotic cells [1]. In accordance with this speculation, the inhibition of Sertoli cell phagocytosis in vivo greatly increases AGC numbers within the seminiferous tubules [3].

Phagocytosis of AGC and RB by Sertoli cells can be assessed by various approaches [10]. Confocal and transmission electron microscopy are reliable approaches that can distinguish apoptotic components ingested by Sertoli cells. However, these expensive and time-consuming approaches are not suitable for routine tests. Several simplified protocols to indirectly measure Sertoli cell phagocytosis have been reported [11-13]. These protocols require further optimization to avoid data misinterpretation. Lipid droplets are cyclically formed in the cytoplasm of Sertoli cells, which coincides with the spermatogenic cycle [14]. Therefore, it has been proposed that lipid droplets in Sertoli cells might result from the degradation of apoptotic components, including RB and AGC. An in vitro study confirmed that phagocytosis of AGC by Sertoli cells resulted in lipid droplet formation in Sertoli cells, which was used for evaluation of phagocytosis of AGC by Sertoli cells [13].

\section{Mechanisms underlying phagocytosis of AGC and RB by Sertoli cells}

\subsection{Role of SR-BI/PS system}

SR-BI is a receptor for high-density lipoprotein and can bind to acidic liposomes and apoptotic cells [15-17]. PS is a type of phospholipid that is located on the inner leaflet of the plasma membrane bilayer of healthy cells [18]. However, PS translocates to the outer leaflet of the cellular membrane during cell apoptosis and is exposed on the surface of apoptotic cells [9]. PS on the apoptotic cell surface can be recognized and bound by SR-BI on phagocytes, which is a key mechanism by 
which phagocytes engulf apoptotic cells (Figure 2). The interaction of PS and SR-BI induces cytoskeletal changes that form phagocytic cup, thereby resulting in the engulfment of apoptotic cells. As shown in Figure 3 (right side), SR-BI is expressed in Sertoli cells, and PS is exposed on the surfaces of AGC and RB [19-21]. Several in vitro studies provide evidence that Sertoli cells engulf AGC and RB through the interaction of SR-BI and PS. The phagocytosis of AGC and RB by Sertoli cells can be inhibited by the presence of annexin $V$ that specifically binds to PS on the surfaces of AGC and RB [3,21]. Moreover, an antibody against SR-BI disables the phagocytosis of AGC by Sertoli cells [19]. The SR-BI/PS-mediated phagocytosis of AGC and RB by Sertoli cells is confirmed in vivo, in which injection of anti-SR-BI antibody and annexin $V$ into the seminiferous tubules increases the number of AGC [3]. Therefore, both in vitro and in vivo studies confirm that Sertoli cells recognize and engulf AGC and RB in the SR-BI/PS-dependent fusion.

\subsection{Role of TAM receptors in mediating Sertoli cell phagocytosis}

TAM receptors belong to a subfamily of the transmembrane receptor tyrosine kinases (Figure 4), which include three members, Tyro3, Axl, and Mer [22]. Gas6 is a functional common ligand of TAM receptors [23]. The TAM/Gas6 system regulates cell survival, innate immune response, and phagocytosis of apoptotic cells [24-27]. TAM receptors are involved in several pathological conditions, such as chronic inflammatory and autoimmune diseases [28, 29], viral infection [30-32], and cancer [33-35]. Notably, TAM receptors are essential for spermatogenesis and male fertility $[36,37]$.

The mechanisms by which the TAM/Gas6 system regulates testicular functions have been intensively investigated [38]. TAM receptors and Gas6 are abundantly expressed in Sertoli and Leydig cells [39]. All three Tyro3, Axl, and Mer receptors are expressed in Sertoli cells, whereas Leydig cells express Axl and Mer. Gas6 is uniquely expressed in Leydig cells. TAM receptors negatively regulate the expression of pro-inflammatory cytokines in both Sertoli and Leydig cells [40, 41], which might contribute to the immunoprivileged status of the testis [42]. In particular, the TAM receptors and Gas6 are essential for the phagocytic removal of AGC by Sertoli cells [43]. TAM receptors cooperatively regulate Sertoli cell phagocytosis of AGC. All three Tyro3, Axl, and Mer receptors participate in recognizing and binding AGC to Sertoli cells, whereas Mer is responsible for triggering phagocytic intracellular signaling that promotes engulfment of AGC. Any individual TAM receptors in Sertoli cells exhibit similar binding ability to AGC. However, Sertoli cells lacking all three TAM receptors remarkably decrease the binding between Sertoli cells and AGC. The TAM-mediated binding of Sertoli cells to AGC cannot be homologous

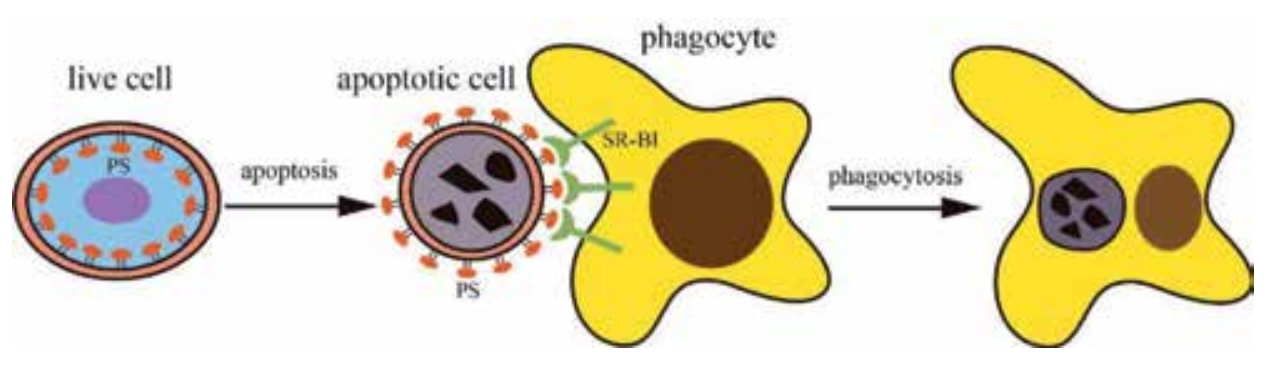

Figure 2.

SR-BI/PS-mediated phagocytosis. PS is translocated from the inner leaflet to outer leaflet of cellular membrane during apoptosis. PS is recognized by SR-BI located on the surface of phagocytes, and subsequently apoptotic cell is engulfed by phagocytosis via cytoskeletal changes. 


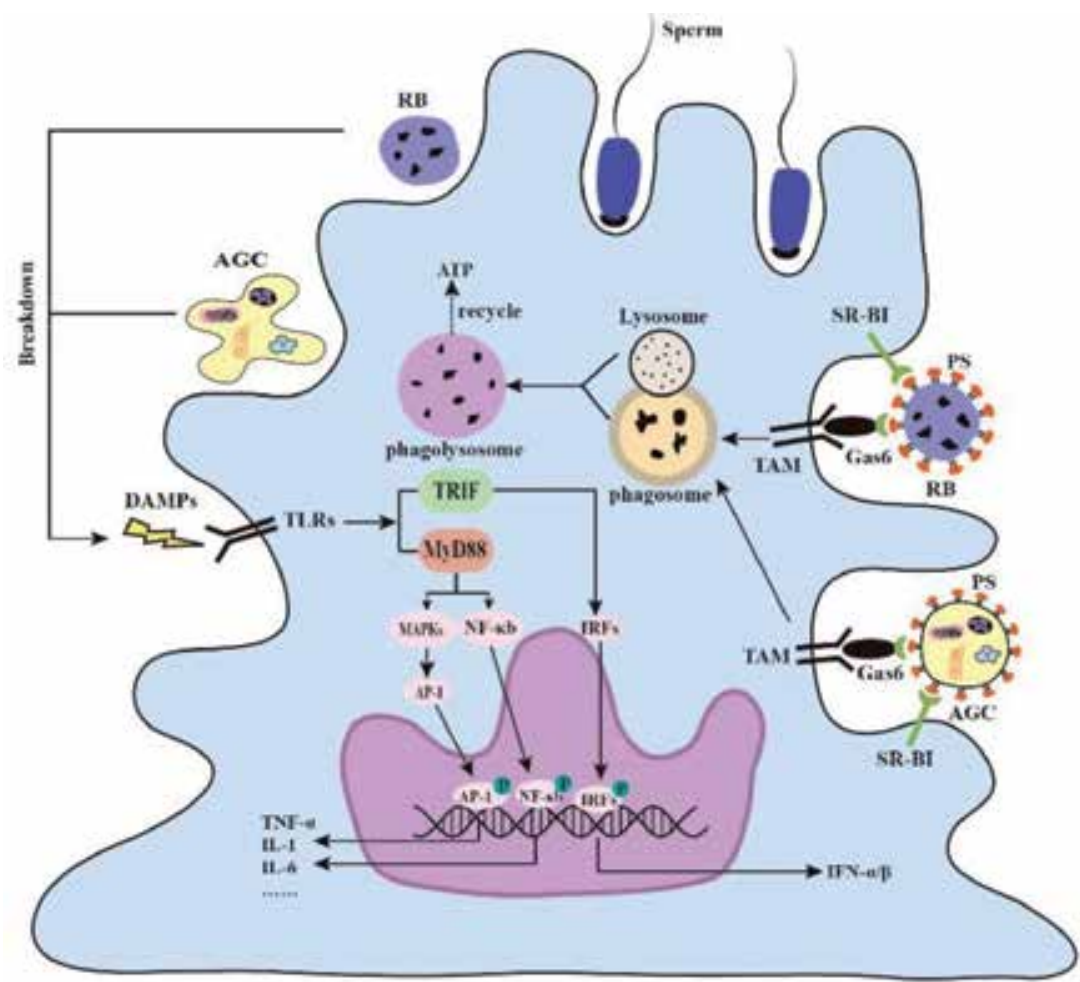

Sertoli cell

Figure 3.

Mechanisms and consequences of Sertoli cell phagocytosis of apoptotic germ cells (AGC) and residual bodies (RB). AGC and RB are phagocytized by Sertoli cells through two mechanisms (right side). SR-BI expressed on the Sertoli cell membrane binds with phosphatidylserine (PS) located on the surfaces of AGC and RB, thereby engulfing AGC and RB. TAM receptors mediate the phagocytosis of AGC and RB by Sertoli cells through Gas6 that bridges TAM receptors on Sertoli cell membrane and PS on the surfaces of AGC and RB. After phagocytosis, AGC and RB fuse with lysosomes and are recycled as energy sources for ATP production. If $A G C$ and RB are not efficiently engulfed by Sertoli cells (left side), AGC and RB break down and release damageassociated molecular patterns (DAMPs). DAMPs can be recognized by toll-like receptors (TLRs) and initiate innate immune responses through TRIF and MyD88 signaling pathways. These pathways activate nuclear factor kappa $B(N F-\kappa B)$, mitosis antigen protein kinases (MAPKs), and interferon regulatory factors (IRFs), thereby inducing the expression of inflammatory cytokines, including TNF- $\alpha, I L-1, I L-6, I N F-\alpha$, and IFN- $\beta$.

adhesion because germ cells do not express any TAM receptors. Gas6 is required for TAM-mediated phagocytosis of AGC by Sertoli cells. The N-terminal region of Gas6 binds to PS on the surface of AGC, and the C-terminal of Gas6 is recognized by TAM receptors, allowing Gas6 to bridge the binding between Sertoli cells and AGC (Figure 3, right side). Gas6 also plays a role in mediating Sertoli cell phagocytosis of AGC through the activation of Mer, thus triggering intracellular phagocytic signaling that modulates the cytoskeleton of Sertoli cells for engulfing AGC.

\subsection{Other molecules regulating Sertoli cell phagocytosis}

Sertoli cells abundantly express dynamin 2, and dynamin 2 is involved in the regulation of Sertoli cell phagocytosis [12]. Dynamin 2 regulates the actin assembly in Sertoli cells during phagocytosis. A dynamin 2 inhibitor reduces Sertoli cell phagocytosis through the impairment of phagocytic cup formation. Knockdown of dynamin 2 perturbs actin polymerization and recruitment to target liposomes. The role of dynamin 2 in regulating Sertoli cell phagocytosis requires the interaction between dynamin and amphiphysin 1 [44]. Dynamin 2 and amphiphysin 1 


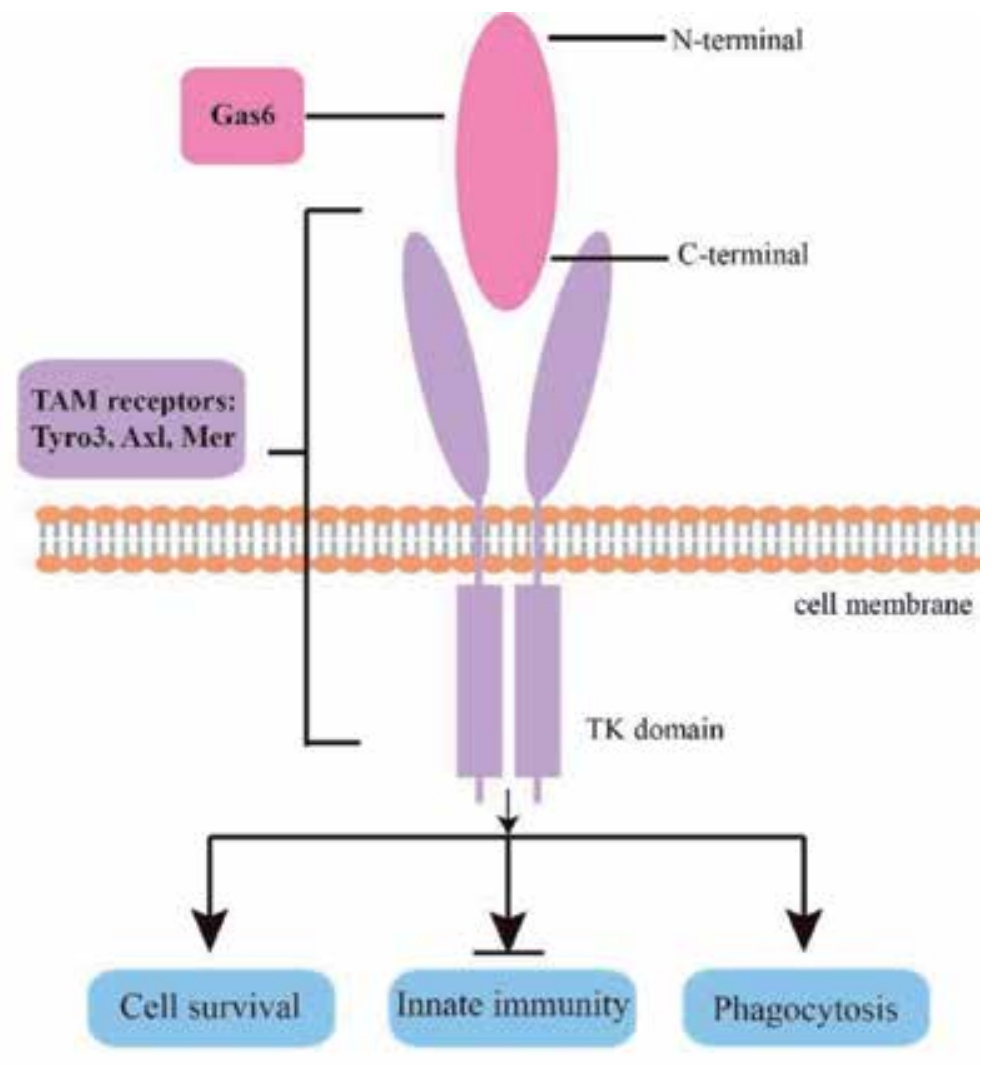

Figure 4.

TAM receptors and Gas6 system. TAM receptors belong to transmembrane proteins. The extracellular $N$-terminal region of TAM receptors binds to C-terminal domain of Gas6. The binding of Gas6 to TAM receptors results in the activation of intracellular tyrosine kinase (TK) domain of TAM receptors, thereby promoting $(\rightarrow)$ cell survival and phagocytosis of apoptotic cells and inhibiting $(\rightarrow-1)$ innate immunity.

can be specifically bound and simultaneously accumulated at ruffles of phagocytic cups. The interaction of dynamin 2 and amphiphysin 1 depends on the PS exposure on AGC.

Dimeric transferrin inhibits phagocytosis of RB by Sertoli cells in an autocrine manner [45]. Transferrin is a glycoprotein that transports iron and is highly expressed in Sertoli cells. Iron is essential for the inhibitory effect of transferrin on Sertoli cell phagocytosis. Transferrin can be physiologically secreted by Sertoli cells and inhibits the phagocytic removal of RB in autocrine manner.

ELMO1 is an evolutionarily conserved engulfment protein that mediates the internalization of apoptotic cells. However, ELMO1-deficient mice are viable and largely normal except for evident testicular pathology [46]. The seminiferous epithelium is disrupted, and AGC number is increased in the testis of ELMO1-deficient mice, therefore reducing sperm output. ELMO1 mediates the phagocytic removal of AGC by Sertoli cells. The engulfment receptors BAL1 and RAC1 (upstream and downstream of ELMO1, respectively) are involved in ELMO1-mediated Sertoli cell phagocytosis of AGC.

Noncoding miRNA regulates Sertoli cell phagocytosis. An early study showed that Dicer, a key enzyme that processes miRNA precursors into its functional form, is required for Sertoli cell function [47]. Dicer knockout mice are fetal lethal. The conditional Dicer knockout in Sertoli cells remarkably increases AGC numbers and leads to primary infertility, suggesting that miRNAs are involved in Sertoli 
cell function and spermatogenesis in mice. Whether phagocytic ability of Sertoli cells is impaired by Dicer mutation remains unclear. However, the miR-471-5p has been recently identified to regulate phagocytosis of AGC by Sertoli cells [48]. The overexpression of miR-471-5p in Sertoli cells increases AGC number due to a defective phagocytic ability of Sertoli cells in transgenic mice. The role of miR-471-5p in regulating Sertoli cell phagocytosis requires its interaction with the autophagy protein LC3. Interestingly, androgen favors Sertoli cell phagocytosis by regulating the expression of miR-471-5p and its target proteins.

\section{Pathophysiological meaning of Sertoli cell phagocytosis}

The sperm production and testosterone synthesis are two major functions of testis. To fulfill these functions, the testis is highly organized, considering its anatomical location, histological structure, and cellular compositions. The testis is constituted by several types of tissue-specific cells. In addition to numerous germ cells, major testicular somatic cell types, including Leydig and Sertoli cells, are crucial for spermatogenesis. Leydig cells, localizing in the interstitial spaces of the testis, synthesize testosterone essential for spermatogenesis and multiple other extratesticular target organs. Sertoli cells embrace developing germ cells and constitute the seminiferous epithelium within the seminiferous tubules where spermatogenesis occurs (Figure 1). Sertoli cells are the only type of somatic cells in the seminiferous epithelium and play critical roles in regulating spermatogenesis by building a niche for germ cell development, providing nutrition to germ cells, and removing AGC and RB by phagocytosis. Sertoli cell phagocytosis is the most noticeable. Several consequences of phagocytotic removal of AGC and RB by Sertoli cells have been proposed. Removal of AGC and RB provides appropriate spaces in the seminiferous epithelium for healthy spermatogenesis. AGC can release autoantigens when necrosis occurs, which may induce autoimmune responses. Therefore, timely elimination of AGC before releasing autoantigens prevents autoimmune responses. After phagocytosis of AGC and RB, Sertoli cells recycle these apoptotic components as an energy source. This energy source would be important for Sertoli cells because circulating nutrients barely reach to the seminiferous epithelium due to the BTB and lacking blood vessels.

\subsection{Space saving}

Based on origin, phagocytes can be classified into professional or nonprofessional phagocytes, respectively [49]. The hematopoietic phagocytes belong to professional and can infiltrate into the infected sites to ingest microbes and clean up damaged cells, which is critical for the innate defense against microbial infection. However, circulating phagocytes cannot migrate into tissues separated by the BTB, where resident tissue-specific phagocytes, which are considered as nonprofessional, are essential for maintaining tissue homeostasis by phagocytic removal of apoptotic substrates. The typical example is the mammalian testis. More than one hundred million sperms are produced each day in men during their whole reproductive age. Since a large number of male germ cells develop simultaneously within the seminiferous epithelium, there is a competition for space and nutrient if all the germ cells would develop into spermatozoa. Therefore, before maturing to sperm, most developing germ cells die through apoptosis, and the remaining spermatids shed most of their cytoplasmic portions as RB. Since the number of germ cells that Sertoli cells can support for finalizing their development is limited, we can speculate that the elimination of AGC and RB by Sertoli cells is important to ensure 
enough spaces for a healthy germ cell production and maintain tissue homeostasis. However, this speculation lacks experimental evidence. By contrast, there is a body of substantial evidence that the phagocytic removal of AGC and RB prevents an autoimmune response.

\subsection{Removal of autoantigens}

Male germ cells, which are mostly developed after the establishment of central immune tolerance, express a large number of novel proteins. These new proteins of male germ cells can be recognized as "foreign antigens" by the immune system. However, male germ cells do not induce an autoimmune response in the male reproductive tracts under physiological conditions due to their special immune microenvironment. The testis is a distinct immunoprivileged organ. Immune privilege represents a special immunological status that exists in several mammalian organs, including the eye, brain, pregnant uterus, and testis, where allografts or/and xenografts can survive without evoking immune rejection [50]. The testis tolerates both alloantigens and immunogenic autoantigens [51]. Various mechanisms are involved in the maintenance of testicular immune privilege [42], in which Sertoli cells play crucial roles.

Sertoli cells modulate testicular immune privilege with different mechanisms (Figure 5). The BTB protects the majority of the antigenic germ cells by sequestering autoantigens behind the BTB from immune components in the interstitial spaces. The BTB is formed between adjacent Sertoli cells near the basal membrane of the seminiferous epithelium (Figure 1). Several cellular junctions, including tight junction, gap junction, and basal ectoplasmic specialization, are involved in the BTB formation. The BTB divides the seminiferous epithelium to the basal and adluminal compartments [52]. The BTB limits the access of immune contents residing in the interstitial spaces into the adluminal compartment and sequesters the germ cell autoantigens within the adluminal compartments. Therefore, the BTB plays an important role in maintaining immune privilege within the adluminal compartments of the seminiferous epithelium. Although the BTB sequesters the late stage of germ cells in the adluminal compartments, the early stage of germ cells, including preleptotene spermatocytes and spermatogonia that reside outside the $\mathrm{BTB}$, also produces antigenic proteins [53]. Moreover, certain germ cell antigens behind the BTB can egress into the interstitial spaces, and these antigens do not induce an immune response in the testis [54]. These observations suggest that the BTB cannot completely sequester germ cell antigens and should be only partially responsible for testicular immune privilege. In fact, the interstitial spaces outside the BTB also enjoy immunoprivileged status. A dense network, including the tissue structure, local immunosuppressive milieu, and systemic immune tolerance, coordinately regulates the immunoprivileged environment in the testis $[42,55]$. In addition to the BTB, Sertoli cells produce various anti-inflammatory factors that regulate the testicular immune microenvironment [56]. Sertoli cells express activin A and activin B [57]. Activin A inhibits the expression of pro-inflammatory cytokines, thereby suppressing the testicular inflammatory responses. TGF- $\beta$ is also predominantly produced by Sertoli cells in the testis. As an anti-inflammatory factor, TGF- $\beta 1$ protects islet $\beta$-cell grafts after co-transplantation with Sertoli cells [58]. Moreover, Sertoli cells express Fas ligand (FasL) and programmed death ligand-1 (PD-L1), two negative immunoregulatory ligands which are both involved in the maintenance of testicular immune privilege [59, 60].

Phagocytosis is a biological process that regulates immunity [61]. The phagocytic removal of AGC and RB by Sertoli cells is critical for timely elimination 


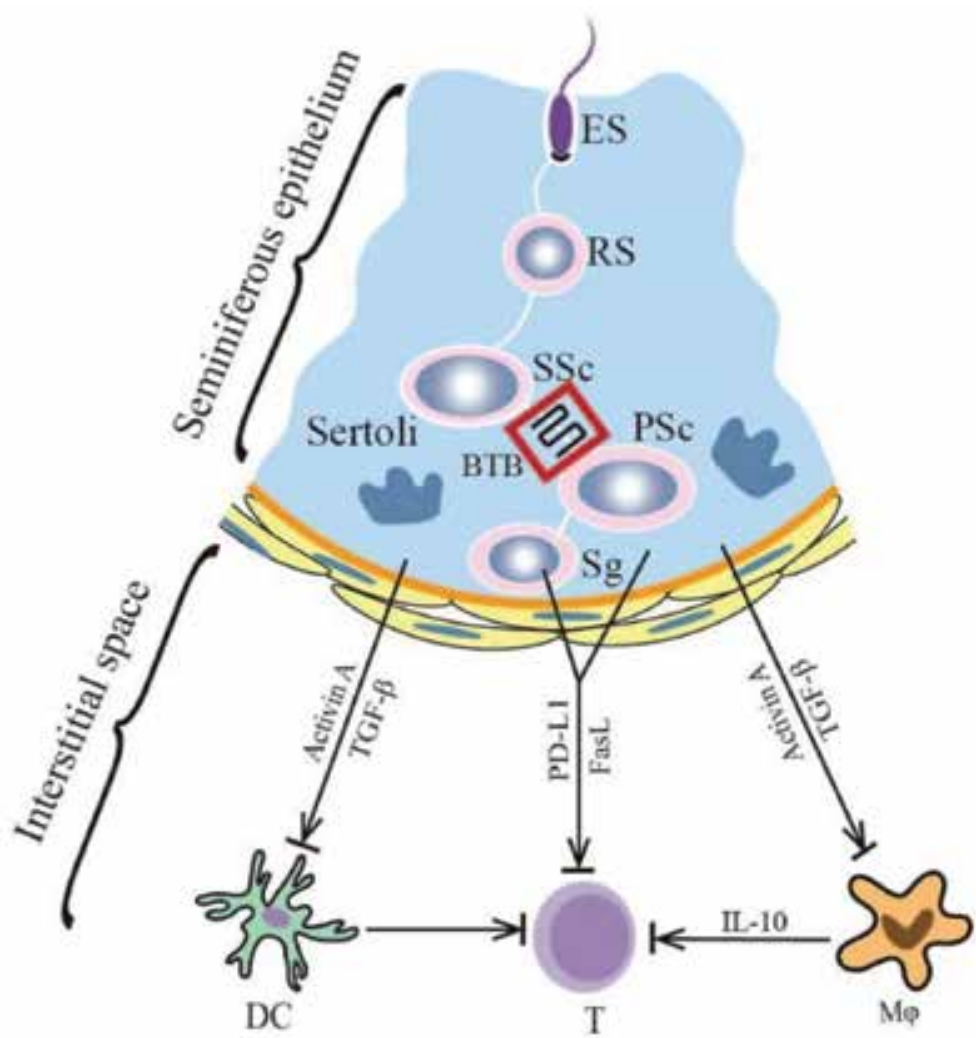

Figure 5.

Role of Sertoli cells in testicular immune privilege. Sertoli cells produce various anti-inflammatory cytokines, including activin $A$ and TGF- $\beta$, which inhibit immune response of dendritic cells (DC) and testicular macrophages $(M \varphi)$. Sertoli cells, together with germ cells, also express high level of Fas ligand (FasL) and programmed death ligand 1 (PD-L1) that can inhibit immune response by inducing apoptosis of Tlymphocytes. Sg, spermatogonia; $P S c$, primary spermatocyte; SSc, secondary spermatocyte; Rs, round sperm; ES, elongated sperm.

of autoantigens that may be released if AGC and RB are broken down. Toll-like receptors (TLRs) belong to a subfamily of pattern recognition receptors that initiate innate immune responses. Several TLRs are expressed in testicular cells and can be activated by their relative ligands $[41,62,63]$. Damaged tissues and necrotic cells may release endogenous TLR ligands, namely, damage-associated molecule patterns (DAMPs), which can induce noninfectious inflammatory response (Figure 3, left side). Various DAMPs, including high-mobility group box 1 (HMGB1) and several heat stock proteins (HSPs), have been recognized to activate TLR2 and TLR4 $[64,65]$. Notably, HMGB1 and HSPs are abundantly expressed in male germ cells and can be released under stress conditions $[66,67]$. Therefore, necrotic germ cells and RB breakdown may release endogenous TLR ligands, thus inducing inflammatory responses. Accordingly, physical trauma and chemical noxae that may damage germ cells are risk factors of chronic testicular orchitis [68]. An impaired removal of AGC leads to autoimmune orchitis [69]. The damaged male germ cells (DMGCs) induce the expression of various inflammatory mediators, including pro-inflammatory factors and chemokines, in Sertoli cells, thereby promoting leukocytes' infiltration to the testis [70]. The DMGC-induced inflammatory cytokine expression and immune cell infiltrations require TLR2 and TLR4 in Sertoli cells. Therefore, timely removal of AGC and RB by Sertoli cells is essential for maintaining immune homeostasis in the testis to prevent autoimmune orchitis. 


\subsection{Providing energy}

Another meaning of male germ cell death and removal of AGC and RB serves as energy sources for Sertoli cells [71]. After phagocytosis by Sertoli cells, AGC and RB fuse with lysosomes. AGC and RB are subsequently broken down and recycled as energy sources for ATP production. The most noticeable phenotype of Sertoli cells is the formation of numerous lipid droplets in the cell cytoplasm. These lipid droplets result from the breakdown of engulfed AGC and RB [13, 72]. Unlike the majority of cell types that mainly use glucose as an energy source, Sertoli cells predominantly use lipids to produce ATP [71]. The lipids from AGC and RB should be the main energy sources for Sertoli cells. Sertoli cells provide essential physical and environmental support for spermatogenesis, which are energy consumers. Corresponding to their function, Sertoli cells exhibit an active energy metabolism and produce high levels of ATP [71, 73]. While lipids and glucoses can be substrates for ATP production within cells under physiological conditions, the majority of cell types use glycogen to produce ATP, whereas lipids serve as energy storage. Only minor cell types, such as adipocytes, myocardial cells, and Sertoli cells, have been confirmed to actively utilize lipids to produce ATP. Why these cell types predominantly use lipids as energy sources remains unclear. However, the active usage of lipids by Sertoli cells is compatible with the special microenvironment in the testis. Sertoli cells are barely reached by the nutrition from the peripheral circulation due to the barriers in the basement membrane, BTB, and the absence of blood capillaries within the seminiferous epithelium. The simplest way for Sertoli cells to have enough energy to support spermatogenesis is to recycle the lipid contents of AGC and RB. Therefore, the phagocytic removal of AGC and RB by Sertoli cells is necessary for Sertoli cells to ensure their functions, which confers a novel meaning for a large number of germ cells to undergo apoptosis during spermatogenesis.

\section{Conclusive remarks}

The mammalian testis possesses a special microenvironment for fulfilling its functions. The adluminal compartments of the seminiferous epithelium are separated from blood circulation by the BTB, and the circulating phagocytes cannot reach these regions. Therefore, Sertoli cells are responsible for the clearance of numerous AGC and RB during spermatogenesis. The phagocytic removal of apoptotic components by Sertoli cells is not only for waste disposal but also confers more meaning. In addition to prevention of autoimmune responses by removing autoantigens, recycling of apoptotic components can be used as an energy source for Sertoli cells. These biological processes would be particularly important in the tissues where immunogenic autoantigens are produced and seldom reached by circulating nutritious substrates. The mechanisms behind cell death and their removal by phagocytes, and their tissue-specific significance, are worthwhile to investigate in depth.

\section{Acknowledgements}

This work was supported by grants from the CAMS Initiative for Innovative Medicine (Nos. 2017-I2M-B\&R-06, 2017-I2M-3-007) and the Major State Basic Research Project of China (Nos. 2016YFA0101001 and 2018YFC1003902). 


\section{Author details}

Fei Wang and Daishu Han*

Institute of Basic Medical Sciences, Chinese Academy of Medical Sciences,

School of Basic Medicine, Peking Union Medical College, Beijing, China

*Address all correspondence to: dshan@ibms.pumc.edu.cn

\section{IntechOpen}

(c) 2019 The Author(s). Licensee IntechOpen. This chapter is distributed under the terms of the Creative Commons Attribution License (http://creativecommons.org/licenses/ by/3.0), which permits unrestricted use, distribution, and reproduction in any medium, provided the original work is properly cited. $(\mathrm{cc}) \mathrm{BY}$ 


\section{References}

[1] Savill J, Fadok V. Corpse clearance defines the meaning of cell death. Nature. 2000;407:784-788. DOI: $10.1038 / 35037722$

[2] Nakanishi Y, Shiratsuchi A. Phagocytic removal of apoptotic spermatogenic cells by Sertoli cells: Mechanisms and consequences. Biological \& Pharmaceutical Bulletin. 2004;27:13-16. DOI: 10.1248/ bpb.27.13

[3] Maeda Y, Shiratsuchi A, Namiki M, et al. Inhibition of sperm production in mice by annexin $\mathrm{V}$ microinjected into seminiferous tubules: Possible etiology of phagocytic clearance of apoptotic spermatogenic cells and male infertility. Cell Death and Differentiation. 2002;9:742-749. DOI: 10.1038/ sj.cdd.4401046

[4] Zhang Y, Li N, Chen Q, et al. Breakdown of immune homeostasis in the testis of mice lacking Tyro3, Axl and Mer receptor tyrosine kinases. Immunology and Cell Biology. 2013;91:416-426. DOI: 10.1038/ icb.2013.22

[5] Braun RE. Every sperm is sacred-or is it? Nature Genetics. 1998;18:202-204. DOI: $10.1038 / \mathrm{ng} 0398-202$

[6] Sinha Hikim AP, Swerdloff RS. Hormonal and genetic control of germ cell apoptosis in the testis. Reviews of Reproduction. 1999;4:38-47

[7] O’Shaughnessy PJ. Hormonal control of germ cell development and spermatogenesis. Seminars in Cell \& Developmental Biology. 2014;29:55-65. DOI: 10.1016/j.semcdb.2014.02.010

[8] Zheng S, Turner TT, Lysiak JJ. Caspase 2 activity contributes to the initial wave of germ cell apoptosis during the first round of spermatogenesis. Biology of
Reproduction. 2006;74:1026-1033. DOI: 10.1095/biolreprod.105.044610

[9] Williamson P, Schlegel RA. Transbilayer phospholipid movement and the clearance of apoptotic cells. Biochimica et Biophysica Acta. 2002;1585:53-63. DOI: 10.1016/ S1388-1981(02)00324-4

[10] Yefimova MG, Messaddeq N, Meunier AC, et al. Phagocytosis by Sertoli cells: Analysis of main phagocytosis steps by confocal and electron microscopy. Methods in Molecular Biology. 2018;1748:85-101. DOI: 10.1007/978-1-4939-7698-0_8

[11] Gillot I, Jehl-Pietri C, Gounon P, et al. Germ cells and fatty acids induce translocation of CD36 scavenger receptor to the plasma membrane of Sertoli cells. Journal of Cell Science. 2005;118:3027-3035. DOI: 10.1242/ jcs. 02430

[12] Otsuka A, Abe T, Watanabe M, et al. Dynamin 2 is required for actin assembly in phagocytosis in Sertoli cells. Biochemical and Biophysical Research Communications. 2009;378:478-482. DOI: 10.1016/j.bbrc.2008.11.066

[13] Wang H, Wang H, Xiong W, et al. Evaluation on the phagocytosis of apoptotic spermatogenic cells by Sertoli cells in vitro through detecting lipid droplet formation by oil red O staining. Reproduction. 2006;132:485-492. DOI: 10.1530/rep.1.01213

[14] Lacy D. Light and electron microscopy and its use in the study of factors influencing spermatogenesis in the rat. Journal of the Royal Microscopical Society. 1960;79:209-225

[15] Rigotti A, Acton SL, Krieger M. The class B scavenger receptors SR-BI and CD36 are receptors for anionic phospholipids. The Journal of Biological 
Chemistry. 1995;270:16221-16224. DOI: $10.1074 / j b c .270 .27 .16221$

[16] Murao K, Terpstra V, Green SR, et al. Characterization of CLA-1, a human homologue of rodent scavenger receptor $\mathrm{BI}$, as a receptor for high density lipoprotein and apoptotic thymocytes. The Journal of Biological Chemistry. 1997;272:17551-17557. DOI: 10.1074/jbc.272.28.17551

[17] Fukasawa M, Adachi H, Hirota K, et al. SRB1, a class B scavenger receptor, recognizes both negatively charged liposomes and apoptotic cells. Experimental Cell Research. 1996;222:246-250. DOI: 10.1006/ excr.1996.0030

[18] Zachowski A. Phospholipids in animal eukaryotic membranes: Transverse asymmetry and movement. The Biochemical Journal. 1993;294 (Pt 1):1-14. DOI: 10.1042/bj2940001

[19] Shiratsuchi A, Kawasaki Y, Ikemoto $\mathrm{M}$, et al. Role of class B scavenger receptor type I in phagocytosis of apoptotic rat spermatogenic cells by Sertoli cells. The Journal of Biological Chemistry. 1999;274:5901-5908. DOI: 10.1074/jbc.274.9.5901

[20] Kawasaki Y, Nakagawa A, Nagaosa $\mathrm{K}$, et al. Phosphatidylserine binding of class B scavenger receptor type I, a phagocytosis receptor of testicular Sertoli cells. The Journal of Biological Chemistry. 2002;277:27559-27566. DOI: 10.1074/jbc.M202879200

[21] Yefimova MG, Messaddeq N, Harnois T, et al. A chimerical phagocytosis model reveals the recruitment by Sertoli cells of autophagy for the degradation of ingested illegitimate substrates. Autophagy. 2013;9:653-666. DOI: 10.4161/auto.23839

[22] Hafizi S, Dahlback B. Signalling and functional diversity within the Axl subfamily of receptor tyrosine kinases. Cytokine \& Growth Factor Reviews. 2006;17:295-304. DOI: 10.1016/j. cytogfr.2006.04.004

[23] Hafizi S, Dahlback B. Gas6 and protein $\mathrm{S}$ vitamin $\mathrm{K}$-dependent ligands for the Axl receptor tyrosine kinase subfamily. The FEBS Journal. 2006;273:5231-5244. DOI: 10.1111/j.1742-4658.2006.05529.x

[24] Lemke G. Biology of the TAM receptors. Cold Spring Harbor Perspectives in Biology. 2013;5:a009076. DOI: $10.1101 /$ cshperspect.a009076

[25] Lemke G, Burstyn-Cohen T. TAM receptors and the clearance of apoptotic cells. Annals of the New York Academy of Sciences. 2010;1209:23-29. DOI: 10.1111/j.1749-6632.2010.05744.x

[26] Qingxian L, Qiutang L, Qingjun L. Regulation of phagocytosis by TAM receptors and their ligands. Frontiers in Biology. 2010;5:227-237. DOI: 10.1007/ s11515-010-0034-5

[27] Rothlin CV, Carrera-Silva EA, Bosurgi L, et al. TAM receptor signaling in immune homeostasis. Annual Review of Immunology. 2015;33:355-391. DOI: 10.1146/ annurev-immunol-032414-112103

[28] Lu Q, Lemke G. Homeostatic regulation of the immune system by receptor tyrosine kinases of the Tyro 3 family. Science. 2001;293:306-311. DOI: 10.1126/science.1061663

[29] Rothlin CV, Lemke G. TAM receptor signaling and autoimmune disease. Current Opinion in Immunology. 2010;22:740-746. DOI: 10.1016/j. coi.2010.10.001

[30] Morizono K, Xie Y, Olafsen T, et al. The soluble serum protein Gas6 bridges virion envelope phosphatidylserine to the TAM receptor tyrosine kinase Axl to mediate viral entry. Cell Host \& 
Microbe. 2011;9:286-298. DOI: 10.1016/j. chom.2011.03.012

[31] Meertens L, Carnec X, Lecoin MP, et al. The TIM and TAM families of phosphatidylserine receptors mediate dengue virus entry. Cell Host \& Microbe. 2012;12:544-557. DOI: 10.1016/j.chom.2012.08.009

[32] Shimojima M, Takada A, Ebihara H, et al. Tyro3 family-mediated cell entry of Ebola and Marburg viruses. Journal of Virology. 2006;80:10109-10116. DOI: 10.1128/JVI.01157-06

[33] Shiozawa Y, Pedersen EA, Patel LR, et al. GAS6/AXL axis regulates prostate cancer invasion, proliferation, and survival in the bone marrow niche. Neoplasia. 2010;12:116-127

[34] Paolino M, Choidas A, Wallner S, et al. The E3 ligase Cbl-b and TAM receptors regulate cancer metastasis via natural killer cells. Nature. 2014;507:508-512. DOI: 10.1038/ nature12998

[35] Akitake-Kawano R, Seno H, Nakatsuji M, et al. Inhibitory role of Gas6 in intestinal tumorigenesis. Carcinogenesis. 2013;34:1567-1574. DOI: $10.1093 /$ carcin/bgt069

[36] Lu Q, Gore M, Zhang Q, et al. Tyro-3 family receptors are essential regulators of mammalian spermatogenesis. Nature.

1999;398:723-728. DOI: 10.1038/19554

[37] Chen Y, Wang H, Qi N, et al. Functions of TAM RTKs in regulating spermatogenesis and male fertility in mice. Reproduction. 2009;138:655-666. DOI: 10.1530/REP-09-0101

[38] Deng T, Chen Q, Han D. The roles of TAM receptor tyrosine kinases in the mammalian testis and immunoprivileged sites. Frontiers in Bioscience. 2016;21:316-327
[39] Wang H, Chen Y, Ge Y, et al. Immunoexpression of Tyro 3 family receptors-Tyro 3, Axl, and Merand their ligand Gas6 in postnatal developing mouse testis. The Journal of Histochemistry and Cytochemistry. 2005;53:1355-1364. DOI: 10.1369/ jhc.5A6637.2005

[40] Sun B, Qi N, Shang T, et al. Sertoli cell-initiated testicular innate immune response through toll-like receptor-3 activation is negatively regulated by Tyro3, Axl, and Mer receptors. Endocrinology. 2010;151:2886-2897. DOI: $10.1210 /$ en.2009-1498

[41] Shang T, Zhang X, Wang T, et al. Toll-like receptor-initiated testicular innate immune responses in mouse Leydig cells. Endocrinology. 2011;152:2827-2836. DOI: 10.1210/ en.2011-0031

[42] Li N, Wang T, Han D. Structural, cellular and molecular aspects of immune privilege in the testis. Frontiers in Immunology. 2012;3:152. DOI: 10.3389/fimmu.2012.00152

[43] Xiong W, Chen Y, Wang H, et al. Gas6 and the Tyro 3 receptor tyrosine kinase subfamily regulate the phagocytic function of Sertoli cells. Reproduction. 2008;135:77-87. DOI: 10.1530/REP-07-0287

[44] Nakanishi A, Abe T, Watanabe M, et al. Dynamin 2 cooperates with amphiphysin 1 in phagocytosis in Sertoli cells. Acta Medica Okayama. 2008;62:385-391. DOI: $10.18926 /$ AMO/30954

[45] Yefimova MG, Sow A, Fontaine I, et al. Dimeric transferrin inhibits phagocytosis of residual bodies by testicular rat Sertoli cells. Biology of Reproduction. 2008;78:697-704. DOI: 10.1095/biolreprod.107.063107

[46] Elliott MR, Zheng S, Park D, et al. Unexpected requirement for ELMO1 in 
clearance of apoptotic germ cells in vivo. Nature. 2010;467:333-337. DOI: 10.1038/ nature 09356

[47] Kim GJ, Georg I, Scherthan H, et al. Dicer is required for Sertoli cell function and survival. The International Journal of Developmental Biology. 2010;54:867875. DOI: $10.1387 / \mathrm{ijdb} .092874 \mathrm{gk}$

[48] Panneerdoss S, Viswanadhapalli S, Abdelfattah N, et al. Cross-talk between miR-471-5p and autophagy component proteins regulates LC3-associated phagocytosis (LAP) of apoptotic germ cells. Nature Communications. 2017;8:598. DOI: $10.1038 /$ s41467-017-00590-9

[49] Rabinovitch M. Professional and non-professional phagocytes: An introduction. Trends in Cell Biology. 1995;5:85-87. DOI: 10.1016/ S0962-8924(00)88955-2

[50] Simpson E. A historical perspective on immunological privilege. Immunological Reviews. 2006;213:12-22. DOI: 10.1111/j.1600-065X.2006.00434.x

[51] Fijak M, Meinhardt A. The testis in immune privilege. Immunological Reviews. 2006;213:66-81. DOI: 10.1111/j.1600-065X.2006.00438.x

[52] Cheng CY, Mruk DD. The bloodtestis barrier and its implications for male contraception. Pharmacological Reviews. 2012;64:16-64. DOI: 10.1124/ pr. 110.002790

[53] Yule TD, Montoya GD, Russell LD, et al. Autoantigenic germ cells exist outside the blood testis barrier. Journal of Immunology. 1988;141:1161-1167

[54] Tung KS, Harakal J, Qiao H, et al. Egress of sperm autoantigen from seminiferous tubules maintains systemic tolerance. The Journal of Clinical Investigation. 2017;127:1046-1060. DOI: 10.1172/JCI89927
[55] Meinhardt A, Hedger MP. Immunological, paracrine and endocrine aspects of testicular immune privilege. Molecular and Cellular Endocrinology. 2011;335:60-68. DOI: 10.1016/j.mce.2010.03.022

[56] Kaur G, Thompson LA, Dufour JM. Sertoli cells-immunological sentinels of spermatogenesis. Seminars in Cell \& Developmental Biology. 2014;30:36-44. DOI: 10.1016/j. semcdb.2014.02.011

[57] Buzzard JJ, Loveland KL, O’Bryan $\mathrm{MK}$, et al. Changes in circulating and testicular levels of inhibin A and $B$ and activin a during postnatal development in the rat. Endocrinology. 2004;145:3532-3541. DOI: 10.1210/ en.2003-1036

[58] Suarez-Pinzon W, Korbutt GS, Power R, et al. Testicular sertoli cells protect islet beta-cells from autoimmune destruction in NOD mice by a transforming growth factor-beta1dependent mechanism. Diabetes. 2000;49:1810-1818. DOI: 10.2337/ diabetes.49.11.1810

[59] Bellgrau D, Gold D, Selawry H, et al. A role for $\mathrm{CD} 95$ ligand in preventing graft rejection. Nature. 1995;377:630-632. DOI: 10.1038/377630a0

[60] Cheng X, Dai H, Wan N, et al. Interaction of programmed death-1 and programmed death-1 ligand-1 contributes to testicular immune privilege. Transplantation. 2009;87:1778-1786. DOI: $10.1097 /$ TP.0b013e3181a75633

[61] Greenberg S, Grinstein S. Phagocytosis and innate immunity. Current Opinion in Immunology. 2002;14:136-145. DOI: $10.1016 /$ S0952-7915(01)00309-0

[62] Wu H, Wang H, Xiong W, et al. Expression patterns and functions of toll-like receptors in mouse Sertoli cells. 
Endocrinology. 2008;149:4402-4412. DOI: $10.1210 /$ en.2007-1776

[63] Wang T, Zhang X, Chen Q, et al. Toll-like receptor 3-initiated antiviral responses in mouse male germ cells in vitro. Biology of Reproduction. 2012;86. DOI: 106. DOI: 10.1095/ biolreprod.111.096719

[64] Curtin JF, Liu N, Candolfi M, et al. HMGB1 mediates endogenous TLR2 activation and brain tumor regression. PLoS Medicine. 2009;6:e10. DOI: 10.1371/journal.pmed.1000010

[65] Vabulas RM, Ahmad-Nejad P, da Costa C, et al. Endocytosed HSP60s use toll-like receptor 2 (TLR2) and TLR4 to activate the toll/interleukin-1 receptor signaling pathway in innate immune cells. The Journal of Biological Chemistry. 2001;276:31332-31339. DOI: 10.1074/jbc.M103217200

[66] Biggiogera M, Tanguay RM, Marin $\mathrm{R}$, et al. Localization of heat shock proteins in mouse male germ cells: An immunoelectron microscopical study. Experimental Cell Research. 1996;229:77-85. DOI: 10.1006/ excr.1996.0345

[67] Zetterstrom CK, Strand ML, Soder O. The high mobility group box chromosomal protein 1 is expressed in the human and rat testis where it may function as an antibacterial factor. Human Reproduction. 2006;21:28012809. DOI: $10.1093 /$ humrep/del256

[68] Schuppe HC, Meinhardt A, Allam JP, et al. Chronic orchitis: A neglected cause of male infertility? Andrologia. 2008;40:84-91. DOI: 10.1111/j.1439-0272.2008.00837.x

[69] Pelletier RM, Yoon SR, Akpovi CD, et al. Defects in the regulatory clearance mechanisms favor the breakdown of self-tolerance during spontaneous autoimmune orchitis. American Journal of Physiology. Regulatory,
Integrative and Comparative Physiology. 2009;296:R743-R762. DOI: 10.1152/ ajpregu.90751.2008

[70] Zhang X, Wang T, Deng T, et al. Damaged spermatogenic cells induce inflammatory gene expression in mouse Sertoli cells through the activation of toll-like receptors 2 and 4 . Molecular and Cellular Endocrinology. 2013;365:162-173. DOI: 10.1016/j. mce.2012.10.016

[71] Xiong W, Wang H, Wu H, et al. Apoptotic spermatogenic cells can be energy sources for Sertoli cells. Reproduction. 2009;137:469-479. DOI: 10.1530/REP-08-0343

[72] Sasso-Cerri E, Giovanoni M, Hayashi $\mathrm{H}$, et al. Morphological alterations and intratubular lipid inclusions as indicative of spermatogenic damage in cimetidinetreated rats. Archives of Andrology. 2001;46:5-13

[73] Floridi A, Marcante ML, D’Atri S, et al. Energy metabolism of normal and lonidamine-treated Sertoli cells of rats. Experimental and Molecular Pathology. 1983;38:137-147. DOI: 10.1016/0014-4800(83)90105-3 


\title{
Polymorphism of Xenobiotic Detoxification Genes and Male Infertility
}

\author{
Nguyen Thi Trang and Vu Thi Huyen
}

\begin{abstract}
Infertility is a multifactorial disease caused by both genetic and environmental factors. It is observed in 10-15\% of couples, among which male infertility contributes for half the cases. Thus, identifying underlying causes of male infertility and for proper methods for treating and/or preventing sperm damage is of paramount importance. It is found that one of the factors that has been recently implicated in male infertility is oxidative stress, mediated by reactive oxygen species (ROS) that are produced during the metabolic process, as well as during the exposure to environmental chemical agents and their interaction with tissue-specific enzymes. Several studies have identified genetic variations at different loci, connected with male infertility, that may shed light on some idiopathic cases of seminal fluid abnormalities. In this chapter, we make an effort to decipher the contribution of polymorphisms in xenobiotic detoxification genes in the male infertility development.
\end{abstract}

Keywords: male infertility, xenobiotics, arylamine N-acetyltransferase 2, GSTM1, GSTT1, GSTP1, cytochrome P4501A1, genetic polymorphism, oxidative stress, DNA fragmentation, detoxification

\section{Introduction}

Deterioration of male reproductive health has become a serious problem in most countries [1]. Contributing factors for male infertility comprise genital infections, ejaculatory duct obstruction (EDO), hypogonadism, varicoceles, or exposure to environmental factors (e.g., xenobiotics, ionizing radiation), lifestyle factors (e.g., alcohol, smoking and obesity), genetic causes, systemic diseases, and abnormal ejaculation [2]. However, in approximately $30-45 \%$ of male infertility cases, the etiology remains undetermined and is called the idiopathic infertility [3]. Genetic factors make a significant contribution to the development of idiopathic male infertility. For example, oligozoospermia and azoospermia have been recently determined to be tied with such genetic deviations as translocations, microdeletions and mutations [4] in genes that play a role in testicular development, gametogenesis and metabolism of xenobiotics associated with reproductive system disorders. Xenobiotic metabolism causes the main damage to the organism by creating covalent bounds with cellular macromolecules (DNA or protein). This indicates that the expression regulation and activity of xenobiotic-metabolizing enzymes may play the crucial role in determination of male reproductive system 
susceptibility to chemically induced damages. Thus, xenobiotic-mediated adverse effects of male reproductive system are associated with the polymorphisms in xenobiotic detoxification genes. Different variants of one gene are categorized as polymorphism if their frequency in the population exceeds 1\% [5]. In contrast to mutations, polymorphisms have indirect connections with particular seminal fluid abnormalities but may be indispensable during the investigation of multifactorial diseases. Polymorphic variants may change the expression or function of encoded protein, leading to its conformational changes that would result in different pharmacokinetics, chemical reaction capacities and efficiency of the xenobioticdetoxifying enzymes. In this chapter, we discuss polymorphisms in the main enzymes capable of maintaining the oxidants/antioxidants balance in reproductive tissues, focusing mainly on phase I cytochrome P4501A1 (CYP1A1) and phase II (GSTM1, GSTT1, GSTP1 and arylamine N-acetyltransferase 2 (NAT2)) detoxifying enzymes.

\section{Xenobiotic metabolism}

The foreign environmental chemicals are known as xenobiotics (Gk. xenos"stranger") and include drugs, drug metabolites and environmental pollutants (such as synthetic pesticides, herbicides and industrial pollutants). Xenobiotics may cause damages in the innate state (alkyl iodides, acyl halides and nitrogen mustards) or after activation in the metabolizing process.

Xenobiotic metabolism is performed in three stages (Figure 1):

1. Phase I enzymes initiate the detoxification process, during which the lipophilic xenobiotics become more polar and acquire sites for subsequent conjugation reactions. Phase I enzymes comprise mainly the cytochrome P450 (CYP) superfamily of microsomal enzymes, which include the 36 gene families. It is considered that CYP1, CYP2, CYP3, CYP4 and CYP7 families play the key roles in hepatic and extra-hepatic metabolism and in the elimination of xenobiotics and drugs in human [6].

2. Phase II enzymes catalyze the conjugation process. These enzymes can interact with xenobiotics either directly or, more generally, interact with the metabolites produced by phase I enzymes. Phase II enzymes include a lot of superfamilies, namely, the sulfotransferases (SULT), UDP-glucuronosyltransferases (UGT), DT-diaphorase or NAD(P)H quinone oxidoreductase (NQO) or $\mathrm{NAD}(\mathrm{P}) \mathrm{H}$ menadione reductase (NMO), glutathione S-transferases (GST) and N-acetyltransferases (NAT). Each superfamily consists of families and subfamilies of genes encoding the various isoforms with different substrate and tissue specificities [7].

3. Phase III elimination via transporters or passive transport. Phase III transporters involve $\mathrm{P}$-glycoprotein (P-gp), multidrug resistance-associated protein (MRP), which belongs to the subfamily of the ATP binding cassette (ABC) transporters and organic anion transporting polypeptide 2 (OATP2).

\section{Potential mechanisms for idiopathic male infertility}

Male infertility is a complex, multifactorial disorder and often its etiology remains poorly understood. Increasing volume of data suggests that oxidative 


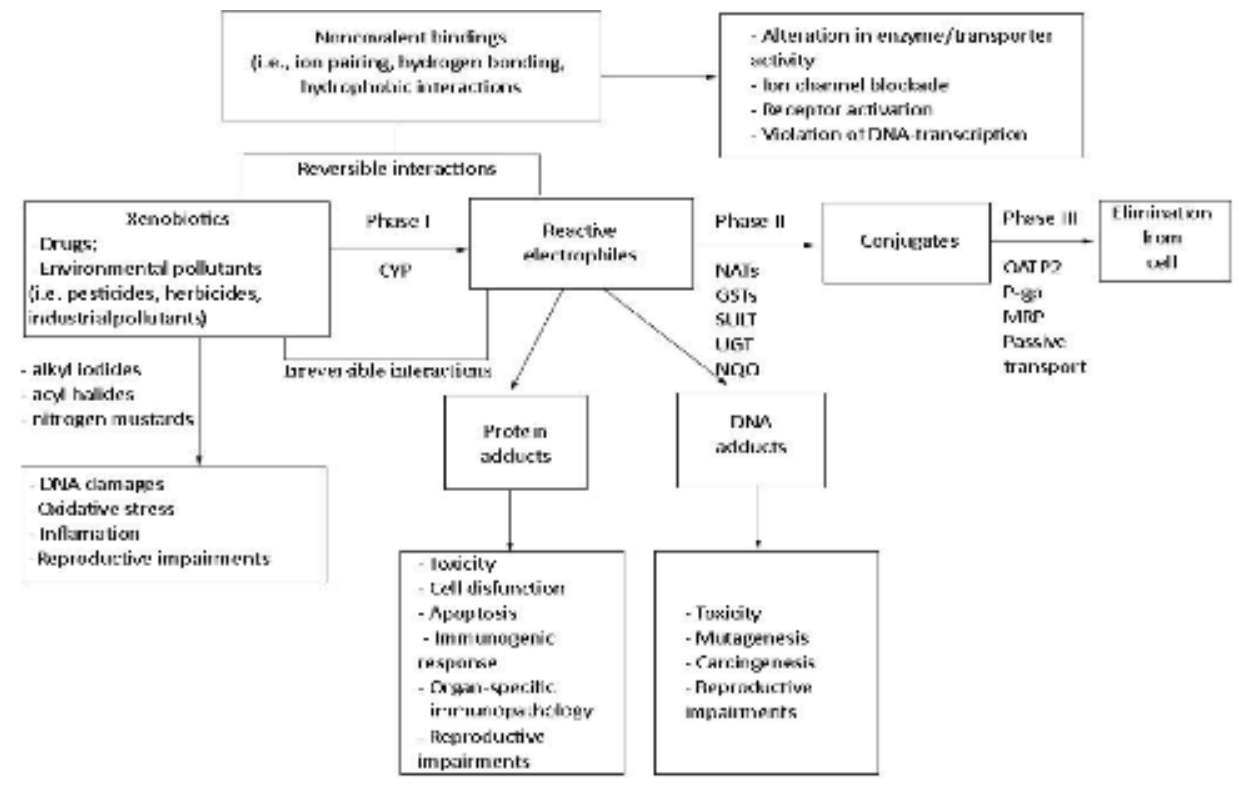

Figure 1.

The three-step detoxification of xenobiotics. Lipophilic substances subjected to metabolic activation by phase I enzyme cytochrome P450 (CYP) acquire reactive center for phase II conjugation reactions that lead to formation of hydrophilic compounds, following elimination by phase III transporters or passive transport. Most of the noxious effects are caused by reactive electrophiles after phase I activation, but some xenobiotics pose a threat before metabolic activation. CYP_cytochrome P450; NATs-N-acetyltransferases; GSTs—glutathione S-transferases; SULT_-sulfotransferase; UGT_UDP-glucuronosyltransferase; NQO-NAD $(P) H$ quinone oxidoreductase; $\mathrm{OATP} 2$-organic anion transporting polypeptide 2; $P$-gp $-P$-glycoprotein; $M R P-m u l t i d r u g$ resistance-associated protein.

stress is the most probable cause of idiopathic male infertility. Oxidative stress is mediated by reactive oxygen species (ROS), if their level exceeds antioxidant capacity of the organism. An increased ROS level is observed in $40-80 \%$ of infertile men and in 11-78.5\% of infertile men with normal sperm count [8]. Elevated ROS levels can be explained by several reasons such as increased leukocytes' activity due to inflammation in the genital tract, varicocele or presence of immature spermatozoa as well as external causes like exposure to noxious chemical compounds, radiation and lifestyle factors [9]. A small amount of ROS is necessary in some physiological processes such as capacitation [10], while excessive ROS may damage sperms. Spermatozoa have restricted volume of cytoplasm, therefore the quantity of ROS-metabolizing enzymes is also limited and make them more vulnerable to ROS compared to other cells [9]. ROS cause sperm damages in several ways: first, ROS are capable of interacting with the sperm plasma membrane, which is rich in polyunsaturated fatty acids, promoting the decrease of its flexibility and, hence, tail motility [11]. Second, ROS may lead to the sperm's acrosome membrane peroxidation and decline in acrosin activity, thus making fertilization less probable [12]. Lastly, an increased ROS level is associated with the increase in sperm DNA fragmentation (that is used as an assessment tool for unexplained male infertility) and diminished sperm motility [13]. Moreover, considering that ROS are intensively produced in the mitochondria of stressed spermatozoids, they may cause mutations of mitochondrial DNA of different cells which participate in spermatogenesis. As a result, sperm maturation and functioning could be violated. Thus, the development of effective antioxidant treatment and antistress strategies has become one of the paramount tasks for the scientific society [10]. 
Mutations (that include both chromosomal and single-gene alterations) in several hundred genes are the other important and significant factor that potentially may lead to male infertility. For instance, Y-chromosome microdeletions (YCM), which influence genes responsible for spermatogenesis, are one of the best-studied types of mutations that may cause male infertility. Thus, recent meta-analysis has shown that oligospermic men with sperm concentration $>1 \mathrm{million} / \mathrm{mL}$ had significantly higher rates of YCM compared to normospermic men [14]. Among the other examples of mutations, there are the Cystic Fibrosis Transmembrane Conductance Regulator (CFTR) gene mutations, which lead to the absence of vas deferens; deletions of the autosomal Doublesex and Mab-3 Related Transcription factor 1 (DMRT1) gene in the azoospermic men (which is critical for germ cells development), ranging in size from $54 \mathrm{~kb}$ to over $2 \mathrm{Mb}$; and alterations in autosomal PLEC1 (plectin) and microRNA 661 (MIR661) genes in an azoospermic and oligozoospermic men and various single-nucleotide polymorphisms (SNPs) [15]. The latter is one of the most promising candidates for the elucidation of "hidden" genetic factors responsible for idiopathic male infertility. For example, rs1801133 (677C > T) variant in the methylenetetrahydrof $>$ olate reductase (MTHFR) (NAD (P) H) gene found in males with impaired spermatogenesis [16], rs4986938 $(1406+1872 \mathrm{G}>\mathrm{A})$ polymorphism of estrogen receptor 2 (ESR2) gene, rs2070744 (786C > T in the promoter region) and rs61722009 (27 bp Variable Number Tandem Repeat (VNTR) polymorphisms in the intron 4 , also known as $4 \mathrm{a} 4 \mathrm{~b}$ polymorphisms) variants of NOS3 (nitric oxide synthase 3 ) are the potential predisposal factors of male infertility [15].

Still, male infertility depends not only on mutations alone but also on the complex system of gene-environmental interactions and epigenetic factors. A bright example of environmental factors, which may cause seminal fluid abnormalities in the corresponding genetic background, is xenobiotics, which is discussed in the following sections.

\section{Association of xenobiotics with male infertility}

Xenobiotics may interact with macromolecules in reversible (forming noncovalent bindings, for example, ion pairing, hydrogen bonding, hydrophobic interactions, etc.) or irreversible ways through covalent bond formation between electrophilic xenobiotics or their active metabolites and endogenous molecules. The first variant may lead to the alteration in enzyme and transporter activity, ion channels blockade, activation of specific receptors and violation in DNA transcription, if the specific structure of the xenobiotic fits to macromolecule-binding sites. Irreversible covalent interaction does not demand such fitness of structures and leads to the formation of endogenous adducts of nucleophiles (such as nucleophilic amino acid or nucleic acids). As a result, such reactions may cause genetic mutations, carcinogenesis (if the violated gene participates in regulation of cell reproduction and differentiation) and protein malfunctions, which consequently may promote cell death and tissue toxicity.

It is worth mentioning that xenobiotics injure the male reproductive system not only by themselves and their metabolites but also via defensive reactions of the organism, such as innate and specific acquired immune responses. Thus, locally available reactive metabolites may cause disruption of testis immunoprivilege through the immunocompetent cells activation. This would lead to organ-specific immunopathology. Xenobiotics may have a toxic effect due to the malfunction of both the first and the second phase enzymes because of their hyperactive or inhibited functioning. In the case of increased phase I enzyme activity, or decreased 
phase II enzyme activity, electrophilic intermediates of the xenobiotic metabolism are accumulated in the cells and mediate the abovementioned damages. At the same time, the reduced activity of the first phase enzymes leads to metabolism retardation and accumulation of noxious chemical compounds in different tissues of the organism, including in those of the reproductive system. For example, decreased activity of GST (phase II enzyme that transfers glutathione (GSH) to activated environmental chemicals) will probably lead to the formation of reactive intermediates that will mediate cell damage mechanisms. On the other hand, phase I enzyme CYP1A1 is able to metabolize the polycyclic aromatic hydrocarbons (PAHs) to intermediate substances, which prompt genotoxic and mutagenic effects before they are further detoxified by phase II enzymes. This indicates that the increased activity of CYP1A1 may contribute to the accumulation of these compounds in the organism and to the elevation of the PAH-DNA adducts level. Although the liver performs the main functions of detoxification, reactive metabolites can also be generated in a particular organ, mediating organ specific toxicity. For example, experiments on laboratory animals such as rats and mice showed the presence of both phase I and phase II enzymes in their testicles. [17, 18]. The possibility of PAHs (benzo(a)pyrene) detoxification was also shown on the rats' Leydig cells [19]. The xenobiotic-detoxification enzymes are much needed in the reproductive system, since some endocrine-deteriorating agents (phthalates, dioxins, polychlorinated biphenyls (PCBs) and pesticides) have been shown to exert a negative influence on the reproductive tissues [20]. Thus, stable and lipophilic chlorinated hydrocarbons are capable of penetrating into the male reproductive tract, promoting idiopathic sterility and other reproductive impairments. One of the well-studied examples of male testicular toxins is occupational xenobiotic nematocide 1,2-dibromo 3-chloropropane $(\mathrm{DBCP})$ that causes a partially reversible damage to the seminiferous epithelium, leading to diminished sperm counts and sterility [21]. Another occupational and environmental toxin dichlorodiphenyldichloroethylene also reduces sperm count and mediates male infertility [22].

\section{Polymorphism of genes that affect spermatogenesis}

Except xenobiotic detoxification gene polymorphisms, another target group of genes that are most probably involved in development of male infertility is genes take part in spermatogenesis. This group includes genes with different functions such as endocrine regulation of spermatogenesis (i.e., androgen receptor (AR), follicle-stimulating hormone receptor (FSHR) and Estrogen receptor $\alpha$ and $\beta$ ), specific spermatogenic functions (i.e., deleted azoospermia-like (DAZL), Ubiquitin carboxyl-terminal hydrolase 26 (USP26), protamine-1 (PRM1) and gonadotrophin-regulated testicular helicase (GRTH)), regulation of cell functions such as metabolism, cell cycle and mutation repair (i.e., mtDNA polymerase $\gamma$ (POLG) and Methylene tetrahydrofolate reductase (MTHFR)) and Y-chromosome haplogroups. Y-chromosome abnormalities are the best studied, while data about association of male infertility with the other spermatogenesis regulation genes remain contradictory. For example, the spermatogenesis locus azoospermia factor c (AZFc) region partial deletion (gr/gr deletions, which include DAZ (Deleted in azoospermia) genes) is regarded as classical Y-chromosome mutation. Its role in male infertility was proven by several studies, although it is present in normospermic men as well $[16,23]$. Here are some examples of the other probable risk factors obtained by meta-analysis [23]. One of gene candidates, which is regarded as the most probable risk factor of male infertility, is MTHFR, which encodes methylenetetrahydrofolate reductase-one of the key enzymes in folate metabolism. The $\mathrm{C} \rightarrow \mathrm{T}$ substitution in 
the position 667 changes an alanine to a valine (Ala222Val) and decreases activity of enzyme, thus leading to the decrement of spermatogenesis. FSHR SNP showed a significant association with seminal fluid abnormalities only in the case when both the exon 10 SNPs and SNP of promoter at position 29 are present. G197 T SNP in PRM1 gene, which encodes DNA-binding protein, responsible for packing of DNA into the sperm head, may by a novel risk factor for patients with a normal sperm count but elevated levels of sperm DNA fragmentation and/or teratozoospermia. Studying of the genes affecting spermatogenesis also demonstrated significant influence of ethnicity on the association of polymorphisms and the risk of male infertility. Thus, AR repeat length polymorphism with repeat number more than 23 is a risk factor for Asiatic but not the European population. T54A mutation in exon 3 of DAZL gene was significantly associated with oligospermia or azoospermia in the Chinese population, while in Japanese or Caucasian populations, such an association was not established. The POLG gene, which encodes mtDNA polymerase $\gamma$ and thus important for mitochondria functioning, has common 10-fold repeated CAG motif in the first exon. It is known that mitochondria are one of the main determinants of sperm motility, and their altered regulation may be connected with asthenozoospermia (which is characterized by reduced sperm motility). Nevertheless, only one study [24] among four considered [24-27] established that the absence of this allele was significantly associated with male infertility. These results may not be relevant enough, as far as the sample size was not sufficiently big, (verum group included 99 infertile men, while control, 98 fertile men). In spite of the increased interest in the genetic causes of male infertility, there are no clear predictive and diagnostic criteria, except few polymorphisms such as AZF gr/gr deletions (OR $1.81,1.46-2.24 \mathrm{CI}, \mathrm{P}<0.00001)$ and MTHFR 677C $\rightarrow$ T $($ OR 1.39, 1.15-2.69 95\% $\mathrm{CI}, \mathrm{P}=0.0006$ ) [16]. The only way to build an adequate picture of reasons standing behind idiopathic male infertility is application of methods based on whole genome analysis, taking into account environmental factors.

\section{Polymorphism of xenobiotic detoxification genes}

The reasons behind the idiopathic cases of male infertility can probably be explained by the existence of unidentified genetic abnormalities involving several hundred genes, environmental interaction and epigenetics. Each of these genes is accountable for only a small part of the cases. In the late 1990s, the polymorphismsbased approach to searching for genetic factors in patients with idiopathic infertility was reinforced because of the findings of other investigations related to multifactorial impairments. Potential polymorphic genes that participate in male infertility development were determined from the increasing data on model organisms, expression analyses (transcriptome and proteome analyses) associated with poor germ cells quality and from data available from the Genome-Wide Association Studies (GWAS). In total, 2000 genes (housekeeping and germ cell specific genes) are engaged in spermatogenesis [28], but 314 single-nucleotide polymorphisms (SNPs) have been reported only in 123 genes for the year 2015 [15]. Nearly 70\% of these SNPs are responsible for general cell functions (regulation of apoptosis, DNA repair, xenobiotic metabolism and detoxification of reactive oxygen species), while the rest are involved in specific processes associated with spermatogenesis, meiosis and endocrine regulation of the reproductive system. However, available data are often contradictory and only a small amount of genetic polymorphisms are well studied. Meta-analyses were conducted for such genes as AR, CYP1A1, GSTP1, GSTM1, GSTT1, DAZL, ESR1, ESR2, MTHFR, NOS3, POLG, TP53 and USP26, among which CYP1A1, GSTP1, GSTM1 and GSTT1 detoxify the environmental 
chemicals and are of great interest. In addition to the abovementioned genes, NAT2 will also be regarded as an important candidate carrying SNPs that alter xenobiotic detoxification phenotypes. Readers considering the represented data should always bear in mind that determination of connections between xenobiotic detoxification genes polymorphisms and male infertility is significantly complicated by the existence of intricate interactions among phase I and phase II metabolizing enzymes, as well as among the phase III transporters and their nuclear receptors (aryl hydrocarbon receptor (AhR), orphan nuclear receptors, nuclear factorerythroid 2 p45-related factor 2 (Nrf2), constitutive androstane receptor (CAR) and pregnane $\mathrm{X}$ receptor (PXR)). These receptors can act as transcriptional factors for some xenobiotic metabolizing enzymes. For instance, CYP1 genes can be induced by AhR in response to PAHs, while CYP2B and CYP3A genes are activated by CAR and PXR in response to phenobarbital-like compounds and dexamethasone and rifampin-type of agents, respectively. It was also assumed that Nrf2 is the most likely transcriptional factor for phase II detoxification enzymes (such as GST) [29]. Thus, mutations or polymorphisms of these genes may contribute to alteration of xenobiotic metabolism indirectly that can also lead to a damage of the male reproductive system.

\subsection{Cytochrome P4501A1 polymorphism}

Cytochrome P4501A1 (CYP1A1) is a heme-thiolate containing monooxygenase that plays a central role in phase I extra-hepatic metabolism of lipophilic xenobiotics, such as polycyclic aromatic hydrocarbons (PAHs) that are produced during the combustion of fossil fuels, protein pyrolysis in well-fried meat, as well as from aromatic amines, which are present in cigarette smoke, pesticides, dyes, drugs and industrial products. CYP1A1 is expressed in male reproductive organs. Thus, its polymorphisms may define susceptibility to male infertility [30]. In addition to PAHs metabolism, CYP1A1 participates in the synthesis of cholesterol, steroids and other lipids, as well as in steroid hormone metabolism. Thus, its polymorphic variants can intervene in the endocrine and paracrine regulation of testicular function [31]. Cytochrome P4501A1 gene is located on 15q22-q24 chromosome. It is 5987-bp long and encodes a 512 amino acid protein. Benzo(a)pyrene, 3-methylcholanthrene, PCBs or 2,3,7,8-tetrachlorodibenzo-p-dioxin (TCDD) activate its expression. Although the CYP1A1 is a polymorphic gene, only two common SNPs have been found to be functionally significant, namely, CYP1A1*2A $(3801 \mathrm{~T}>\mathrm{C}$ in the 3'-flanking region, rs4646903) and CYP1A1*2C (Ile462Val, 2455A > G (exon 7), rs1048943) [32]. The $\mathrm{T}>\mathrm{C}$ substitution in CYP1A1*2A promotes the creation of a new MspI restriction site in the noncoding 3'-flanking region that causes elevation of transcript half-life and consequently enzyme activity, leading to increased levels of reactive metabolites [33]. The A > G substitution prompts an isoleucinevaline exchange in the heme-binding region of the enzyme, and according to some studies, it changes the enzyme's kinetics during the generation of diol metabolites of benzo[a]pyrene or causes a -threefold increase in transcripts quantity and microsomal enzyme activity in Asians [34]. Such data can be explained by the fact that the CYP1A1*2A and CYP1A1*2C allelic variants appear much more frequently in Asians compared with other ethnic groups, namely, Caucasians and African Americans [35]. However, these data are contradictory. A recent meta-analysis of 1060 cases and 1225 controls from 7 published case-control studies revealed that the homozygous CYP1A1*2A genotype was significantly associated with the susceptibility to idiopathic male infertility in Asians (CC vs. TT: OR $=2.88,95 \%$ CI: $1.20-6.89$, TC vs. TT: OR $=1.42,95 \%$ CI: $1.03-1.98$, recessive model: $\mathrm{OR}=1.63$, 95\% CI: 1.08-2.45.) but not in Caucasians, while no association with male infertility 
risk was found in the case of CYP1A1*2C genotype (GG vs. AA: OR $=1.03,95 \% \mathrm{CI}$ : 0.53-1.99, GA vs. AA: OR = 1.51, 95\% CI: 0.51-4.43, dominant model: $\mathrm{OR}=0.81$, 95\% CI: 0.42-1.54, recessive model: OR $=1.57,95 \%$ CI: 0.55-4.47) [36]. Still, these results seem to be preliminary, since such individual characteristics as age, body mass index, smoking status and environmental factors, as well as the sperm concentration, motility and other semen parameters were not taken into account during the data analysis. Another meta-analysis of 6 studies including 1060 cases and 1225 controls also confirmed a valid association between CYP1A1*2A genotype and the male infertility risk with the highest figures for the homozygous variant $(\mathrm{OR}=2.18$, 95\% CI: 1.15-4.12) [37]. Subgroup analysis based on ethnicity, sample size and quality assessment score failed to expose any significant level probably due to limited studies and population numbers discussed in the meta-analysis. Moreover, these conclusions may be irrelevant and need to be confirmed, as only two of six considered studies showed significant correlation and the abovementioned metaanalysis did not account the differences in exposure to environmental factors. The latter factor is of prime importance in the case of xenobiotic detoxification genes. Thus, Yarosh et al. [38] revealed a significant association between CYP1A1*2C and idiopathic male infertility risk only among smokers but not among nonsmokers. Finally, CYP1A1 may participate in male infertility through induction of the oxidative imbalance in cells as far as together with ligand-dependent transcription factor-Aryl hydrocarbon receptor (AhR) - it is capable of generating local reactive oxygen species (ROS) [39]. Considering that morphologically abnormal semen has reduced antioxidant capacity and increased ROS production [40], CYP1A1 may play a crucial role in male infertility development.

\subsection{GSTM1, GSTT1 and GSTP1 polymorphisms}

Human semen is rich in Glutathione S-transferases (GSTs) [41], which belongs to phase II superfamily of antioxidant enzymes involved in the cellular detoxification of various physiological substances (e.g., excessive ROS) or exogenous electrophiles. Detoxification process depends on the gene family class. At least seven gene classes of GSTs can be allocated: alpha $(\alpha)$, mu $(\mu)$, pi $(\pi)$, sigma $(\varsigma)$, theta $(\theta)$, kappa $(\mathrm{k})$ and zeta $(\zeta)$. They are coding GSTA, GSTM, GSTP, GSTS, GSTT, GSTK and GSTZ enzymes, respectively. Polymorphisms are encountered most frequently in GSTM1, GSTT1 and GSTP1 subfamilies. According to the available data, GSTM1 and GSTT1 null polymorphic variants are the most studied GST SNPs and are associated with the increased susceptibility to several diseases and hypersensitivity to toxic xenobiotics [42]. For instance, GSTM1 was shown to have homozygous deletion in nearly half of the people from various ethnicities. Such deletion results in decreased enzyme function [43]. In general, inhibited GST activity leads to diminished semen motility via membrane damage. Considering that unmetabolized toxic substances, which accumulate in the cellular matrix of the testis, cause spermatogenesis deterioration, another probable reason for sperm impairment in subjects with GSTM1 or GSTT1 null genotypes may be considered to be the insufficient functioning of seminiferous tubules and fibrosis developed in the testicular tissue [44].

GSTM1 is located on 1p13.3 chromosome; three alleles have been identified at its locus: GSTM1*A, GSTM1*B (causing the lysine 172 replacement by aspartic acid $(534 \mathrm{C}>\mathrm{G})$ and not exhibiting alterations in enzyme activity) and GSTM1 null genotype (gene deletion) [45].

GSTT1 is located on 22q11 chromosome and has one polymorphism (GSTT1 null genotype) that leads to the inhibition of enzyme production in homozygote [46]. 
Several studies have suggested that GSTM1, as well as GSTT1, might be crucial isozymes in the metabolism of ROS $[47,48]$; meanwhile, diminished antioxidant capacity of seminal plasma turned out to promote subfertility.

Numerous studies reported the connection between the polymorphisms of GST genes and the DNA fragmentation increased due to the impaired defense against oxidative stress [49], which may result in some kinds of cancers. Considering that surplus of reactive oxygen species is a damaging factor for spermatozoa, GST SNPs most likely contribute to idiopathic male infertility. A possible explanation for the spermatogenesis impairment in GSTT1 and GSTM1 null allele carriers was proposed by $\mathrm{Wu}$ et al. [50]. Considering that null genotypes eliminate the binding site for some transcription factors, such as nuclear factor 1 (NF-1) (may act as transcriptional repressor or activator, determined by target gene expression), specificity protein 1 (SP1) (involved in cell differentiation, cell growth, apoptosis, immune responses, response to DNA damage and chromatin remodeling) and serum response factor (SRF) (participates in transforming extracellular signals into specific nuclear responses), GSTT1 and GSTM1 null variants may cause changes in gene expression through the removal of transcription factors. Such alterations in gene expression may entail deterioration of sperm maturation and impaired fertility.

Another polymorphic gene (GSTP1) is approximately $4 \mathrm{~kb}$ in length and is located on 11q13.2 chromosome. It includes 7 exons and encodes a 210 amino acid protein. Two polymorphisms of GSTP1 rs1138272 (341C > T (exon 6) leading to the alanine 114 replacement by valine) and rs1695 (313A > G (exon 5) encoding the amino acid exchange (replacement of isoleucine in the position 105 by valine) were associated with a decreased heat stability and the detoxification ability of this enzyme [51].

Most of the current data on the polymorphisms of xenobiotic detoxification gene are devoted to GST SNPs. A pooled analysis of 11 studies ( 7 involve Asians and 4 involve Caucasians), which included 1323 cases and 1054 controls, revealed that GSTM1 (OR = 2.75, 95\%; CI: 1.72-3.84, P = 0.003) and GSTT1 null (OR = 1.54, 95\%; CI: 1.43-3.47, $\mathrm{P}=0.02$ ) genotypes showed significant association with strong/ moderate risk of impaired male fertility, respectively. At the same time, GSTP1 Ile/Val genotype was proved to mediate the protective effect on male reproductive system (OR $=0.48,95 \%$; CI: 0.27-0.77) [52]. These results are reliable enough, as far as researchers took into account the age, ethnicity and the smoking status. Interestingly, that in contrast to CYP1A1 polymorphism, there was no difference between smokers and nonsmokers $(P=0.26)$. At the same time, GSTM1 null genotype, considered in the research on Indian subjects, showed 8.6 times increment of infertility risk if the subject was a smoker. Going back to the pooled analysis, synergistic effects of GSTM1 null allele, GSTT1 null allele and GSTP1 Ile/Ile polymorphism on male infertility was recognized as a valuable feature of this research [53]. However, further analysis showed that GSTM1 null genotype was associated with male infertility only at a borderline level of significance [53]. Such inconsistency may be explained by more rigid selection criteria in the latter meta-analysis. Since 161 of 168 studies were excluded, only 6 case-control studies concerning the GSTM1 genotype and 5 studies concerning the GSTT1 were eligible. Moreover, most studies referred to Caucasian subjects (except one, concerning the GSTM1 polymorphism, and two, concerning the GSTT1 polymorphism). On this basis, no ethnic variations were analyzed. Another doubtful issue touches upon the possibility of association between GSTP1 Ile/Ile polymorphism and the susceptibility to idiopathic male infertility. The fact is that in human population, Ile allele is encountered more frequently than the Val allele is. Thus, its positioning as a risk factor for male infertility contradicts the principles of evolutionary genetics, as Ile allele should have disappeared from the population. Furthermore, recent meta-analysis, 
devoted to the association between GSTP1 polymorphism and cancer susceptibility, revealed that Val allele was a risk factor for carcinogenesis, and no accumulation effect of Ile/Ile genotype was revealed [54]. All this indicates the necessity of additional researches that would comprise GSTP1 Ile/Ile polymorphism.

Another GSTP1 polymorphism-Ala/Val (rs1138272) substitution-was studied even less extensively than the Ile/Val polymorphism. Recently, this SNP was shown to be associated with the increased risks of infertility in Vietnam male subjects (OR = 7.42, 95\%; CI: 3.86-14.30) [55], while previously, another work, devoted to the oxidative damage in infertile men with varicoceles, revealed no significant differences between the indices recorded in the patient and control groups [56]. Further metaanalysis that focused on the relationship between the prostate cancer and the GSTP1 Ala/Val polymorphism revealed no significant associations [57]. Although Aydemir et al. did not report such a correlation, they revealed a connection between the GSTM1 null polymorphic variant with markers of oxidative stress in patients and the idiopathic male infertility [58]. Thus, most investigations, including five meta-analyses, confirmed the GSTM1 association with the risk of male infertility [52, 59-61].

A meta-analysis of 15 researches (8 involve Asian people, 6-European people, and 1 comprises a mixed population) that included 1897 cases and 1785 controls showed that GSTM1 null genotype was significantly associated with susceptibility to idiopathic male infertility, but not with sperm concentration. In the case of GSTT1 null genotype, no association with oligoasthenoteratozoospermia and sperm concentration was revealed. Subgroup analysis on ethnicity did not show any reliable association between the idiopathic male infertility and the GSTM1 null or GSTT1 null genotype [59].

Contradicting data were obtained via the case-control study of Han people from East China, which included 1476 infertile men with normozoospermia, oligozoospermia and nonobstructive azoospermia and 895 healthy controls, matched by age, drinking and smoking status, body mass index and semen volume [50]. The research revealed that GSTT1 null genotype is a predisposing factor for idiopathic male infertility $(\mathrm{OR}=1.26 ; 95 \%$; CI: $1.07-1.50 ; \mathrm{P}=0.007)$, while GSTM1 null genotype showed no significant association with the idiopathic male infertility risk (OR $=1.15$; 95\%; CI: $0.97-1.36 ; \mathrm{P}=0.116)$. At the same time, GSTM1 null variant was prevalent in oligozoospermic patients $(\mathrm{OR}=1.55$; 95\%; CI: $1.15-2.08$; $\mathrm{P}=0.004)$, while the GSTT1 null polymorphism was associated with normozoospermia (OR = 1.23; 95\%; CI: 1.03-1.48; $\mathrm{P}=0.025)$ and azoospermia $(\mathrm{OR}=1.58 ; 95 \%$; $\mathrm{CI}$ : 1.18-2.11; $\mathrm{P}=0.002)$. Interestingly, no differences were found in GSTM1 expression between the present and deleted genotypes, but such were found in the GSTT1 null polymorphism, which expression was significantly decreased in comparison with the present variant.

The authors also conducted a meta-analysis of 19 case-control studies in 2002-2013. The meta-analysis included 3981 cases and 2953 controls involving the Asian and Caucasian ethnic groups [50]. As a result, GSTM1 null allele carriers were subjected to the risk of male infertility $(\mathrm{OR}=1.39 ; 95 \%$; CI: $1.14-1.70 ; \mathrm{P}=0.001)$ and to oligoasthenoteratozoospermia ( $\mathrm{OR}=1.53$; 95\%; CI: 1.25-1.89; $\mathrm{P}<0.001)$. This association persisted in the case of subgroup analyses that involved Asians $(\mathrm{OR}=1.51 ; 95 \%$; CI: 1.13-2.10; $\mathrm{P}=0.005)$ and Caucasians $(\mathrm{OR}=1.24 ; 95 \%$; $\mathrm{CI}$ : $1.00-1.52 ; \mathrm{P}=0.046)$. The GSTT1 null variant, however, was significantly associated with male infertility only among Asian people (OR = 1.44; 95\%; CI: 1.10-1.90; $\mathrm{P}=0.009$ ). Such results may be explained by the fact that the GSTT1 null genotype is most frequently encountered in individuals of Asian origin than in other populations [62]. On the whole, differences from the previous meta-analysis [59] may be explained by the fact that they have added some recent studies.

Data of numerous studies revealing the GST polymorphism effect on the male infertility development remain contradictory. The list of the most probable 
underlying causes includes the relatively small number of participants, ignoring some gene-environment and gene-gene interactions and the possible small influence of the GST SNPs on the risk of idiopathic male infertility.

\subsection{Arylamine $\mathrm{N}$-acetyltransferase 2 polymorphism}

Arylamine N-acetyltransferase 2 (NAT2) is a phase II xenobiotic detoxification enzyme metabolizing such chemicals as arylamines, aromatic and heterocyclic amines and hydrazines via $\mathrm{N}$-acetylation and $\mathrm{O}$-acetylation. In other words, it transfers the acetyl group from acetyl-coenzyme A to the nitrogen or oxygen of the substrate. It takes part in the metabolism of such drugs as sulfadimidine, sulfamethazine, isoniazid, nitrazepam, dapsone or caffeine [63]. Therefore, it determines human susceptibility to cancer and the side effects of drugs [64].

Biological significance of NAT2 could be demonstrated through the association between its polymorphisms with susceptibility and different types of cancer-lung, colon or bladder cancer $[65,66]$.

NAT2 is expressed in the male reproductive organs (genital ducts, testicular tissues, exocrine and prostate glands), promoting protective effect against the environmental chemicals that may lead to male urogenital diseases [67].

NAT2 is a 290 amino acid protein, encoded by intronless $9.9 \mathrm{~kb}$ gene, located on the 8p22 chromosome and consists of 3 exons. Scientists identified the acetylation polymorphism more than 60 years ago in tuberculosis patients, who reacted to isoniazid toxicity in different ways [68]. NAT2 is characterized by a high number of polymorphic genes, comprising more than 66 alleles [69]. Most of these polymorphisms are synonymous and do not always cause variations in enzyme activity [70]. The most common and important variants of SNPs are rs1799929 (481C > T that does not cause leucine alteration at amino acid 161, L161 L) marked as NAT2*11A and rs1799930 (590G > A that leads to the charged arginine replacement by polar glutamine at the codon 197 (R197Q)) marked as NAT2*6 [71]. NAT2*6 corresponds to a slow acetylator phenotype, while the NAT2*11A to a rapid one that may differ from the NAT2* 6 by a threefold incensement in the metabolic rate [72]. These two extreme acetylator phenotypes are considered as risk factors for disease development after the subjection to arylamines and other NAT2 targets. For instance, NAT1 and NAT2 slow acetylator phenotypes were shown to be predisposing factors for prostate cancer [73], while the rapid NAT2 phenotypes had higher frequencies in contact-allergic patients [74]. It is considered that the existence of canonical isoniazid slow acetylator phenotype is caused by the reduction in NAT2 protein [75]. Among the other reasons, there are low levels of expression, instability or reduced catalytic activities [76].

There are substantial interethnic variations of the slow acetylator phenotype. Thus, it can be found in $40-70 \%$ of Caucasian and African people. At the same time, its frequency ranges from 10 to $30 \%$ in Japanese, Chinese, Korean and Thai people [77].

There is a lack of evidence to confirm the role of NAT2 polymorphism in the development of male infertility. However, recently it was proved that gene-environment interactions play a very important role in the case of NAT2 polymorphism and determine whether it will predispose male infertility. Thus, several data have showed that rs1799929 and rs1799929 SNPs themselves were not associated with the increased risks of idiopathic male infertility [78]. However, if the subject was exposed to cigarette smoking ( $\mathrm{OR}=1.71,95 \% \mathrm{CI}$ : 1.02-2.87, $\mathrm{P}=0.042)$, alcohol abuse $(\mathrm{OR}=2.14,95 \% \mathrm{CI}: 1.08-4.27, \mathrm{P}=0.029)$ and low fruit/vegetable intake $(\mathrm{OR}=1.68,95 \% \mathrm{CI}: 1.01-2.79, \mathrm{P}=0.04)$, the risk of male infertility significantly increased in the case of slow acetylator phenotype rs1799930.

Contrariwise, rapid acetylator phenotype was found to cause higher DNAfragmentation levels after 2 days of meat diet [79]. Considering that the level of 
DNA fragmentation is significantly higher in infertile men [80], this study also proves that NAT2 polymorphism is involved in the process of impaired reproductive development in men.

The latest study, conducted on Vietnam males, revealed that idiopathic male infertility is associated with both the rs1799930 (OR = 3.10, 95\%; CI: 1.92-5.01) and the rs1799929 (OR = 3.74, 95\%; CI: 2.26-6.18) alleles. The current research also shows that GSTP1 and NAT2 have a synergetic effect - they cause the biggest risk of infertility only when both polymorphisms are present. Namely, the 481C > T rs1799929 (NAT2) and the $341 \mathrm{C}>\mathrm{T}$ or $341 \mathrm{~T}>\mathrm{T}$ rs1138272 (GSTP1) cause the 17-fold increase in the risk of idiopathic male infertility $(\mathrm{OR}=17.24,95 \%$; CI: 7.30-40.74, $\mathrm{P}=0.0001)$ [55].

Thereby, the NAT2 involvement in the process of male infertility development is highly probable, but more data are needed to confirm its role in mediating the impaired male reproduction.

\section{Conclusions}

Male infertility is a worldwide health problem with multifactorial etiology, showing an upward trend during the last decade. One of the most significant reasons behind this trend is the exposure to environmental factors-xenobiotics, hypo/ hyperthermia, stress or harmful radiations (such as X-rays). All this phenomena may lead to oxidative stress, treated as one of the most common trigger of male infertility and found in nearly half of all the infertile men [81]. It causes impairment of sperm maturation, testis injury, sperm motility reduction and DNA damages. Research on the polymorphisms of xenobiotic detoxification genes may be helpful for determining the interethnic and interindividual peculiarities of noxious chemicals metabolism (including possible risks of male infertility development) based on gene-environment interactions. Overall, knowledge about the SNPs of xenobiotic metabolizing genes associated with male infertility is rather inconsistent or even contradictory. Thus, more comprehensive analysis is required that would be stratified according to the age, body mass index, ethnic background, diet, smoking and drinking status, environmental exposures and other lifestyle factors. Moreover, many studies were carried out on small samples. This factor increases the probability of overestimating the association. Numerous studies indicated that such polymorphisms as CYP1A1, GSTM1, GSTT1, GSTP1 and NAT2 are most likely to be involved in male infertility development. Their polymorphic transcripts were shown to change the xenobiotic metabolism. In some cases, they failed to provide sufficient antioxidant defense. Knowledge of the role that the polymorphisms of xenobiotic detoxification genes have in male infertility development could be useful for providing sufficient diagnostic methods, as well as for providing reliable recommendations for infertile men on disease prevention and treatment.

\section{Acknowledgements}

The authors would like to take this opportunity to extend their sincere thanks to the Ministry of Health for providing financial support for this study. We are also grateful for the technical support of the Hanoi Medical University Hospital. We thank Dr. Shkurat TP for a critical reading of the chapter.

\section{Conflict of interest}

The authors declare that they have no conflict of interest. 
Polymorphism of Xenobiotic Detoxification Genes and Male Infertility DOI: http://dx.doi.org/10.5772/intechopen.79233

\section{Author details}

Nguyen Thi Trang* and Vu Thi Huyen

Hanoi Medical University, Hanoi, Vietnam

*Address all correspondence to: trangnguyen@hmu.edu..vn

\section{IntechOpen}

(C) 2018 The Author(s). Licensee IntechOpen. This chapter is distributed under the terms of the Creative Commons Attribution License (http://creativecommons.org/licenses/ by/3.0), which permits unrestricted use, distribution, and reproduction in any medium, provided the original work is properly cited. (cc) BY 


\section{References}

[1] Lassen TH, Iwamoto T, Jensen TK, Skakkebæk NE. Trends in male reproductive health and decreasing fertility: Possible influence of endocrine disrupters. Low fertility and reproductive health in East Asia. International Studies in Population. 2015:11

[2] Abad Gairín C, Gual Frau J, Hannaoui Hadi N, García Peiró A. Antioxidant Treatment and Prevention of Human Sperm DNA Fragmentation: Role in Health and Fertility. Handbook of Fertility; 2015. pp. 397-409

[3] Jungwirth A, Giwercman A, Tournaye H, Diemer T, Kopa Z, Dohle G, Krausz C. European Association of Urology guidelines on male infertility: The 2012 update. European Urology. 2012;62(2):324-332

[4] O’Flynn KLOF, O’Brien KL, Varghese AC, Agarwal A. The genetic causes of male factor infertility: A review. Fertility and Sterility. 2010;93:1-12

[5] Spitsyn VA. Ecological genetics of human. Moscow, 2008. Russian, DNA polymorphism and human disease. Annual Review of Biochemistry. 1986;55(1):831-854

[6] Lewis DE. P450 structures and oxidative metabolism of xenobiotics. Pharmacogenomics. 2003;4:387-395

[7] Hinson JA, Forkert PG. Phase II enzymes and bioactivation. Canadian Journal of Physiology and Pharmacology. 1995;73:1407-1413

[8] Hamada A, Esteves SC, Agarwal A. Unexplained male infertility: Potential causes and management. Human Andrology. 2011;38:2-16

[9] Brache A, Peeters K, Punjabi U, Hoogewijs D, Dewilde S. A search for molecular mechanisms underlying male idiopathic infertility. Reproductive BioMedicine Online. 2018;36(3):327-339

[10] Aitken RJ, Baker MA, Nixon B. Are sperm capacitation and apoptosis the opposite ends of a continuum driven by oxidative stress? Asian Journal of Andrology. 2015;17:633-639

[11] Jones R, Mann T, Sherins R. Peroxidative breakdown of phospholipids in human spermatozoa, spemicidal properties of fatty acid peroxides, and protective action of seminal plasma. Fertility and Sterility. 1979;31:531-537

[12] Aitken RJ, Gordon E, Harkiss D, Twigg JP, Milne P, Jennings Z, Irvine DS. Relative impact of oxidative stress on the functional competence and genomic integrity of human spermatozoa. Biology of Reproduction. 1998;59:1037-1046

[13] Mahfouz R, Sharma R, Thiyagarajan A, Kale V, Gupta S, Sabanegh E, Agarwal A. Semen characteristics and sperm DNA fragmentation in infertile men with low and high levels of seminal reactive oxygen species. Fertility and Sterility. 2010;94(6):2141-2146

[14] Kohn TP, Kohn JR, Owen RC, Coward RM. The prevalence of Y-chromosome microdeletions in oligospermic men stratified by sperm concentration: A systematic review and meta-analysis. The Journal of Urology. 2018;199(4):e223-e224

[15] Krausz C, Escamilla AR, Chianese C. Genetics of male infertility: From research to clinic. Reproduction. 2015;150(5):R159-R174

[16] Tüttelmann F, Rajpert-De Meyts E, Nieschlag E, Simoni M. Gene polymorphisms and male infertility - A 
meta-analysis and literature review. Symposium: Endocrinology of male reproduction and infertility. Reproductive BioMedicine Online. 2007;15(6):643-658

[17] Gandy J, Primiano T, Novak RF, Kelce WR, York JL. Differential expression of glutathione S-transferase isoforms in compartments of the testis and segments of the epididy mis of the rat. Drug Metabolism and Disposition. 1996;24:725-733

[18] Seng JE, Gandy J, Turturro A, Lipman R, Bronson RT, Prtkinson A, Johnson W, Hart RW, Leakey JEA. Effects of caloric restriction on expression of testicular cytochrome $\mathrm{P} 450$ enzymes associated with the metabolic activation of carcinogens. Archives of Biochemistry and Biophysics. 1996;335:42-52

[19] Georgellis A, Rydström J. Cellspecific metabolic activation of 7,12-Dimethylbenz(a)anthracene in rat testis. Chemico-Biological Interactions. 1987;72:65-78

[20] Sonnenschein C, Soto AM. An updated review of environmental estrogen and androgen mimics and antagonists. The Journal of Steroid Biochemistry and Molecular Biology. 1998;65(1-6):143-150

[21] Whorton D, Krauss RM, Marshall S, Milby TH. Infertility in male pesticide workers. The Lancet. 1977;310(8051):1259-1261

[22] Bonde JP, Giwercman

A. Environmental xenobiotics and male reproductive health. Asian Journal of Andrology. 2014;16(1):3-4

[23] Krausz C. Polymorphisms and male infertility. In: The Genetics of Male Infertility. Humana Press; 2007. pp. 275-289
[24] Rovio AT, Marchington DR, Donat

S, Schuppe H-C, Abel J, Fritsche

E, Elliott DJ, Laippala P, Ahola AL, McNay D, Harrison RF, Hughes B, Barrett T, Bailey DMD, Mehmet D, Jequier AM, Hargreave TB, Kao S-H, Cummins JM, Barton DE, Cooke HJ, Wei Y-H, Wichmann L, Poulton J, Jacobs HT. Mutations at the mitochondrial DNA polymeras e (POLG) locus associated with male infertility. Nature Genetics. 2001;29:261-262

[25] Jensen M, Leffers H, Petersen JH, Andersen AN, Jørgensen N, Carlsen E, Jensen TK, Skakkebæk NE, Rajpert-De Meyts E. Frequent polymorphism of the mitochondrial DNA polymerase gamma gene (POLG) in patients with normal spermiograms and unexplained subfertility. Human Reproduction. 2004;19:65-70

[26] Krausz C, Guarducci E, Becherini L, degl'Innocenti S, Gerace L, Balercia G, Forti G. The clinical significance of the POLG gene polymorphism in male infertility. The Journal of Clinical Endocrinology and Metabolism. 2004;89:4292-4297

[27] Aknin-Seifer IE, Touraine RL, Lejeune H, Jimenez C, Chouteau J, Siffroi JP, McElreavey K, Bienvenu T, Patrat C, Levy R. Is the CAG repeat of mitochondrial DNA polymerase gamma (POLG) associated with male infertility? A multicentre French study. Human Reproduction. 2005;20:736-740

[28] Hochstenbach R, Hackstein $\mathrm{JH}$. The comparative genetics of human spermatogenesis: Clues from flies and other model organisms. Results and Problems in Cell Differentiation. 2000;28:271-298

[29] Kwak MK, Itoh K, Yamamoto M, Sutter TR, Kensler TW. Role of transcription factor Nrf2 in the induction of hepatic phase 2 and antioxidative enzymes in vivo by the cancer chemoprotective agent, $3 \mathrm{H}-1$, 
2-dimethiole-3-thione. Molecular

Medicine. 2001;7:135-145

[30] McManus ME, Burgess WM, Veronese ME, Huggett A, Quattrochi LC, Tukey RH. Metabolism of 2-acetylaminofluorene and benzo(a) pyrene and activation of food-derived heterocyclic amine mutagens by human cytochromes P-450. Cancer Research. 1990;50:3367-3376

[31] Yager JD. Molecular mechanisms of estrogen carcinogenesis. Annual Review of Pharmacology and Toxicology. 1996;36:203-232

[32] Hayashi S, Watanabe J, Nakachi $\mathrm{K}$, Kawajiri K. Genetic linkage of lung cancerassociated MspI polymorphisms with amino acid replacement in the heme binding region of the human cytochrome P450IA1 gene. Journal of Biochemistry. 1991;110:407-411

[33] Manfredi S, Federici C, Picano E, Botto N, Rizza A, Andreassi MG. GSTM1, GSTT1 and CYP1A1 detoxification gene polymorphisms and susceptibility to smokingrelated coronary artery disease: A case-only study. Mutation Research. 2007;621:106-112

[34] Crofts F, Taioli E, Trachman J, Cosma GN, Currie D, Toniolo P, Garte SJ. Functional significance of different human CYP1A1 genotypes. Carcinogenesis. 1994;15:2961-2963

[35] Boyapati SM, Shu XO, Gao Y, Cai $\mathrm{Q}$ Jin F, Zheng W. Polymorphisms in CYP1A1 and breast carcinoma risk in a population-based case-control study of Chinese women. Cancer. 2005;103:2228-2235

[36] Fang J, Wang S, Wang H, Zhang S, Su S, Song Z, Deng Y, Qian J, Gu J, Liu B, Cao J, Wang Z. The cytochrome $\mathrm{P} 4501 \mathrm{~A} 1$ gene polymorphisms and idiopathic male infertility risk: A metaanalysis. Gene. 2014;535(2):93-96
[37] Luo H, Li H, Yao N, Hu L, He

T. Association between $3801 \mathrm{~T}>\mathrm{C}$ polymorphism of CYP1A1 and idiopathic male infertility risk: A systematic review and meta-analysis. PLoS One. 2014;9:e86649

[38] Yarosh SL, Kokhtenko EV, Starodubova NI, Churnosov MI, Polonikov AV. Smoking status modifies the relation between CYP1A1*2C gene polymorphism and idiopathic male infertility: The importance of gene-environment interaction analysis for genetic studies of the disease. Reproductive Sciences. 2013;20:1302-1307

[39] Aitken RJ. A free radical theory of male infertility. Reproduction, Fertility, and Development. 1994;6:19-24

[40] Gharagozloo P, Aitken RJ. The role of sperm oxidative stress in male infertility and the significance of oral antioxidant therapy. Human Reproduction. 2011;26:1628-1640

[41] Mann CL, Davies MB, Boggild MD, Aldersea J, Fryer AA, Jones PW, Koko C, Young C, Strange RC, Hawkins CP. Glutathione S-transferase polymorphisms in MS: Their relationship to disability. Neurology. 2000;54:552-557

[42] Bolt HM, Thier R. Relevance of the deletion polymorphisms of the glutathione S-transferases GSTT1 and GSTM1 in pharmacology and toxicology. Current Drug Metabolism. 2006;7:613-628

[43] Board P, Coggan M, Johnston P, Ross V, Suzuki T, Webb G. Genetic heterogeneity of the human glutathione S-transferases: A complex of gene families. Pharmacology \& Therapeutics. 1990;48:357-369

[44] Pajarinen J, Savolainen V, Perola M, Penttila A, Karhunen PJ, Pajarinen J, 
Savolainen V, Perola M. Glutathione S-transferase-M1 'null' genotype and alcoholinduced disorders of human spermatogenesis. International Journal of Andrology. 1996;19:155-163

[45] Suzuki TGW, Coggan M, Shaw DC, Board PG. Electrophoretic and immunological analysis of human glutathione S-transferase isoenzymes. Annals of Human Genetics. 1987;51:95-106

[46] Pemble S, Schroeder KR, Spencer SR, Meyer DJ, Hallier E, Bolt HM, Ketterer B, Taylor JB. Human glutathione S-transferase Theta (GSTT1): cDNA cloning and the characterization of a genetic polymorphism. The Biochemical Journal. 1994;300:271-276

[47] Alvarez CA, Moraes GV. Effect of the selenomethionine and vitamin $C$ on the semen. SaBios-Revista de Saúde e Biologia. 2006;1:42-51

[48] Shamsi MB, Venkatesh S, Kumar R, Gupta NP, Malhotra N, Singh N, Mittal S, Arora S, Arya DS, Talwar P, Sharma RK, Dada R. Antioxidant levels in blood and seminal plasma and their impact on sperm parameters in infertile men. Indian Journal of Biochemistry \& Biophysics. 2010;47:38-43

[49] Saleh RA, Agarwal A. Oxidative stress and male infertility: From research bench to clinical practice. Journal of Andrology. 2002;23:737-752

[50] Wu W, Lu J, Tang Q, Zhang S, Yuan B, Li J, Wu D, Sun H, Lu C, Xia Y, Chen D, Sha J, Wang X. GSTM1 and GSTT1 null polymorphisms and male infertility risk: An updated meta-analysis encompassing 6934 subjects. Scientific Reports. 2013;3

[51] Ferlin A. New genetic markers for male fertility. Asian Journal of Andrology. 2012;14:807-808
[52] Safarinejad MR, Dadkhah F, Asgari MA, Hosseini SY, Kolahi AA, Iran-Pour E. Glutathione S-transferase polymorphisms (GSTM1, GSTT1, GSTP1) and male factor infertility risk: A pooled analysis of studies. Urology Journal. 2012;(9):541-548

[53] Konstantinos PE, Sergentanis TN, Choussein S. Glutathione-Stransferase gene polymorphisms (GSTM1, GSTT1, GSTP1) and idiopathic male infertility: Novel perspectives versus facts. Journal of Human Genetics. 2010;55:557-558

[54] Cote ML, Chen W, Smith DW, Benhamou S, Bouchardy C, Butkiewicz D, Fong KM, Gene M, Hirvoven A, Larsen CKEJ, Lin P, Raaschou-Nielsen O, Povey AC, Reszka E, Risch A, Schneider J, Schwartz AG, Sorensen M, To-Figueras J, Tokudome S, Pu Y, Yang P, Wenzlaff AS, Wikman H, Taioli E. Meta- and pooled analysis of GSTP1 polymorphism and lung cancer: A HuGE-GSEC review. American Journal of Epidemiology. 2009;169:802-814

[55] Trang NT, Huyen VT, Tuan NT, Phan TD. Association of $\mathrm{N}$-acetyltransferase- 2 and glutathione S-transferase polymorphisms with idiopathic male infertility in Vietnam male subjects. Chemico-Biological Interactions. 2018;286:11-16

[56] Tang K, Xue W, Xing Y, Xu S, Wu Q, Liu R, Wang X, Xing J. Genetic polymorphisms of glutathione S-Transferase M1, T1, and P1, and the assessment of oxidative damage in infertile men with Varicoceles from Northwestern China. Journal of Andrology. 2012;33:257-263

[57] Mo Z, Gao Y, Cao Y, Gao F, Jian L. An updating meta-analysis of the GSTM1, GSTT1, and GSTP1 polymorphisms and prostate cancer: A HuGE review. The Prostate. 2009;69:662-688 
[58] Aydemir B, Onaran I, Kiziler AR, Alici B, Akyolcu MC. Increased oxidative damage of sperm and seminal plasma in men with idiopathic infertility is higher in patients with glutathione S-transferase $\mathrm{Mu}-1$ null genotype. Asian Journal of Andrology. 2007;9:108-115

[59] Tang M, Wang S, Wang W, Cao Q, Qin C, Liu B, Li P, Zhang W. The glutathione-S-transferase gene polymorphisms (GSTM1 and GSTT1) and idiopathic male infertility risk: A meta-analysis. Gene. 2012;511:218-223

[60] Song X, Zhao Y, Cai Q, Zhang Y, Niu Y. Association of the Glutathione S-transferases M1 and $\mathrm{T} 1$ polymorphism with male infertility: A meta-analysis. Journal of Assisted Reproduction and Genetics. 2013;30:131-141

[61] Li X, Pan J, Liu Q, Xiong E, Chen Z, Zhou Z, Su Y, Lu G. Glutathione S-transferases gene polymorphisms and risk of male idiopathic infertility: A systematic review and meta-analysis. Molecular Biology Reports. 2012

[62] Polimanti R, Carboni C, Baesso I, Piacentini S, Iorio A, De Stefano GF, Fuciarelli M. Genetic variability of glutathione S-transferase enzymes in human populations: Functional interethnic differences in detoxification systems. Gene. 2013;512:102-107

[63] Sabbagh A, Darlu P. SNP selection at the NAT2 locus for an accurate prediction of the acetylation phenotype. Genetics in Medicine. 2006;8:76-85

[64] Hein DW, Doll MA. Accuracy of various human NAT2 SNP genotyping panels to infer rapid, intermediate and slow acetylator phenotypes. Pharmacogenomics. 2012;13:31-41

[65] Marcus PM, Vineis P, Rothman N. NAT2 slow acetylation and bladder cancer risk: A meta-analysis of 22 case-control studies conducted in the general population. Pharmacogenetics and Genomics. 2000;10(2):115-122

[66] Borlak J, Reamon-Buettner SM. N-acetyltransferase 2 (NAT2) gene polymorphisms in colon and lung cancer patients. BMC Medical Genetics. 2006;7:58

[67] Wu C, MacLeod I, Su AI. BioGPS and MyGene.info: Organizing online, gene-entric information. Nucleic Acids Research. 2013;41:D561-D565

[68] Hughes HB, Biehl JP, Jones AP, Schmidt LH. Metabolism of isoniazid in man as related to the occurrence of peripheral neuritis. American Review of Tuberculosis. 1954;70:266-273

[69] Lakkakula S, Pathapati RM, Chaubey G, Munirajan AK, Lakkakula BVKS, Maram R. NAT2 genetic variations among south Indian populations. Human Genome Variation. 2014;1

[70] Human NAT2 Alleles (Haplotypes). Available from: http://nat.mbg.duth.gr/ Human\%20NAT2\%20alleles_2013.htm

[71] Hein DW. Molecular genetics and function of NAT1 and NAT2: Role in aromatic amine metabolism and carcinogenesis. Mutation Research. 2002;506-507:65-77

[72] Dorne JL, Walton K, Renwick AG. Polymorphic CYP2C19 and $\mathrm{N}$-acetylation: Human variability in kinetics and pathway-related uncertainty factors. Food and Chemical Toxicology. 2003;41: 225-245

[73] Hein DW, Leff MA, Ishibe N, Sinha R, Frazier HA, Doll MA, Xiao GH, Weinrich MC, Caporaso NE. Association of prostate cancer with rapid $\mathrm{N}$-acetyltransferase 1 (NAT1*10) in combination with slow $\mathrm{N}$-acetyltransferase 2 acetylator 
genotypes in a pilot case-control study. Environmental and Molecular Mutagenesis. 2002;40:161-167

[74] Schnuch A, Westphal GA, Müller MM, Schulz TG, Geier J, Brasch J, Merk HF, Kawakubo Y, Richter G, Koch P, Fuchs T, Gutgesell T, Reich K, Gebhardt M, Becker D, Grabbe J, Szliska C, Aberer W, Hallier E. Genotype and phenotype of $\mathrm{N}$-acetyltransferase 2 (NAT2) polymorphism in patients with contact allergy. Contact Dermatitis. 1998;38:209-211

[75] Deguchi T. Sequences and expression of alleles of polymorphic arylamine $\mathrm{N}$-acetyltransferase of human liver. The Journal of Biological Chemistry. 1992;267:18140-18147

[76] Badawi AF, Hirvonen A, Bell DA, Lang NP, Kadlubar FF. Role of aromatic amine acetyltransferases, NAT1 and NAT2, in carcinogen-DNA adduct formation in the human urinary bladder. Cancer Research. 1995;55:5230-5237

[77] Meyer UA, Zanger UM. Molecular mechanisms of genetic polymorphisms of drug metabolism. Annual Review of Pharmacology and Toxicology. 1997;37:269-296

[78] Yarosh SL, Kokhtenko EV, SChurnosov MI, Ataman AV, Solodilova MA, Polonikov AV. Synergism between the Nacetyltransferase 2 gene and oxidant exposure increases the risk of idiopathic male infertility. Reproductive Health. 2014;29(3):362-369

[79] Kiss I, Sandor J, Ember I. Allelic polymorphism of GSTM1 and NAT2 genes modifies dietary-induced DNA damage in colorectal mucosa. European Journal of Cancer Prevention. 2000;9:429-432

[80] Sergerie M, Laforest G, Bujan L, Bissonnette F, Bleau G. Sperm DNA fragmentation: Threshold value in male fertility. Human Reproduction. 2005;20(12):3446-3451

[81] Tremellen K. Oxidative stress and male infertility-A clinical perspective. Human Reproduction Update. 2008;14(3):243-258 



\title{
Mesenchymal Stem Cell Therapy of Male Infertility
}

\author{
Amin Tamadon, Ulanbek Zhan-byrbekuly, Ilyas Kairgaliyev \\ and Arezoo Khoradmehr
}

\begin{abstract}
Nowadays mesenchymal stem cell (MSC) therapy offers a broad spectrum of treatment of different conditions, including male infertility. Lots of studies suggest that injection of MSC promotes differentiation of germ cells and/or stimulates gonadal tissue development. Currently, there are plenty of MSC therapies of azoospermia which have been studied on animal models and demonstrated good results. Most of the studies were conducted using MSC derived from adipose tissue, the bone marrow, and umbilical cord. Despite the fact that this type of treatment in humans is not established as a first choice option, the use of these techniques gives us hope for a gradual introduction into our daily practice.
\end{abstract}

Keywords: infertility, azoospermia, stem cell therapy, mesenchymal stem cell

\section{Introduction}

Infertility is a disease of the reproductive system defined by the failure to achieve a clinical pregnancy after 12 months or more of regular unprotected sexual intercourse [1]. This disorder affects one in six couples [2]. Different factors including genetics, environmental factors, and anatomical defects have been illustrated to play a role in the fertility ability of individuals $[3,4]$.

After identifying the high capability of stem cells to produce different cell types, a number of scientists have proposed the use of stem cells and cell-based therapies as a possible new therapeutic choice for male infertility [5]. Stem cells are undifferentiated cell types that have two main characteristics, self-renewal with the production of identical daughter cells, and the ability to differentiate into more specialized cell types. The two main non-manipulated stem cell classes are embryonic (ESCs) and adult stem cells (ASCs) [5]. The next type of stem cells is induced pluripotent stem cells (iPSCs) which are genetically manipulated somatic cells [6]. The experimental platform for understanding the development of germ cells could be provided by the in vitro generation of male germ cells from stem cells [7, 8].

The ESCs, iPSCs, and spermatogonial stem cells (SSCs) are among the most investigated stem cells for the production of male germ cells in in vitro conditions $[9,10]$. Application of these cell types has some limitations. ESCs present with some ethical problems and their sources are limited. iPSCs have both oncological and genetic instabilities. SSCs have low content in the testis, and their isolation, identification, and culturing are difficult in vitro. 
On the other hand, mesenchymal stem cells (MSCs) do not have such problems in applications. MSCs are a group of ASCs which are available in most tissues. These cells were separated from the bone marrow [11], adipose tissue [12-14], hair follicle [15], endometrium [16, 17], dental pulp [18], nose [19], umbilical cord [20], and menstrual blood [21]. The MSCs in bone marrow stromal comprise a restricted area; but it can be easily proliferated [22]. These cells have the potential to proliferate and differentiate into other cells such as osteoblast [23, 24], adipocyte [25], chondroblasts [26], and neuron-like cells $[27,28]$ which can be a good candidate for treatment of male infertility. MSCs contains heterogeneous population of cells and contain pluripotent stem cells, namely multilineage-differentiating stress-enduring cells, which is the same as ESCs, which has the ability to differentiate into all cells from three germ layers spontaneously $[29,30]$.

\section{Treatment of male infertility by MSC transplantation}

Several animal studies have been conducted to investigate the effect of MSC transplantation on azoospermia. The effect of bone marrow-derived MSCs (BM-MSCs) and adipose tissue-derived MSCs (AD-MSCs) in induced azoospermia rodents was explored [11, 12, 24, 26, 31, 32]. After busulfan injection for azoospermia induction [33], the rats were injected with the MSCs into rete testes. After 2 months, testes treated with MSCs appeared morphologically normal. Spermatogenesis was detected, not in every but in some tubules of cell-treated testes. The trans-differentiation of MSCs into spermatogenetic cells in the appropriate microenvironment has been shown in some studies [32]. To demonstrate the entire recovery of spermatogenesis, rats, which were under cell treatment, were mated, and consequently next generations were obtained. The GFP expression was identified in the MSCs derived from the bone marrow and adipose tissue and in the sperm of offsprings as well [32].

Numerous in vivo research surveys have been conducted to assess the spermatogenesis induction potential of mesenchymal stem cells in mouse and rat animal models. In the mentioned study groups, bone marrow-derived mesenchymal stem cells have been used for the induction of spermatogenesis. There are some disputes, in mice model, regarding advisability of bone marrow-derived mesenchymal stem cell transplantation in azoospermic mice, for example, there was a report that bone marrow-derived mesenchymal stem cells could not differentiate into sperm [34], but other studies confirmed the generation of germ cells in vivo in BM-MSC-transplanted mice $[35,36]$. At the same time, in azoospermic rat model, BM-MSC allotransplantation amplified endogenous fertility recovery in both testicular torsion model and busulfan-induced model of azoospermia induction [26, 37-40]. The potential of BM-MSCs to differentiate or trans-differentiate into multi-lineage cells, secrete paracrine factors to recruit the resident stem cells to participate in tissue regeneration, or fuse with the local cells in the affected region has been demonstrated [39].

The next group used AT-MSCs for induction of spermatogenesis. Intra-tubal injection of AT-MSCs in rat model of busulfan-treated azoospermia led to recovery of fertility $[12,32]$. The last group of studies induces spermatogenesis using xenotransplantation of human umbilical cord MSCs in immunodeficient mice seminiferous tubule [41] or a combination of in vitro differentiation of induced pluripotent stem cells from mice and humans into germ cells, and also their transplantation was performed to obtain advanced differentiated spermatozoa [42]. Interestingly, the capability of human umbilical cord MSCs (UC-MSCs) for differentiation into germ cells in the lumen of seminiferous tubules of immunocompetent mice has been shown [41, 43]. Furthermore, the therapeutic effects of BM-MSCs against toxic effects of lead $(\mathrm{Pb})$ in the male gonads of rats have been shown [44]. 
MSC transplantation may induce reconstitution of the tubular microenvironment in azoospermic hamster which helps the remaining inactivated germinal cells to proliferate in the host seminiferous tubules. Sertoli cells play a major role in cooperation with seminiferous tubules, providing cyclic and dynamic regulation of spermatogenesis. In recent time, it has been demonstrated that in in vitro co-culture system, there is an availability of Sertoli cells to mediate differentiation of male germ cell-like cells, which were derived from human umbilical cord mesenchymal stem cells [45]. Moreover, Sertoli cells are considered as immune tolerant cells [46], and they can cause protection and survival of the allotransplanted donor AT-MSCs against inflammatory or immune reaction. In contrast, the hypoimmunogenic character of mesenchymal stem cells makes them appropriate for allogenic transplantation [47]. Nevertheless, mesenchymal stem cells generate immunosuppression or immunosurveillance upon transplantation [48]. It is interesting to mention that, related to the treatment of azoospermia, IV allogenic bone marrow-derived mesenchymal stem cell transfusion encourages the production of antisperm antibody modulated by immune system, after testis rupture in mice [49], which illustrates the other therapeutic potential of mesenchymal stem cells in the treatment of infertility. In fact, the possible mechanisms of azoospermia healing by mesenchymal stem cells are unclear; three main mechanisms could be responsible for the recovering of testicular function during the tissue regeneration process period by mesenchymal stem cells. The first option of mesenchymal stem cells differentiation into the spermatozoa via appropriate induction conditions as it has been demonstrated in rats models [32]. Another mechanism which is not confirmed yet is that secretion of growth factors by mesenchymal stem cells stimulates the restoration of spermatogenesis in the inactivated spermatogonia stem cells or Sertoli cells. And the last one is that mesenchymal stem cells merged with the endogenous spermatogonia stem cells recover the spermatogenesis, which is also needed to be further studied deeply.

The necessity for consideration of another point in cell therapy of azoospermia was illustrated by histomorphometric analysis of the treated seminiferous tubules [31]. The increase of the area of the seminiferous tubules before transplantation caused the decline of the number of tubes per unit area in azoospermia. This pathological condition may be created due to decrease of cellular layers which caused the reduction of the tubal structure and collapsing of several tubules under the pressure of intratubular hydrostatic pressure of hamster seminiferous tubules. The growth of the amount of the spaces in testis may result in rise of the other tubes' diameter and also decrease in intratubular hydrostatic pressure. It is necessary to mention that the role of this pressure in the mechanism of spermatogenesis has not been clarified, but it could be the one reason for the increase of diameter of cellular layer in mesenchymal stem cell-treated tubes. Next, histomorphometric analysis with the increase of the number of tubules per unit area in mesenchymal stem cells treated tubes has been obtained [31]. This alteration may be caused by the decline of the volumes of intertubular spaces or by the busulfan therapy complications. Moreover, the increase of the whole area of tubes during azoospermia induction could reduce the ability of contraction of contractile myofibroblast cells, in which the decrease of intratubular hydrostatic pressure in peritubular layer probably resulted in the reduction of spermatozoa concentration in epididymis after mesenchymal stem cell therapy.

\section{Conclusion}

The obtained results of performed research trials on animal models provide a better and deeper overview of MSC therapy in male infertility conditions. The 
demonstrated results of used options in the treatment of these conditions revealed that methods using the MSCs derived from umbilical cord, adipose tissue, and the bone marrow appear more appropriate to recover the fertility due to better results. Although a case report is available for treatment of azoospermia in man [50], applying those methods into the human practice seems to be investigated before introducing this method into clinic.

\section{Conflict of interest}

The authors declare no conflict of interest.

\section{Author details}

Amin Tamadon ${ }^{1}$, Ulanbek Zhan-byrbekuly ${ }^{2}$, Ilyas Kairgaliyev ${ }^{2 *}$ and Arezoo Khoradmehr ${ }^{3}$

1 The Persian Gulf Marine Biotechnology Research Center, The Persian Gulf Biomedical Sciences Research Institute, Bushehr University of Medical Sciences, Bushehr, Iran

\section{Astana Medical University, Nur-Sultan, Kazakhstan}

3 Research and Clinical Center for Infertility, Shahid Sadoughi University of Medical Sciences, Yazd, Iran

*Address all correspondence to: ilyas_1795@mail.ru

\section{IntechOpen}

(C) 2019 The Author(s). Licensee IntechOpen. This chapter is distributed under the terms of the Creative Commons Attribution License (http://creativecommons.org/licenses/ by/3.0), which permits unrestricted use, distribution, and reproduction in any medium, provided the original work is properly cited. (cc) BY 


\section{References}

[1] Zegers-Hochschild F, Adamson GD, de Mouzon J, Ishihara O, Mansour $\mathrm{R}$, Nygren $\mathrm{K}$, et al. The International Committee for Monitoring Assisted Reproductive Technology (ICMART) and the World Health Organization (WHO) revised glossary on ART terminology, 2009. Human Reproduction. 2009;24(11):2683-2687

[2] Boivin J, Bunting L, Collins JA, Nygren KG. International estimates of infertility prevalence and treatmentseeking: Potential need and demand for infertility medical care. Human Reproduction. 2007;22(6):1506-1512

[3] Miyamoto T, Minase G, Okabe K, Ueda H, Sengoku K. Male infertility and its genetic causes. Journal of Obstetrics and Gynaecology Research. 2015;41(10):1501-1505

[4] Miyamoto T, Tsujimura A, Miyagawa Y, Koh E, Namiki M, Sengoku K. Male infertility and its causes in human. Advances in Urology. 2012;2012:384520

[5] Volarevic V, Bojic S, Nurkovic J, Volarevic A, Ljujic B, Arsenijevic N, et al. Stem cells as new agents for the treatment of infertility: Current and future perspectives and challenges. BioMed Research International. 2014;2014:507234

[6] Takahashi K, Yamanaka S. Induction of pluripotent stem cells from mouse embryonic and adult fibroblast cultures by defined factors. Cell. 2006;126(4):663-676

[7] Fang F, Li Z, Zhao Q, Li H, Xiong C. Human induced pluripotent stem cells and male infertility: An overview of current progress and perspectives. Human Reproduction. 2018;33(2):188-195

[8] Valli H, Phillips BT, Shetty G, Byrne JA, Clark AT, Meistrich ML, et al. Germline stem cells: Toward the regeneration of spermatogenesis.

Fertility and Sterility. 2014;101(1):3-13

[9] Hou J, Yang S, Yang H, Liu Y, Liu Y, Hai Y, et al. Generation of male differentiated germ cells from various types of stem cells. Reproduction. 2014;147(6):R179-RR88

[10] Nagamatsu G, Hayashi K. Stem cells, in vitro gametogenesis and male fertility. Reproduction. 2017;154(6):F79-F91

[11] Hajihoseini M, Vahdati A, Ebrahim Hosseini S, Mehrabani D, Tamadon A. Induction of spermatogenesis after stem cell therapy of azoospermic guinea pigs. Veterinarski Arhiv. 2017;87(3):333-350

[12] Mehrabani D, Hassanshahi MA, Tamadon A, Zare S, Keshavarz S, Rahmanifar F, et al. Adipose tissuederived mesenchymal stem cells repair germinal cells of seminiferous tubules of busulfan-induced azoospermic rats. Journal of Human Reproductive Sciences. 2015;8(2):103-110

[13] Mehrabani D, Rabiee M, Tamadon A, Zare S, Jahromi IR, Dianatpour $\mathrm{M}$, et al. The growth kinetic, differentiation properties, karyotyping, and characterization of adipose tissue-derived stem cells in hamster. Comparative Clinical Pathology. 2016;25(5):1017-1022

[14] Shaterzadeh-Yazdi H, Mehrabani D, Khodakaram-Tafti A, Dianatpour M, Zare SH, Tamadon A, et al. Osteogenic potential of subcutaneous adiposederived stem cells in a rabbit model. Online Journal of Veterinary Research. 2015;19(6):436-445

[15] Liu JY, Peng HF, Gopinath S, Tian J, Andreadis ST. Derivation of functional smooth muscle cells from multipotent human hair follicle mesenchymal stem cells. Tissue Engineering Parts A. 2010;16(8):2553-2564 
[16] Mehrabani D, Rahmanifar F, Mellinejad M, Tamadon A, Dianatpour $\mathrm{M}$, Zare $\mathrm{S}$, et al. Isolation, culture, characterization, and adipogenic differentiation of heifer endometrial mesenchymal stem cells. Comparative Clinical Pathology. 2015;24(5):1159-1164

[17] Tamadon A, Mehrabani D, Zarezadeh Y, Rahmanifar F, Dianatpour $\mathrm{M}$, Zare S. Caprine endometrial mesenchymal stromal stem cell: Multilineage potential, characterization and growth kinetics in breeding and anestrous stages. Veterinary Medicine International. 2017;2017:5052801

[18] Mehrabani D, Mahdiyar P, Torabi K, Robati R, Zare S, Dianatpour M, et al. Growth kinetics and characterization of human dental pulp stem cells: Comparison between third molar and first premolar teeth. Journal of Clinical and Experimental Dentistry. 2017;9(2):e172-e1e7

[19] Delorme B, Nivet E, Gaillard J, Häupl T, Ringe J, Devèze A, et al. The human nose harbors a niche of olfactory ectomesenchymal stem cells displaying neurogenic and osteogenic properties. Stem Cells and Development. 2009;19(6):853-866

[20] Khodabandeh Z, Vojdani Z, TalaeiKhozani T, Jaberipour M, Hosseini A, Bahmanpour S. Comparison of the expression of hepatic genes by human Wharton's jelly mesenchymal stem cells cultured in 2D and 3D collagen culture systems. Iranian Journal of Medical Sciences. 2016;41(1):28-36

[21] Mehrabani D, Bahrami Nazarabadi R, Dianatpour M, Vahdati A, Tamadon A, Kasraeian M, et al. Growth kinetics, characterization and plasticity of human menstrual blood stem cells. Iranian Journal of Medical Sciences. 2015;41(2):132-139

[22] Mehrabani D, Khodakaram-Tafti A, Asadi-Yousefabad SL, Dianatpour
M, Zare S, Tamadon A, et al. Effect of age and passage on canine bone marrow derived mesenchymal stem cells. Online Journal of Veterinary Research. 2015;19(10):663-671

[23] Khajehahmadi Z, Mehrabani D, Ashraf MJ, Rahmanifar F, Tanideh N, Tamadon A, et al. Healing effect of conditioned media from bone marrowderived stem cells in thioacetamideinduced liver fibrosis of rat. Journal of Medical Sciences. 2016;16(1-2):7-15

[24] Tamadon A, Mehrabani D, Rahmanifar F, Raayat Jahromi A, Panahi M, Zare S, et al. Induction of spermatogenesis by bone marrowderived mesenchymal stem cells in busulfan-induced azoospermia in hamster. International Journal of Stem Cells. 2015;8:134-145

[25] Aliborzi G, Vahdati A, Mehrabani D, Ebrahim Hosseini S, Tamadon A. Isolation, characterization and growth kinetic comparison of bone marrow and adipose tissue mesenchymal stem cells of Guinea pig. International Journal of Stem Cells. 2015;9(1):115-123

[26] Rahmanifar F, Tamadon A, Mehrabani D, Zare S, Abasi S, Keshavarz S, et al. Histomorphometric evaluation of treatment of rat azoospermic seminiferous tubules by allotransplantation of bone marrowderived mesenchymal stem cells. Iranian Journal of Basic Medical Sciences. 2016;19(6):653

[27] Razeghian Jahromi I, Mehrabani D, Mohammadi A, Dianatpour M, Tamadon A, Zare S, et al. The effect of fetal rat brain extract on morphology of bone marrow-derived mesenchymal stem cells. Comparative Clinical Pathology. 2016;25(2):343-349

[28] Razeghian Jahromi I, Mehrabani D, Mohammadi A, Ghahremani Seno MM, Dianatpour M, Zare S, et al. Emergence of signs of neural cells after exposure 
of bone marrow-derived mesenchymal stem cells to fetal brain extract. Iranian Journal of Basic Medical Sciences. 2017;20:301-307

[29] Dezawa M. Muse cells provide the pluripotency of mesenchymal stem cells: Direct contribution of muse cells to tissue regeneration. Cell Transplantation. 2016;25(5):849-861

[30] Kuroda Y, Wakao S, Kitada M, Murakami T, Nojima M, Dezawa M. Isolation, culture and evaluation of multilineage-differentiating stress-enduring (Muse) cells. Nature Protocols. 2013;8(7):1391

[31] Karimaghai N, Tamadon A, Rahmanifar F, Mehrabani D, Jahromi $\mathrm{AR}$, Zare $\mathrm{S}$, et al. Spermatogenesis after transplantation of adipose tissuederived mesenchymal stem cells in busulfan-induced azoospermic hamster. Iranian Journal of Basic Medical Sciences. 2018;21(7):660

[32] Cakici C, Buyrukcu B, Duruksu G, Haliloglu AH, Aksoy A, Isık A, et al. Recovery of fertility in azoospermia rats after injection of adipose-tissuederived mesenchymal stem cells: The sperm generation. BioMed Research International. 2013;2013:529589

[33] Panahi M, Keshavarz S, Rahmanifar F, Tamadon A, Mehrabani D, Karimaghai N, et al. Busulfan induced azoospermia: Stereological evaluation of testes in rat. Veterinary Research Forum. 2015;6(4):273

[34] Van Saen D, Goossens E, De Block $\mathrm{G}$, Tournaye $\mathrm{H}$. Bone marrow stem cells transplanted to the testis of sterile mice do not differentiate into spermatogonial stem cells and have no protective effect on fertility. Fertility and Sterility. 2009;91(4):1549-1552

[35] Yang S, Bo J, Hu H, Guo X, Tian $\mathrm{R}$, Sun C, et al. Derivation of male germ cells from induced pluripotent stem cells in vitro and in reconstituted seminiferous tubules. Cell Proliferation. 2012;45(2):91-100

[36] Lue YH, Erkkila K, Liu PY, Ma K, Wang C, Hikim AS, et al. Fate of bone marrow stem cells transplanted into the testis: Potential implication for men with testicular failure. The American Journal of Pathology. 2007;170(3):899-908

[37] Monsefi M, Fereydouni B, Rohani L, Talaei T. Mesenchymal stem cells repair germinal cells of seminiferous tubules of sterile rats. Iranian Journal of Reproductive Medicine. 2013;11(7):537

[38] Zahkook SA, Atwa A, Shahat M, Mansour AM, Bakry S. Mesenchymal stem cells restore fertility in induced azoospermic rats following chemotherapy administration. Journal of Reproduction and Infertility. 2014;5(2):50-57

[39] Zhang D, Liu X, Peng J, He $\mathrm{D}$, Lin T, Zhu J, et al. Potential spermatogenesis recovery with bone marrow mesenchymal stem cells in an azoospermic rat model. International Journal of Molecular Sciences.

2014;15(8):13151-13165

[40] Sabbaghi MA, Bahrami AR, Feizzade B, Kalantar SM, Matin MM, Kalantari M, et al. Trial evaluation of bone marrow derived mesenchymal stem cells (MSCs) transplantation in revival of spermatogenesis in testicular torsion. Middle East Fertility Society Journal. 2012;17(4):243-249

[41] Chen H, Tang QL, Wu XY, Xie LC, Lin LM, Ho GY, et al. Differentiation of human umbilical cord mesenchymal stem cells into germ-like cells in mouse seminiferous tubules. Molecular Medicine Reports. 2015;12(1):819-828

[42] Zhu Y, Hu H-L, Li P, Yang S, Zhang W, Ding H, et al. Generation of male germ cells from induced pluripotent 
stem cells (iPS cells): An in vitro and in vivo study. Asian Journal of Andrology. 2012;14(4):574-579

[43] Allah SHA, Pasha HF, Abdelrahman AA, Mazen NF. Molecular effect of human umbilical cord blood CD34positive and CD34-negative stem cells and their conjugate in azoospermic mice. Molecular and Cellular Biochemistry. 2017;428(12):179-191

[44] Hassan AI, Alam SS. Evaluation of mesenchymal stem cells in treatment of infertility in male rats. Stem Cell Research \& Therapy. 2014;5(6):131

[45] Xie L, Lin L, Tang Q, Li W, Huang T, Huo X, et al. Sertoli cell-mediated differentiation of male germ cell-like cells from human umbilical cord Wharton's jelly-derived mesenchymal stem cells in an in vitro co-culture system. European Journal of Medical Research. 2015;20(1):9

[46] Mital P, Kaur G, Dufour JM. Immunoprotective sertoli cells: Making allogeneic and xenogeneic transplantation feasible. Reproduction. 2010;139(3):495-504

[47] Ryan JM, Barry FP, Murphy JM, Mahon BP. Mesenchymal stem cells avoid allogeneic rejection. Journal of Inflammation. 2005;2:8

[48] Bibber B, Sinha G, Lobba ARM, Greco SJ, Rameshwar P. A review of stem cell translation and potential confounds by cancer stem cells. Stem Cells International. 2013;2013:8, Article ID: 241048

[49] Aghamir SMK, Salavati A, Yousefie R, Tootian Z, Ghazaleh N, Jamali $\mathrm{M}$, et al. Does bone marrow-derived mesenchymal stem cell transfusion prevent antisperm antibody production after traumatic testis rupture? Urology. 2014;84(1):82-86

[50] Cassim MI, Mohamed T. A novel therapy for the treatment of malefactor infertility due to non-obstructive azoospermia: A case report. Crescent Journal of Medical and Biological Sciences. 2019;6(1):129-131 
Section 2

\section{Testicular Cancer and Prostate Cancer}





\title{
Chapter 8
}

\section{Testicular Cancer and the Importance of Early Diagnosis}

\author{
Serife Zehra Altunkurek
}

\begin{abstract}
Prevalence of cancers is growing rapidly in all parts of the world. Testicular cancer (TC) is one of the greatest threats to health among 15- to 34-year-old males. Since testicular cancer peaks in incidence among young men of reproductive age, it is an important type of cancer for men. Risk factors for testicular cancer include cryptorchidism (i.e., undescended testicles), family history, infertility, tobacco use, and white race. Therefore increasing awareness in this regard, a joint effort that encourages risk factors and preventive measures, must be shown. The treatments are very effective, which greatly increases the 5 -year survival rate by approximately $98 \%$. Prevention is the best option to tackle TC. Secondary preventive measures, the most important testicular self-examination (TSE), are well known and are encouraged to them. TSE helps prevent the diagnosis of late-stage TSE. Because the treatment of testicular cancer detected early is often associated with very positive results, routine screening and monthly self-examination in young men have been suggested. Although testicular cancer is rare, it is very effective to treat symptoms when they are diagnosed by TSE. As with breast cancer, early detection of TC is best done through self-examination.
\end{abstract}

Keywords: testicular cancer, men's health, early diagnosis, self examination

\section{Introduction}

Cancer is the second leading cause of death globally and is responsible for an estimated 9.6 million deaths in 2018 [1]. A number of malignancies can be prevented through screening; an example is predominantly affecting males between 15 to 35 years of age and a relatively rare testicular malignancy that is a treatable cancer $[2,3]$. However, TC incidence has risen worldwide in the past two decades [4]. Advances in the treatment of TC over the last 25 years have resulted in survival figures of $80-90 \%$. Since TC peaks in incidence among young men of reproductive age, it is an important type of cancer for men [5]. Early diagnosis and treatment of TC is very important. TC is completely cured when detected at an early stage. Early diagnosis and 5-year survival rate is $99 \%$ [6-8]. Ninety to ninety-five percent of testicular tumors are caused by germinal tissue [9]. In this group, seminoma is the most common tumor with $40 \%$ [10]. The rate of cure with radiotherapy following orchiectomy in stage I seminoma is 99\% [11]. Risk factors for TC include cryptorchidism (undescended testicles), abnormal development of testicles, adolescent and young adult age, family history, infertility, and white race [12-14]. Treatment is highly effective even when the diagnosis is made through 
examination or because of symptoms [15]. As with breast cancer, early detection of TC is best done through self-examination [16]. Although routine screening and monthly self-examination in young men have been recommended, studies have not shown that they improve outcomes [17].

This chapter explains the epidemiology, etiology, stages, treatment of TC, and importance of early diagnosis for TC as well as TSE, as far as possible, with special considerations for adolescent and young adult populations.

\section{Epidemiology}

TC incidence is increasing worldwide, but the reasons for this increase are not fully documented [18]. There were a total of 36,747 cases of TC in the Scandinavian countries from 1960 to 2014 [19]. 9.4 affected individuals per 100,000 males in Denmark had the highest incidence of TC for decades, but while the incidence rate stabilized in Denmark, the rate is now highest, 9.9 affected individuals per 100,000 males in Norway [20, 21]. In the United States, TC is more common in white individuals (6.9 affected individuals per 100,000 males) than in African Americans (1.2 affected individuals per 100,000 males) [18]. TC took first place with 24.8 percent of men in the 15-24 age group in Turkey [22]. An analysis from the International Agency for Research on Cancer indicates age-standardized rates of TC varied from less than 1/100,000 person 14-35 years in Africa and Asia [23]. Worldwide, there are approximately 72,000 cases and 9000 deaths per year attributable to TC [24]. TC death in the United States accounts for approximately $4 \%$ of the annual incidence [25]. There is a significant global variability in mortality rates that are largely inverse in incidence rates. TC mortality is highest in low-income countries compared with higher-income countries [20]. Also, in spite of the highest incidences of this disease in Europe, North America and New Zealand account for only one-fifth of mortalities caused by TC [26]. About $50 \%$ of patients worldwide with TC are diagnosed with seminoma and the median ages at diagnosis 37 years [27].

\subsection{Risk factors}

The majority of TC (98\%) had germ cell tumors; therefore, the terms testicular germ cell tumor and TC are often used interchangeably [28]. While most cancers occur in adulthood, the incidence of TC does not increase with age. The peak ages of occurrence are 25-29 years for non-seminomas and 35-39 years for seminomas [29]. The risk factors for TC are not well understood, but the risk factors most consistently associated with cryptorchidism, contralateral testicular tumor, a family history of TC, male factor infertility, and testicular microlithiasis [30-32].

Cryptorchidism, also referred to as maldescended testis, is the failure of descent of one or both of the testes into the scrotum and is a common clinical diagnosis in newborn boys and one of the strongest risk factors for infertility and testicular cancer [33-35]. Approximately 10\% of all cases of testicular tumors occur in boys with a history of cryptorchidism [36]. In a study of patients with bilateral germ cell tumor, while $9.5 \%$ had cryptorchidism history, cryptorchidism was found in $2.2 \%$ of patients with unilateral tumors [37]. In addition, in a cohort study, cryptorchidism repair prior to puberty was associated with a doubling in risk of testicular cancer; postponement of the repair after the age of 12 showed that the risk increased fivefold [38].

TC is associated with a family history link as well [33-35]. Men, who have a firstdegree relative with testicular cancer, have a reasonably increased risk [39]. Patients 
with a history of personal testicular cancer have a 12-fold higher risk of developing TC than the general population [40]. Family cancer studies have shown that sons whose fathers have TC have four times the risk of testicular cancer and brothers of patients with TC have eight times the risk of having testicular cancer [41]. Family history of this relationship is white men are more likely than black men to develop TC [15]. In a study with a large population, contralateral testicular cancer explained that a man younger than age of 30 with testicular seminoma has a $3.1 \%$ risk of developing a TC [42].

TC has increased in the last 30 years, while in Western countries there has been a decrease in semen quality and fertility [41]. Men with infertility have an increased risk of TC, with an incidence ratio of 1.6-2.8 [43]. The cohort study, based on more than 22,000 men undergoing evaluation for infertility, examined an association between infertility and the development of testicular cancer [44]. Other risk factors in TC are vasectomy, scrotal trauma, inguinal hernia, diet, smoking, the gene, environment (such as heavy metals exposure and endocrine disruptors), and hormones [45-50].

\section{Diagnosing testicular cancer}

TC is often seen as a painless mass in the testis, but in many patients there is a widespread pain, swelling, or stiffness in the scrotum [51]. Testicular masses appear more often on the right side [8]. Acute testicular pain is less widespread and is reasoned by swift expansion of the testis owing to intratumor hemorrhage or infarction caused by swift tumor growth [39]. Men often notice a history of testicular trauma, though accidental trauma is probably liable for leading the testicular mass to the men's attention, firstly. Men may complain of unclear scrotal pain or heaviness [39]. Testicular masses can be urgently evaluated by physical exam and bilateral testicular ultrasound [6]. Physical examination may be determinative but is sometimes vague in differentiating a malignancy from nonmalignant testicular masses [52].

The physician should carefully examine the testes, noting their notional size and density and palpating for any testicular masses [39]. Any doubtful symptoms should give rise to adjuvant studies [53]. Table 1 shows the signs and symptoms of TC [15].

\begin{tabular}{ll}
\hline Discomfort & Metastases* $^{*}$ \\
\hline Dull ache in the scrotum or abdomen & Gastrointestinal symptoms \\
\hline Acute pain in the testicle or scrotum & Gynecomastia \\
\hline Scrotal heaviness & Lumbar back pain \\
\hline Mass effect & Neck mass \\
\hline Firmness of the testicle & Respiratory symptoms (e.g., cough, hemoptysis, dyspnea) \\
\hline Infertility & \\
\hline Intratesticular mass & \\
\hline Painless swelling and redness & \\
\hline About $5 \%$ of patients with testicular cancer have symptoms of metastases. \\
Information from Ref. [15].
\end{tabular}

Table 1.

Signs and symptoms of testicular cancer. 
In men showing with testicular mass, unexplained scrotal pain or signs, ultrasonography should be regarded an appendage of the physical examination due to being broadly existing, cheap, and noninvasive [54]. After Physical examination, for revealing a mass in the testicle and the first radiological evaluation was Ultrasonography [55]. First of all intratesticular mass or the extratesticular location is examined. The intratesticular masses tend to be malignant, and the extratesticular masses tend to be benign. The nature of the detected masses (solid or cystic) is determined by Ultrasonografi (US). Solid masses suggest more malignancy, whereas cystic masses are often benign, such as rete testis ectasia, simple cyst, and tunica albuginea cyst [55].

Tumor markers are also an important part of the diagnostic workup. Betahuman chorionic gonadotropin (Bhcg), alpha-fetoprotein (AFP), and lactate dehydrogenase (LDH) levels are checked for the diagnosis of testicular tumors [56]. At the same time, these marker levels should be acquired after orchiectomy and to monitor chemotherapy treatment [39]. At the beginning of cancer, levels of these markers tend to be in the normal level. LDH levels are often elevated metastatic testicular cancer [15].

A biopsy can damage the testicles and spread the cancer into scrotum, so biopsy is not recommended [57]. But if suspected of having testicular tumor, one should undergo a radical inguinal orchiectomy for pathologic evaluation [39].

\section{The stages of testicular cancer}

Testicular cancers are classified as seminomas or non-seminomas. The seminomas are most common tumor with $40 \%$. Three histological subtypes are defined. The most common type is classical type seminoma with $85 \%$. Firstly, it makes lenfoj metastasis. It responds to radiotherapy and chemotherapy very well [58]. Nonseminoma tumors account for $4 \%$ of all testicular tumors. Leydig cell tumors are the most common and this tumor constitutes $1-2 \%$ of all testicular tumors. It has a benign character in children but it is 10\% malignant in adults [59].

Staging in TC is useful for determining prognosis and treatment. Patients are classified as Stage I (limited to the testis), Stage II (lymph node involvement), and Stage III (metastasis to visceral organs) [60] (Table 2). Among the important factors to be considered when staging are the degree of metastasis, elevation of tumor markers, and histology (seminoma or nonseminoma).

\begin{tabular}{cl}
\hline Stage I & The tumor is in the testis. No evidence of metastasis was found in any of the testis \\
\hline Stage IM & After orchiectomy tumor markers in height is observed \\
\hline Stage II & Retroperitoneal lymphadenopathy is present \\
\hline IIA & Lymphadenopathy $<2$ cm across \\
\hline IIB & $=2-5$ cm across \\
\hline IIC & $>5$ cm across \\
\hline Stage III & Supradiaphragmatic lymphadenopathies are present \\
\hline Stage IV & Organ metastasis/hematogenous spread \\
\hline Information from Refs. [61, 62].
\end{tabular}

Table 2.

Classifications of testicular cancer staging. 


\section{Treating testicular cancer}

The primary treatment for testicular tumors is radical inguinal orchiectomy involving the removal of the testis and spermatic cord. After orchiectomy, the type of tumor (seminoma or nonseminoma tumor) and its stage are determined by microscopic diagnosis for further treatment [63]. Treatment options include observation, dissection of the retroperitoneal lymph node, radiation, and chemotherapy [15]. Treatment options for specific stages of disease are summarized in Table 3. To determine the success and continuity of treatment, evaluation is made by looking at the changes in serum tumor markers [15].

\begin{tabular}{|c|c|c|}
\hline Stage & Seminoma & Nonseminoma \\
\hline I & $\begin{array}{l}\text { Usually low-dose radiotherapy as a } \\
\text { preservative }\end{array}$ & $\begin{array}{l}\text { Retroperitoneal lymph node dissection or monthly } \\
\text { follow-up observations } \\
\text { IB: Take into two courses of chemotherapy } \\
\text { IS: The whole-dose chemotherapy if serum tumor } \\
\text { marker levels do not drop swiftly after surgery }\end{array}$ \\
\hline II & $\begin{array}{l}\text { IIA: Radiation therapy of the local lymph } \\
\text { nodes } \\
\text { IIB or IIC: Three courses of three-drug } \\
\text { chemotherapy }\end{array}$ & $\begin{array}{l}\text { IIA: Retroperitoneal lymph node dissection, } \\
\text { followed by monthly monitoring and frequent lab } \\
\text { tests or observation, was made by two courses of } \\
\text { chemotherapy, two drugs } \\
\text { IIB or IIC: If computed tomography still indicates } \\
\text { lymph nodes, three or four courses of three-drug } \\
\text { chemotherapy followed by retroperitoneal lymph } \\
\text { node dissection }\end{array}$ \\
\hline III & $\begin{array}{l}\text { Three-drug chemotherapy: If there is no } \\
\text { answer, think of the clinical tests of other } \\
\text { chemotherapy drugs in combination } \\
\text { Have brain metastasis: Treat with brain } \\
\text { radiation or operating disposal }\end{array}$ & $\begin{array}{l}\text { Three-drug chemotherapy: operating disposal of } \\
\text { permanent tumors } \\
\text { High serum tumor marker levels: These patients } \\
\text { often do not respond to usual chemotherapy; } \\
\text { therefore, more aggressive clinical trials may be } \\
\text { considered } \\
\text { High serum tumor marker levels: These } \\
\text { patients frequently do not answer to normal } \\
\text { chemotherapy; hence, more aggressive clinical } \\
\text { trials can be thought }\end{array}$ \\
\hline
\end{tabular}

Information from Ref. [15].

Table 3.

Treatment types for the stages of testicular cancer.

\section{Fertility issue}

Studies have shown that fertility decreased after treatment in TC patients. In addition, treatment with chemotherapy and radiotherapy was reported to cause significant gonadal damage in men $[64,65]$.

In one study, half of the patients wanted to have children after TC treatment. However, according to the results of the study, fertility rate was lower after treatment than before treatment [66]. In the other study after treating for TC, 13 percent of patients developed hypogonadism [67]. Therefore, since the treatments to be applied to TC patients have a negative effect on fertility, solutions such as sperm banking, testicular tissue freezing, or removal of testicular sperm should be discussed with the patient before starting the treatment $[68,69]$. 


\section{The importance of early detection of TC and TSE}

The aim of any cancer screening program is to diagnose the disease at an earlier and more easily treatable stage by improving disease-specific survival and minimizing treatment morbidity [70].

As with all cancer cases, when testicular cancer is diagnosed in early stages, the rate of treatment for TC is approximately $96 \%$, significantly affecting survival [71]. Unfortunately, more than $50 \%$ of cases are diagnosed after the disease has spread to the primary site, and men must be persuaded to avoid medical treatment as soon as a mass is detected [72]. Once the cancer has expanded over the local nodes (Stage III), the survival rate decreases extremely. This is because approximately every 10-30 days, the tumor doubling times were fast. Therefore, early diagnosis equates with a better long-term overall prognosis [6]. Obviously, for testicular cancer, a potentially lethal disease, early detection and early treatment are very important [6]. Rapid diagnosis of these neoplasms provides the opportunity to treat these patients at the earliest stage of the disease and thus minimize long-term morbidity [70].

Despite the importance of early diagnosis, invisible dangers are common in early and definitive diagnosis of testicular tumors. There are many studies based on delay in the diagnosis of testicular cancer [73-75]. In a comprehensive study on delayed diagnosis (DD) in testicular cancer, DD confirmed that it had a significant effect on survival in TC patients receiving modern treatments, including chemotherapy [76]. On the other hand, Nikzas et al. found no effect on survival in delay between 1980 and 1987 in 232 patients studied in Great Britain [77].

Both patients and health professionals can contribute to delay in diagnosis. Patient-induced delays due to unawareness, embarrassment, fear of cancer, or fear of emasculation are accepted [75, 78-80]. The results of literature reviews suggest that approximately $20-30 \%$ of cancer patients delay seeking help for more than 3 months after having experienced possible symptoms of cancer [81].

TC affects young and generally healthy males who do not accept the threat of deadly disease. Moreover, that testicular cancer requires loss of external genitals during a time in the man's life when sexuality is very important is additionally stressful [70]. The physician-mediated delay is most often the misdiagnosis of a testicular tumor as an infection. Unluckily for clinicians, classic painless testicular mass of patients ultimately diagnosed with TC is only half the resulting symptoms [82].

For early diagnosis several organizations, including the American Cancer Society and American Urological Association, recommend that physicians include testicular examination as part of routine control [83].It is also recommended that primary healthcare professionals teach and encourage TSE to males between the ages of 15 and 35 years [84]. At the same time, the American Cancer Society recommends to men, especially who at high risk for TC, TSE as an effective and cost-free method [71]. Studies have shown that men at risk for TC are not educated and do not know how to perform TSE [6]. Moreover, many studies reported that close to all men of the risk group (adult men below age 35) had never performed TSE and very few knew that men who were in the 18 - to 50 -year-old age group should perform TSE every month $[16,85]$.

TSE is the cheapest and easiest method for screening firstly taught by the nurses or physicians to the man. The man is taught to perform the TSE when the scrotum is soft and relaxed, usually after a shower. In addition, TSE is recommended to be done at least once a month starting at the onset of puberty [17]. TSE teaching begins when the man becomes familiar with the major structures of the testis, scrotum, testicle, and epididymis [86]. After being familiar with the normal tissue and structures of the testes, the man is better readied to identify normal physiological structures. Any suspicious masses are notified to a healthcare professional as soon 
as possible [86]. However, the role of TSE in screening of testicular cancer is still a matter of debate. In testicular cancer, regular TSE to prove the relationship between life and life US Preventive Services Task Force Some organizations such as the Canadian Task Force are out of the ordinary they do not recommend regular TSE because they can cause anxiety and unnecessary doctor visits [87, 88]. However, self-testis may be useful in increasing the incidence of testicular cancer and in early diagnosis because of the very low number of men participating in preventive healthcare [89]. TSE is a convenient method to detect testicular cancer and contribute to healthier lifestyles for men at risk [71]. Furthermore, TSE, potentially positive, can produce sustainable health behavior choices [90].

\section{Conclusions}

In conclusion, studies have shown that the incidence of TC is increasing, especially in developed countries, where it is the most commonly diagnosed malignancy in young men. For this reason, young men should be encouraged to be aware of early detection of TC, to raise awareness and to apply to the health institution. In general, with rates of treatment above $95 \%$ ( $80 \%$ for metastatic disease), TC is considered to be a curable cancer when diagnosed early. At the same time, contrary to the supposition of men, treatment of TC is generally a type of cancer that does not cause sexual problems and does not affect fertility, and men's masculinity is maintained unless both testicles are affected for a long time. The men that will be given TSE training may need to be present as educators because some men find the discussion of their testicles embarrassing. Furthermore, teaching young men to conduct TSE may result in these men taking increased responsibility for their own healthcare. When men are aware of what is normal for themselves, they are more likely to consult in the absence of false assurances from the absence of a lack of precariousness when they detect any abnormal condition. It is equally important to tell men that the diagnosis of testicular cancer is not death and the rate of treatment is excellent. Efforts should be made to make men aware that there may be a disease in their testicles even when there is no pain.

\section{Conflict of interest}

The author declared no potential conflicts of interest with respect to the publication of this chapter.

\section{Thanks}

Thanks to my students who are Cansu Yasar, Kardelen Ozcoban, and Kezban Kaya. 


\section{Author details}

Serife Zehra Altunkurek

Gulhane Faculty of Nursing, Public Health Nursing Department, University of Health Sciences, Ankara, Turkey

*Address all correspondence to: serifezehra.atunkurek@sbu.edu.tr

\section{IntechOpen}

(C) 2020 The Author(s). Licensee IntechOpen. This chapter is distributed under the terms of the Creative Commons Attribution License (http://creativecommons.org/licenses/ by/3.0), which permits unrestricted use, distribution, and reproduction in any medium, provided the original work is properly cited. (cc) BY 


\section{References}

[1] Cancer. World Health Organization [Internet]. 2018. Available from: https:// www.who.int/news-room/fact-sheets/ detail/cancer [Accessed: June 21, 2018]

[2] Nigam M, Aschebrook-Kilfoy B, Shikanov S, Eggener S. Increasing incidence of testicular cancer in the United States and Europe between 1992 and 2009. World Journal of Urology. 2015;33(5):623-631. DOI: 10.1007/ S00345-014-1361-Y

[3] Saab MM, Landers M, Hegarty J. Promoting testicular cancer awareness and screening: A systematic review of interventions. Cancer Nursing. 2016;39(6):473-487. DOI: $10.1097 /$ NCC. 0000000000000333

[4] Siegel RL, Miller KD, Jemal A. Cancer statistics, 2018. CA: A Cancer Journal for Clinicians. 2018;68:7-30. DOI: $10.3322 /$ caac. 21442

[5] Shanmugalingam T, Soultati A, Chowdhury S, Rudman S, Van Hemelrijck M. Global incidence and outcome of testicular cancer. Clinical Epidemiology. 2013;5:417. DOI: 10.2147/ CLEP.S34430. https://www.nhs.uk/ conditions/testicular-cancer/

[6] Brown CG. Testicular cancer: An overview. Urologic Nursing. 2004;24:83-93

[7] Bahrami A, Ro JY, Ayala AG. An overview of testicular germ cell tumors. Archives of Pathology \& Laboratory Medicine. 2007;131(8):1267-1280. DOI: 10.1043/1543-2165(2007)131[1267:AOO TGC]2.0.CO;2

[8] Viatori M. Testicular cancer. Seminars in Oncology Nursing. 2012;28(3):180-189. DOI: 10.1016/j. soncn.2012.05.007. WB Saunders

[9] Coursey Moreno C, Small WC, Camacho JC, et al. Testicular tumors: What radiologists need to know--differential diagnosis, staging, and management. Radiographics. 2015;35:400-415. DOI: $10.1148 /$ rg.352140097

[10] Akyüz M, Topaktaş R, Ürkmez A, Koca O, Öztürk Mİ. Evaluation of germ-cell neoplasia in situ entity in testicular tumors. Turkish Journal of Urology. 2018;16:1-5. DOI: 10.5152/ tud.2018.48855

[11] Birch R, Williams S, Cone A, Einhorn L, Roark P, Turner S, et al. Prognosis factors for favorable outcome in disseminated germ cell tumors. Journal of Clinical Oncology. 1986;4:400-407. DOI: 10.1200/ JCO.1986.4.3.400

[12] Gurney JK, McGlynn KA, Stanley J, Merriman T, Signal V, Shaw C, et al. Risk factors for cryptorchidism. Nature Reviews Urology. 2017;14(9):534. DOI: 10.1038/nrurol.2017.90

[13] Garner MJ, Turner MC, Ghadirian P, Krewski D. Epidemiology of testicular cancer: An overview. International Journal of Cancer. 2005;116(3):331339. DOI: $10.1002 /$ ijc.21032. Available at: http://www.ncbi.nlm.nih.gov/ pubmed/15818625 [Accessed: August 21, 2013]

[14] Akre O, Ekbom A, Hsieh CC, Trichopoulos D, Adami HO. Testicular nonseminoma and seminoma in relation to perinatal characteristics. Journal of the National Cancer Institute. 1996;88(13):883-889. DOI: $10.1093 /$ jnci/88.13.883. Available at: http://www. ncbi.nlm.nih.gov/pubmed/8656440

[Accessed: October 24, 2013]

[15] Shaw J. Diagnosis and treatment of testicular cancer. American Family Physician. 2008;77:469-474

[16] Ugboma HA, Aburoma HLS. Public awareness of testicular cancer and 
testicular self-examination in academic environments: A lost opportunity. Clinics. 2011;66(7):1125-1128. DOI: 10.1590/S1807-59322011000700001

[17] Fadich A, Giorgianni SJ, Rovito MJ, Pecchia GA, Bonhomme JJ, Adams WB, et al. USPSTF testicular examination nomination-self-examinations and examinations in a clinical setting. American Journal of Men's Health. Sep 2018;12(5):1510-1516. DOI: 10.1177/1557988318768597

[18] Ghazarian AA, Trabert B, Devesa SS, McGlynn KA. Recent trends in the incidence of testicular germ cell tumors in the United States. Andrology. 2015;3:13-18. DOI: 10.1111/andr.288

[19] Engholm G, Ferlay J, Christensen N, et al. NORDCAN: Cancer incidence, mortality, prevalence and prediction in the Nordic countries, Version 7.3 (08.07.2016). Association of the Nordic Cancer Registries, Danish Cancer Society. Available at: https://www.ancr. nu/ [Accessed: January 2017]

[20] Znaor A, Lortet-Tieulent J, Jemal A, Bray F. International variations and trends in testicular cancer incidence and mortality. European Urology. 2014;65:1095-1106. DOI: 10.1016/j. eururo.2013.11.004

[21] Ylönen O, Jyrkkiö S, Pukkala E, Syvänen K, Boström PJ. Time trends and occupational variation in the incidence of testicular cancer in the Nordic countries. BJU International. 2018;122(3):384-393. DOI: 10.1111/ bju. 14148

\section{[22] Turkey of Cancer Statistics} [Internet]. 2015. Available from: https:// hsgm.saglik.gov.tr/depo/birimler/ kanserdb/istatistik/Turkiye_Kanser_ Istatistikleri_2015.pdf [Accessed:June 11, 2018]

[23] Woldu SL, Bagrodia A. Update on epidemiologic considerations and treatment trends in testicular cancer. Current Opinion in Urology. 2018;28(5):440-447. DOI: 10.1097/ MOU.0000000000000532

[24] Fitzmaurice C, Allen C, Barber RM, et al. Global, regional, and National cancer incidence, mortality, years of life lost, years lived with disability, and disability-adjusted life-years for 32 cancer groups, 1990 to 2015: A systematic analysis for the global burden of disease study. JAMA Oncology. 2017;3(4):524-548. DOI: 10.1001/ jamaoncol.2016.5688

[25] Society AC. Key Statistics for Testicular Cancer. Atlanta, GA: The American Cancer Society; 2018. Available from: https://www.cancer. org/cancer/testicular-cancer/about/ key-statistics.html. [Updated: January 4, 2018]

[26] Ferlay J, Soerjomataram I, Dikshit R, Eser S, Mathers C, Rebelo M, et al. Cancer incidence and mortality worldwide: Sources, methods and major patterns in GLOBOCAN 2012. International Journal of Cancer. 2015;136(5):359-386. DOI: 10.1002 / ijc. 29210

[27] Mortensen MS et al. A nationwide cohort study of stage I seminoma patients followed on a surveillance program. European Urology. 2014;66:1172-1178. DOI: 10.1016/j. eururo.2014.07.001

[28] Surveillance, Epidemiology, and End Results (SEER) Program. SEER*Stat. Database: Incidence-SEER 9 Regs Research Data; 2011

[29] McGlynn KA et al. Trends in the incidence of testicular germ cell tumors in the United States. Cancer. 2003;97: 63-70. DOI: $10.1002 /$ cncr.11054

[30] Purdue MP, Devesa SS, Sigurdson AJ, McGlynn KA. International patterns and trends in testis cancer incidence. 
International Journal of Cancer. 2005;115:822-827. DOI: 10.1002/ ijc. 20931

[31] Bray F et al. Trends in testicular cancer incidence and mortality in 22 European countries: Continuing increases in incidence and declines in mortality. International Journal of Cancer. 2006;118:3099-3111. DOI: 10.1002/ijc.21747

[32] Osterlind A, Berthelsen JG, Abildgaard N, et al. Risk of bilateral testicular germ cell tumor in Denmark: 1960-84. Journal of the National Cancer Institute. 1991;83:1391-1395. DOI: 10.1093/jnci/83.19.1391

[33] Ferguson L, Agoulnik AI. Testicular cancer and cryptorchidism. Frontiers in Endocrinology. 2013;4:32. DOI: 10.3389/ fendo.2013.00032

[34] Herrinton LJ, Zhao W, Husson G. Management of cryptorchidism and risk of testicular cancer. American Journal of Epidemiology. 2003;157:602-605. DOI: 10.1093/aje/kwg012

[35] Roy RK, Casson K. Attitudes toward testicular cancer and self-examination among northern Irish males. American Journal of Men's Health. 2017;11(2):253261. DOI: $10.1177 / 1557988316668131$

[36] Mannuel HD, Mitikiri N, Khan M, Hussain A. Testicular germ cell tumors: Biology and clinical update. Current Opinion in Oncology. 2012;24:266-271. DOI: $10.1097 / C C O .0 b 013 e 32835167 f c$

[37] Sarıcı H, Telli O, Eroğlu M. Bilateral testicular germ cell tumors. Turkish Journal of Urology. 2013;39(4):249. DOI: 10.5152/tud.2013.062

[38] Pettersson A, Richiardi L, Nordenskjold A, Kaijser M, Akre O. Age at surgery for undescended testis and risk of testicular cancer. The New England Journal of Medicine. 2007;356(18):1835-1841. DOI: $10.1056 /$ NEJMoa067588
[39] McDougal WS, Wein AJ, Kavoussi LR, Partin AW, Peters CA. Campbell-Walsh Urology 11th Edition Review E-Book. Philadelphia: Elsevier Health Sciences; 2015

[40] Hu JS, Baird DC, Meyers GJ. Testicular cancer: Diagnosis and treatment. American Family Physician. 2018;97(4):261-268

[41] Manecksha RP, Fitzpatrick JM. Epidemiology of testicular cancer. BJU International. 2009;104(9b):1329-1333. DOI: 10.1111/j.1464-410X.2009.08854.x

[42] Fosså SD, Chen J, Schonfeld SJ, McGlynn KA, McMaster ML, Gail MH, et al. Risk of contralateral testicular cancer: A population-based study of 29515 US men. Journal of the National Cancer Institute. 2005;97(14):10561066. DOI: $10.1093 /$ jnci/dji185

[43] Eisenberg ML, Li S, Brooks JD, Cullen MR, Baker LC. Increased risk of cancer in infertile men. The Journal of Urology. 2015;193(5):1596-1601. DOI: 10.1016/j.juro.2014.11.080

[44] Walsh TJ, Croughan MS, Schembri M, Chan JM, Turek PJ. Increased risk of testicular germ cell cancer among infertile men. Archives of Internal Medicine. 2009;169(4):351-356. DOI: 10.1001/archinternmed.2008.562

[45] Tamimi RULLA, Adami HO. Testicular cancer. In: Textbook of Cancer Epidemiology. Hans-Olov A, David H, Dimitrios T. editors. Oxford University; 2002. p. 429. DOI: $10.1093 /$ acprof:oso/9780195311174.003.0021

[46] Cale AR, Farouk M, Prescott RJ, Wallace IW. Does vasectomy accelerate testicular tumour? Importance of testicular examinations before and after vasectomy. BMJ. 1990;300(6721):370. DOI: $10.1136 / \mathrm{bmj} .300 .6721 .370$

[47] Møller H, Prener A, Skakkebxk NE. Testicular cancer, cryptorchidism, 
inguinal hernia, testicular atrophy, and genital malformations: Case-control studies in Denmark. Cancer Causes \& Control. 1996;7(2):264-274. DOI: 10.1007/BF00051302

[48] Srivastava A, Kreiger N. Relation of physical activity to risk of testicular cancer. American Journal of Epidemiology. 2000;151(1):78-87. DOI: 10.1093/oxfordjournals.aje. a010126

[49] UK Testicular Cancer Study Group. Social, behavioural and medical factors in the aetiology of testicular cancer: Results from the UK study. British Journal of Cancer. 1994;70:513-520. DOI: 10.1038/bjc.1994.337

[50] Garner MJ, Birkett NJ, Johnson KC, Shatenstein B, Ghadirian P, Krewski D. Canadian cancer registries epidemiology research group. Dietary risk factors for testicular carcinoma. International Journal of Cancer. 2003;106(6):934-941. DOI: $10.1002 / \mathrm{ijc} .11327$

[51] Cheng L, Albers P, Berney DM, Feldman DR, Daugaard G, Gilligan T, et al. Testicular cancer. Nature Reviews Disease Primers. 2018;4(1):29. DOI: 10.1038/s41572-018-0029-0

[52] Dieckmann KP, Frey U, Lock G. Contemporary diagnostic work-up of testicular germ cell tumours. Nature Reviews Urology. 2013;10(12):703-712. DOI: $10.1038 /$ nrurol.2013.254

[53] Schmoll HJ, Jordan K, Huddart R, Pes ML, Horwich A, Fizazi K. ESMO guidelines working group. Testicular non-seminoma: ESMO clinical practice guidelines for diagnosis, treatment and follow-up. Annals of Oncology. 2010;21(5):147-154. DOI: 10.1093/ annonc/mdq177

[54] DeCastro BJ, Peterson AC, Costabile RA. A 5-year followup study of asymptomatic men with testicular microlithiasis. The Journal of Urology. 2008;179:1420-1423. DOI: 10.1016/j. juro.2007.11.080

[55] Yagil Y, Naroditsky I, Milhem J, et al. Role of Doppler ultrasonography in the triage of acute scrotum in the emergency department. Journal of Ultrasound in Medicine. 2010;29:11-21. DOI: 10.7863/jum.2010.29.1.11

[56] Murray MJ, Huddart RA, Coleman N. The present and future of serum diagnostic tests for testicular germ cell tumours. Nature Reviews Urology. 2016;13(12):715-725. DOI: 10.1038/nrurol.2016.170

[57] National Comprehensive Cancer Center (NCCN). Clinical practice guidelines in oncology: testicular cancer. 2012. National Comprehensive Cancer Network. Available from: http://www. nccn.org/professionals/physician_gls/ pdf/testicular.pdf [Accessed: March 20, 2019]

[58] Rashid HH, Cos LR, Weinberg E, et al. Testicular microlithiasis: A review and its association with testicular cancer. Urologic Oncology. 2004;22(4):285-289. DOI: 10.1016/ S1078-1439(03)00177-7

[59] Petersen PM, Giwercman A, Daugaard G, et al. Effect of graded testicular doses of radiotherapy in patients treated for carcinoma-in-situ in the testis. Journal of Clinical Oncology. 2002;20(6):1537-1543. DOI: 10.1200/ JCO.2002.20.6.1537

[60] Oldenburg J et al. Testicular seminoma and non-seminoma: ESMO clinical practice guidelines for diagnosis, treatment and follow- up. Annals of Oncology. 2013;24(6):125-132. DOI: 10.1093/annonc/mdt304

[61] Tanagho EA, McAninch JW. In: Kazancı G, editor. Smith Genel Üroloji, JenitalTümörler. İstanbul: Nobel Tip Kitabevleri; 1999. pp. 435-441 
[62] Anafarta K, Göğüş O, Bedük Y, Arıkan N, editors. Temel Üroloji, Testis Tümörleri. Ankara: Güneş Kitabevi; 1998. pp. 751-759

[63] American Cancer Society.

Treatment options by stage. Available from: http://www.cancer.org/docroot/ CRI/content/CRI_2_4_4X_Treatment_ Options_by_stage_41.asp?rnav=cri [Accessed: March 1, 2019]

[64] Fosså SD, Kravdal O. Fertility in Norwegian testicular cancer patients. British Journal of Cancer. 2000;82:737741. DOI: 10.1054/bjoc.1999.0989

[65] Fosså SD. Long-term sequelae after cancer therapy-Survivorship after treatment for testicular cancer. Acta Oncologica. 2004;43:134-141. Review

[66] Matos E, Škrbinc B, Zakotnik B. Fertility in patients treated for testicular cancer. Journal of Cancer Survivorship. 2010;4(3):274-278. DOI: $10.1007 / \mathrm{s} 11764-010-0135-9$

[67] Huddart RA, Norman A, Moynihan C, et al. Fertility, gonadal and sexual function in survivors of testicular cancer. British Journal of Cancer. 2005;93(2):200-207. DOI: 10.1038/ sj.bjc. 6602677

[68] King L, Quinn GP, Vadaparampil ST, et al. Oncology nurses' perceptions of barriers to discussion of fertility preservation with patients with cancer. Clinical Journal of Oncology Nursing. 2008;12:467-476. DOI: 10.1188/08. CJON.467-476

[69] Rodriguez-Wallberg KA, Oktay K. Fertility preservation during cancer treatment: Clinical guidelines. Cancer Management and Research. 2014;6:105. DOI: 10.2147/CMAR.S32380

[70] Moul JW. Timely diagnosis of testicular cancer. The Urologic Clinics of North America. 2007;34(2):109-117.

DOI: 10.1016/j.ucl.2007.02.003

[71] Rovito MJ, Cavayero C, Leone JE, Harlin S. Interventions promoting testicular self-examination (TSE) performance: A systematic review. American Journal of Men's Health. 2015;9(6):506-518. DOI: $10.1177 / 1557988314555360$

[72] Steadman L, Quine L. Encouraging young males to perform testicular self-examination: A simple, but effective, implementation intentions intervention. British Journal of Health Psychology. 2004;9(4):479-487. DOI: $10.1348 / 1359107042304551$

[73] Moul JW, Paulson DF, Dodge RK, et al. Delay in diagnosis and survival in testicular cancer: Impact of effective therapy and changes during 18 years. The Journal of Urology. 1990;143:520. DOI: 10.1016/s0022-5347(17)40007-3

[74] Hernes EH, Harstad K, Fossa SD. Changing incidence and delay of testicular cancer in southern Norway (1981-1992). European Urology. 1996;30:349-357

[75] Wishnow KI, Johnson DE, Preston WL, Tenney DM, Brown BW. Prompt orchiectomy reduces morbidity and mortality from testicular carcinoma. British Journal of Urology. 1990;65:629-633. DOI: 10.1111/j.1464410x.1990.tb14834.x

[76] Huyghe E, Muller A, Mieusset R, Bujan L, Bachaud JM, Chevreau C, et al. Impact of diagnostic delay in testis cancer: Results of a large populationbased study. European Urology. 2007;52(6):1710-1716. DOI: 10.1016/j. eururo.2007.06.003

[77] Nikzas D, Champion AE, Fox M. Germ cell tumors of testis: Prognostic factors and results. European Urology. 1990;18:242. DOI: 10.1159/000463922 
[78] Chapple A, Ziebland S, McPherson A. Qualitative study of men's perceptions of why treatment delays occur in the UK for those with testicular cancer. The British Journal of General Practice. 2004;54(498):25-32

[79] Smith LK, Pope C, Botha JL. Patients' help-seeking experiences and delay in cancer presentation: A qualitative synthesis. The Lancet. 2005;366(9488):825-831. DOI: $10.1016 /$ S0140-6736(05)67030-4

[80] Oliver RT. Factors contributing to delay in diagnosis of testicular tumours. British Medical Journal. 1985;290(6465):356. DOI: $10.1136 /$ bmj.290.6465.356

[81] Pedersen AF, Olesen F, Hansen RP, Zachariae R, Vedsted P. Social support, gender and patient delay. British Journal of Cancer. 2011;104(8):1249. DOI: $10.1038 /$ bjc. 2011.87

[82] Bosl GJ, Vogelzang NJ, Goldman A, Fraley EE, Lange PH, Levitt SH, et al. Impact of delay in diagnosis on clinical stage of testicular cancer. Lancet. 1981;2:970-972. DOI: 10.1016/ s0140-6736(81)91165-x

[83] American Cancer Society [Internet]. 2004. Available from: http://www. cancer.org/ [Accessed: March 10, 2019]

[84] Ward KD, Vander Weg MW, Read MC, Sell MA, Beech BM. Testicular cancer awareness and self-examination among adolescent males in a community-based youth organization. Preventive Medicine. 2005;41(2):386398. DOI: 10.1016/j.ypmed.2005.02.003

[85] Ugurlu Z, Akkuzu G, Karahan A, et al. Testicular cancer awareness and testicular self -examination among university students. Asian Pacific Journal of Cancer Prevention. 2011;12(3):695-698

[86] Cook R. Teaching and promoting testicular self-examination. Nursing
Standard. 2000;14(24):48-54. DOI: 10.7748/ns2000.03.14.24.48.c2774

[87] Rovito MJ, Leone JE, Cavayero CT. "Off-label" usage of testicular selfexamination (TSE): Benefits beyond cancer detection. American Journal of Men's Health. 2018;12(3):505-513. DOI: $10.1177 / 1557988315584942$

[88] Canadian Task Force on the Periodic Health Examination. Canadian Guide to Clinical Preventive Health Care. Ottawa: Canada Communication Group; 1994. pp. 892-898. DOI: $10.1177 / 1557988315584942$

[89] Cronholm PF, Mao JJ, Nguyen GT, Paris RT. A dilemma in male engagement in preventive services: Adolescent males' knowledge and attitudes toward testicular cancer and testicular self-exam. American Journal of Men's Health. 2009;3(2):134-140. DOI: $10.1177 / 1557988308315071$

[90] Murphy WG, Brubaker RG. Effects of a brief theory-based intervention on the practice of testicular selfexamination by high school males. The Journal of School Health. 1990;60:459462. DOI: 10.1111/j.1746-1561.1990. tb05977.x 


\title{
The Role of MRI-TRUS Fusion Biopsy in the Diagnosis of Clinical Significant Prostate Cancer (CsPca)
}

\author{
Benelli Andrea, Vaccaro Chiara, Guzzo Sonia, \\ Varca Virginia and Gregori Andrea
}

\begin{abstract}
Despite its limitations, ultrasound-guided biopsy is still the "gold standard" for the diagnosis of prostate cancer (PCa). Multiparametric magnetic resonance imaging (mp-MRI) plays an increasingly important role in patients with prior negative biopsy; several studies report an improved clinically significant prostate cancer (Cs PCa) detection rate for MRI-targeted biopsy compared to the standard biopsy. There are currently three techniques for the MRI-targeted biopsy: the cognitive registration, the software-assisted fusion registration, and the in-bore biopsy. The best MRI-targeted biopsy technique is still a matter of debate in literature; however, MRI/TRUS fusion-guided biopsy is often described as the most accurate and cost-effective approach; we describe the technique and its results.
\end{abstract}

Keywords: fusion biopsy, prostate cancer, prostate biopsy, prostate magnetic resonance, PI-RADS score

\section{Introduction}

Prostate cancer is the most common cancer expected to occur in men, accounting for $19 \%$ of the new cancer cases diagnosed worldwide [1, 2].

Currently, the only way to make a definitive diagnosis of prostate cancer is considered to be the prostate biopsy and the subsequent histopathological examination. For many years, the transrectal ultrasound (TRUS)-guided biopsy has been considered the gold standard in the diagnosis of prostate adenocarcinoma. This standard technique makes use of random 12-cores to sample the entire prostate gland [3].

The criteria for submitting patients to prostate biopsy are either a persistently elevated/rising prostate-specific antigen (PSA) level or an abnormal digital rectal examination (DRE). Prostate biopsy may also be recommended on the basis of the pathologic results of previous biopsy specimens: men who are found to have a highgrade prostatic intraepithelial neoplasia (HG-PIN), atypical small acinar proliferation (ASAP), or low-risk prostate cancer should be subjected to a follow-up biopsy [2]. The TRUS-guided biopsy has significant limitations; several nonmalignant conditions of the prostate (such as inflammation, prostatitis, and benign prostatic 
hyperplasia) can appear hypoechoic, and some carcinoma can appear isoechoic [4]. A cancer detection rate (DR) of 33-57\% can be achieved with the standard biopsy, and following the first negative biopsy, the detection rate decreases further [5]. Furthermore, the standard biopsy may lead to an underdiagnosis of clinically significant prostate cancers, missing $50-80 \%$ of cases [6]. The multiparametric magnetic resonance imaging plays nowadays an increasingly important role in the diagnostic approach to prostate cancer. It provides anatomic and functional images allowing detection and localization of the suspicious lesions that could harbor prostate cancer.

Several studies indicate that the MRI-targeted biopsy approach improves the overall and clinically significant PCa detection rate. It also strongly reduces the number of clinically insignificant prostate cancers diagnosed, therefore preventing overtreatment.

According to the European Association of Urology (EAU) guidelines, an mpMRI evaluation and a subsequent MRI-targeted biopsy should be recommended for patients with persistent clinical suspicion of prostate cancers even if a previous standard biopsy has provided negative results. Based on the guideline recommendations, if the targeted and standard biopsies are used in conjunction, significantly better results can be achieved [7].

The role of mp-MRI in the diagnostic pathway of biopsy-naïve patients is instead still a matter of debate.

\section{Technology and techniques}

\subsection{Interpretation and reporting of multiparametric MRI}

The magnetic resonance imaging (MRI) has been used for locoregional staging in patients with proven prostate cancers since the 1980s [8]. The multiparametric protocol has been introduced to discriminate nonmalignant tissue and potentially cancerous lesions. Since its introduction, the field of PCa diagnosis has been revolutionized.

According to the European Society of Urogenital Radiology (ESUR) guidelines, the multiparametric MRI protocol should include three MRI modalities: triplanar T2-weighted (T2W) sequences, axial diffusion-weighted imaging (DWI) with apparent diffusion coefficient (ADC) mapping, and dynamic contrast-enhanced images (DCE) $[8,9]$.

To standardize the evaluation and reporting of prostate mp-MRI examinations, a consensus-based guideline, known as Prostate Imaging Reporting and Data System (PI-RADS) version 1, was introduced in 2012. Most recently, a revised version of the document (PI-RADS v2) was published.

One of the main aims of the PI-RADS v2 document was to develop categories summarizing the levels of suspicion; each detected lesion in the prostate gland is assigned a score that goes from 1 to 5 . The 5-point scoring, based on the likelihood that MRI findings correlate with the presence of Cs PCa, is defined as follows:

1. very low risk (clinically significant PCa is highly unlikely to be present)

2. low risk (clinically significant PCa is unlikely to be present)

3. intermediate risk (the presence of clinically significant PCa is equivocal) 
The Role of MRI-TRUS Fusion Biopsy in the Diagnosis of Clinical Significant...

DOI: http://dx.doi.org/10.5772/intechopen.85243

4. high risk (clinically significant PCa is likely to be present)

5. very high risk (clinically significant PCa is highly likely to be present)

According to PI-RADS v2, a cancer is considered to be clinically significant when Gleason score (GS) $>7$, and/or tumor volume $>0.5 \mathrm{ml}$, and/or an extraprostatic extension is diagnosed $[8,9]$.

A meta-analysis related to the diagnostic accuracy of PI-RADS v2 shows that the PCa detection sensitivity is 0.85 and the specificity is 0.71 [10].

The most significant difference between PI-RADS v1 and PI-RADS v2 is that DWI and T2W are used as the primary determining sequences, respectively, for peripheral zone (PZ) and transitional zone (PZ) (refer to Tables 1 and 2), while DCE plays a limited role in the detection of PZ lesions classified as PI-RADS 3. Likewise, when a TZ lesion has a T2W score 3, DWI may increase the likelihood that the finding corresponds to a score 4.

Another significant difference is that a size criterion (smaller or larger than $1.5 \mathrm{~cm}$ ) is taken into account by PI-RADS v2 to differentiate score 4 from 5 in both the peripheral and transitional zones. Moreover, a 39-sector map has been introduced to locate the suspicious findings $[8,9]$. This has led to an improvement of the interdisciplinary communications between radiologists and urologists.

Following the PI-RADS score assignment to the suspicious lesion, the region of interest (ROI) detected through mp-MRI can be biopsied to confirm the diagnosis.

\begin{tabular}{|c|c|c|}
\hline $\begin{array}{l}\text { DWI } \\
\text { score }\end{array}$ & Peripheral zone lesion & PI-RADS category \\
\hline 1 & No abnormality on ADC and high b-value DWI & 1 \\
\hline 2 & Indistinct hypointense on ADC & 2 \\
\hline 3 & $\begin{array}{l}\text { Focal mildly/moderately hypointense on ADC and isointense/mildly } \\
\text { hyperintense on high b-value DWI }\end{array}$ & $\begin{array}{l}3 \text { if DCE is negative } \\
4 \text { if DCE is positive }\end{array}$ \\
\hline 4 & $\begin{array}{l}\text { Focal markedly hypointense on ADC and markedly hyperintense on } \\
\text { high b-value DWI; }<1.5 \mathrm{~cm} \text { in greatest dimension }\end{array}$ & 4 \\
\hline 5 & $\begin{array}{c}\text { Same as } 4 \text {, but }>1.5 \mathrm{~cm} \text { in greatest dimension or definite } \\
\text { extraprostatic extension/invasive behavior }\end{array}$ & 5 \\
\hline
\end{tabular}

Table 1

PI-RADS v2 categories assignment to peripheral zone lesions based on the scoring of DWI sequence.

\begin{tabular}{|c|c|c|}
\hline $\begin{array}{l}\text { T2W } \\
\text { score }\end{array}$ & Transition zone lesion & PI-RADS category \\
\hline 1 & Homogeneous intermediate signal intensity (normal) & 1 \\
\hline 2 & Circumscribed hypointense or heterogeneous encapsulated nodules & 2 \\
\hline 3 & $\begin{array}{l}\text { Heterogeneous signal intensity with obscured margins } \\
\text { Includes others that do not qualify as } 2,4 \text {, or } 5\end{array}$ & $\begin{array}{c}3 \text { if DWI score is }<4 \\
4 \text { if DWI score is } 5\end{array}$ \\
\hline 4 & $\begin{array}{l}\text { Lenticular or noncircumscribed, homogeneous, moderately } \\
\text { hypointense, and }<1.5 \mathrm{~cm} \text { in greatest dimension }\end{array}$ & 4 \\
\hline 5 & $\begin{array}{c}\text { Same as } 4 \text {, but }>1.5 \mathrm{~cm} \text { in greatest dimension or definite } \\
\text { extraprostatic extension/invasive behavior }\end{array}$ & 5 \\
\hline
\end{tabular}

Table 2

PI-RADS v2 categories assignment to transitional zone lesions based on the scoring of $T 2 W$ sequence. 
Several studies recommend that the MRI-targeted biopsy be performed for findings classified as PI-RADS 4 and 5 [11-13]. According to the ESUR guidelines, biopsy for PI-RADS 3 lesions may or may not be appropriate. Clinical factors should be considered for lesions pertaining to this category. For findings with PI-RADS 1 or 2, biopsy is not recommended [8,9].

\subsection{Methods of MRI-targeted biopsy}

There are currently three techniques for the MRI-targeted biopsy: the cognitive registration, the software-assisted fusion registration and the in-bore biopsy [14-17]. This paragraph provides an overview of the pro and cons of these techniques (Table 3).

In the cognitive registration, also known as visual registration, a prebiopsy $\mathrm{mp}-\mathrm{MRI}$ is performed to localize the suspicious lesions. The targeted biopsy is then performed using TRUS guidance with the objective of estimating the area where the lesion is $[14,15]$.

Despite its low cost, the cognitive registration technique is strictly operatordependent and is more prone to errors when compared to the other techniques. In addition, with this technique it is not possible to track the location of each biopsy core $[15,18]$.

In the software-assisted fusion registration, known as MRI/TRUS fusion-guided biopsy, the region of interest is identified in the mp-MRI images. Through a specific software platform, the MRI images are fused with the real-time ultrasound images $[14,17,19]$.

The targeted prostate biopsy based on mp-MRI and TRUS imaging combine the advantages of both techniques, i.e., the superior sensitivity of MRI for targeting suspicious lesions and the practicality of TRUS $[5,18]$. The greater reproducibility, high precision, and lower operator dependence represent some of the main advantages of the MRI/TRUS fusion-guided biopsy [17].

Various fusion platforms are currently registered by the Food and Drug Administration (FDA), which differ with respect to image registration (rigid or elastic), tracking (electromagnetic tracking, mechanical position encoders, and image-based software tracking) and biopsy approaches (transrectal or transperineal) [19].

In our institution the MRI/TRUS fusion-guided biopsy is performed in an outpatient setting; we use the BioJet system (DK Technologies $\mathrm{GmbH}$ ) which is one of the most approved systems by the FDA [19] (Figure 1).

\begin{tabular}{lll}
\hline Techniques & Advantages & Disadvantages \\
\hline Cognitive registration & - Low cost & - Operator-dependent \\
& - Additional training not & - Less accurate \\
& required & \\
\hline MRI/TRUS fusion-guided & • High precision & - Additional software platform required \\
biopsy & - Less operator-dependent & - Specialized operators required \\
\hline In-bore biopsy & - High precision & - Few sampled cores can be taken \\
& & - Specialized MRI equipment and \\
& & operators required \\
& & - High cost \\
& & Long time required \\
\hline
\end{tabular}

Table 3.

Comparison between the three techniques for the MRI-targeted biopsy. 
T2 traversal MRI images are used to contour the prostate and the lesions; then, the system fuses the marked MRI images with live transrectal ultrasound on both the axial and sagittal image planes to guarantee the best needle placement.

During the biopsy procedure, the TRUS probe is fixed to a stepper provided with position sensors that transmit the exact position of the probe to the software.

The location of biopsy cores can be tracked and recorded on a 3D map of the prostate, and a report of the cores collected is provided at the end of the procedure; it guarantees reproducible re-biopsies which is a very important advantage particularly for patients in active surveillance (Figures 2-5).

The system supports both transrectal and transperineal biopsies depending on the surgeon preference; the transperineal route with patients placed in lithotomy position is our preferred approach. All biopsy samples are obtained after a local anesthesia with $2 \%$ lidocaine and ropivacaine. At least three biopsy cores from each lesion are taken. Standard 12-core biopsies from the lateral and medial aspects of the base, mid, and apical prostate are taken during the same procedure.

With the in-bore biopsy technique the target lesion is biopsied with the patient placed in a fixed position inside the mp-MRI scanner.

Unlike the MRI/TRUS fusion-guided biopsy, the in-bore biopsy procedure is performed and tracked under MRI fluoroscopy guidance; real-time ultrasound images are not used. A transrectal, transperineal or transgluteal approach can be used during the in-bore biopsy $[14,15]$.

One of the main advantages of this technique is the high precision of the targeted cores as the high-quality MRI images provide a visual feedback of the biopsy needle localization $[12,15,16]$. However, the significant time required in the MRI scanner and the availability of specialized MRI equipment make the costs associated with this technique higher than the others [14-16].

Even if the determination of the most effective MRI-targeted biopsy technique is still a matter of debate in literature, some authors have concluded that the MRI/

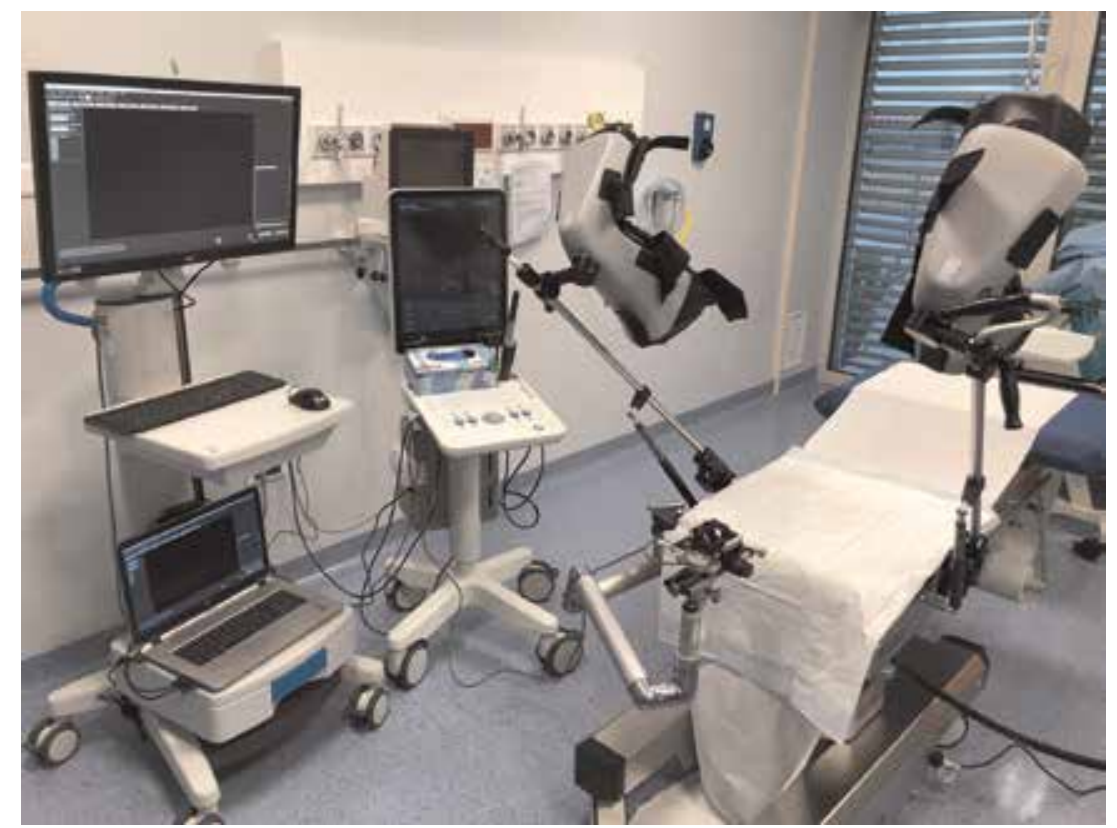

Figure 1.

Biojet system. 


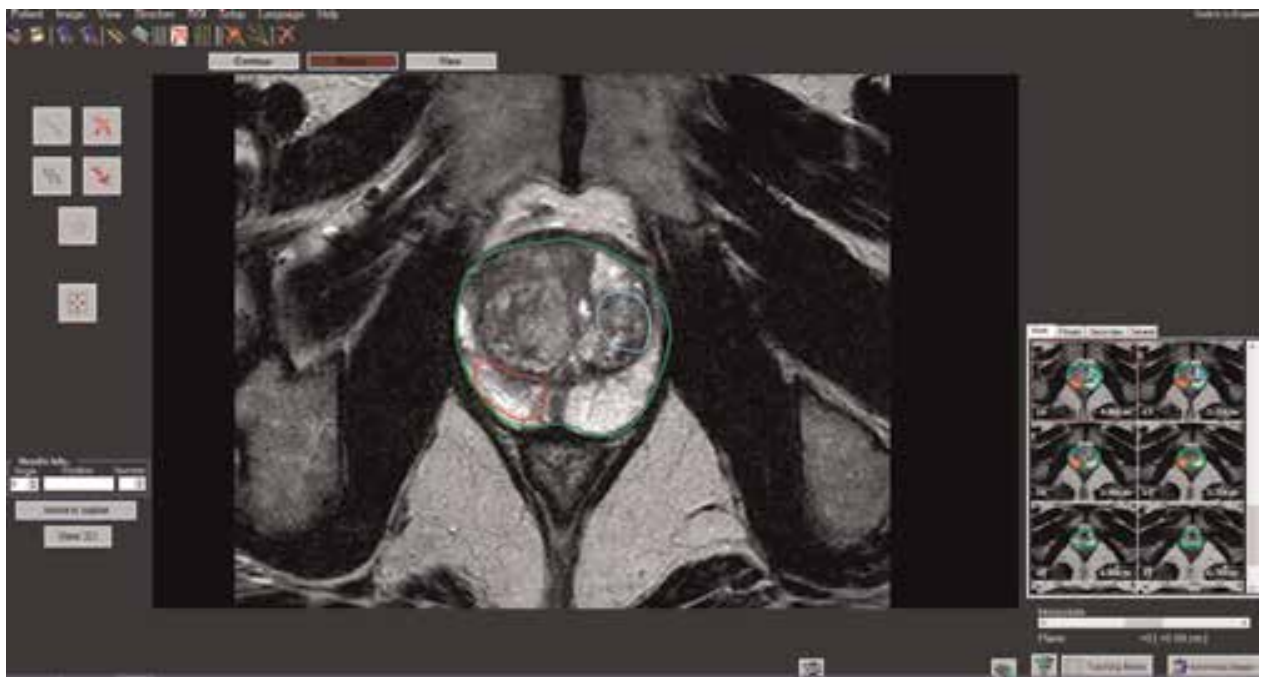

Figure 2.

Lesions contour.

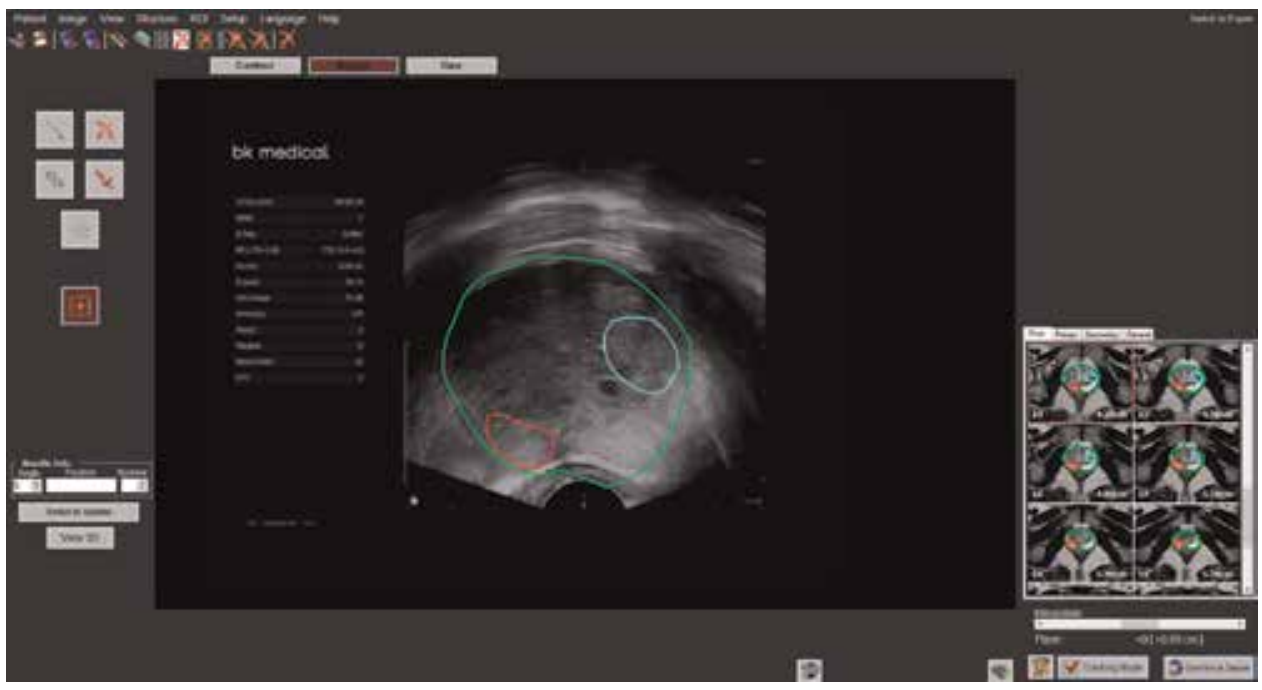

Figure 3 .

Fusion process trasverse.

TRUS fusion-guided biopsy is much more accurate and cost-effective than the other techniques [3, 14, 20-22].

Oberlin et al. have recently compared the MRI/TRUS fusion biopsy with the cognitive approach. About 231 patients have been enrolled in the study. The study shows that the targeted biopsy has a greater overall detection rate for prostate cancer (48.1 vs. $34.6 \%$ ) and clinically significant PCa when compared with cognitive registration [20]. Similar results were obtained by Cool that performed a study on 100 patients with the objective of comparing targeted biopsy accuracies of cognitive registration using 2D or 3D TRUS guidance with MRI/TRUS fusion biopsy. The detection rate of cognitive registration, with both 2D and 3D TRUS probe, appears to be lower than that achieved through the MRI/TRUS fusion biopsy, with less than $50 \%$ of the clinically significant PCa successfully sampled (48 and $45 \%$, respectively, for 2D and 3D TRUS). Even when the Cs PCa is successfully 


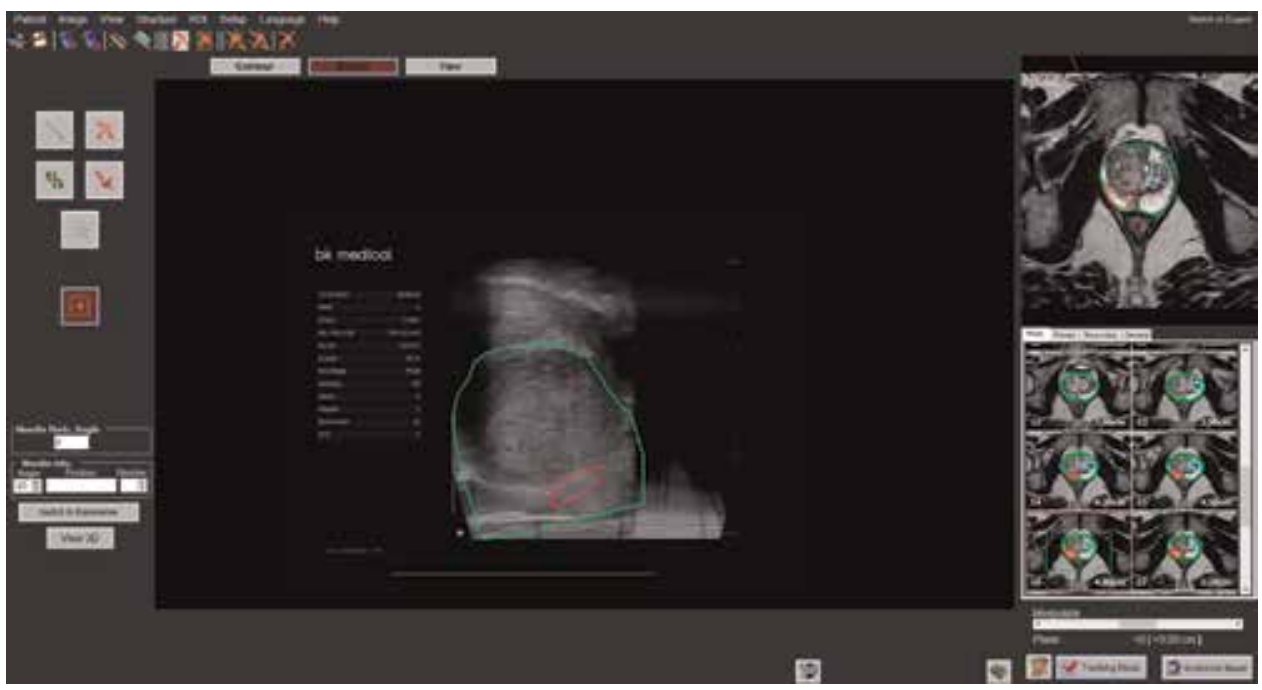

Figure 4 .

Fusion process sagittal.

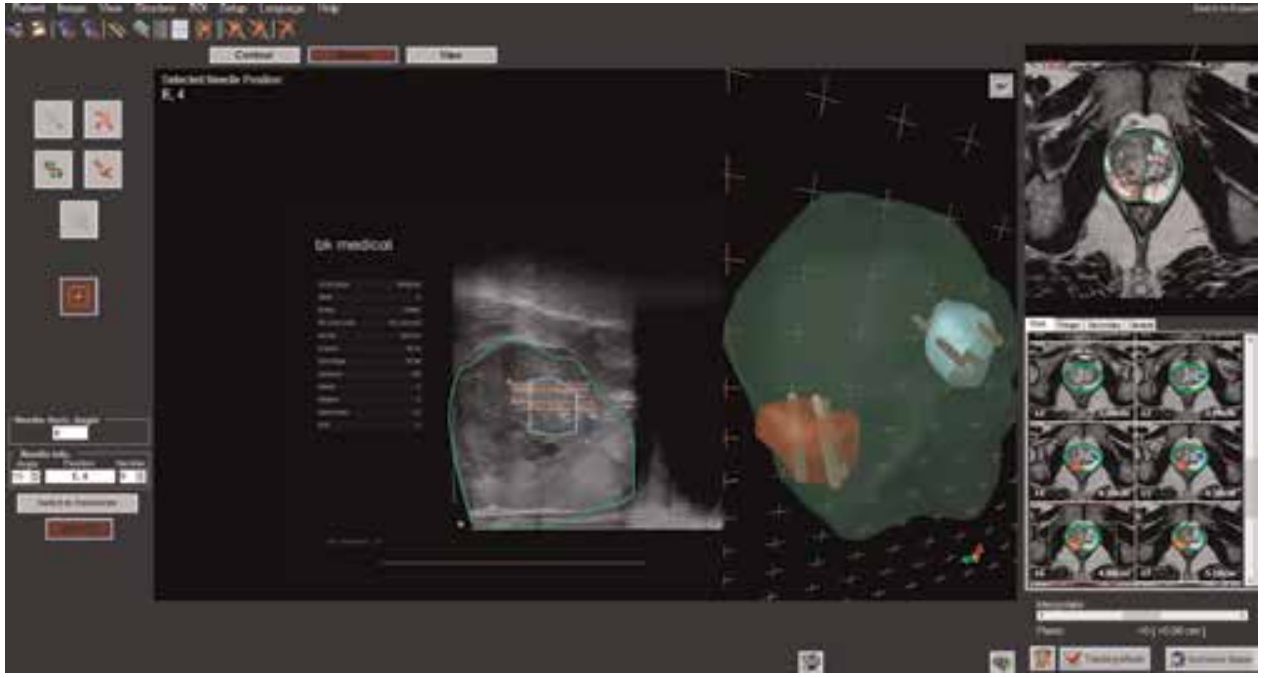

Figure 5 .

Biopsy.

sampled by cognitive registration, the percentage of cancerous tissue detected by the MRI/TRUS fusion biopsy in each biopsy core was significantly higher [21].

A randomized trial was carried out on 210 patients to compare the MRI/TRUS fusion biopsy and the in-bore technique [23]. No significant difference in the overall and Cs PCa detection rates was observed between the two groups; the first constituted of 104 patients that were subjected to fusion biopsy (39 and 32\%, respectively, for the PCa and Cs PCa detection rate), while an in-bore biopsy was performed on the other 106 patients (37 and 29\%, respectively, for the PCa and Cs PCa detection rate). This is in agreement with the study performed by Vanderink et al. according to which there is no significant difference in the detection rate between the two biopsy techniques [24].

It should be noted however that, due to its significant costs, the in-bore technique is less commonly adopted than visual registration and fusion biopsy. 


\subsection{Route of biopsy}

The route of prostate biopsy (transrectal, transperineal, or transgluteal) may differ between the various operators, but the transrectal (TR) and transperineal (TP) are the two primary approaches through which the prostate tissue can be taken $[15,16]$.

The TP biopsy is performed with the patient in the lithotomy position with the needle passing through the perineum skin; the TR biopsy is instead performed in the left lateral decubitus with the knees and hips flexed $90^{\circ}$ and the needle passing through the anterior rectal wall [25].

Both the TP and TR biopsies are very effective in diagnosing PCa and provide a superimposable detection rate. However, the TP approach allows a better sampling of the lesions located in the anterior part of the gland, therefore resulting in a greater percentage of PCa of the anterior zone compared with the TR approach (86.7 vs. $46.7 \%)$ [26, 27].

Even if there is no significant difference between the TP and TR biopsies in terms of the overall complication rate, rectal bleeding and infection-related complications are more frequently observed when adopting the TR approach [25, 26, $28,29]$. As the access to the prostate is via the rectal mucosa, the TR biopsy increases the likelihood of introducing rectal flora into the urinary tract and the blood circulation. Most of the reported infections result from Escherichia coli [29]. The overall risk of infectious complications, including bacteriuria, bacteremia, fever, urinary tract infections and sepsis may be up to $6.3 \%[15,28]$.

The likelihood of infections may be reduced by adopting the TP biopsy approach $[15,28]$. To further minimize infectious complications, patients are required to have antibiotic prophylaxis [28].

According to the EAU guidelines, quinolones are recommended as the first-line option: ciprofloxacin is prescribed in more than $90 \%$ of cases. Although no different outcomes were observed between oral and systemic administration, a single oral dose is usually preferred. In the event of antimicrobial resistance to quinolones, alternative antibiotics of choice are cephalosporins and aminoglycosides [28].

On the other hand, pain management is more challenging with the TP approach [26]. The average VAS score, used to measure the symptom severity and pain control, is higher than that related to the TR biopsy. To ensure pain control, the TP biopsy is usually performed under local anesthesia of both the perineum skin and the periprostatic region $[25,26,29]$.

Another issue to consider is that the TP-targeted biopsy is a relatively complex procedure requiring a longer learning curve.

In conclusion, the choice of the biopsy method depends on several factors, such as lesion localization, patients' risk factors, operators' preference, and technique availability.

\section{Outcomes}

\subsection{Overall results}

Urologists frequently face the dilemma of patients with a negative prostate biopsy and an elevated PSA value or a suspicious digital rectal examination (DRE) [2].

Prior to the introduction of the MRI/TRUS fusion biopsy, patients with negative TRUS-guided biopsies were regularly subjected to multiple biopsy procedures. This approach resulted in a higher detection rate of insignificant low-grade tumors, 
therefore increasing overtreatment. The MRI/TRUS fusion biopsy is considered to be a significant enhancement through which the weaknesses of the systematic random biopsy can be overcome. Through the use of the mp-MRI for the identification of suspicious lesions and the execution of the subsequent targeted biopsy, a greater number of prostate cancers can be detected [3, 6, 30-34].

The most significant strength of the targeted biopsy, when compared to the standard technique, is related to its improved detection capability of Cs PCas needing a definitive treatment. Another advantage relates to the possibility of avoiding biopsy for patients with a normal mp-MRI therefore reducing the detection of clinically insignificant cancers and preventing overtreatment of indolent tumors.

A summary of the results in terms of the overall and Cs PCa detection rates in the available literature is provided in Table 4 . The systematic review performed by Valerio et al. is aimed to compare the standard and MRI/TRUS fusion biopsy in terms of detection rate and efficiency [3]. The overall detection rate reported is 43.4 and $50.5 \%$, respectively, whereas the detection rate for clinically significant PCa is 23.6 and $33.3 \%$, respectively. The above study also shows that a considerable number of Cs PCas can be detected only if a targeted biopsy is performed, particularly if the anatomical locations of cancer are the transition zone and the anterior fibromuscular stroma [35].

Moreover, according to Valerio et al., fewer core samples (9.2 vs. 37.2\%) are required to detect the same number of clinically significant cancers making the targeted approach less uncomfortable for patients [3].

In another study involving more than 1000 patients, Siddiqui et al. show that the standard and targeted biopsies have diagnosed a similar number of prostate cancers (469 vs. 461). The significant difference highlighted is that the MRI/TRUS fusion biopsy has diagnosed a greater percentage $(+30 \%)$ of high-risk cancers and a lower percentage $(-17 \%)$ of low-risk cancers than the standard biopsy [30]. Similar results were obtained by other recent studies [12, 13, 35-37].

However, the diagnostic accuracy of the MRI/TRUS fusion-guided biopsy does not allow the prostate standard biopsy to be avoided: the combined execution of the standard and targeted biopsy will result in the detection of a greater number of PCa cases $[30,36,38]$.

The most significant predictive factor for the detection of prostate cancers through the targeted biopsy is the ROI grade. As several studies have demonstrated, the likelihood of diagnosing clinically significant PCas increases with the PI-RADS score, i.e., the greater is the PI-RADS score, the higher is the probability of detecting PCas $[12,13,36,37,39,40]$.

The study performed by Borkowetz et al., including 625 patients subjected to standard and MRI/TRUS fusion-guided biopsies, shows that PCa was detected in 20, 33 and $70 \%$ of patients with PI-RADS 3, 4 and 5 lesions, respectively [37].

These results are consistent with the data recently published by Kasivisvanathan and Cash $[13,39]$. In particular, the Cs PCa detection rates resulting from the latter study were 16.8, 46.1 and $84.7 \%$, respectively, for PI-RADS categories 3, 4 and 5 [39]. Based on the above, the ESUR guidelines recommend that an MRI-targeted biopsy be performed in patients with PI-RADS 4 and 5 lesions $[8,9]$. The management of PI-RADS 3 lesions still remains a challenge. An mp-MRI presenting PIRADS 3 lesions should be assessed considering clinical parameters such as PSA density (PSAD) and total PSA value [36, 33]. An increased PSA density, i.e., the PSA level related to the total prostate volume, is considered to be the most significant clinical predictive factor for prostate cancers. Some studies recommend that the patient should be subjected to targeted biopsy if the PSA density $>0.10 \mathrm{ng} / \mathrm{ml} / \mathrm{cc}$ [33]. 


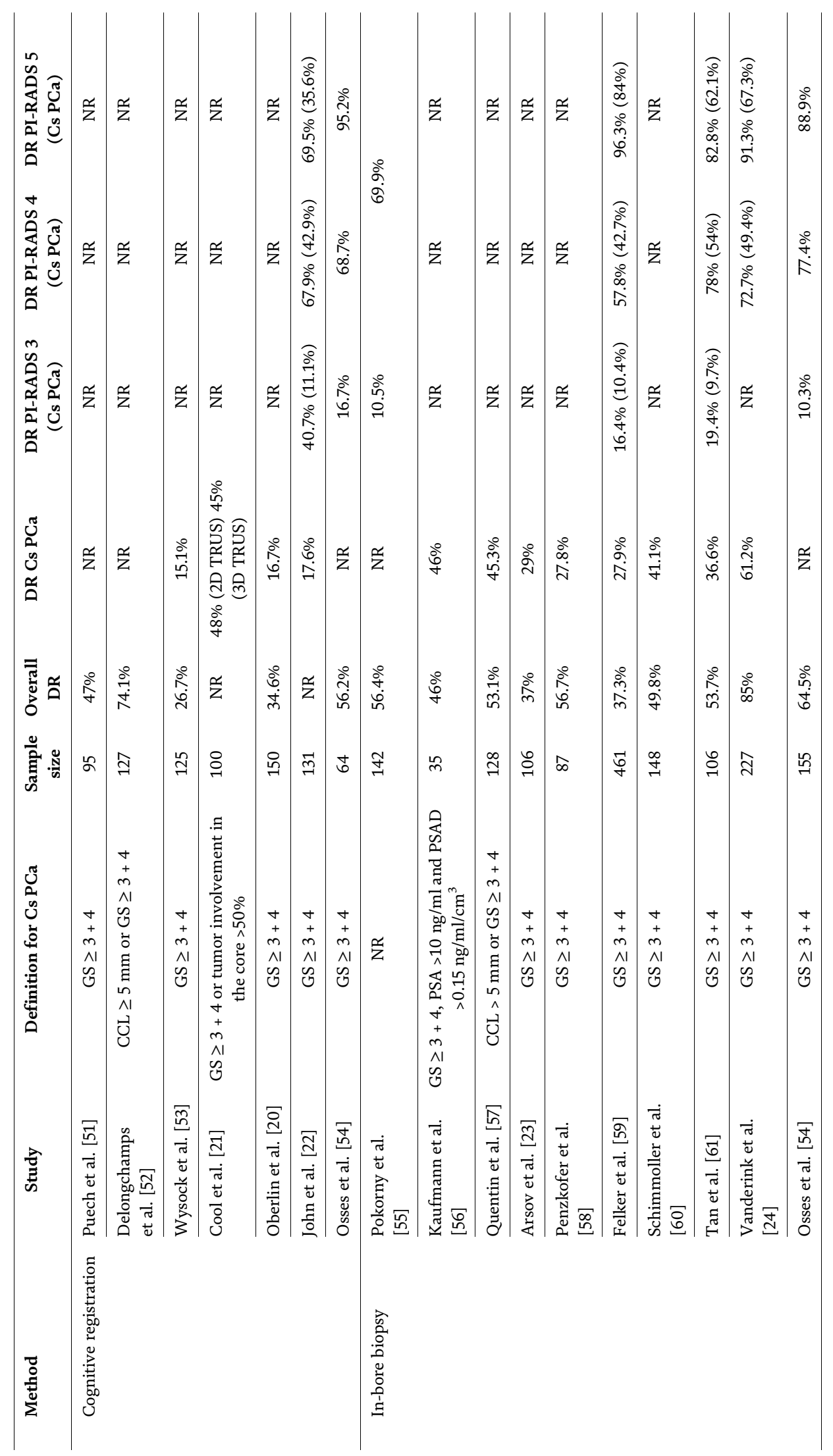


The Role of MRI-TRUS Fusion Biopsy in the Diagnosis of Clinical Significant...

DOI: http://dx.doi.org/10.5772/intechopen.85243

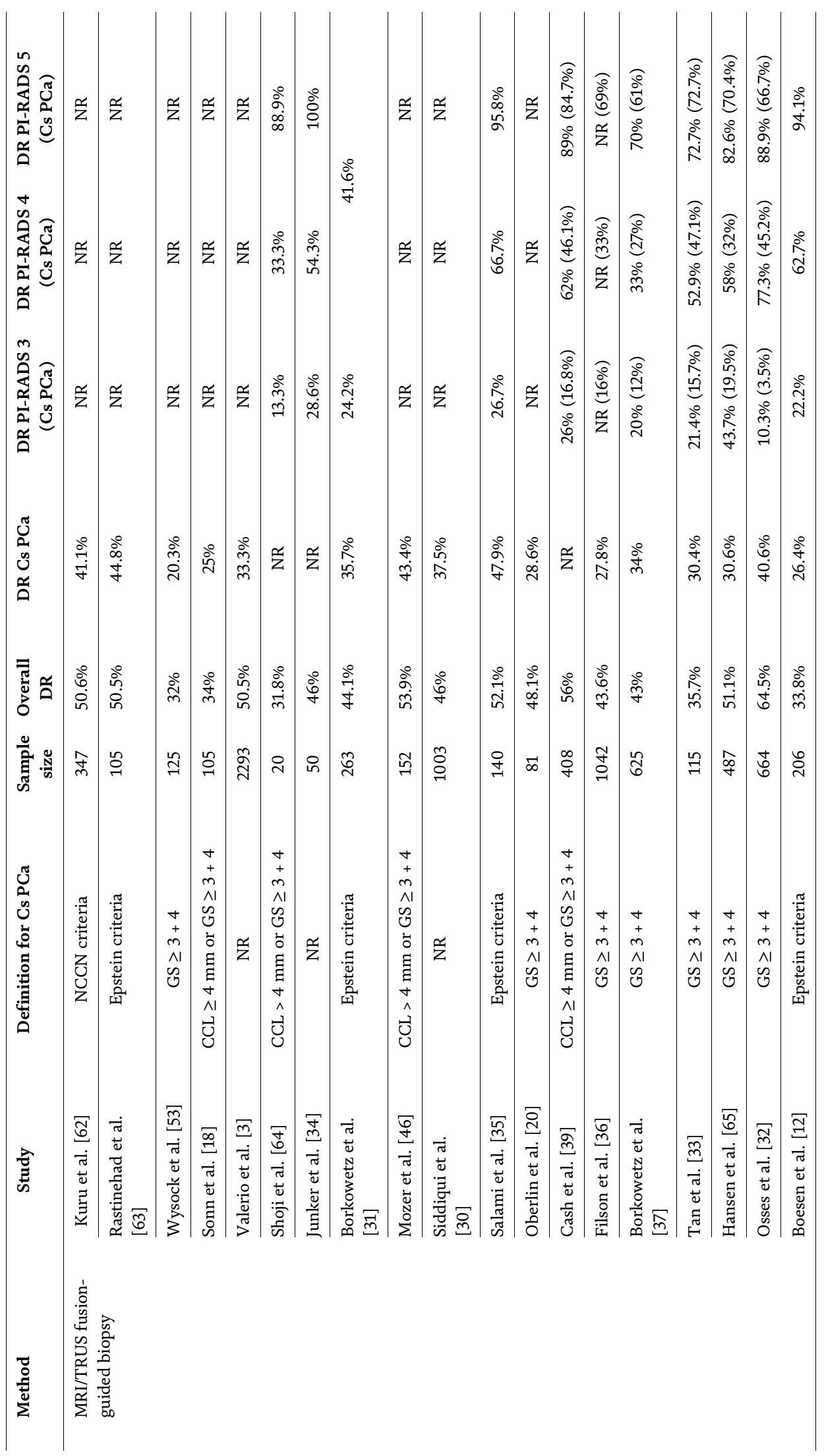


Male Reproductive Health

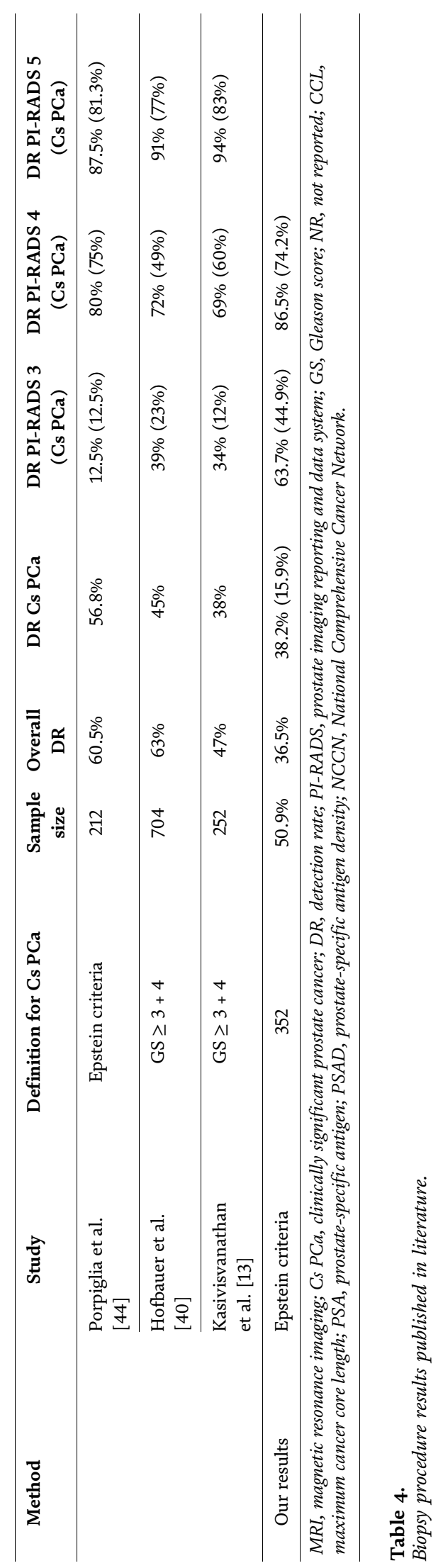


Another issue to consider is that, prior to the introduction of the MRI/TRUS fusion biopsy, literature did not describe a strong concordance between biopsy and radical prostatectomy Gleason score (GS). A significant pathological GS (pGS) upgrading, when compared with that of standard biopsy specimens (bGS), was observed in $50 \%$ of patients, while up to $80 \%$ of patients were downgraded [41, 42].

As the GS is a significant decision-making tool for patient treatment, its correct attribution is absolutely essential [2, 41].

With the introduction of the MRI/TRUS fusion biopsy, a high consistency between bGS and pGS has been achieved. Its accuracy in predicting the pathological GS allows minimizing the risk of possible cancer upgradings or downgradings [37, 42].

The MRI/TRUS fusion biopsy superior performance has been demonstrated by Porpiglia. About 246 patients subjected to robot-assisted RP were enrolled. For $91.5 \%$ of patients the anatomopathological results of surgical specimens were consistent with those achieved through biopsy cores. Also, with the targeted biopsy, the GS upgrading and downgrading was 7.8 and $0.8 \%$, respectively, significantly lower than the rates achieved with the standard biopsy (39.3 and 6.8\%, respectively) [42].

\subsection{Naïve-biopsy patients}

The current guidelines of the European Association of Urology and National Institute for Health and Care Excellence (NICE) recommend that an mp-MRI evaluation and a subsequent targeted biopsy be performed in patients with a persistent clinical suspicion of PCa (elevated PSA level and/or abnormal DRE) after a previous negative biopsy $[7,43]$.

The use of mp-MRI as the primary diagnostic tool for biopsy-naïve patients is controversial. However, recent studies support the excellent performance of mpMRI in the detection of PCa in biopsy-naïve patients [30, 38, 44-46].

A clinical trial was recently performed with 212 biopsy-naïve patients randomly assigned to either the targeted or the standard biopsy group. Results shows that targeted biopsy provides a greater detection rate for both PCa (50.5 vs. 29.5\%) and clinically significant PCa (43.9 vs. 18.1\%) [44]. These results agree with those achieved by a multicentric trial involving 214 biopsy-naïve patients with at least one suspicious lesion detected through mp-MRI [38].

Although further confirmation is required, men who have never been biopsied before may benefit from the use of mp-MRI as a preliminary test. In case of a positive MRI, the combined execution of MRI/TRUS fusion and standard biopsies would then be recommended and improve the detection of CsPca [38, 45].

A critical issue to consider are the economic resources required if the MRI were used as the primary diagnostic tool in all patients with clinical suspicious of PCa. Nevertheless, recent analyses have shown that mp-MRI for the initial detection of PCa appears to be cost-effective when compared with repeated standard biopsies [38, 45].

\subsection{Patients on active surveillance}

Active surveillance (AS) is the strategy of choice in men with localized and very low/low-risk prostate cancer to avoid or delay treatment that might not be immediately necessary [47-49].

Even if there is still no definitive agreement with regard to the selection criteria for AS candidates, a widely accepted criteria is based on the following: clinical T1c or T2a, PSA $<10 \mathrm{ng} / \mathrm{ml}$, fewer than two to three positive cores with $<50 \%$ cancer 
involvement of every positive core, and GS $3+3$ [7]. Patients fulfilling this criteria may benefit from AS, reducing treatment-related complications without compromising their survival.

AS consists of a close disease monitoring through clinical and histological parameters: commonly used tools are serial PSA measurements, DRE, and repeat biopsies [2, 7]. If biochemical or histological evidence of cancer progression is observed, a radical treatment will then be proposed $[2,47,48]$.

The main limitation associated with the AS protocol is the risk of underestimating the extent and aggressiveness of prostate cancer. Some authors have reported that TRUS-guided biopsies may lead to an underestimation in one third of cases $[47,48,50]$.

mp-MRI is currently emerging as a significant diagnostic tool through which the above risk can be minimized. It can be used in one of the three following stages: at the time of initial diagnosis of men with low-risk cancer, before confirmatory biopsy and during follow-up [49].

At the time of initial diagnosis, the mp-MRI is much more accurate in the identification and characterization of prostate cancers, resulting in a more accurate patients enrollment for the AS protocol. Its use is recommended to rule out significant PCas that were missed by the initial biopsy.

Before the confirmatory biopsy, usually performed within the first year from the initial diagnosis, the mp-MRI can reveal the need to perform a targeted biopsy in addition to the commonly adopted standard biopsy. The combined use of these two techniques may lead to a more accurate evidence of disease progression [47-49]. This is in line with the review performed by Schoots et al. [48] according to which the combined execution of targeted and standard biopsies resulted in $27 \%$ cancer upgrading. It is therefore recommended that both biopsy techniques be adopted at the stage of the confirmatory biopsy $[48,49]$.

During the follow-up period, a yearly mp-MRI might allow the annual biopsy to be avoided for those patients with stable MRI findings. The repeat biopsy should be performed only in the event that a disease progression is detected by the mp-MRI [47]. It should be noted however that there is still no definitive agreement on the use of the mp-MRI as a replacement for the repeat biopsy during the follow-up period [49].

\section{Key points}

- For many years the TRUS-guided biopsy has been considered as the gold standard in the diagnosis of PCa. Even if the ultrasound-based imaging is a great tool for guiding a biopsy needle, it cannot identify regions of interest that could harbor PCa in all cases. This is the reason why in the last decade, the research activities have focused on the development of imaging methods that can differentiate between noncancerous tissue and malignant lesions with greater accuracy.

- The introduction of mp-MRI as an imaging modality for the detection and localization of regions of interest has nowadays revolutionized the way through which PCa is managed and treated. According to the ESUR guidelines, the mpMRI protocol should include T2W, DWI, and DCE sequences.

- PI-RADS v2 was introduced by the ESUR to standardize the evaluation and reporting of mp-MRI examinations. This 5-point scoring system is based on the likelihood that MRI findings correlate with the presence of Cs PCa. 
- According to the EAU guidelines, an mp-MRI followed by an MRI-targeted biopsy should be recommended for patients with persistent clinical suspicion of prostate cancer (elevated PSA level and/or abnormal DRE) after a previous negative standard biopsy.

- mp-MRI is currently emerging as a significant diagnostic tool in patients on active surveillance protocol both for the enrollment of patients with low-risk indolent disease and before the confirmatory biopsy.

- The role of mp-MRI in the management of biopsy-naïve patients is still a matter of debate. However, its diagnostic accuracy is such that recent studies support the use of mp-MRI as a preliminary test in patients with no prior biopsies.

- The cognitive registration, software-assisted fusion registration, and in-bore biopsy are the techniques currently available for the MRI-targeted biopsy. The MRI/TRUS fusion-guided biopsy appears to be the most accurate and costeffective approach when compared with other biopsy procedures.

- A greater number of prostate cancers can be diagnosed through the MRItargeted biopsy, resulting in an increased overall detection rate. The great advantage of this technique is that it increases the detection rate of Cs PCas, reducing the detection of clinically insignificant cancers.

- The MRI-targeted biopsy has been shown to be more accurate in predicting the pathological GS, providing a strong consistency between bGS and pGS. The rate of a possible cancer underestimation or overestimation is therefore minimized.

\section{Acknowledgements}

Funder: TECNOGAMMA snc; Corso Lombardia 75; San Mauro Torinese; Italy.

\section{Conflict of interest}

The authors declares that there is no conflict of interest. 


\section{Author details}

Benelli Andrea*, Vaccaro Chiara, Guzzo Sonia, Varca Virginia and Gregori Andrea Department of Urology, ASST Rhodense, G. Salvini Hospital, Milan, Italy

*Address all correspondence to: abenelli@asst-rhodense.it

\section{IntechOpen}

(C) 2019 The Author(s). Licensee IntechOpen. This chapter is distributed under the terms of the Creative Commons Attribution License (http://creativecommons.org/licenses/ by/3.0), which permits unrestricted use, distribution, and reproduction in any medium, provided the original work is properly cited. (c) BY 
The Role of MRI-TRUS Fusion Biopsy in the Diagnosis of Clinical Significant...

DOI: http://dx.doi.org/10.5772/intechopen.85243

\section{References}

[1] Siegel R, Miller K, Jemal A. Cancer statistics, 2018. CA: A Cancer Journal for Clinicians. 2018;69:7-34

[2] Wein A, Kavoussi L, Partin A, Peters C. Campbell-Walsh Urolog. 10th ed. Saunders: Elsevier; 2012

[3] Valerio M, Donaldson I, Emberton $\mathrm{M}$, et al. Detection of clinically significant prostate cancer using magnetic resonance imaging-ultrasound fusion targeted biopsy: A systematic review. European Urology. 2015;68:8-19

[4] Sarkar S, Das S. A review of imaging methods for prostate cancer detection.

Biomedical Engineering and

Computational Biology. 2016;7(S1):1-15

[5] Gayet M, van der Aa A, Beerlage HP, et al. The value of magnetic resonance imaging and ultrasonography (MRI/ US)-fusion biopsy platforms in prostate cancer detection: A systematic review. BJU International. 2016;117: 392-400

[6] $\mathrm{Wu}$ J, Ji A, Xie B, et al. Is magnetic resonance/ultrasound fusion prostate biopsy better than systematic prostate biopsy? An updated meta- and trial sequential analysis. Oncotarget. 2015; 6(41):43571-43580

[7] Mottet NN, Bellmunt J, Bolla M, et al. EAU-ESTRO-SIOG guidelines on prostate cancer. Part 1: Screening, diagnosis, and local treatment with curative intent. European Urology. 2017;71(4):618-629

[8] Weinreb JC, Barentsz JO, Choyke PL, et al. PI-RADS prostate imaging reporting and data system: 2015 , version 2. European Urology. 2016;69:16-40

[9] Barentsz J, Weinreb J, Verma S, et al. Synopsis of the PI-RADS v2 guidelines for multiparametric prostate magnetic resonance imaging and recommendations for use. European

Urology. 2016;69:41-49

[10] Zhang L, Tang M, Chen S, et al. A meta-analysis of use of prostate imaging reporting and data system version 2 (PI-RADS V2) with multiparametric MR imaging for the detection of prostate cancer. European Radiology. 2017;27(12):5204-5214

[11] Rosenkrantz A, Verma A, Choyke P, et al. Prostate magnetic resonance imaging and magnetic resonance imaging targeted biopsy in patients with a prior negative biopsy: A consensus statement by AUA and SAR. The Journal of Urology. 2016;196:1616-1618

[12] Boesen L, Nørgaard N, Løgager V, et al. A prospective comparison of selective multiparametric magnetic resonance imaging fusion-targeted and systematic transrectal ultrasoundguided biopsies for detecting prostate cancer in men undergoing repeated biopsies. Urologia Internationalis. 2017; 99:384-391

[13] Kasivisvanathan V, Rannikko A, Borghi M, et al. MRI-targeted or standard biopsy for prostate-cancer diagnosis. The New England Journal of Medicine. 2018;278(19):1767-1777

[14] Giganti F, Moore C. A critical comparison of techniques for MRItargeted biopsy of the prostate. Translational Andrology and Urology. 2017;6(3):432-443

[15] Kongnyuy MM, George AKA, Rastinehad A, Pinto P. Magnetic resonance imaging-ultrasound fusionguided prostate biopsy: Review of technology, techniques, and outcomes. Current Urology Reports. 2016;17(4):32

[16] Robertson N, Emberton M, Moore C. MRI-targeted prostate biopsy: A 
review of technique and results. Nature Reviews. Urology. 2013;10:589-597

[17] Bjurlin M, Rosenkrantz A, Taneja S. MRI-fusion biopsy: The contemporary experience. Translational Andrology and Urology. 2017;6(3):483-489

[18] Sonn G, Margolis D, Marks L. Target detection: Magnetic resonance imagingultrasound fusion-guided prostate biopsy. Urologic Oncology. 2014;32(6): 903-911

[19] Tewes S, Hueper K, Hartung D, et al. Targeted MRI/TRUS fusion-guided biopsy in men with previous prostate biopsies using a novel registration software and multiparametric MRI PIRADS scores: First results. World Journal of Urology. 2015;33:1707-1714

[20] Oberlin D, Casalino D, Miller F, et al. Diagnostic value of guided biopsies: Fusion and cognitiveregistration magnetic resonance imaging versus conventional ultrasound biopsy of the prostate. Urology. 2016;92: 75-79

[21] Cool D, Zhang X, Romagnoli C, et al. Evaluation of MRI-TRUS fusion versus cognitive registration accuracy for MRI-targeted, TRUS-guided prostate biopsy. AJR. 2015;204:83-91

[22] John S, Cooper S, Breau R, et al. Multiparametric magnetic resonance imaging-transrectal ultrasound-guided cognitive fusion biopsy of the prostate: Clinically significant cancer detection rates stratified by the prostate imaging and data reporting system version 2 assessment categories. Canadian Urological Association Journal. 2018; 12(12):401-406

[23] Arsov C, Rabenalt R, Blondin D, et al. Prospective randomized trial comparing magnetic resonance imaging (MRI)-guided in bore biopsy to MRIultrasound fusion and transrectal ultrasound-guided prostate biopsy in patients with prior negative biopsy. European Urology. 2015;68:713-720

[24] Venderink W, van der Leest M, van Luijtelaar A, et al. Retrospective comparison of direct in-bore magnetic resonance imaging (MRI)-guided biopsy and fusion-guided biopsy in patients with MRI lesions which are likely or highly likely to be clinically significant prostate cancer. World Journal of Urology. 2017;35:1849-1855

[25] Guo L, Wu R, Xu H, et al.

Comparison between ultrasound guided transperineal and transrectal prostate biopsy: A prospective, randomized, and controlled trial. Scientific Reports. 2015;5:16089

[26] Tewes S, Peters I, Tiemeyer A, et al. Evaluation of MRI/ultrasound fusionguided prostate biopsy using transrectal and transperineal approaches. BioMed Research International. 2017:2176471

[27] Pepe P, Garufi A, Priolo G, Pennisi M. Multiparametric MRI/TRUS fusion prostate biopsy: Advantages of a transperineal approach. Anticancer Research. 2017;37:3291-3294

[28] Ploussard G, Scattoni V, Giannarini G, Jones J. Approaches for initial prostate biopsy and antibiotic prophylaxis. European Urology. 2015;1: 109-116. Focus

[29] Loeb S, Vellekoop A, Ahmed H, et al. Systematic review of complications of prostate biopsy. European Urology. 2013;64:876-892

[30] Siddiqui M, Rais-Bahrami S, Turkbey B, et al. Comparison of MR/ ultrasound fusion-guided biopsy with ultrasound-guided biopsy for the diagnosis of prostate cancer. Journal of the American Medical Association. 2015; 313(4):390-397

[31] Borkowetz A, Platzek I, Toma M, et al. Comparison of systematic 
transrectal biopsy to transperineal magnetic resonance imaging/ultrasound-fusion biopsy for the diagnosis of prostate cancer. BJU International. 2015;116:873-879

[32] Osses D, van Asten J, Kleft G, Tijsterman J. Prostate cancer detection rates of magnetic resonance imagingguided prostate biopsy related to prostate imaging reporting and data system score. World Journal of Urology. 2017;35:207-212

[33] Tan T, Siang Png K, Lee C, et al. MRI fusion-targeted transrectal prostate biopsy and the role of prostate-specific antigen density and prostate health index for the detection of clinically significant prostate cancer in southeast asian men. Journal of Endourology. 2017;31(11):1111-1116

[34] Junker D, Schäfer G, Heidegge I, et al. Multiparametric magnetic resonance imaging/transrectal ultrasound fusion targeted biopsy of the prostate: Preliminary results of a prospective single-Centre study. Urologia Internationalis. 2015;94: 313-318

[35] Salami S, Ben-Levi E, Yaskiv O, et al. In patients with a previous negative prostate biopsy and a suspicious lesion on magnetic resonance imaging, is a 12-core biopsy still necessary in addition to a targeted biopsy? BJU International. 2015;115: 562-570

[36] Filson C, Natarajan S, Margolis D, et al. Prostate cancer detection with magnetic resonance-ultrasound fusion biopsy: The role of systematic and targeted biopsies. Cancer. 2016;122: 884-892

[37] Borkowetz A, Platzek I, Toma M, et al. Evaluation of prostate imaging reporting and data system classification in the prediction of tumor aggressiveness in targeted magnetic resonance imaging/ultrasound-fusion biopsy. Urologia Internationalis. 2017;99(2): 177-185

[38] Borkowetz A, Hadaschik B, Platzek I, et al. Prospective comparison of transperineal magnetic resonance imaging/ultrasonography fusion biopsy and transrectal systematic biopsy in biopsy-naive patients. BJU International. 2018;121:53-60

[39] Cash H, Maxeiner A, Stephan C, et al. The detection of significant prostate cancer is correlated with the prostate imaging reporting and data system (PI-RADS) in MRI/transrectal ultrasound fusion biopsy. World Journal of Urology. 2016;34:252-232

[40] Hofbauer S, Kittner B, Maxeiner A, et al. Validation of PI-RADS version 2 for the detection of prostate cancer. The Journal of Urology. 2018;200(4):767-773

[41] Grasso A, Cozzi G, Palumbo C, et al. Concordance between biopsy and radical prostatectomy specimen Gleason score in internal external pathology facilities. Anticancer Research. 2014;34: 5585-5588

[42] Porpiglia F, De Luca S, Passera R, et al. Multiparametric-magnetic resonance/ultrasound fusion targeted prostate biopsy improves agreement between biopsy and radical prostatectomy Gleason score. Anticancer Research. 2016;36: 4833-4840

[43] Graham J, Kirkbride P, Cann K, et al. Prostate cancer: Summary of updated NICE guidance. BMJ. Jun 8, 2014;348:f7524

[44] Porpiglia F, Manfredi M, Mele F, et al. Diagnostic pathway with multiparametric magnetic resonance imaging versus standard pathway: Results from a randomized prospective study in biopsy-naive patients with 
suspected prostate cancer. European Urology. 2017;72:282-288

[45] Maxeiner A, Kittner B, Blobel C, et al. Primary magnetic resonance imaging/ultrasonography fusion-guided biopsy of the prostate. BJU International. 2018;122(2):211-218

[46] Mozer P, Roupret M, Le Cossec C, et al. First round of targeted biopsies using magnetic resonance imaging/ ultrasonography fusion compared with conventional transrectal ultrasonography-guided biopsies for the diagnosis of localised prostate cancer. BJU International. 2015;115:50-57

[47] Barrett T, Haider M. The emerging role of MRI in prostate cancer active surveillance and ongoing challenges.

AJR - Genitourinary Imaging. 2017;208: 131-139

[48] Schoots I, Nieboer D, Giganti F, et al. Is magnetic resonance imagingtargeted biopsy a useful addition to systematic confirmatory biopsy in men on active surveillance for low-risk prostate cancer? A systematic review and meta-analysis. BJU International. 2018;122(6):946-958

[49] Briganti A, Fossati N, Catto J, et al. Active surveillance for low-risk prostate cancer: The European Association of Urology position in 2018. European Urology. 2018;74:357-368

[50] Ma T, Tosoian J, Schaeffer E, et al. The role of multiparametric magnetic resonance imaging/ultrasound fusion biopsy in active surveillance. European Urology. 2017;71:174-180

[51] Puech P, Rouviere O, Renard-Penna $R$, et al. Prostate cancer diagnosis: Multiparametric MR-targeted biopsy with cognitive and transrectal US-MR fusion guidance versus systematic biopsy - prospective multicentre study. Radiology. 2013;268:461-469
[52] Delongchamps N, Peyromaure M, Schull A, et al. Prebiopsy magnetic resonance imaging and prostate cancer detection: Comparison of random and targeted biopsies. The Journal of Urology. 2013;189:493-499

[53] Wysock J, Rosenkrantz A, Huang $\mathrm{W}$, et al. A prospective, blinded comparison of magnetic resonance (MR) imaging-ultrasound fusion and visual estimation in the performance of MR-targeted prostate biopsy: The PROFUS trial. European Urology. 2014; 66:343-351

[54] Osses D, van Asten J, Tijsterman J. Cognitive-targeted versus magnetic resonance imaging-guided prostate biopsy in prostate cancer detection. Current Urology. 2017;11:182-188

[55] Pokorny M, de Rooij M, Duncan E, et al. Prospective study of diagnostic accuracy comparing prostate cancer detection by transrectal ultrasoundguided biopsy versus magnetic resonance (MR) imaging with subsequent MR-guided biopsy in men without previous prostate biopsies. European Urology. 2014;66:22-29

[56] Kaufmann S, Kruck S, Kramer U, et al. Direct comparison of targeted MRI-guided biopsy with systematic transrectal ultrasound-guided biopsy in patients with previous negative prostate biopsies. Urologia Internationalis. 2015; 94(3):319-325

[57] Quentin M, Blondin D, Arsov C, et al. Prospective evaluation of MRIguided in-bore prostate biopsy versus systematic transrectal ultrasound transrectal ultrasound guided prostate biopsy in biopsy-naïve men with elevated prostate-specific antigen levels. The Journal of Urology. 2014;192(5): 1374-1379

[58] Penzkofer T, Tuncali K, Fedorov A, et al. Transperineal in-bore 3-T MR imaging-guided prostate biopsy: A 
prospective clinical observational study. Radiology. 2015;274(1):170-180

[59] Felker E, Lee-Felker S, Fel J, et al. In-bore magnetic resonance-guided transrectal biopsy for the detection of clinically significant prostate cancer. Abdominal Radiology. 2016;41(5): 954-962

[60] Schimmöller L, Blondin D, Arsov C, et al. MRI-guided in-bore biopsy: Differences between prostate cancer detection and localization in primary and secondary biopsy settings. AJR Genitourinary Imaging. 2016;206:92-99

[61] Tan N, Lin W, Khoshnoodi P, et al. In-bore 3-T MR-guided transrectal targeted prostate biopsy: Prostate imaging reporting and data system version 2 - based diagnostic performance for detection of prostate cancer. Radiology. 2017;283(1):130-139

[62] Kuru T, Roethke M, Seidenar J, et al. Critical evaluation of magnetic resonance imaging targeted, transrectal ultrasound guided transperineal fusion biopsy for detection of prostate cancer. The Journal of Urology. 2013;190: 1380-1386

[63] Rastinehad A, Turkbey B, Salami S, et al. Improving detection of clinically significant prostate cancer: Magnetic resonance imaging/transrectal ultrasound fusion guided prostate biopsy. The Journal of Urology. 2014; 191:1749-1754

[64] Shoji S, Hiraiwa S, Endo J, et al. Manually controlled targeted prostate biopsy with real-time fusion imaging of multiparametric magnetic resonance imaging and transrectal ultrasound: An early experience. International Journal of Urology. 2015;22:173-178

[65] Hansen N, Kesch C, Barre T, et al. Multicentre evaluation of targeted and systematic biopsies using magnetic resonance and ultrasound image-fusion guided transperineal prostate biopsy in patients with a previous negative biopsy. BJU International. 2017;120: 631-638 



\title{
The Pelvic Health Physical Therapy and the Prostatectomy
}

\author{
Mauro Luis Barbosa Junior, Ericka Kirsthine Valentin \\ and Karoline Camargo Bragante
}

\begin{abstract}
Considering prostate adenocarcinoma, the cancer of higher incidence in men, having as treatment of choice the prostatectomy, and the high prevalence of urinary incontinence (UI) and erectile dysfunction (ED) after the surgery, the physiotherapy becomes an eligible treatment for such alterations. The rehabilitation of postprostatectomy effort urinary incontinence is considered a recommendation grade B. Erectile dysfunction has as its first line of treatment penile vacuum therapy. Pelvic health physical therapy has as its main tool the rehabilitation of the pelvic floor muscles (PFM), which can be assisted by biofeedback and electrotherapy. The training of these muscles accelerates the recovery process of post-prostatectomy stress urinary incontinence and has greater therapeutic relevance when the physiotherapeutic treatment is initiated in the pre-surgical period. Post-micturition dribble is also treated by training the pelvic floor muscles. Urinary urgency, associated or not with incontinence, can be treated with electrotherapy, which is considered second or third line of treatment. Erectile rehabilitation has two physical resources of treatment, physical therapy, one through the vacuum and the other of the shock wave. Both penile vacuum therapy and shock wave therapy are considered the first line of treatment in the approach to erectile dysfunction.
\end{abstract}

Keywords: physical therapy, erectile dysfunction, urinary incontinence, prostate cancer, prostatectomy

\section{Pelvic health physiotherapy}

Pelvic health physiotherapy has as its main therapeutic pillar the rehabilitation of the pelvic floor muscles (PFM). Since the work done by the gynecologist Arnold Kegel in the 1940s, the treatment of the pelvic floor has been evolving and being recognized by the scientific community. Kegel began his work in this area by creating exercises for PFM for the treatment of female urinary incontinence. When assumed by physical therapy, the exercises became perineal kinesiotherapy, currently having a gold standard of recommendation grade $\mathrm{A}$, in the rehabilitation of female urinary stress incontinence (SUI).

With evolution, the "Kegel exercises" also reached male pelvic health. However, because the anatomy and pathophysiology of urinary incontinence (UI) in men are distinct from women, which also influences the lower prevalence of SUI in the male population, around $10 \%$, the effectiveness of the treatment may be variable, when compared to the woman's. The detrusor hyperactivity associated with 
urinary urgency with or without loss of urine is commonly associated with prostatic disease, needing to be investigated, with the pelvic floor having little influence on male urinary incontinence.

\section{Rehabilitation of urinary continence after prostatectomy}

The prostatectomized patient has transient SUI, and maintenance of this condition may still prevail in $8 \%$ of patients, 2 years after surgery. The prevalence that precedes this period is variable, since it depends on the definition of incontinence, severity, degree of discomfort, and methodology for evaluating the magnitude. The evolution of surgical techniques, with regard to the greater or less prevalence of post-prostatectomy UI, has still been the subject of debate [1].

When talking about robot-assisted laparoscopic prostatectomy, the prevalence of incontinence can be influenced by the patient's preoperative characteristics, surgeon's experience, surgical technique, and methods used to collect and present data. The characteristics of patients that may influence postsurgical continence are age, body mass index, comorbidity, presence of lower urinary tract symptoms, and prostate volume [2].

The damage generated during the surgical procedure can occur in the urethral sphincter complex, in the supporting structures, or in its innervations, leading to the high prevalence of UI, being the anatomical support and pelvic innervation, important etiological factors of the loss of the continence post-prostatectomy. Excessive dissection during surgery, neurovascular bundle injury, and postoperative fibrosis also contribute negatively to the maintenance of continence. On the other hand, the maintenance of the bladder neck and fixation of the bladder-urethral anastomosis, before and after, are favorable for continence [3].

Prostate removal surgery favors stress urinary incontinence and urgency. The urgency, associated or not with incontinence, is also present in the detrusor overactivity not infrequently found in patients, making it more prevalent, since they add to the age factors, which reduces bladder complacence and prostatic enlargement, which leads to emptying dysfunction, obstructive [4].

Post-micturition dribble may also be present post-prostatectomy. There is usually no bladder alteration, but rather the inability of PFM, the bulbospongiosus muscle in particular, to eject the urinary volume contained in the ureter after the end of urination [5].

\subsection{Physiotherapeutic treatment of urinary incontinence after prostatectomy}

The prostatectomized patient has a great impact on their quality of social life and often with important limitations in their physical activities and daily life due to loss of urine. Considering the social and pathophysiological aspects of post-prostatectomy urinary incontinence (PPUI), physical therapy for male pelvic health has been offering therapeutic strategies through perineal kinesiotherapy, biofeedback, electrostimulation, behavioral therapies, and lifestyle changes [6].

\subsection{Functional assessment of the pelvic floor}

Perineal kinesiotherapy, also known as pelvic floor muscle training (PFMT), is performed after a careful functional assessment of the PFM where the muscular capacity of resistance and strength, symmetry, tone, and presence of pain are observed. This evaluation is not yet standardized for the male pelvic floor, and most of the protocols used to evaluate the female PFM are used, such as the modified 
Oxford scale, for example, which has a bidigital touch reference in the vagina and with the patient evaluated in supine. The Ortiz scale (Table 1) does not assume patient positioning and does not mention the female anatomy, being quite reasonable for the evaluation of the pelvic floor of the man.

In the inspection of the male pelvic floor, we observe the retraction of the anus and elevation of the penis, which is presented subtly. Dynamic palpation is one of the few methods, if not the only one at present, for the assessment of the pelvic floor of both sexes. The anorectal touch is necessary for the evaluation of the pubococcygeus muscle, assessing its contractile capacity bilaterally, strength, and endurance. Palpation of the perineal body can also assess muscle activity and tone [8].

The pad test can be a useful tool to quantify urinary loss. It can be 24 or 1 hour. However, there is evidence that the 24 hour pad test is statistically more relevant for PPUI assessment. The accomplishment of this one becomes important, since some authors have it like a criterion of discharge of the treatment or cure of the incontinence. It can enter such criteria from the use of a pad by day to none [9].

The voiding diary is a semi-objective method to quantify symptoms such as urinary frequency and incontinence and degree of urgency, use of absorbents, and fluid intake. Urinary volume may contribute to the diagnosis of overactive bladder (OAB) and polyuria. The diary can be carried out for 3-7 days. Although it is a level of evidence 3 and recommendation grade $\mathrm{D}$, it is recommended for the evaluation and measurement of the symptoms and discomforts of urinary incontinence, both at the beginning of treatment and to assess the impact of therapy [10].

The questionnaires, as well as the scales and index, also serve to measure some factors related to urinary incontinence, such as the severity of symptoms and quality of life. Some are more generic like Medical Outcomes Study SF-36 Health Status Profile, and others bring more specific conditions like the King's Health Questionnaire [3].

Although physical therapy is part of the pull first-line treatment offers, the urodynamic examination, requested in the failure of these primary resources, offers a functional evaluation of the lower urinary tract. There is limited evidence that the preliminary urodynamic examination influences the results of the treatment for male urinary incontinence, although it is able to distinguish the different causes of incontinence [11].

After the evaluation and a kinetic-functional diagnosis of the pelvic floor, as well as a functional diagnosis of the lower urinary tract, a therapeutic program can be developed. For pelvic health physiotherapy, the rehabilitation of urinary incontinence consists of behavioral and physical therapies, such as bladder training (BT) and the therapeutic exercises of the pelvic floor muscles, respectively.

\begin{tabular}{ll}
\hline \multicolumn{2}{l}{ Functional assessment of pelvic floor } \\
\hline 0 & No objective perineal function, even to palpation \\
\hline 1 & Objective perineal function absent, detectable only by palpation \\
\hline 2 & Weak objective perineal function, detectable by palpation \\
\hline 3 & Objective perineal function, without resistance to palpation \\
\hline 4 & $\begin{array}{l}\text { Objective perineal function and resistance not maintained by } \\
\text { palpation }\end{array}$ \\
\hline 5 & $\begin{array}{l}\text { Objective perineal function and resistance by palpation maintained } \\
\text { for more than } 5 \text { seconds }\end{array}$ \\
\hline
\end{tabular}

Table 1.

Functional assessment of pelvic floor by [7]. 


\subsection{Physiotherapeutic resources}

In bladder training, the patient is instructed on bladder function and fluid intake, including bowel habits and restriction of caffeine use, for example. Patients with independent urination may be advised of micturition habit and time. In the case of urgency and nocturnal incontinence, BT is as effective as oxybutynin, tolterodine, and solifenacin. It may also promote some improvement in frequency and nocturia when associated with other pharmacological therapies [6].

The PFMT increases urethral closure pressure and stabilizes the urethra. It can be performed with the aid of biofeedback which can be pressure, electromyography, and manual. Visual, auditory, or tactile resources are used to guide the patient in performing the contraction and relaxation of the pelvic floor musculature. Electrotherapy may be another alternative associated with PFMT. Both resources are not superior to PFMT, but when used as a combination therapy, it can favor the evolution of the condition, improving the performance and coordination of the PFM [12].

The PFMT should be offered as first-line therapy [10]. The therapeutic exercises are proposed after a thorough evaluation of the PFM, where the effective time and the repetition of the contraction, without reaching the fatigue, are determined. From there an exercise program is developed, aiming at endurance, strength, coordination, and pre-contraction of muscles.

It should be noted that during PFMT, the patient does not use accessory muscles, such as the abdominals, buttocks, and thigh adductors. The inadequate use of these muscles leads to poor perception of the effective performance of the PFM. The physiotherapist needs to guide the patient on how to perform the most effective contraction without using the accessory muscles. Although the abdominal muscles are considered accessory, the transverse abdominis muscle in particular has a synergistic function to the pelvic floor [13].

The transverse abdomen muscle and the PFM are considered postural muscles, with the support function, that is, they have predominance of tonic muscle fibers and are responsible for the maintenance of orthostatism. Performing a therapeutic exercise program for these synergistic muscles is critical to the functionality and daily life activities of the patient. These muscles activated together favor the dissipation of abdominal load, which would lead to increased intra-abdominal pressure and consequently loss of urine to the effort [14].

Biofeedback for pelvic floor rehabilitation is used to gain a greater awareness of the functions of the PFM, mainly using instruments that provide information about the activity of these muscles. Intracavitary (anal) pressure probes can be used, measuring the contraction in millimeters of mercury or electromyographic that detects the potential of muscular action in microvolt, the latter being also possible through a perineal surface electrode. Its purpose is to better muscle functionality, providing greater proprioception, consequently greater effectiveness in the coordination, strength, and endurance of the PFM [15].

Functional electral stimulation (FES) is a biphasic current transmitted from transcutaneous (Figure 1) or intracavitary (Figure 2) electrodes. The intensity of the current is given according to the patient's sensitivity, without generating any discomfort or pain [16].

Usually the contractions generated by the electric current assist the voluntary activation of the PFM. Because it is a muscle with a predominance of tonic fibers, the frequency (in hertz) used is low and the pulse width (in microseconds) higher, for example, $20 \mathrm{~Hz}$ and $700 \mu \mathrm{s}$. The contraction time is variable, on average over 4 seconds, but given individually according to the PFM functional evaluation. The resting time may be one to two times the contraction time. 


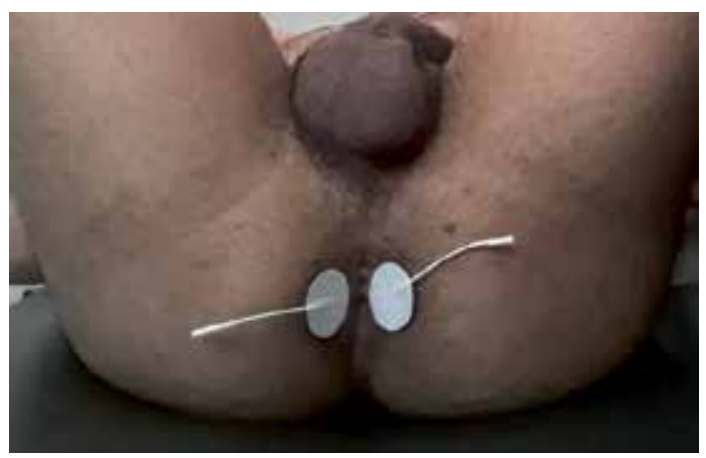

Figure 1.

Transcutaneous electrodes.

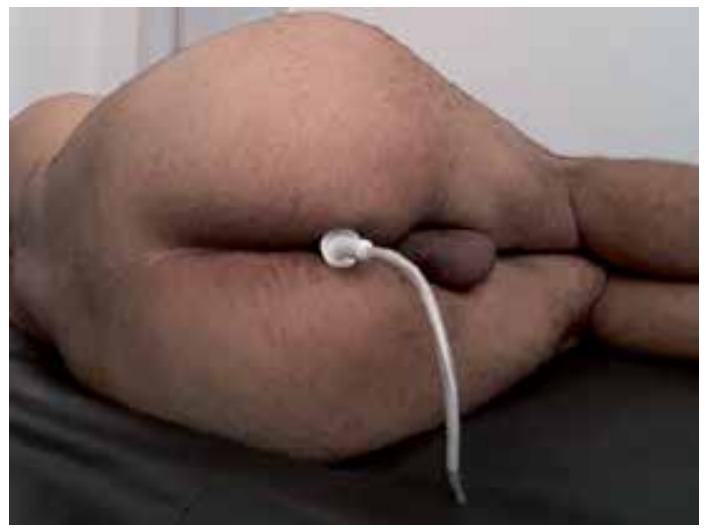

Figure 2.

Intracavitary electrode.

It is not uncommon for patients who have undergone prostatectomy to also have urinary urgency, associated or not with incontinence. Sometimes the urgency is related to a detrusor overactivity, and complaints of nocturia and polaciuria are present. OAB may already manifest even before prostate withdrawal surgery. Changes in the bladder wall, as well as the increase in prostatic volume related to age (elderly), may be related to OAB [17].

In the cases of post-prostatectomy patients who present $\mathrm{OAB}$, the electral therapy with (neuro) modulation objective should be used. A different action in PFM, the electral therapy used in this case is transcutaneous electrical nerve stimulation (TENS). Surface electrodes may be used in the parasacral (Figure 3) or tibial (Figure 4) regions. The frequency usually used varies between 5 and $10 \mathrm{~Hz}$ and the pulse width between 300 and $700 \mu$ s; the intensity is given before reaching the motor point, remaining at sensitive levels. The treatment should be performed under physiotherapeutic assistance, with prescription of the home and/or outpatient electrotherapy device. The treatment time is around 12 weeks [15].

In addition to electrotherapy, BT is also indicated. In the case of urinary urgency, it may also be performed through contraction of PFM and inhibition of voiding reflex, allowing the patient to lose the urge to urinate and being able to reach the bathroom more comfortably or delaying urination, in the case of polaciuria.

Post-micturition dribbling may also be another complaint in prostatectomized patients. This situation does not influence the function, or dysfunction, of the bladder. It occurs due to the inability of the bulbospongiosus muscle to eliminate 


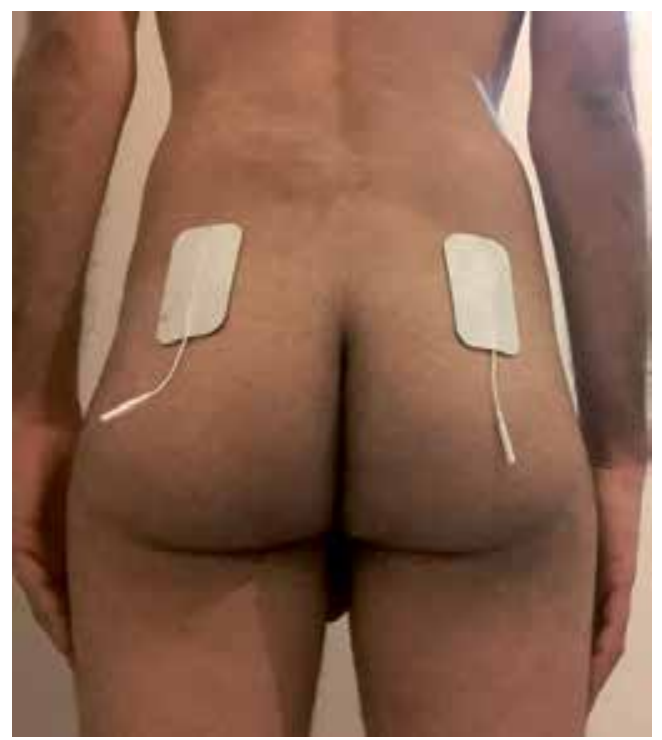

Figure 3.

Parasacral electrodes.

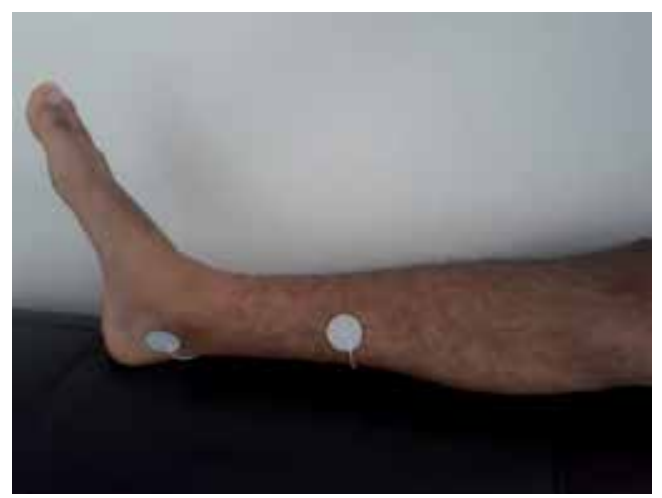

Figure 4.

Transcutaneous tibial nerve stimulation.

the voiding residue present in the bulbar urethra. The treatment consists of the therapeutic exercises of this musculature, aiming to acquire greater muscular force for the expulsion of the urine of the urethra, after the urination. The urethral milking maneuver and bulbar massage may also be associated, but the effectiveness of bulbospongiosus muscle contraction is greater [5].

The loss of urine during orgasm, climacturia, is not uncommon in these patients. The inevitable surgical damages generated in the bladder neck, as well as the event in the sympathetic fibers, responsible for contraction of the bladder neck and relaxation of the external sphincter during the ejaculation expulsion phase, are one of the suggested mechanisms for climacturia [18]. And the proposed physiotherapeutic treatment is PFMT.

\section{Rehabilitation of erectile function after prostatectomy}

Climacturia, an orgasmic dysfunction, is one of the affected aspects of the sexual quality of life of prostatectomized patients. Before it manifests, it has erectile 
dysfunction (ED), highly prevalent in the second postoperative month, reaching around $90 \%$. Complaints about the quality of erection remain frequent even after 12 months postoperatively in around $75 \%$ of patients. At the same time, the prevalence of orgasm difficulty was $45 \%$ (Table 2) [19].

When talking about the post-prostatectomy sexual quality of life, before the complaint of climacturia, which may be presumed that there is penetration, the patient usually presents with a severe erectile dysfunction. The impact on sexual life may be even greater when ED is associated with urinary loss, requiring a much more integral approach to the case, since the patient begins to have an affective distancing from the partner and consequently sexual avoidance. The sexual behavioral approach (Figure 5) is necessary in order to keep the patient stimulated sexually, within its limitations. This is the beginning of sexual rehab [20].

Once the behavioral framework is handled, the erectile rehabilitation comes to the scene. Because it is a multifactor ED, which begins with neuropraxia of the cavernous nerve, which promotes pro-apoptotic and pro-fibrotic factors in the penile tissue, thus evolving into a veno-occlusive dysfunction, resources that act in these frames are taken into account for the treatment [21].

Penile vacuum therapy (Figure 6) is a physical rehabilitation resource, therefore a physiotherapy, which aims to promote, through a negative pressure, daily erections with the protective function of the erectile tissue, in the same way that nocturnal erections did that no longer occur [22].

By getting into the place of nocturnal erections, which were daily, penile vacuotherapy also needs to be performed daily. In the Engel [22] and Raina and collaborators [23] studies, the mean time of application of the therapeutic vacuum is 10 minutes. However it is known that in 5 minutes of use, the arterial blood is equivalent to the venous one, becoming poor in oxygen. It is also known that a rest of 30-60 seconds in the vacuum normalizes penile oxygenation, suggesting that the application should be done intermittently, with rest between one application and another. The therapeutic pressure is between -150 and $-200 \mathrm{mmHg}$ [24]. The treatment time is over 6 months.

Due to the safety of the patient, the prescription and orientation of use should be made by a professional qualified to do so, thus avoiding possible intercurrences during the application, such as penile pain, edema, and hematoma. The patient is taught to perform the penile vacuotherapy, recognizing the perceptions and sensations, regarding the sensitivity, size, and color of the penis, being performed by the physiotherapist in the office, in order to make home treatment safe.

Sound therapy has been used in the treatment of ED. The main treatment currently offered is extracorporeal shock wave therapy. But it is common to the treatment by sound waves; this includes the therapeutic ultrasound, to cause mechanical stress and microtrauma in the place of its application. This vascular stress and microtrauma, which generates a shear stress, induce a cascade of biological

\begin{tabular}{llll}
\hline Sexual function & $\mathbf{2}$ Mo & $\mathbf{6} \mathbf{M o}$ & $\mathbf{1 2} \mathbf{M o}$ \\
\hline Poor erections & $88 \%$ & $80 \%$ & $67 \%$ \\
\hline Difficulty with orgasm & $62 \%$ & $51 \%$ & $45 \%$ \\
\hline Erections not firm & $90 \%$ & $84 \%$ & $75 \%$ \\
\hline Erections not reliable & $83 \%$ & $75 \%$ & $60 \%$ \\
\hline Poor sexual function & $83 \%$ & $74 \%$ & $61 \%$ \\
\hline Overall sexuality problem & $59 \%$ & $59 \%$ & $50 \%$ \\
\hline
\end{tabular}

Table 2.

Post-prostatectomy sexual disorders. 


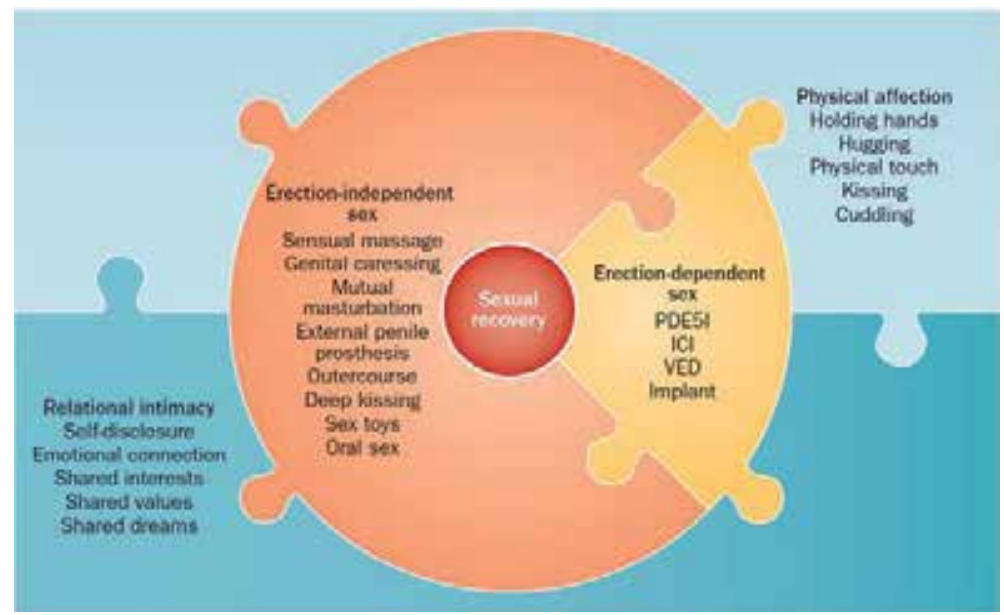

Figure 5.

ICI, intracavernosal injection; VED, vacuum erection device.

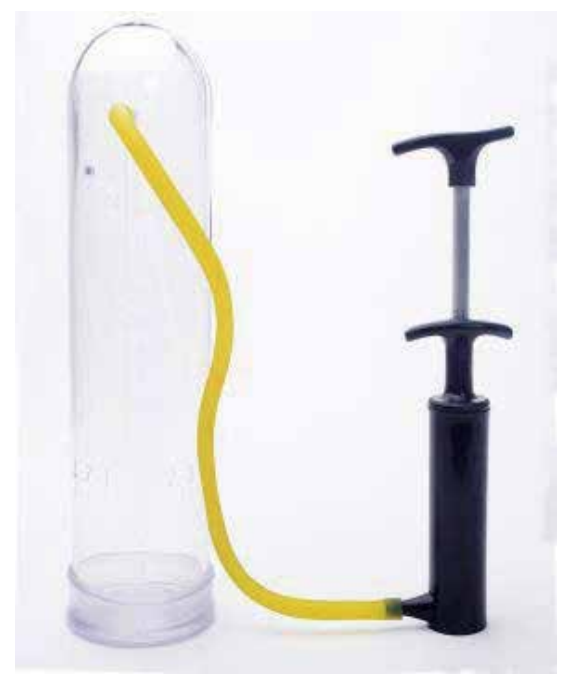

Figure 6.

Vacuum erection device.

reactions that result in the release of angiogenic factors which in turn triggers tissue neovascularization with subsequent improvement of blood supply [25].

Penile electrical stimulation (Figure 7) has also been studied for penile rehabilitation. Its action consists in the endothelial action. The current generates release of endothelium-dependent nitric oxide, leading to increased blood supply and vasodilation. Favoring the action of endothelial progenitor cells, which secrete proangiogenic factors, induces neovascularization, repair, and endothelial function. Endothelial progenitor cells release vascular endothelial growth factor, acting as a mediator of angiogenesis [26].

The erectile latency of the post-prostatectomy patient is variable in duration, and we already know the possible damage to penile erectile tissue. But from the perspective of the striated muscles, it is known that the penis muscles who have a veno-occlusive function, the ischiocavernosus and bulbospongiosus muscles (Figure 8), which, besides being in the process of sarcopenia inherent to the senility of the patient, may also pass through atrophy due to disuse. 


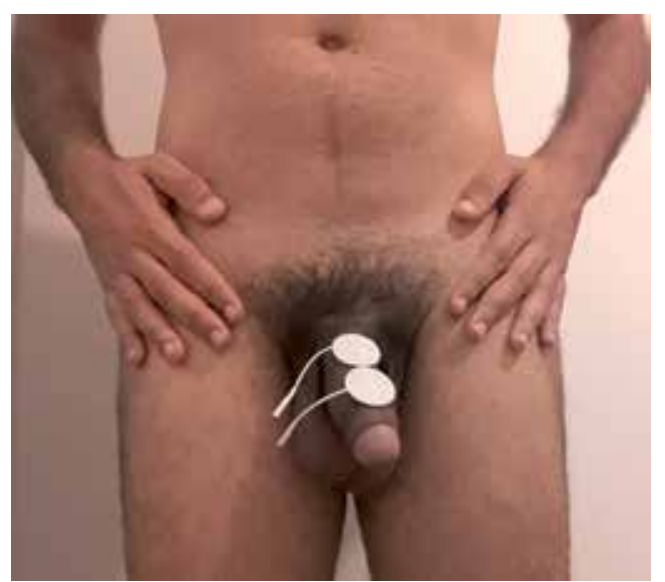

Figure 7.

Penile electrodes placement.

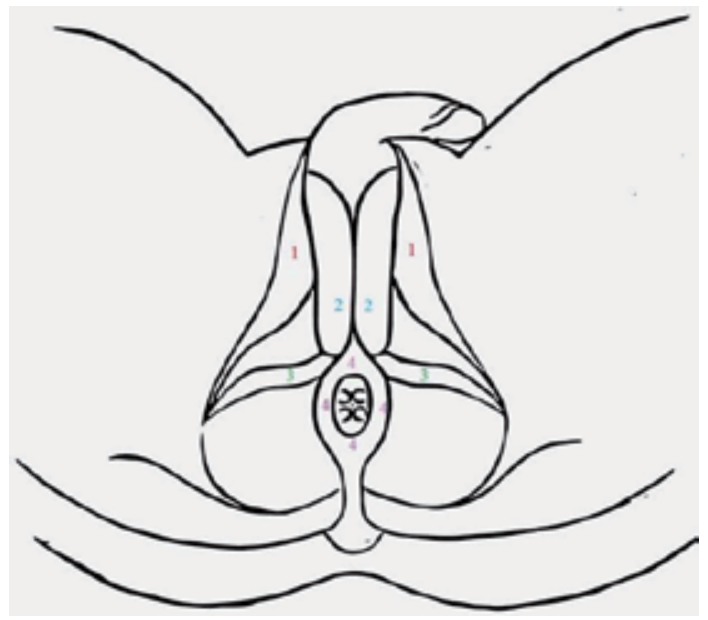

Figure 8.

Perineal muscles ((1) ischiocavernosus muscles, (2) bulbocavernosus muscle, (3) transverse perineal muscle, (4) external anal sphincter muscle).

PFMT, focusing on the penile muscles, acts on the veno-occlusion favoring penile stiffness. However, the ischiocavernosus muscle in particular does not have great relevance in the penile intumescence phase. This suggests that to activate them in a functional PFMT, the penis would need to be at least in its maximum turgidity, considering that this patient has great impairment of the postsurgical erectile function [27].

\section{Conclusion}

Several studies show the predictive factors for the evolution of both urinary incontinence and erectile dysfunction and that to date no conservative treatment has curative action in both situations. However, it is consensual in the rehabilitation process of the post-prostatectomy patient, offering treatments, based on the levels of evidence and recommendation grade, with the objective of improving the quality of life of the patient and whenever possible accelerate the recovery of continence and erectile function. 


\section{Author details}

Mauro Luis Barbosa Junior ${ }^{1 *}$, Ericka Kirsthine Valentin ${ }^{1}$ and Karoline Camargo Bragante ${ }^{2}$

1 Rio de Janeiro State University, Rio de Janeiro, Brazil

2 Federal University of Health Sciences of Porto Alegre, Porto Alegra, Brazil

*Address all correspondence to: maurolbarbosajr@gmail.com

\section{IntechOpen}

(C) 2019 The Author(s). Licensee IntechOpen. This chapter is distributed under the terms of the Creative Commons Attribution License (http://creativecommons.org/licenses/ by/3.0), which permits unrestricted use, distribution, and reproduction in any medium, provided the original work is properly cited. (cc) BY 


\section{References}

[1] Sacco E et al. Urinary incontinence after radical prostatectomy: Incidence by definition, risk factors and temporal trend in a large series with a longterm follow-up. BJU International. 2006;97(6):1234-1241

[2] Heesakkers J, Farag F, Bauer RM, Sandhu J, De Ridder D, Stenzl A. Pathophysiology and contributing factors in postprostatectomy incontinence: A review. European Urology. 2017;71(6):936-944

[3] Abrams P et al. Incontinence: 5th International Consultation on Incontinence; February 2012; Paris: ICUD-EAU. 2013. p. 2

[4] Griebling TL. Overactive bladder in elderly men: Epidemiology, evaluation, clinical effects, and management. Current Urology Reports. 2014;6:131-138

[5] Dorey G et al. Pelvic floor exercises for treating post micturition dribble in men with erectile dysfunction. Urologic Nursing. 2004;24(6):490497

[6] Nambiar AK et al. EAU guidelines on assessment and nonsurgical management of urinary incontinence. European Urology. 2018;73:596-609

[7] Ortiz OC, Gutnisky R, Nunez FC, Cotese G. Valoración dinámica de la disfunción perineal en la mujer. Propuesta de classificación. Bol Soc Latinoam Uroginecol Cir Vaginal. 1994;1(2):7-9

[8] Shull BL et al. Physical examination. In: Abrams P, Saad K, Wein A, editors. Incontinence: Proceedings of the 1st International Consultation on Incontinence. Monaco; June 28-July 1 1998

[9] Kannan P, Winser SJ, Fung B, Cheing $\mathrm{G}$. Effectiveness of pelvic floor muscle training alone and in combination with biofeedback, electrical stimulation, or both compared to control for urinary incontinence in men following prostatectomy: Systematic review and meta-analysis. Physical Therapy. 2018;98:932-945

[10] Lucas MG et al. Guidelines on Urinary Incontinence; European Association of Urology; 2014

[11] Lee $\mathrm{H}$ et al. Urodynamic Assessment of Bladder and Urethral Function Among Men with Lower Urinary Tract Symptoms After Radical Prostatectomy: A Comparison Between Men With and Without Urinary Incontinence. The Korean Urological Association; 2015

[12] Chang JI et al. Preoperative pelvic floor muscle exercise and postprostatectomy incontinence: A systematic review and meta-analysis. European Urology. Mar 2016;69(3): 460-467

[13] Neumann P, Gill V. Pelvic floor and abdominal muscle interaction: EMG activity and intraabdominal pressure. International Urogynecology Journal. 2002;13:125-132

[14] Kimiko Tajiri RN et al. Effects of Co-contraction of both transverse abdominal muscle and pelvic floor muscle exercises for stress urinary incontinence: A randomized controlled trial. Journal of Physical Therapy Science. 2014;26(8):1161-1163

[15] Anderson CA et al. Conservative management for postprostatectomy urinary incontinence. Cochrane Database of Systematic Reviews. 2015;1:CD001843

[16] Zaidan P et al. Electrical stimulation, pelvic floor muscle exercises, and urinary incontinence in post-prostatectomy patients: Controlled 
randomized double-blind experiment. International Journal of Current Research. 2016;8(11):41859-41863

[17] Abrams P et al. Evaluation and Treatment of Urinary Incontinence, Pelvic Organ Prolapse and Faecal Incontinence. 2009. p. 1

[18] Capogrosso P et al. Orgasmic dysfunction after radical prostatectomy. The World Journal of Men's Health. 2017;35(1):1-13

[19] Sanda MG et al. Quality of life and satisfaction with outcome among prostate cancer survivors. The New England Journal of Medicine. 2008;358(12):1250-1261

[20] Katz A, Dizon DS. Sexuality after cancer: A model for male survivors. The Journal of Sexual Medicine. 2016;13:70-78

[21] Salonia A et al. Prevention and management of postprostatectomy sexual dysfunctions part 2: Recovery and preservation of erectile function, sexual desire, and orgasmic function. European Urology. 2012;62(2):273-286

[22] Engel JD. Effect on sexual function of a vacuum erection device postprostatectomy. The Canadian Journal of Urology. 2011;18:5721-5725

[23] Raina R et al. Early use of vacuum constriction device following radical prostatectomy facilitates early sexual activity and potentially earlier return of erectile function. International Journal of Impotence Research. 2006;18:77-81

[24] Qian SQ et al. Vacuum therapy in penile rehabilitation after radical prostatectomy: Review of hemodynamic and antihypoxic evidence. Asian Journal of Andrology. 2016;18:446-451

[25] Xin Z et al. Clinical applications of low-intensity pulsed ultrasound and its potential role in urology.
Translational Andrology and Urology. 2016;5(2):255-266

[26] Ignarro LJ et al. Nitric oxide and cyclic GMP formation upon electrical field stimulation cause relaxation of corpus cavernosum smooth muscle. Biochemical and Biophysical Research Communications. 31 Jul 1990;170(2):843-850

[27] Lavoisier P, Roy P, Dantony E, et al. Pelvic-floor muscle rehabilitation in erectile dysfunction and premature ejaculation. Physical Therapy 2014;94:1731-1743 


\title{
Combinatorial Drug Therapy with Phytochemicals as Adjuvants in Prostate Cancer Management
}

\author{
Rajalakshmi Manikkam and Indu Sabapathy
}

\begin{abstract}
Prostate cancer is one of the leading cancers in men needs a long period for development from small lesion to become a clinical manifestation. The prostate specific antigen is a prominent tumor marker for prostate cancer. Androgens are involved in the development and progression of prostate cancer regulating the androgen receptor as androgen-dependent or androgen-independent types. The latter occurs in metastatic conditions of prostate cancer developed as hormone resistant prostate cancer (HRPC) that inappropriately activates transcription of other genes involved in molecular pathways inducing cellular proliferation and inhibiting apoptosis. Since prostate cancer is characterized by slow growth and long latency period and thus integration of phytochemicals/compounds in combination with other existing therapies have promising future to manage cancer, thus controlling the disease progression and mortality rate. Therefore, the medicinal plants therapeutic or prophylactic activities on prostate cancer exhibiting anti-androgenic effects, depleting PSA, down-regulating expression of androgen receptor, regulating cell cycle regulators have promising future to be applied as adjuvant drugs in prostate cancer treatment.
\end{abstract}

Keywords: prostate cancer, androgen receptor, PSA, systemic therapy, phytochemicals, molecular pathways

\section{Introduction}

Statistical reports revealed that prostate cancer is the third leading cause of cancer deaths in men [1] causing the life of one in every 39 men in United States. Related to prostate cancer rates in India, the rates are more than 20 times higher in US whites, more than 10 times higher in US Asian Indians/Pakistanis, seven times higher among UK South Asians and twice as high among Singapore Indians [2]. Factors escalating the risk of prostate cancer include age above 50 years, cancer incidence in family, ethnicity, modern diet, environmental factor, pollutants, etc. The role of inflammation in prostate diseases is suggested by the presence of inflammatory cells within the prostate of cancer patients [3]. The molecular mechanism responsible for inflammation mediated prostate cancer is not yet clear.

However, prostate cancer needs a long period for development from small lesion to become a clinical manifestation [4]. Tumor progression is revealed with complications in erectile dysfunction, skeletal bone pain, obstruction of lymph vessels, 
and veins causing lower body edema. The development of high-grade prostatic intraepithelial neoplasia (HGPIN) is identified as an intermediate stage between benign epithelium and the invasive malignant carcinoma at the outset of prostate cancer. Four main patterns of high-grade PIN (HGPIN) have been described as tufting, micropapillary, cribriform, and flat [5].

Prostate specific antigen (PSA), major constituent in prostatic secretion and is used for screening prostatism. PSA testing is primarily associated with benign prostatic hyperplasia (BPH), however there is only rare connectivity of patients having $\mathrm{BPH}$ to develop prostate cancer. With conditions like BPH, inflammation, and disruption of prostate basal membrane increases the permeability and releases PSA into the circulation. Prostate cancer antigen 3 (PCA3) is more specific than PSA which is an important biomarker in personalized medicine. Also analysis of urinary protein markers, such as TMPRSS2-ERG and PCA3 are helpful in early diagnosis of the disease. The other tumors markers reported as prostatic acid phosphatase (PAP), cytoskeletal proteins, and annexin I are downregulated in PIN whereas C-erbB-2 (HER-2/neu) and C-erbB-3 oncoproteins, c-met protooncogene, Bcl-2 oncoprotein, several growth factors, nitric oxide synthase, alpha-methylacyl-CoA racemase, glycoprotein A-80, and apolipoprotein D, are upregulated in PIN. The histological grading system of prostate cancer is obtained from the Gleason score [6] which provides information that score 1-5 indicates low-grade prostate cancer and score 8-10 indicates high-grade prostate cancer. Digital rectal examination (DRE), examination of PSA levels, prostate ultrasound, and prostate biopsy are the current diagnostic methods in examining the primary and metastatic stages for prostate cancer [7, 8]. Prostate cancer stages are generally classified into three categories-T category, $\mathrm{N}$ category, and $\mathrm{M}$ category. T represents the primary tumor, $\mathrm{N}$ represents the cancer that has spread to regional (nearby) lymph nodes and $M$ represents the distant metastasis cancer. The treatment strategies are administered based on the stage of cancer progression.

\section{Androgen-dependent and androgen-independent prostate cancer}

Human prostate is a walnut shaped, fibromuscular organ located beneath the urinary bladder and is made-up of several glandular and non-glandular components that are tightly fused together within a common capsule [9]. It is an exocrine gland functioning in secretion of complex proteolytic solution into the urethra during ejaculation which is important for sperm motility and nourishment. The growth and function of the prostate are regulated by androgens. The growth and development of normal prostate requires functioning androgen signaling pathway, which is regulated by hypothalamic-pituitary gonadal axis. Androgens (includes testosterone and DHT) are responsible for the male secondary sexual characteristics. Testosterone is synthesized in the testes and released into the circulation in response to specific hormonal signals regulated by GnRH, FSH, and LH. Testosterone is transported by steroid hormone binding globulin (SHBG) to the prostate, where it is converted by $5 \alpha$-reductase to its active metabolite $5 \alpha$-dihydrotestosterone (DHT).

In the prostate, androgens mediate their effects via high affinity to the androgen receptor (AR), a nuclear transcription factor that controls expression of genes involved in growth, differentiation, homeostatsis, and apoptosis. Receptor for steroid and thyroid hormones are mostly cytoplasmic/nuclear receptors and hormonereceptor complex binding to the promoter regions of responsive genes and stimulate or inhibit transcription from those genes. Nuclear receptors are ligand-inducible transcription factors that mediate the signals of a broad variety of fat-soluble hormones, including the steroid and vitamin D3 hormones, thyroid hormones retinoids. 
Upon ligand binding, AR translocates to the nucleus, binds to DNA recognition sequences, and activates transcription of genes involved in cell proliferation, apoptosis, and differentiation [10]. Androgens are involved in the development and progression of prostate cancer [11] regulating the AR. During this phase the tumors are referred to as androgen sensitive or dependent. The most common therapies done with prostate cancer patients are androgen deprivation therapy removing testicles partially or completely in addition to administration of drugs inhibiting LHRH secretion and anti-androgen therapy blocking the androgen receptor interaction.

Prostate cancer can evolve into castration resistant cancers which is independent of androgen levels [12]. The AR signaling pathway continues to be active in hormone resistant prostate cancer (HRPC) and can inappropriately activate transcription [13]. Recent studies show that cancer progression and metastasis lead to alteration in the androgen receptor pathway genes with transition of prostate cancer from the androgen dependent to independent stage [14]. Mutations in the ligandbinding domain alter the specificity of the AR enhancing the binding of estrogens, progesterone, and anti-androgens; and thereby decreasing its dependency on androgens while stimulating cell growth. In addition to AR mutations, a variety of growth factors, including insulin-like growth factor I, epidermal growth factor, and keratinocyte growth factor, can activate androgen-responsive genes via the AR, suggesting that androgen independence which occurs due to the over expression of growth factors in the local environment [15]. There are multiple evidences suggesting that estrogens are involved in prostate carcinogenesis. In worldwide the AfricanAmericans have the higher risk of prostate cancer with elevated levels of serum estrone and estradiol levels even in healthy young men [16]. CCDC62/ERAP75 is a new co-activator of ER and this protein is mainly present in the nucleus and widely expressed in many prostate cancer cell lines (PC-3, DU145, LNCaP, 22Rv1) than in the normal prostate epithelial cells (BPH-1) [17].

\section{Molecular regulations in prostate cancer}

The inappropriate expression of the growth inhibitory factors appears to contribute to prostate cancer progression. Epidermal growth factor (EGF) promotes chemo-migration of metastatic prostate cancer cells to lymph node and medullary bone sites [18]. In insulin signaling pathway, the ligand insulin binds to its receptor followed by tyrosine phosphorylation of insulin receptor substrates (IRS) by the insulin receptor tyrosine kinase. Several studies suggested that alteration in the IGF signaling axis is associated with an increased risk of prostate cancer [19]. Signal transduction proteins interact with IRS including GRB2. GRB2 is a part of the cascade including SOS, RAS, RAF, and MEK that leads to activation of MAPK and mitogenic response in the form of gene transcription.

In AKT signaling pathway, PTEN is a regulator which is down regulated to protect the cell from tumor growth. The phosphatase activity on phosphatidylinositol 3,4,5-triphosphate allows dephosphorylation of PIP3 to PIP2. The PIP2 inhibits the $\mathrm{P} 13 \mathrm{~K}$ which is the membrane bound domain. When the phosphatase activity is lost, P13K transfers its phosphate group to PDK1 and PDK2 which in turn causes phosphorylation of AKT protein and regulatory amino acids Ser473 and Thr308. This leads to activation of MDM2, P21, CASP9, mTOR genes leading to apoptosis inhibition, tumor growth, etc. Smad3 gene plays a key role in prostate cancer serving as an essential mediator of most Smad-dependent TGF-beta responses, including control of gene expression, cell growth, apoptosis, and tumor suppression. Deregulated/ enhanced expression and activation of AR in prostate carcinomas may intercept the tumor suppressor function of TGF- $\beta$ through transcriptional suppression of Smad3. 
TNFRs are activated by TNF in order to exhibit cellular response. TNF triggers the transcription of apoptotic proteins through NF- $\mathrm{kB}$ thereby achieving cell survival. Activation of TRAFs, such as TRAF2, TRAF5, and TRAF6 results in transduction of cellular response by TNFRs. In TNFRs pathway, TRAF3 acts as a repressor. APRL, BAFF, BAFF-R, BCMA, and TACI belong to the TNF superfamilies and play vital roles in immunity through $B$ cells and T cells. BAFF binds to BAFF-R, BCMA, and TACI, while APRIL bands to two of them-BCMA and TACI only. In this pathway nuclear factors $(\mathrm{NF}-\mathrm{\kappa B})$ are activated in signaling cascades. This activation process can be triggered by canonical and non-canonical pathways. The latter is activated by activation of BCMA, TCAI, and BAFF-R by BAFF. This counter activates TRAF2 and TRAF5 that signals NIK, a mitogen activated protein kinase. Once NIK is activated, phosphorylation of IKK-alpha that restrain processing NK- $\mathrm{KB} 2$ into NF- $\mathrm{\kappa B} 2$ onsets. Along with RelB, NF- $\mathrm{KB} 2$ activates $\mathrm{Bcl} 2$ or $\mathrm{Bcl}-\mathrm{XL}$ or both. Upon this activation cell survival is promoted. BAFF transcription is activated by NF- $\mathrm{KB} 2$ resulting in a positive feedback. I-kB is phosphorylated by IKK alpha, beta, and gamma which is activated by TRAF2 by canonical pathway. I-kB is disintegrated and ubiquitylated inside proteosome 26S. This process discharges NF- $\mathrm{kB} 2$ and RelA which are swiftly repositioned from cytoplasm to nucleus. Following which anti-apoptotic components, such as Bcl-2, Bcl-XL, and BFL1 are activated by transcription by NF- $\mathrm{\kappa B}$ transfactors.

In non-canonical pathway, IKK alpha is activated by its phosphorylation once NIK kinase is promoted by TRAF. NF- $\mathrm{KB} 2$ is processed from $\mathrm{p} 100$ to $\mathrm{p} 52$ by IKK alpha which is adhered to RelB. The dimer (RelB-p52-NF- $\mathrm{kB}$ ) engages in affecting gene transcription once it shifts to the nucleus. This pathway does not involve IKK beta and gamma. IKK, RelB, and NIK are mediated by TNF-R1 signal or TNF-R2 signal as well. NF- $\mathrm{KB}$ promoted cell growth and proliferation in prostate cancer cells by regulating expression of genes, such as c-myc, cyclin D1, and IL-6. Furthermore, $\mathrm{NF}-\kappa \mathrm{B}-$ mediated expression of genes involved in angiogenesis (IL-8, VEGF), and invasion and metastasis (MMP 9, uPA, and $\mathrm{uPA}$ receptor) may further contribute to the progression of androgen depleted prostate cancer [20].

Apoptosis is programmed cell death involving sequential events of elimination of cells without releasing harmful substances into the surrounding area. Apoptosis plays a crucial role in developing and maintaining the health of the body by eliminating old cells, unnecessary cells, and unhealthy cells. The two classes of regulatory molecules play vital role in the cell cycle progression and apoptosis processes are protein kinases, such as cyclin dependent kinases (CDKs), and cyclins. Disturbances in the cell cycle regulation due to uncontrolled cell growth and divisions through and escaping of the cell cycle checkpoints occur in the mutated cells. The cell cycle events are facilitated through the activated cyclin D-CDK4/6 complexes phosphorylating the retinoblastoma protein $(\mathrm{pRb})$ bound with E2F transcriptional factors. This in turn inactivates $\mathrm{pRb}$ and weakening its affinity for E2F which then becomes free to enter the nucleus and transcription of cell cycle progression genes. The hypophosphorylated $\mathrm{pRb}$ impounds the transcription factor E2F in the cytosol, thus blocking the cell cycle at G1 phase.

Similarly B-cell lymphoma (Bcl-2) family genes are involved in the apoptosis pathway, including prostate, breast, and ovarian cancers. The Bcl-2 family proteins had the anti-apoptotic subgroup, such as, Bcl-extra-large (Bcl-xL), Bcl2-like 2 (Bcl-W), myeloid cell leukemia (Mcl-1) that interacted with another subgroup of proteins called the pro-apoptotic proteins (Bcl2-associated X protein (Bax) and $\mathrm{Bcl} 2$ antagonist/killer (Bak)). In the signal transduction cascade of apoptosis the pro-apoptotic proteins began induction of apoptosis via mitochondrial outermembrane permeabilization, followed by the release of cytochrome c, and finally the activation of cysteine aspartyl proteases (caspases). Second is the intrinsic pathway, with the release of cyt-c into the cytosol from mitochondria, a multiprotein 


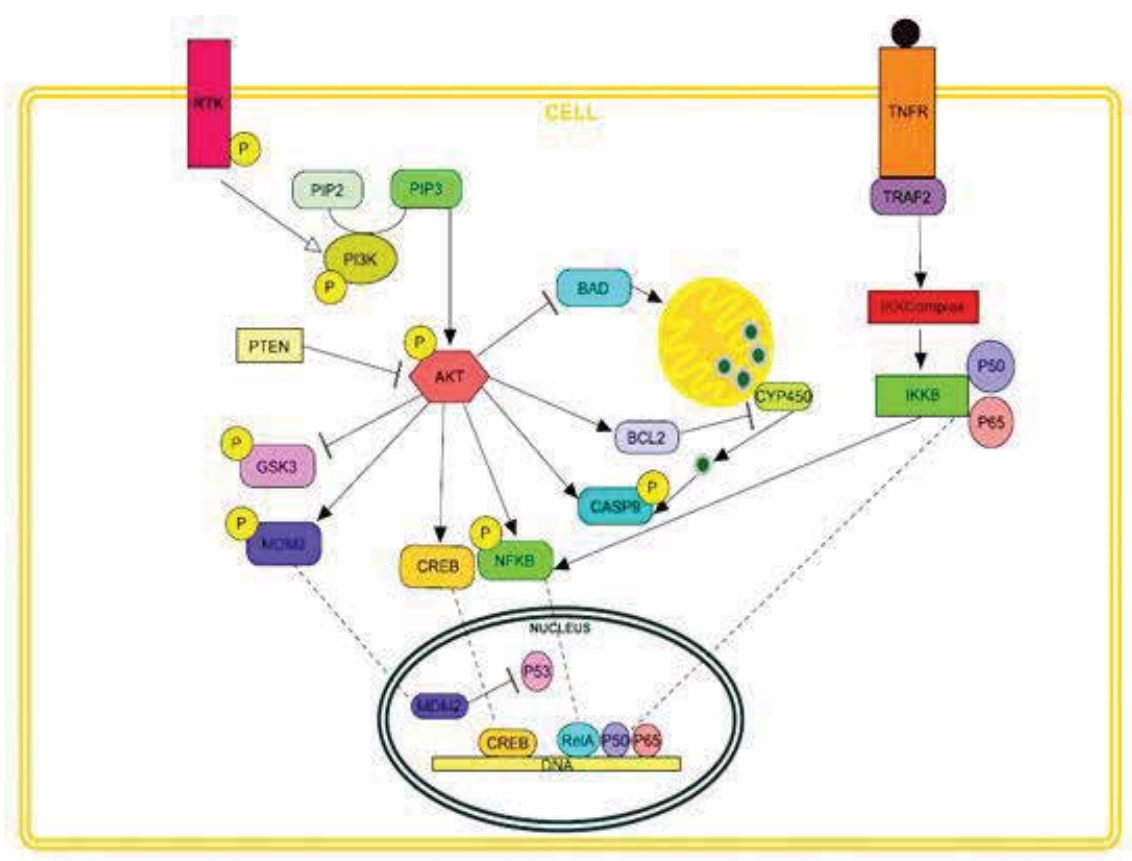

Figure 1.

Molecular pathways involved in prostate cancer progression (developed by pathway construction tool_PathVisio).

caspase-activating complex, called "apoptosome" binds procaspase- 9 and cyt-c with its central component Apaf1, and activates apoptosis. Thus there should be a balance in the levels of anti-apoptotic and pro-apoptotic proteins for the proper progression of apoptosis (Figure 1).

\section{Phytomedicine: promoting synergistic actions in prostate cancer management}

The history of ayurvedic and traditional systems of medicine showed that the medicinal plants have global importance in treating human diseases and disorders [21]. The references of ancient literature, a Sumerian clay slab from Nagpur, approximately 5000 years old suggested that people were depended on drugs from the nature [22]. Theophrast (371-287 BC) in his scientific book titled "De Causis Plantarium" has referred and classified nearly 500 medicinal plants. About 700 plant species including pomegranate, castor oil plant, aloe, senna, garlic, onion, fig, willow, coriander, juniper, common centaury, etc. [23] were reported having medicinal properties. The World Health Organization (WHO) estimated that trades of plantderived pharmaceutical drugs would account for five trillion US dollars by 2050.

The survey reports on these medicinally valued plants and their preparations as tinctures, teas, poultices, powders, and other herbal formulations [24] served as the basis for novel drug discovery wherein a large number of synthetic drugs are developed on the small-molecule natural chemical entities and has been introduced as potential drugs worldwide [25]. Even our natural food intake relays on the medicinal aspects followed in our tradition thus have a strong impact on determining health at different stages/phases of life. In addition many food-based nutrients contribute to the prevention and management of deadly diseases like cancer. Wholesome diet including vegetables, fruit, and vitamins lowers the risk up to $80 \%$ of cancers of the large bowel, breast, and prostate. 
Based on the studies done at the US National Cancer Institute, selenium, vitamin E, and Omega-3 fatty acid have preventive roles in prostate carcinoma [26]. Plants produce a wide range of chemical compounds as by-products of their metabolic pathways known as secondary metabolites. These compounds have no direct role in growth yet they have significant role in defense mechanisms. The secondary metabolites generally flavonoids, tannins, curcumin, resveratrol, and gallocatechin are reported as effective anti-cancer drugs [27]. Molecular studies have proved that luteolin, quercetin, and kaempferol rich in onions, olives, grapes, tea, pomegranate, broccoli, and cauliflower [28] are effective in suppressing tumor development with low dose-limiting toxicities and negligible side effects [29].

Plants in nature contain many active compounds which elicit the synergistic effects in combination with chemical drugs through its own molecular mechanisms of targeting signaling pathways in cancer cells in order to overcome drug resistant cancers, also strengthens the therapeutic activity of chemical drugs and subsides drug-induced toxicity. The pharmacological efficacies of chemotherapeutic drugs are improvised by alteration in the pharmacokinetics of drug compounds regulating the receptor targets and downstream effector molecules in the cancer cells.

Sporadically, anti-androgens (anti-hormones) are administered for initial stages of prostate cancer which is prone to frequent failures in patients diagnosed with recurrent androgen-independent prostate cancer and metastasis. Radiotherapy and/or androgen deprivation therapy can be considered as an adjunct to surgery, in either the adjuvant or salvage setting, to further control the disease course. These combinatorial therapies are highly recommended in combating primary tumors, but metastatic tumors are more challenging due to loss of remedial activity and disease remission. Also these therapies are reported in exerting complications of damaging the normal cells in vicinity of tumor growth, disturbing the functioning of immune system, triggering autoimmunity [30], damage to adjacent gastrointestinal tract, and bladder incontinence. Hence, multifaceted therapies producing synergistic effects and long-term outcomes by lowering the local tumor burden and eradicating metastatic disease compared to each individual change are required for cancer management.

Prostate cancer is characterized by slow growth and long latency period and thus integration of phytochemicals/compounds in combination with other existing therapies have promising future to manage cancer, controlling the disease progression and mortality rate. The WHO has estimated that approximately $80 \%$ of the world's population depends on traditional plant-based medicines for meeting their primary health care needs [31]. In prostate cancer, there is an imbalance between prostate cell growth and apoptosis. In prostate cancer these proteins are over expressed which lead to progression of metastatic prostate cancer through inhibition of apoptotic cell death. This over expression also causes resistance to heat-shock stress, several chemotherapies, and radiotherapy. Phytochemicals are routinely used as an adjuvant to conventional chemo and radio therapies of cancer in order to manage the drug-resistance mechanisms and resensitize tumor cells.

Many medicinal plants are reported to possess chemopreventive activities on prostate cancer exhibiting significant oestrogenic and anti-androgen effects, such as Agathosma betulina [32], Bidens pilosa [33], Prunus Africana, Cucurbita pepo L. [34], Andrographis paniculata [35], Vaccinium macrocarpon [36], Linum persicum and Euphorbia cheradania [37], Panax ginseng [38], Scutellaria baicalensis [39], Wedelia chinensis [40], Urtica membranaceae, Artemisia monosperma and Origanum dayi [41], Vitis vinifera [42], an eight-herb Chinese formulation, that consists of Isatis indigotica, Glycyrrhiza glabra, Glycyrrhiza uralensis, Scutellaria baicalensis, Ganoderma lucidum, Panax ginseng, Dendranthema morifolium, Rabdosia rubescens [43]. Combined drugs made of vinca alkaloids, Taxus diterpenes, Podophyllum 
lignans, and Camptotheca alkaloids were proved with anticancer effects [44]. Pentacyclic triterpenoids reported in Hypoxis hemerocallidea reduced the inflammation and swelling in the prostate. Garlic and green tea catechins act as potential chemopreventive agents against cancer by inhibiting PIN [45]. Phytochemicals like geneistin and quercitin [46], lycopene [47], curcumin, epigallocatechin-gallate, resveratrol [48], brassinosteroid [49], derived from medicinal plants have been reported through in-vitro studies with potentials of anti-proliferative effects on prostate cancer cell lines, such as PC-3, DU-145, and LNCaP. Their protective action against cancer may be due to their high concentration of antioxidants that react with free radicals thereby neutralizing them [50].

Quercetin and curcumin, plant-derived flavanoids are well established drugs in cancer treatment exhibiting antioxidant, anti-inflammatory, and anti-proliferative activities [51]. Quercetin has anti-inflammatory role through regulation of NF- $\kappa B$ pathway genes [52] inhibiting the expression of pro-inflammatory cytokines, TNF- $\alpha$, IL-6, and IL-1 $\beta$ and inflammatory mediators, nitric oxide, and catalase. Combination of quercetin with doxorubicin increases the sensitivity of PC3resistant cells by inducing apoptosis via reduction of mitochondrial membrane potential, activation of the PI3K/AKT pathway, and acceleration of chemo resistance [53]. The chemopreventive and anti-neoplastic activity of the phytochemicals could be achieved through multiple effects including reduction of PSA and AR expression, induction of apoptotic pathways, inhibition of angiogenesis, induction of PKC- $\alpha$, suppression of TrkE, induction of $\mathrm{p} 53$, inhibition of proteasome activity, induction of S-phase and G0/G1 phase and G2/M cell-cycle arrest, suppression of DNA synthesis, up-regulation of protein expression WAF1/p21, KIP1/p27, INK4a/ p16, INK4c/p18, down-regulation of protein expression cyclin D1 and D3, cyclin E, cdk2, cdk4, cdk6, inhibition of PI3K/PKB phosphorylation of AKT, Inhibition of COX-2 expression [54]. Wedelia chinensis extract possesses the ability in reducing the gene expressions of proinflammatory cytokines and STAT3 activity in tumorelicited myeloid cells [40]. Altogether, the combination of herbal compounds includes pharmacokinetic and pharmacodynamic synergisms to provide significant therapeutic effects. Baicalein form Scutellaria baicalensis [39] reduces the synthesis of eicosanoid that function as important mediators in inflammatory responses through inhibiting enzymatic oxidation of essential fatty acids.

One of our studies reported that, a potential medicinal herb Gymnema sylvestre has been proved for its potency to control prostate cancer progression [55]. It is (family: Asclepiadaceae) described as miracle fruit, is native to central and western India that has been used in the traditional health care system, for several centuries [56]. The leaves are rich in triterpene classes of oleanane saponins (gymnemic acids and gymnemasaponins) and dammarene saponins (gymnemasides). The phytocompound dihydroxy gymnemic triacetate (DGT) isolated from acetone extract of G. sylvestre leaves were effective in inhibiting prostate cancer cell growth, inducing apoptosis, modulation of cell cycle, and downregulation of the protein expressions. Also the depletion of PSA observed in the PC-3 cell line caused by DGT was observed. Since PSA gene is positively regulated via binding of $\mathrm{AR}$ to the androgen responsive elements in the promoter of PSA, decline of PSA levels proves down-regulation of AR [57].

\section{Conclusion}

Thus multimodal approach of treating prostate cancer with the integration of phytochemicals as chemopreventive agents in down-regulation of cell proliferation and induction of apoptosis has taken forefront in development of potential therapeutic drugs in cancer management. 


\section{Author details}

Rajalakshmi Manikkam* and Indu Sabapathy

Department of Biotechnology and Bioinformatics, Holy Cross College

(Autonomous), Tamil Nadu, India

*Address all correspondence to: mdraji@gmail.com

\section{IntechOpen}

(C) 2019 The Author(s). Licensee IntechOpen. This chapter is distributed under the terms of the Creative Commons Attribution License (http://creativecommons.org/licenses/ by/3.0), which permits unrestricted use, distribution, and reproduction in any medium, provided the original work is properly cited. (cc) BY 


\section{References}

[1] Torre LA, Bray F, Siegel RL, Ferlay J, Lortet-Tieulent J, Jemal A. Global cancer statistics, 2012. CA: A Cancer Journal for Clinicians. 2015;65:87-108

[2] Rastogi T, Devesa S, Mangtani P, Mathew A, Cooper N, Kao R, et al. Cancer incidence rates among south Asians in four geographic regions: India, Singapore, UK and US. International Journal of Epidemiology.

2008;37:147-160

[3] Novara G, Galfano A, Berto RB, Ficarra V, Navarrete RV, Artibani W. Inflammation, apoptosis, and $\mathrm{BPH}$ : What is the evidence. European Association of Urology. 2006;5:401-409

[4] Griffiths K, Prezioso D, Turkes A, Denis LJ. The prevention of prostate cancer. Recent Results in Cancer Research. 2007;175:33-63

[5] Bostwick DG. High-grade prostatic intraepithelial neoplasia: The most likely precursor of prostate cancer. Cancer. 1995;75:1823-1836

[6] Humphrey PA. Gleason grading and prognostic factors in carcinoma of the prostate. Modern Pathology. 2004;17:292-306

[7] Heidenreich A, Bellmunt J, Bolla M, Joniau S, Mason M, Matveev V, et al. EAU guidelines on prostate cancer. Part I: Screening, diagnosis, and treatment of clinically localised disease. European Urology. 2011;59:61-71

[8] Kabalin JN, Hodge KK, McNeal JE, Freiha FS, Stamey TA. Identification of residual cancer in the prostate following radiation therapy: Role of transrectal ultrasound guided biopsy and prostate specific antigen. The Journal of Urology. 1989;142:326-331

[9] Mc Neal JE. The prostate gland: Morphology and pathophysiology. Monograph Urology. 1983;4:3-12
[10] Lonergan PE, Tindall DJ. Androgen receptor signaling in prostate cancer development and progression. Journal of Carcinogen. 2011;10:20

[11] Ross RK, Bernstein L, Judd H, Hanisch R, Pike M, Henderson B. Serum testosterone levels in healthy young black and white men. Journal of the National Cancer Institute. 1986;76:45-48

[12] Quayle SN, Mawji NR, Wang J, Sadar MD. Androgen receptor decoy molecules block the growth of prostate cancer. Proceedings of the National Academy of Sciences of the United States of America. 2007;104:1331-1336

[13] Kasper S, Cookson MS. Mechanisms leading to the development of hormone-resistant prostate cancer. The Urologic Clinics of North America. 2006;33:201-210

[14] Edwards J, Bartlett JM. The androgen receptor and signal transduction pathways in hormonerefractory prostate cancer. Part 2: Androgen-receptor cofactors and bypass pathways. BJU International. 2005;95:1327-1335

[15] Culig Z, Hobisch A, Cronauer MV, Radmayr C, Trapman J, Hittmair A, et al. Androgen receptor activation in prostatic tumor cell lines by insulin-like growth factor-I, keratinocyte growth factor and epidermal growth factor. Cancer Research. 1994;54:5474-5478

[16] Srinivasan SR, Freedman DS, Sundaram GS, Webber LS, Berenson GS. Racial (black-white) comparisons of the relationship of levels of endogenous sex hormones to serum lipoproteins during male adolescence, the Bogalusa heart study. Circulation. 1986;74:1226-1232

[17] Chen M, Ni J, Chang HC, Lin CY, Muyan M, Yeh S. CCDC62/ERAP75 functions as a coactivator to enhance 
estrogen receptor beta-mediated transactivation and target gene expression in prostate cancer cells. Carcinogenesis. 2009;30:841-850

[18] Rajah R, Vanderslice R, Kapur S, Lynch J, Thompson R, Djakjew D. Epidermal growth factor (EGF) promotes chemomigration of a human prostate tumor cell line and EGF immunoreactive proteins are present at sites of metastasis in the stroma of lymph nodes and medullary bone. The Prostate. 1996;28:1-9

[19] Chokkalingam A, Pollak M, Fillmore C, Gao Y, Stanczyk F, Deng J, et al. Insulin-like growth factors and prostate cancer: A population based case-control study in China. Cancer Epidemiology, Biomarkers \& Prevention. 2001;10:421-427

[20] Suh J, Rabson AB. NF-kappaB activation in human prostate cancer: Important mediator or epiphenomenon? Journal of Cellular Biochemistry. 2004;91:100-117

[21] Platel K, Srinivasan K. Plant foods in the management of diabetes mellitus: Vegetables as potential hypoglycaemic agents. Die Nahrung. 1997;41:68-74

[22] Stojanoski N. Development of health culture in Veles and its region from the past to the end of the 20th century. Veles: Society of Science and Art. 1999:13-34

[23] Glesinger L. Medicine through Centuries. Zagreb: Zora; 1954. pp. 21-38

[24] Samuelsson G. Drugs of Natural Origin: A Textbook of Pharmacognosy. Stockholm: 5th Swedish Pharmaceutical Press; 2004

[25] Newman DJ, Cragg GM. Natural products as sources of new drugs over the last 25 years. Journal of Natural Products. 2007;70:461-477
[26] Lippman SM, Goodman PJ, Klein EA, Parnes HL, Thompson IM Jr, Kristal AR, et al. Designing the selenium and vitamin $\mathrm{E}$ cancer prevention trial (SELECT). Journal of the National Cancer Institute. 2005;97:94-102

[27] Azmi AS, Bhat SH, Hanif S, Hadi SM. Plant polyphenols mobilize endogenous copper in human peripheral lymphocytes leading to oxidative DNA breakage: A putative mechanism for anticancer properties. FEBS Letters. 2006;580:533-538

[28] Kozlowska A, Szostak-Wegierek D. Flavonoids-Food sources and health benefits. Roczniki Państwowego Zakładu Higieny. 2014;65:79-85

[29] Kallifatidis G, Hoy JJ, Lokeshwar BL. Bioactive natural products for chemoprevention and treatment of castration-resistant prostate cancer. Seminars in Cancer Biology. 2016;40-41:160-169

[30] James N. Primer on Prostate Cancer. London, UK: Springer Healthcare Ltd; 2014

[31] Biswa K, Chattopadhyay I, Banerjee RK, Bandopadhyay U. Biological activities and medicinal properties of neem (Azadirachta indica). Current Science. 2002;82:1336-1345

[32] Watt JM, Breyer-Brandwijk MG. The Medicinal and Poisonous Plants of Southern and Eastern Africa: Being an Account of their Medicinal and Other Uses, Chemical Composition, Pharmacological Effects and Toxicology in Man and Animal. 2nd ed. Teviot Place, Edinburgh: E. \& S. Livingstone Ltd.; 1962:16-17

[33] Hutchings A, Scott AH, Lewis G, Cunningham A. Zulu, Medicinal Plants: An Inventory. Pietermaritzburg: University of Natal Press; 1996 
[34] Steenkamp V. Phytomedicines for the prostate. Fitoterapia.

2003;74:545-552

[35] Kumar RA, Sridevi K, Kumar NV, Nanduri S, Rajagopal S. Anticancer and immunostimulatory compounds from Andrographis paniculata. Journal of Ethnopharmacology. 2004;92(2-3):291-295

[36] Neto CC. Cranberry and its phytochemicals: A review of in vitro anticancer studies. The Journal of Nutrition. 2007;137:186S

[37] Raffo AJ, Perlman H, Chen MW, Day ML, Streitman JS, Buttyan R. Overexpression of bcl-2 protects prostate cancer cells from apoptosis in vitro and confers resistance to androgen depletion in vivo. Cancer Research. 1995;55:4438-4445

[38] Wang W, Zhao Y, Rayburn ER, Hill DL, Wang H. Zhang, in vitro anti cancer and structure activity relationships of natural products isolated from fruits of Panax ginseng. Cancer Chemotherapy and Pharmacology. 2007;59(55):89-601

[39] Chen S, Ruan Q, Bedner E, et al. Effects of the flavonoid baicalin and its metabolite baicalein on androgen receptor expression, cell cycle progression and apoptosis of prostate cancer cell lines. Cell Proliferation. 2001;34:293-304

[40] Lin FM, Chen LR, Lin EH, et al. Compounds from Wedelia chinensis synergistically suppress androgen activity and growth in prostate cancer cells. Carcinogenesis. 2007;28:2521-2529

[41] Solowey E, Lichtenstein M, Sallo S, Paavilainen H, Solowet E, LorberboumGalski H. Evaluating medicinal plants for anticancer activity. The Scientific World Journal. 2014:1-12

[42] Stagos D, Amoutzias GD, Matakos A, Spyrou A, Tsatsakis AM, Kouretas
D. Chemoprevention of liver cancer by plant polyphenols. Food and Chemical Toxicology. 2012;50:2155-2170

[43] Small EJ, Frohlich MW, Bok R, Shinohara K, Grossfeld G, Rozenblat $Z$, et al. Prospective trial of the herbal supplement PC-SPES in patients with progressive prostate cancer. Journal of Clinical Oncology. 2000;18:3595-3603

[44] Khazir J, Mir BA, Pilcher L, Riley DL. Role of plants in anticancer drug discovery. Phytochemistry Letters. 2014;7:173-181

[45] Arunkumar A, Vijayababu MR, Venkataraman P, Senthilkumar K, Arunakaran J. Chemoprevention of rat prostate carcinogenesis by diallyl disulfide, an organosulfur compound of garlic. Biological \& Pharmaceutical Bulletin. 2006;29:375-379

[46] Phillip CJ, Christopher K, Giardina CK, Bilir B, Cutler DJ, Lai YH, et al. Genistein cooperates with the histone deacetylase inhibitor vorinostat to induce cell death in prostate cancer cells. BMC Cancer. 2012;12:145

[47] Von Low EC, Perabo FG, Siener $\mathrm{R}$, Muller SC. Facts and fiction of phytotherapy for prostate cancer: A critical assessment of preclinical and clinical data. In Vivo. 2007;21:189-204

[48] Ratan HL, Steward WP, Gescher AJ, Mellon JK. Resveratrol-A prostate cancer chemopreventive agent. Urologic Oncology. 2002;7:223-227

[49] Cimino S, Sortino G, Favilla V, Castelli T, Madonia MS, Russo GI, et al. Polyphenols: Key issues involved in chemoprevention of prostate cancer. Oxidative Medicine and Cellular Longevity; 2012;2012:632959

[50] Malíková J, Swaczynová J, Koláŕ Z, Strnad M. Anticancer and antiproliferative activity of natural 
brasinosteroids. Phtyochemistry.

2008;69:418-426

[51] Bischoff SC. Quercetin: Potentials in the prevention and therapy of disease. Current Opinion in Clinical Nutrition and Metabolic Care. 2008;11:733-740

[52] Li Y, Yao J, Han C, Yang J, Chaudhry MT, Wang S, et al. Quercetin, inflammation and immunity. Nutrients. 2016;8:167

[53] Tang KD, Ling MT. Targeting drugresistant prostate cancer with dual PI3K/ mTOR inhibition. Current Medicinal Chemistry. 2014;21:3048-3056

[54] Ravindran J, Prasad S, Aggarwa BB. Curcumin and cancer cells: How many ways can curry kill tumor cells selectively? The AAPS Journal. 2009;11:495-510

[55] Nivedha RP, Venkatesan S, Singh SK, Selvaraj C, Rajalakshmi M. Chemopreventive effect of saponin isolated from Gymnema sylevestre on prostate cancer through in silico and in vivo analysis. Medicinal Chemistry Research. 2017;26:1915-1925

[56] Porchezhian E, Dobriyal RM. An overview on the advances of Gymnema sylvestre: Chemistry. pharmacology and patents. Pharmazie. 2003;58:5-12

[57] Mostaghel EA, Page ST, Lin DW, et al. Intraprostatic androgens and androgen-regulated gene expression persist after testosterone suppression: Therapeutic implications for castrationresistant prostate cancer. Cancer

Research. 2007;67:5033-5041 


\title{
Sexual and Psychoemotional Disorders in Male Patients Treated for Prostate Carcinoma
}

\author{
Marta Dąbrowska-Bender, Robert Stoniewski, \\ Urszula Religioni, Anna Stoniewska, Anna Staniszewska, \\ Karolina Jabtkowska-Górecka, Magdalena Milewska, \\ Adrianna Sobol and Anna Kupiecka
}

\begin{abstract}
The prostate carcinoma affect the quality of life of most male patients, including in particular their sexual and emotional life. The aim of study was to assess sexual and psychoemotional disorders in male patients diagnosed with prostate carcinoma and receiving cancer treatment. The study's patients were recruited at the Oncological Hospital in Wieliszew, Poland, between September 2016 and December 2017. The study was performed in 166 male patients diagnosed with prostate cancer. Two standardized questionnaires were used in the study, EORTC QLQ-C30 and QLQ-PR25, for patients with prostate cancer, developed by the European Quality of Life Group. The type and stage of cancer treatments were a significant contributor to feeling tense, worried, depressed, and irritable among the study patients. The stage of treatment, however, caused a negative effect on these parameters. Pretreatment patients declared high or very high satisfaction with their sexual life, while posttreatment patients and those on cancer treatment indicated low sexual satisfaction. However, a feeling of embarrassment during intimate contact as well as erectile disorders correlated both with the type and stage of cancer treatment. Our results show that affected male patients should be offered continuous psychological care, especially those waiting for treatment and those on treatment.
\end{abstract}

Keywords: prostate carcinoma, quality of life, sexual disorders, psychoemotional disorders, oncological treatment

\section{Background}

Prostate carcinoma ( $\mathrm{PCa}$ ) is one of the most frequent malignant cancers in the male population. In terms of incidence, it is second only to lung cancer. Treatment of prostate carcinoma includes surgical procedures, radiotherapy, chemotherapy, and hormone therapy, and all these procedures have an adverse impact on the sexual functioning of men. Erectile disorders, loss of sex drive, and difficulty achieving orgasm are the most frequent problems in the course of disease and its treatment $[1,2]$. The existing studies show that few men with sexual dysfunctions and on cancer treatment seek the help of a specialist to effectively eliminate such problems 
[3]. Other studies show that this population of patients frequently experiences, as a result of changes in the sexual functioning, fear, anxiety, and depression as well as loss of male identity [4]. Therefore, psychological care and social support (including their closest family and friends) are increasingly considered an important component of many chronic diseases. At the same time, studies suggest that men who find no emotional support in their social environment are more exposed to depression and more seldom achieve positive mental well-being [5]. Additionally, it was demonstrated that specialist (psychological) and social support are associated with significantly reduced mental stress and general improvement of the quality of life in the population of men with prostate carcinoma.

\section{Material and methods}

The study's patients were recruited at the Oncological Hospital in Wieliszew, Poland, between September 2016 to December 2017. The study was performed 166 male patients diagnosed with prostate cancer. The study included men who gave informed, written consent to participate. In the study was used two standardized questionnaire: EORTC QLQ-C30 (version 3.0) and QLQ-PR25 for patients with prostate cancer, developed by the European Quality of Life Group. These questionnaires are used to research the summary sense of health and evaluation of performance in various dimensions (physical, emotional and social) and typical symptoms of prostate cancer.

\subsection{Ethics}

The Ethical Committee consent for the presented research is not required. According to the statement of the Ethical Committee of the Medical University of Warsaw: "The Committee does not provide opinions on surveys, retrospective studies, or other non-invasive research" (Detailed information and templates of documents of Ethics Committee of Medical University of Warsaw (Accessed 2016-10-01): http://komisjabioetyczna.wum.edu.pl/content/ szczeg\%C3\%B3\%C5\%82owe-informacje-orazwzory-dokument\%C3\%B3w).

\section{Results}

The study included 166 men. The mean age of participants was $67.66 \pm 7.25$ (range: 51-84 years). The main part of population taking part in the study comprised people aged $65-69$ years $(37.35 \%)$. The majority $(68.7 \%)$ of patients, during the study, were undergoing the treatment. The treatment analysis revealed that $66 \%$ of the participants subjected to radiotherapy. Smaller numbers were found for the remaining therapy: $16.9 \%$ hormonal therapy, $2.38 \%$ surgery (4.8\%), and $3.6 \%$ chemotherapy. The proportion of patients was treated with combined therapies: radiotherapy + surgery $(8.33 \%)$, radiation + hormonal therapy $(6.03 \%)$, and surgery + hormonal + chemotherapy (2.41\%). The characteristics of the patients are shown in Table 1.

\subsection{Emotional problems}

No correlation was found between the study variable and the health status or quality of life score or the age of patients. However, feeling tense may be affected by the type of treatment administered to the patients $\left(\mathrm{Chi}^{2}=94.15, \mathrm{p}=0.0000\right.$; $\mathrm{R}=0.21, \mathrm{p}>0.05)$. The results of statistical analysis show that the greatest number 


\begin{tabular}{|c|c|}
\hline Characteristics of the patients in the survey & Number of patients $(\mathrm{N}=166(100 \%))$ \\
\hline \multicolumn{2}{|l|}{ Age } \\
\hline$<54$ & $2(1.2)$ \\
\hline $55-59$ & $16(9.6)$ \\
\hline $60-64$ & $26(15.7)$ \\
\hline $65-69$ & $62(37.3)$ \\
\hline $70-74$ & $24(14.5)$ \\
\hline $75-79$ & $24(14.5)$ \\
\hline$>80$ & $12(7.2)$ \\
\hline \multicolumn{2}{|l|}{ Stage of oncology treatment } \\
\hline Before treatment & $20(12)$ \\
\hline During the course of treatment & $114(68.7)$ \\
\hline After treatment & $32(19.3)$ \\
\hline \multicolumn{2}{|l|}{ Type of oncology treatment ${ }^{\mathrm{a}}$} \\
\hline Surgery & $8(4.8)$ \\
\hline Radiotherapy & $110(66)$ \\
\hline Hormonal therapy & $28(16.9)$ \\
\hline Chemotherapy & $6(3.6)$ \\
\hline I do not know & $20(12)$ \\
\hline question with multiple answers. & \\
\hline
\end{tabular}

Table 1.

Characteristics of the group of patients participating in the survey.

of men who declared that they did not feel tense during the last week underwent radiotherapy $(58.82 \%)$ or radiotherapy and surgical treatment $(57.14 \%)$. On the other hand, all the patients who received surgical treatment, chemotherapy, and hormone therapy indicated that they felt very tense. A similar correlation was shown in relation to the stage of cancer treatment $\left(\mathrm{Chi}^{2}=19.73, \mathrm{p}=0.00310\right.$; $\mathrm{R}=-0.00, \mathrm{p}>0.05)$.

Feeling worried also depends on the stage of cancer treatment $\left(\mathrm{Chi}^{2}=21.67\right.$, $\mathrm{p}=0.00139 ; \mathrm{R}=0.20, \mathrm{p}>0.05)$. Posttreatment patients significantly more often indicated that they did not worry during the last week (56.25\% of the group), while patients waiting for treatment more often declared to feel worried or very worried ( $40 \%$ of the group in total). Similarly to the question about feeling tense, the results show that feeling worried affected all the patients undergoing surgical treatment, chemotherapy, and hormone therapy. Patients receiving radiotherapy $(27.45 \%$ of the group) or both radiotherapy and surgical treatment $(28.57 \%)\left(\mathrm{Chi}^{2}=69.06, \mathrm{p}=0.0000\right.$; $\mathrm{R}=0.13, \mathrm{p}>0.05)$ most often indicated that they did not feel worried. However, no correlation was found between feeling worried and the patients' age ( $p>0.05)$.

The impact of health status on patients feeling worried was also insignificant $\left(\mathrm{Chi}^{2}=44.87, \mathrm{p}=0.00043 ; \mathrm{R}=-0.04, \mathrm{p}>0.05\right)$, although it could be observed that patients with a greater health status score more rarely indicated that they felt worried. A similar correlation was observed with regard to the quality of life score $\left(\mathrm{Chi}^{2}=43.38, \mathrm{p}=0.00071 ; \mathrm{R}=-0.11, \mathrm{p}>0.05\right)$.

None of the patients who received cancer treatment declared to be very or significantly irritable. However, these responses were indicated by $40 \%$ of the patients waiting for treatment $\left(\mathrm{Chi}^{2}=16.24, \mathrm{p}=0.01251 ; \mathrm{R}=-0.03, \mathrm{p}>0.05\right)$. The 
least irritability were experienced by patients undergoing radiotherapy or surgical treatment, the greatest irritability-by patients receiving surgical treatment, chemotherapy, and hormone therapy $\left(\mathrm{Chi}^{2}=69.05, \mathrm{p}=0.0000 ; \mathrm{R}=0.06, \mathrm{p}>0.05\right)$. On the other hand, no correlation was found between feeling irritable and the patients' age, health status, or quality of life score ( $p>0.05$ for all the cases).

Even though no correlation was found between the age or the quality of life score and feeling depressed ( $p>0.05)$, a statistical analysis of the study results showed that feeling depressed may depend on the patient's health status $\left(\mathrm{Chi}^{2}=33.34\right.$, $\mathrm{p}=0.01517 ; \mathrm{R}=-0.36, \mathrm{p}=0.00681)$. Patients with a lower health status score much more often declared that they felt depressed during the last week.

As with the above-described correlations, feeling depressed is also correlated (although weakly) with the stage of the patient's treatment $\left(\mathrm{Chi}^{2}=13.11\right.$, $\mathrm{p}=0.04122 ; \mathrm{R}=0.06, \mathrm{p}>0.05)$ and the type of treatment $\left(\mathrm{Chi}^{2}=67.37\right.$, $\mathrm{p}=0.0000 ; \mathrm{R}=0.11, \mathrm{p}>0.05)$. No depression was most often indicated by patients who underwent cancer treatment $(56.25 \%$ of this group), radiotherapy $(45.10 \%)$, or both radiotherapy and surgery $(42.86 \%)$.

The greatest difficulties in remembering were indicated by pretreatment patients (30\% of responses "to a significant degree" and "very much" in this group of patients compared to $7 \%$ of the patients on treatment and $0 \%$ of the posttreatment patients $)\left(\mathrm{Chi}^{2}=19.25, \mathrm{p}=0.00376 ; \mathrm{R}=-0.07, \mathrm{p}>0.05\right)$ and those receiving surgical treatment, hormone therapy, and chemotherapy (100\% of the group) $\left(\mathrm{Chi}^{2}=97.20, \mathrm{p}=0.0000 ; \mathrm{R}=0.08, \mathrm{p}>0.05\right)$. Additionally, a strong correlation was found between difficulties in remembering and health status score $\left(\mathrm{Chi}^{2}=34.89, \mathrm{p}=0.00976 ; \mathrm{R}=-0.45, \mathrm{p}=0.0000\right)$. The higher health status score is correlated with an absence of difficulties in remembering or only slight difficulties in remembering. Serious and very serious difficulties in remembering were indicated only by the patients with a health status score less than 5 . A similar correlation exists with regard to the quality of life score. Patients with the lowest quality of life score did not indicate any considerable or significant problems in remembering. Patients who declared frequent problems in remembering had a lower quality of life score $\left(\mathrm{Chi}^{2}=32.30, \mathrm{p}=0.02024 ; \mathrm{R}=-0.26, \mathrm{p}=0.00071\right)$. However, no correlation was found between difficulties in remembering and the patients' age $(\mathrm{p}>0.05)$

(Tables 2 and 3).

\subsection{Urination problems}

Among the study patients, $12 \%$ of them frequently passed urine during the day. This problem has a significant impact on the quality of life of the patients

\begin{tabular}{lccccc}
\hline Emotional problems & $\begin{array}{c}\text { Question } \\
\text { no. }\end{array}$ & \multicolumn{3}{c}{ Number of patients (N = 166) N (\%) } \\
\cline { 3 - 6 } & & $\begin{array}{c}\text { Not at } \\
\text { all }\end{array}$ & A little & $\begin{array}{c}\text { Quite a } \\
\text { bit }\end{array}$ & $\begin{array}{c}\text { Very } \\
\text { much }\end{array}$ \\
\hline Feeling circuit & 21 & $86(51.8)$ & $72(43.4)$ & $4(2.4)$ & $4(2.4)$ \\
\hline Feeling worried & 22 & $40(24.1)$ & $98(59)$ & $22(13.3)$ & $6(3.6)$ \\
\hline The feeling of annoyance & 23 & $68(40.9)$ & $70(42.2)$ & $22(13.3)$ & $6(3.6)$ \\
\hline Feeling depressed & 24 & $70(42.2)$ & $72(43.4)$ & $18(10.8)$ & $6(3.6)$ \\
\hline Difficulty in remembering & 25 & $84(50.6)$ & $68(41.0)$ & $10(6)$ & $4(2.4)$ \\
\hline${ }^{a}$ Number of issues in accordance with the questionnaire $Q L Q-C 30$. & & & \\
\hline
\end{tabular}

Table 2.

Emotional problems of the patients. 


\begin{tabular}{|c|c|c|c|}
\hline \multirow[t]{2}{*}{ Emotional problems } & \multirow[t]{2}{*}{ Question no. $^{\mathrm{a}}$} & \multicolumn{2}{|c|}{ Quality of life } \\
\hline & & p-value & R-Spearman ${ }^{b}$ \\
\hline Feeling circuit & 21 & 0.727 & - \\
\hline Feeling worried & 22 & 0.000 & - \\
\hline The feeling of annoyance & 23 & 0.353 & - \\
\hline Feeling depressed & 24 & 0.174 & - \\
\hline Difficulty in remembering & 25 & 0.020 & -0.364 \\
\hline \multicolumn{4}{|c|}{$\begin{array}{l}{ }^{a} \text { Number of issues in accordance with the questionnaire QLQ-C30. } \\
{ }^{b} \text { Significant correlation } p<0.05 \text {. }\end{array}$} \\
\hline
\end{tabular}

Table 3.

Emotional problems of the patients and felt the quality of life.

$\left(\mathrm{Chi}^{2}=30.86, \mathrm{p}=0.02988 ; \mathrm{R}=-0.24, \mathrm{p}=0.02967\right)$. Patients with no problems with frequent urination during the day had a higher quality of life score compared to patients who had to urinate very frequently during the day. Similar but significantly weaker correlation was identified between the quality of life score and frequent nighttime urination $\left(\mathrm{Chi}^{2}=33.42, \mathrm{p}=0.01484 ; \mathrm{R}=-0.11, \mathrm{p}>0.05\right)$ or the quality of life score and the need to hurry into the toilet before passing urine $\left(\mathrm{Chi}^{2}=33.83\right.$, $\mathrm{p}=0.01321 ; \mathrm{R}=0.05, \mathrm{p}>0.05)$.

Over $60 \%$ of the patients indicated that having to get up at night to urinate affected their night's rest. This problem had a strong impact on how the patients assessed their quality of life $\left(\mathrm{Chi}^{2}=54.09, \mathrm{p}=0.0000 ; \mathrm{R}=-0.52, \mathrm{p}=0.0000\right)$. The quality of life score was also affected by problems related to going out of the house due to the fact that the patients had to be close to a toilet. Problems with involuntary release of urine were indicated by nearly half of the patients, and $17 \%$ of the patients considered this problem to be considerable or significant. This group of patients usually has a lower quality of life score, even though this correlation is not strong $\left(\mathrm{Chi}^{2}=43.87, \mathrm{p}=0.00060 ; \mathrm{R}=-0.21, \mathrm{p}>0.05\right)$. Nearly $50 \%$ of the patients declared to have painful urination; however, no correlation was found between pain and the quality of life score ( $p>0.05$ ). Among the study patients, $32.53 \%$ of them use protection products against urinary incontinence. Using this type of protection was considered a nuisance only by $40 \%$ of the patients and affected how they perceived their quality of life $\left(\mathrm{Chi}^{2}=55.22, \mathrm{p}=0.00001 ; \mathrm{R}=-0.23\right.$, $\mathrm{p}=0.03563$ ). Generally, limitations related to everyday functioning due to urination problems were indicated by nearly $40 \%$ of men. This effect was considered significant or highly significant by $12 \%$ of the patients. However, the correlation between the limitation of everyday activities and the quality of life score is insignificant $\left(\mathrm{Chi}^{2}=38.50, \mathrm{p}=0.00332 ; \mathrm{R}=0.17, \mathrm{p}>0.05\right)$. Detailed results are given in Tables 4 and 5.

\subsection{Sexual activity of the study patients}

Nearly $60 \%$ of the patients indicated that they experienced a sense of loss of manhood due to the disease or its treatment. Younger patients more often declared a strong or very strong sense of loss of manhood (100\% of patients under the age of 54 years, $62.5 \%$ of patients aged 55 to 59 compared to $50 \%$ of patients aged $75-79$ or $16.67 \%$ of patients over the age of 80 years $)\left(\mathrm{Chi}^{2}=40.61, \mathrm{p}=0.00172\right.$; $\mathrm{R}=0.09, \mathrm{p}>0.05)$. A sense of loss of manhood was mostly declared by the posttreatment patients or the patients on cancer treatment (the responses "very strong" and "strong" were given by 57.89 and $75 \%$ compared to $30 \%$ of patients waiting 


\begin{tabular}{|c|c|c|c|c|c|}
\hline \multirow[t]{2}{*}{ Problems with urination } & \multirow{2}{*}{$\begin{array}{l}\text { Question } \\
\text { no. }^{\mathrm{a}}\end{array}$} & \multicolumn{4}{|c|}{ Number of patients $(\mathrm{N}=166) \mathrm{N}(\%)$} \\
\hline & & Not at all & A little & $\begin{array}{l}\text { Quite a } \\
\text { bit }\end{array}$ & $\begin{array}{l}\text { Very } \\
\text { much }\end{array}$ \\
\hline Frequent urination during the day & 31 & $14(8.4)$ & $76(45.8)$ & $56(33.7)$ & $20(12.1)$ \\
\hline Frequent urination during the night & 32 & $22(13.3)$ & $82(49.4)$ & $44(26.5)$ & $18(10.8)$ \\
\hline $\begin{array}{l}\text { The need to accelerate the toilet before } \\
\text { urinating }\end{array}$ & 33 & $48(28.9)$ & $64(38.6)$ & $28(16.9)$ & $26(15.7)$ \\
\hline $\begin{array}{l}\text { The impact of waking up at night to night } \\
\text { stay }\end{array}$ & 34 & $56(33.7)$ & $64(38.6)$ & $36(21.7)$ & $10(6)$ \\
\hline $\begin{array}{l}\text { Problems with leaving home because of the } \\
\text { frequent need to use the toilet }\end{array}$ & 35 & $80(48.2)$ & $60(36.1)$ & $14(8.43)$ & $12(7.2)$ \\
\hline Involuntary leakage of urine & 36 & $86(51.81)$ & $52(31.33)$ & $18(10.8)$ & $10(6)$ \\
\hline Pain when urinating & 37 & $84(50.6)$ & $70(42.2)$ & $6(3.6)$ & $6(3.6)$ \\
\hline $\begin{array}{l}\text { Problems with wearing protection against } \\
\text { incontinence }\end{array}$ & $38^{\mathrm{b}}$ & $32(59.3)$ & $16(29.6)$ & $6(3.6)$ & $0(0)$ \\
\hline $\begin{array}{l}\text { Limitation of daily activities by problems } \\
\text { with urination }\end{array}$ & 39 & $102(61.5)$ & $44(26.5)$ & $14(8.4)$ & $6(3.6)$ \\
\hline
\end{tabular}

Table 4.

Problems with urinating in the group of patients studied.

\begin{tabular}{|c|c|c|c|}
\hline \multirow[t]{2}{*}{ Problems with urination } & \multirow[t]{2}{*}{ Question no. $^{a}$} & \multicolumn{2}{|c|}{ Quality of life } \\
\hline & & p-value & R-Spearman ${ }^{b}$ \\
\hline Frequent urination during the day & 31 & 0.029 & 0.239 \\
\hline Frequent urination during the night & 32 & 0.014 & - \\
\hline The need to accelerate the toilet before urinating & 33 & 0.013 & - \\
\hline The impact of waking up at night to night stay & 34 & 0.000 & -0.518 \\
\hline $\begin{array}{l}\text { Problems with leaving home because of the frequent need to } \\
\text { use the toilet }\end{array}$ & 35 & 0.002 & -0.314 \\
\hline Involuntary leakage of urine & 36 & 0.000 & - \\
\hline Pain when urinating & 37 & 0.060 & - \\
\hline Problems with wearing protection against incontinence & $38^{\mathrm{c}}$ & 0.000 & -0.231 \\
\hline Limitation of daily activities by problems with urination & 39 & 0.003 & - \\
\hline \multicolumn{4}{|l|}{$\begin{array}{l}{ }^{a} \text { Number of issues in accordance with the questionnaire QLQ-C30. } \\
{ }^{b} \text { Demonstrated statistically significant correlations only; } p<0.05 . \\
{ }^{c} \text { Ouestion applies only to patients wearing protection against urinar }\end{array}$} \\
\hline
\end{tabular}

Table 5.

Problems with urination and the evaluation of the quality of life for patients.

for treatment $)\left(\mathrm{Chi}^{2}=14.74, \mathrm{p}=0.02230 ; \mathrm{R}=0.15, \mathrm{p}>0.05\right)$. The type of treatment had no impact on a sense of loss of manhood ( $p>0.05)$. Nearly half of the patients had no interest in sexual life during the last 4 weeks $(45.8 \%)$. No interest in having sex was mostly indicated by elderly patients over 70 years of age. None of the patients under 60 years of age selected the response "none" $\left(\mathrm{Chi}^{2}=41.22\right.$, 
$\mathrm{p}=0.00142 ; \mathrm{R}=0.08, \mathrm{p}>0.05)$. As regards the stage of oncological treatment, $43.75 \%$ of the posttreatment patients and $52.63 \%$ of the patients on treatment had no interest in sex. Among the patients waiting for treatment, it was $10 \%$ $\left(\mathrm{Chi}^{2}=26.89, \mathrm{p}=0.00015 ; \mathrm{R}=0.18, \mathrm{p}>0.05\right)$. Patients undergoing radiotherapy or radiotherapy and hormone therapy showed least interest in sexual life, while patients undergoing surgical treatment or surgical treatment, chemotherapy, and hormone therapy-greatest interest in sexual life $\left(\mathrm{Chi}^{2}=55.75, \mathrm{p}=0.00001\right.$; $\mathrm{R}=0.09, \mathrm{p}>0.05$ ). Nearly $60 \%$ of the patients were not sexually active during the last 4 months, and there is no correlation between the level of sexual activity and the patient's age $(\mathrm{p}>0.05)$. The posttreatment patients and those on treatment were least sexually active (the response "none" was indicated by $64.91 \%$ and $50 \%$ of the patients in these groups, respectively). Among the patients waiting for treatment, $30 \%$ of the patients declared lack of sexual activities $\left(\mathrm{Chi}^{2}=20.32, \mathrm{p}=0.00234\right.$; $\mathrm{R}=0.12, \mathrm{p}>0.05$ ). Based on an analysis of the type of treatment, it can be shown that patients who underwent surgical treatment or chemotherapy and hormone therapy were characterized by greatest sexual activity ( $100 \%$ in both cases). In the other treatment categories, the percentage of sexually active men was about $40 \%$ $\left(\mathrm{Chi}^{2}=46.43, \mathrm{p}=0.00026 ; \mathrm{R}=0.04, \mathrm{p}>0.05\right)$.

Among the patients who were sexually active during the last 4 months, $37 \%$ of them were satisfied or very satisfied with their sexual life. High or very high satisfaction with sexual life was indicated by $50 \%$ of the patients prior to cancer treatment, $12.5 \%$ of the posttreatment patients, and $7 \%$ of the patients on treatment $\left(\mathrm{Chi}^{2}=23.89, \mathrm{p}=0.00239 ; \mathrm{R}=0.33, \mathrm{p}=0.00228\right)$. The type of treatment also affected satisfaction with sexual life $\left(\mathrm{Chi}^{2}=76.52, \mathrm{p}=0.0000 ; \mathrm{R}=0.05, \mathrm{p}>0.05\right)$. Patients undergoing surgical procedures, hormone therapy, and chemotherapy were very satisfied with their sexual life, while patients undergoing only surgical procedures or surgical procedures combined with radiotherapy declared low or no satisfaction with their sexual life. The patient's age has no effect on his satisfaction with sexual life $(\mathrm{p}>0.05)$.

Difficulties with achieving or maintaining erection were declared by $73.3 \%$ of the sexually active patients, regardless of their age $(p>0.05)$. Significant or considerable difficulties were most often indicated by patients on cancer treatment $(30 \%$ of the patients $)\left(\mathrm{Chi}^{2}=16.71, \mathrm{p}=0.03328 ; \mathrm{R}=0.29, \mathrm{p}=0.00839\right)$ or patients undergoing radiotherapy $(43.33 \%)\left(\mathrm{Chi}^{2}=61.98, \mathrm{p}=0.00003 ; \mathrm{R}=-0.01, \mathrm{p}>0.05\right)$.

Difficulties with ejaculation were declared by $66.7 \%$ of the sexually active patients, even though these problems are not related to the patients' age ( $p>0.05)$. Problems with ejaculation were least frequent among patients prior to cancer treatment $(50 \%)$, while all the posttreatment patients reported having such difficulties $\left(\mathrm{Chi}^{2}=34.44, \mathrm{p}=0.00003 \mathrm{R}=0.27, \mathrm{p}=0.01530\right)$. Patients who received surgical treatment, hormone therapy, or both radiotherapy and hormone therapy had no difficulties with ejaculation $\left(\mathrm{Chi}^{2}=45.58, \mathrm{p}=0.00496 ; \mathrm{R}=0.04, \mathrm{p}>0.05\right)$.

A feeling of embarrassment during intimate contact was indicated only by $56.7 \%$ of the sexually active patients. The above variable was not age-dependent ( $p>0.05)$. However, a feeling of embarrassment was correlated with the stage of cancer treatment $\left(\mathrm{Chi}^{2}=16.85, \mathrm{p}=0.03164 ; \mathrm{R}=0.30, \mathrm{p}=0.00526\right)$ and the type of treatment $\left(\mathrm{Chi}^{2}=40.05, \mathrm{p}=0.02111 ; \mathrm{R}=0.00, \mathrm{p}>0.05\right)$. Embarrassment during sexual contact was not experienced by pretreatment patients, patients receiving surgical treatment, hormone therapy or radiotherapy in combination with hormone therapy.

It should be pointed out that none of the discussed aspects of sexual activity, in relation to all the patients or only those sexually active during the last 4 months, had no impact on the quality of life score ( $p>0.05$ for all cases). The above results are shown in Tables 6 and 7. 


\begin{tabular}{|c|c|c|c|c|c|}
\hline \multirow[t]{2}{*}{ Sexual activity } & \multirow{2}{*}{$\begin{array}{l}\text { Question } \\
\text { no. }^{\mathrm{a}}\end{array}$} & \multicolumn{4}{|c|}{ Number of patients $(N=166) \mathrm{N}(\%)$} \\
\hline & & $\begin{array}{c}\text { Not at } \\
\text { all }\end{array}$ & A little & $\begin{array}{l}\text { Quite a } \\
\text { bit }\end{array}$ & $\begin{array}{l}\text { Very } \\
\text { much }\end{array}$ \\
\hline Feeling perdition masculinity & 49 & $\begin{array}{c}26 \\
(15.7)\end{array}$ & $\begin{array}{c}44 \\
(26.5)\end{array}$ & $\begin{array}{c}40 \\
(24.1)\end{array}$ & $\begin{array}{c}56 \\
(33.7)\end{array}$ \\
\hline The interest in sexual intercourse & 50 & $\begin{array}{c}72 \\
(45.8)\end{array}$ & $\begin{array}{c}48 \\
(28.9)\end{array}$ & $\begin{array}{c}20 \\
(12.1)\end{array}$ & $\begin{array}{c}22 \\
(13.3)\end{array}$ \\
\hline The degree of sexual activity & 51 & $\begin{array}{c}96 \\
(57.8)\end{array}$ & $\begin{array}{c}34 \\
(20.5)\end{array}$ & $\begin{array}{c}18 \\
(10.8)\end{array}$ & $\begin{array}{c}18 \\
(10.8)\end{array}$ \\
\hline Satisfaction with sexual intercourse & $52^{\mathrm{b}}$ & $\begin{array}{c}28 \\
(46.8)\end{array}$ & $\begin{array}{c}10 \\
(16.7)\end{array}$ & $\begin{array}{c}8 \\
(13.3)\end{array}$ & $\begin{array}{c}14 \\
(23.3)\end{array}$ \\
\hline $\begin{array}{l}\text { Difficulty getting or maintaining an } \\
\text { erection }\end{array}$ & $53^{\mathrm{b}}$ & $\begin{array}{c}16 \\
(26.7)\end{array}$ & $\begin{array}{c}12 \\
(20.0)\end{array}$ & $\begin{array}{c}14 \\
(23.3)\end{array}$ & $\begin{array}{c}18 \\
(30.0)\end{array}$ \\
\hline Difficulties with ejaculation & $54^{\mathrm{b}}$ & $\begin{array}{c}20 \\
(33.3)\end{array}$ & $\begin{array}{c}12 \\
(20.0)\end{array}$ & $\begin{array}{c}6 \\
(10.0)\end{array}$ & $\begin{array}{c}22 \\
(36.7)\end{array}$ \\
\hline $\begin{array}{l}\text { The feeling of embarrassment during } \\
\text { intimacy }\end{array}$ & $55^{\mathrm{b}}$ & $\begin{array}{c}26 \\
(43.3)\end{array}$ & $\begin{array}{c}4 \\
(6.7)\end{array}$ & $\begin{array}{c}12 \\
(20.0)\end{array}$ & $\begin{array}{c}18 \\
(30.0)\end{array}$ \\
\hline
\end{tabular}

Table 6.

Sexual activity patients.

\begin{tabular}{|c|c|c|c|}
\hline \multirow[t]{2}{*}{ Problems with urination } & \multirow{2}{*}{$\begin{array}{c}\text { Question } \\
\text { no. }^{\mathrm{a}}\end{array}$} & \multicolumn{2}{|c|}{ Quality of life } \\
\hline & & p-value & R-Spearman ${ }^{\mathrm{b}}$ \\
\hline Feeling perdition masculinity & 49 & 0.134 & - \\
\hline The interest in sexual intercourse & 50 & 0.420 & - \\
\hline The degree of sexual activity & 51 & 0.384 & - \\
\hline Satisfaction with sexual intercourse & $52^{c}$ & 0.509 & - \\
\hline Difficulty getting or maintaining an erection & $53^{c}$ & 0.142 & - \\
\hline Difficulties with ejaculation & $54^{\mathrm{c}}$ & 0.361 & - \\
\hline The feeling of embarrassment during intimacy & $55^{\mathrm{c}}$ & 0.585 & - \\
\hline \multicolumn{4}{|c|}{$\begin{array}{l}{ }^{a} N u m b e r \text { of issues in accordance with the questionnaire } Q L Q-C 30 . \\
{ }^{b} \text { Demonstrated statistically significant correlations only; } p<0.05 . \\
{ }^{c} \text { Question applies only to patients who are sexually active within the last } 4 \text { weeks }(N=60) \text {. }\end{array}$} \\
\hline
\end{tabular}

Table 7 .

Sexual activity and quality of life of the patients.

\section{Discussion}

Sexuality is an important aspect of human life, and emotions related to sexual activity influence mental well-being, relationship, or how we see ourselves. Sexual function disorders (e.g., erectile dysfunction) caused by prostate carcinoma significantly reduces the quality of life of men [6-8]. Cancer treatment is also related to reduced sex drive and penile dysfunction manifesting itself through, for example, reduced ability to have an orgasm, erectile disorders, or urinary incontinence $[9,10]$. The above changes in sexual functions are also related to anxiety and depression, challenges in everyday life, and disrupted intimate relations with the patient's partner [11-14]. However, other studies indicated that many patients with 
prostate carcinoma suffer at a later stage from complications in the course of disease and its treatment $[15,16]$.

On the other hand, feeling worried also depends on the stage of cancer treatment. Patients waiting for treatment more often declared to be worried (to a considerable or significant extent) than posttreatment patients. At the same time, all the patients who received surgical treatment, chemotherapy, and hormone therapy indicated that they felt worried. No fatigue was most often indicated by patients receiving radiotherapy or both radiotherapy and surgical treatment. However, health status also had an insignificant impact on patients feeling worried, even though patients with a greater quality of life score more rarely declared that they felt worried. Other studies suggest that hot flushes were strongly associated with insomnia and they caused depression particularly in the group of elderly men receiving hormone therapy [17-19]. However, Yang et al. [20] determined that physical condition of cancer patients was closely related to the fatigue index and it was also the major factor affecting the quality of life of patients. Other studies showed that regular monitoring of fatigue and its elimination could improve physical condition of patients and therefore improve their quality of life [21, 22]. It is well documented in the literature that all types of cancer treatment, and especially chemotherapy, are associated with side effects such as fatigue, depression, pain, and many other problems [23-25]. Urination problems during the day had a significant negative impact on the quality of life of patients. A similar but significantly weaker correlation was identified between the quality of life score and frequent nighttime urination or the quality of life score and the need to hurry into the toilet before passing urine. At the same time, having to get up frequently at night to urinate affects the night's rest and has a strong impact on how patients perceive their quality of life. However, pain during urination was declared by half of the patients, and no correlation was found between pain and the quality of life score. Vogl et al. [26] showed that an insignificant number of men undergoing cancer treatment had certain difficulties passing urine which were reversible over time. However, Arscott et al. [27] demonstrated that urinary tract symptoms are frequently associated with sexual disorders after surgical treatment and radiotherapy.

An analysis of the sexual activity of the study patients showed that younger men more often indicated a strong or very strong sense of loss of manhood due to the disease or its treatment. A sense of loss of manhood was mostly declared by posttreatment patients or patients on cancer treatment. The type of treatment had no impact on a sense of loss of manhood ( $p>0.05$ ). In one of their studies, Zaider et al. [1] found that $1 / 3$ of the male patients lost an important aspect of their manhood as a side effect of disease treatment, which proved to be a significant obstacle to their sexuality. O' Shaughnessy et al. [2] determined that the affected patients may not be fully aware of their sexual losses. In another study, an inability to perform sexually by men diagnosed with a chronic disease was described as a source of suffering $[28,29]$. Harrington et al. [30] argued that a body image is an important aspect of human quality of life, especially in patients diagnosed with cancer. On the other hand, the loss of sexual functions in posttreatment patients may undermine their concept of manhood [31, 32].

Patients undergoing surgical treatment or chemotherapy and hormone therapy showed the least interest in sexual life. On the other hand, there is no correlation between the level of sexual activity and the patients' age ( $p>0.05)$. Posttreatment patients and patients on treatment were least sexually active. Additionally, taking into account the type of treatment, patients receiving surgical treatment or chemotherapy and hormone therapy were characterized by greatest sexual activity. Another study demonstrated that unwillingness to meet people or have sex is more common among men treated for cancer and it is most likely best observable 
in men with prostate carcinoma who receive hormone therapy. The study at hand showed that more than $95 \%$ of men treated with this method reported subjective sex drive disorders [6]. However, DiBlasio et al. [13] demonstrated that more than $95 \%$ of men receiving hormone therapy reported libido and sex drive disorders. The loss of libido is frequently observable in patients with Hodgkin disease (Hodgkin lymphoma), where more than $40 \%$ of men reported this side effect [14]. The loss of libido was also observable in patients with hematologic cancers $[15,16]$. Different results were obtained by Olsson et al. [33] who argued that low libido may originate from fatigue and/or feeling unwell. Furthermore, this condition may be associated with the stage of disease and intensive cancer therapy.

Our study showed that among sexually active men, pretreatment and posttreatment patients as well as patients on cancer treatment were satisfied or very satisfied with their sexual life. The level of satisfaction with sexual life was also affected by the type of treatment, while the patients' age had no effect on their satisfaction with sexual life ( $p$ > 0.05). Given that good mental well-being depends on many factors, it cannot be stated without ambiguity that men can achieve sexual satisfaction only through a successful sexual intercourse. However, for men with chronic erectile disorders, inability to achieve penetration may be a source of considerable difficulties and frustration. For example, couples open to changes and willing to cooperate were able to adapt to the needs of the affected partner and to accept the side effects of cancer treatment [34-36].

However, our studies showed that men receiving treatment or radiotherapy have considerable or major difficulties in achieving or maintaining erection. Other study [3] shown that erectile disorders were observed in $77 \%$ of men treated for prostate carcinoma who underwent radical prostatectomy and in $60 \%$ of patients receiving radiotherapy. It was also observed that post-radiotherapy erectile disorders were usually delayed ( 1 or 2 years after therapy) in contrast to a quick response achieved in a group of patients immediately after surgical treatment [28]. Erectile disorders were also observed in other populations, for example, in patients treated for anal diseases or rectal and testicular cancer $[9,11]$. Difficulties with ejaculation were not correlated with the age of patients $(p>0.05)$. Problems with ejaculation were least frequent among patients prior to cancer treatment, while all the posttreatment patients reported having such difficulties. Patients who received surgical treatment, hormone therapy or both radiotherapy and hormone therapy had no problems with ejaculation. Sullivan et al. [37] determined that radiotherapy, especially if it is focused on the prostate gland, may be associated with anejaculation (inability to ejaculate). A study in 364 men diagnosed with prostate carcinoma and undergoing radiotherapy showed that as many as $72 \%$ of the patients experienced anejaculation. However, elderly men and patients receiving lower doses of radiation were less exposed to this side effect. This situation may lead to an intentional avoidance of orgasm by men suffering from prostate carcinoma. On the other hand, Wassersug et al. [12] noticed that the lack of ejaculation in men having homosexual relations caused particular discomfort. However, in our study, a feeling of embarrassment during intimate contact (in sexually active men) was not correlated with age but with the stage of cancer treatment and the type of therapy.

Embarrassment during sexual contact was not experienced by pretreatment patients, patients receiving surgical treatment, hormone therapy, or radiotherapy combined with hormone therapy. Additionally, none of the discussed aspects of sexual activity, in relation to all the patients or only those sexually active during the last 4 months, had no impact on the quality of life score ( $p>0.05$ for all cases). Harrington et al. [38] showed that men who underwent hormone therapy are exposed to verbal abuse due to changes in their appearance as a side effect of the 
therapy (weight gain, loss of muscle mass, reduced hair, gynecomastia). Reduced embarrassment and dissatisfaction with one's own body was reported by men with the same diagnosis but undergoing treatment other than hormone therapy. A feeling of embarrassment is also caused by changes in body weight (weight gain or weight loss) which in turn affects the image of one's own manhood $[39,40]$. However, problems related to the body image are not necessarily focused only on the penis. In male patients treated for colorectal cancer, intestinal stoma was associated not only with erectile disorders but also with a feeling of shame before themselves and their partner.

\section{Conclusions}

1. Despite the existing psychoemotional disorders, no correlation was found between the age of patients and feeling tense, worried, irritable, or depressed. Additionally, complaints reported by sexually active patients showed no correlation between age and a sense of loss of manhood, erectile disorders, satisfaction with sexual life, or embarrassment during intimate contact.

2. The type and stage of cancer treatment (mostly prior to therapy) had a significant impact on feeling tense, worried, depressed, and irritable. It was also shown that feeling depressed affects the patient's health status to a considerable extent. Our results show the urgent need to provide the patients with continuous psychological care, especially those waiting for treatment and those on treatment.

3. The method of treatment had no major impact on a sense of loss of manhood and the degree of sexual activity, while the stage of treatment (posttreatment patients and patients on treatment) had a negative effect on these parameters. Pretreatment patients declared high or very high satisfaction with their sexual life, while posttreatment patients and those on cancer treatment indicated low sexual satisfaction. However, feeling embarrassed during intimate contact as well as erectile disorders correlated both with the type and stage of cancer treatment. An analysis of the sexual functioning of prostate carcinoma men suggests that the patients should be under the care of a clinical sex therapist.

\section{Conflict of interest}

All authors declare no conflict of interests.

\section{Funding}

The study was financed from own funds.

\section{Ethical approval (animals)}

This article does not contain any studies with animals performed by any of the authors. 


\section{Ethical approval (human)}

The Ethical Committee consent for the presented research is not required. According to the statement of the Ethical Committee of the Medical University of Warsaw: "The Committee does not provide opinions on surveys, retrospective studies, or other non-invasive research" (Detailed information and templates of documents of Ethics Committee of Medical University of Warsaw (Accessed 2016-10-01): http://komisjabioetyczna.wum.edu.pl/content/ szczeg\%C3\%B3\%C5\%82owe-informacje-orazwzory-dokument\%C3\%B3w).

\section{Informed consent}

Informed consent was obtained from all individual participants included in the study.

\section{Author details}

Marta Dąbrowska-Bender ${ }^{1,7}$, Robert Słoniewski ${ }^{2}$, Urszula Religioni ${ }^{3}$, Anna Słoniewska ${ }^{4}$, Anna Staniszewska ${ }^{5 *}$, Karolina Jabłkowska-Górecka ${ }^{2}$, Magdalena Milewska ${ }^{1}$, Adrianna Sobol ${ }^{6,7}$ and Anna Kupiecka ${ }^{7}$

1 Department of Clinical Dietetics, Medical University of Warsaw, Poland

2 Department of Public Health, Medical University of Warsaw, Poland

3 Collegium of Business Administration, Warsaw School of Economics, Poland

4 Masovian Oncological Hospital in Wieliszew, Warsaw, Poland

5 Department of Experimental and Clinical Pharmacology, Medical University of Warsaw, Poland

6 Department of Oncological Prevention, Medical University of Warsaw, Poland

7 Foundation OnkoCafe-Together Better, Warsaw, Poland

*Address all correspondence to: anna.staniszewska@wum.edu.pl

\section{IntechOpen}

(C) 2019 The Author(s). Licensee IntechOpen. This chapter is distributed under the terms of the Creative Commons Attribution License (http://creativecommons.org/licenses/ by/3.0), which permits unrestricted use, distribution, and reproduction in any medium, provided the original work is properly cited. (cc) BY 


\section{References}

[1] Zaider T, Manne S, Nelson C, et al. Loss of masculine identity, marital affection, and sexual bother in men with localized prostate cancer. The Journal of Sexual Medicine. 2012;9:2724

[2] O’Shaughnessy PK, Ireland C, Pelentsov L, et al. Impaired sexual function and prostate cancer: A mixed method investigation into the experiences of men and their partners. Journal of Clinical Nursing. 2013;22:3492

[3] Mulhall J. Defining and reporting erectile function outcomes after radical prostatectomy: Challenges and misconceptions. The Journal of Urolology. 2009;181:462

[4] Perz J, Ussher JM, Gilbert E. Feeling well and talking about sex: Psycho-social predictors of sexual functioning after cancer. BMC Cancer. 2014;14(1):228-247

[5] Poole G, Poon C, Achille M, et al. Social support for patients with prostate cancer. Journal of Psychosocial Oncology. 2010;19:1-16

[6] Corona G, Gacci M, Baldi E, et al. Androgen deprivation therapy in prostate cancer: Focusing on sexual side effects. The Journal of Sexual Medicine. 2012;9:887

[7] Dutz A, Agolli L, Baumann M, Troost EGC, Krause M, Hölscher T, et al. Early and late side effects, dosimetric parameters and quality of life after proton beam therapy and IMRT for prostate cancer: A matchedpair analysis. Acta Oncologica. 2019;58(6):916-925

[8] Tharakan T, Miah S, Jayasena C, Minhas S. Investigating the basis of sexual dysfunction during late-onset hypogonadism. F1000Research. 2019;8:Faculty Rev 1000: 331
[9] Breukink S, Donovan K. Physical and psychological effects of treatment on sexual functioning in colorectal cancer survivors. The Journal of Sexual Medicine. 2013;10(Suppl. 1):74

[10] Kyung JC, Sung-Ryul S, Suzana B, Young SS, Ie BP, Khae-Hawn K. Does early depressive mood expire following radical retropubic prostatectomy in patients with localized prostate cancer? Journal of Exercise Rehabilitation. 2019;15(2):264-269

[11] Nagpal K, Bennett N. Colorectal surgery and its impact on male sexual function. Current Urology Reports. 2013;14:279

[12] Wassersug RJ, Lyons A, Duncan D, et al. Diagnostic and outcome differences between heterosexual and nonheterosexual men treated for prostate cancer. Urology. 2013;82:565

[13] DiBlasio C, Malcolm J, Derweesh I, et al. Patterns of sexual and erectile dysfunction and response to treatment in patients receiving androgen deprivation therapy for prostate cancer. BJU International. 2008;102:39

[14] Recklitis C, Sanchez Varela V, Ng A, et al. Sexual functioning in long-term survivors of Hodgkin's lymphoma. Psycho-Oncology. 2010;1:1229

[15] Lee JJ. Sexual dysfunction after hematopoietic stem cell transplantation. Oncology Nursing Forum. 2011;38:409

[16] Beckjord EB, Arora NK, Bellizzi K, et al. Sexual well-being among survivors of non-Hodgkin lymphoma. Oncology Nursing Forum. 2011;38:E351

[17] Cherrier MM, Aubin S, Higano CS. Cognitive and mood changes in men undergoing intermittent combined androgen blockade for non-metastatic 
prostate cancer. Psycho-Oncology. 2009;1:237-247

[18] Beca J, Majeed H, Chan KKW, Hotte SJ, Loblaw A, Hoch JS. Costeffectiveness of docetaxel in highvolume hormone-sensitive metastatic prostate cancer. Canadian Urological Association Journal. 26 Apr 2019

[19] Algotar A, Hsu CH, Sherry Chow HH, Dougherty S, Babiker HM, Marrero D, et al. Comprehensive lifestyle improvement program for prostate cancer (CLIPP): Protocol for a feasibility and exploratory efficacy study in men on androgen deprivation therapy. JMIR Research Protocols. 2019;8(2):e12579

[20] Yang SW, Na YG, Song KH, et al. Lower urinary tract symptoms and efficacy of anticholinergic drugs in patients remaining disease-free after radical retropubic prostatectomy. Urologic Oncology. 2016;13(3):2684-2689

[21] Dhillon HM, van der Ploeg HP, Bell ML, et al. The impact of physical activity on fatigue and quality of life in lung cancer patients: A randomized controlled trial protocol. BMC Cancer. 2012;12:572

[22] Doherty M, Miller-Sonet E, Gardner D, Epstein I. Exploring the role of psychosocial care in value-based oncology: Results from a survey of 3000 cancer patients and survivors. Journal of Psychosocial Oncology. 2019;37(4):441-455

[23] Gilliam LLA, Daret KSC. Chemotherapy-induced weakness and fatigue in skeletal muscle: The role of oxidative stress. Antioxidants \& Redox Signaling. 2011;15(9):2543-2563

[24] Religioni U, Czerw A, Deptała A. Strategies of coping with pain in cancer on the basis of lung, breast, colorectal, and prostate carcinoma. Journal of
Cancer Education. 2016;32:771-777.

DOI: $10.1007 / \mathrm{s} 13187-016-1040-3$

[25] Bower JE, Bak K, Berger A, et al. Screening, assessment, and management of fatigue in adult survivors of cancer: An American Society of Clinical Oncology clinical practice guideline adaptation. Journal of Clinical Oncology. 2014;32(17):1840-1850

[26] Vogl TJ, Mayer HP, Zangos S, et al. Prostate cancer: MR imaging-guided galvanotherapy-technical development and first clinical results. Radiology. 2007;245(3):895-902

[27] Arscott WT, Chen LN, Wilson N, et al. Obstructive voiding symptoms following stereotactic body radiation therapy for prostate cancer. Radiation Oncology. 2014;9:163

[28] Saarnio L, Arman M, Ekstrand P. Power relations in patient's experiences of suffering during reatment for cancer. Journal of Advanced Nursing. 2011;68:271

[29] Blazevski A, Scheltema MJ, Yuen B, Masand N, Nguyen TV, Delprado W, et al. Oncological and quality-of-life outcomes following focal irreversible electroporation as primary treatment for localised prostate cancer: A biopsy-monitored prospective cohort. European Urology Oncology. 16 May 2019:S2588-9311(19)30057-4

[30] Harrington CB, Hansen JA, Moskowitz M, et al. It's not over when it's over: Long-term symptoms in cancer survivors - a systematic review. The International Journal of Psychiatry in Medicine. 2010;40:163

[31] Cecil R, McMaughan E, Parahoo K. 'It's hard to take because I am a man's man': An ethnographic exploration of cancer and masculinity. European Journal of Cancer Care. 2009;19:501 
[32] Manne SL, Kashy DA, Zaider T, D3 K, Lee D, Kim IY, et al. Couplefocused interventions for men with localized prostate cancer and their spouses: A randomized clinical trial. British Journal of Health Psychology. 2019;24(2):396-418

[33] Olsson C, Sandin-Bojo AK, Bjuresater K, et al. Patients treated for hematologic malignancies: Affected sexuality and health related quality of life. Cancer Nursing. 2015;38:99

[34] Perz J, Ussher JM, Gilbert E. Constructions of sex and intimacy after cancer: Q methodology study of people with cancer, their partners, and health professionals. BMC Cancer. 2013;13:270

[35] Mehta A, Pollack CE, Gillespie TW, Duby A, Carter C, Thelen-Perry S, et al. What patients and partners want in interventions that support sexual recovery after prostate cancer treatment: An exploratory convergent mixed methods study. Sexual Medicine. 2019;7(2):184-191

[36] Bossio JA, Miller F, O’Loughlin JI, Brotto LA. Sexual health recovery for prostate cancer survivors: The proposed role of acceptance and mindfulness-based interventions. Sexual Medicine Reviews. 24 Apr 2019. DOI: S2050-0521(19)30018-6

[37] Sullivan J, Stember D, Deveci S, et al. Ejaculation profiles of men following radiation therapy for prostate cancer. The Journal of Sexual Medicine. 2013;10:1410

[38] Harrington JB. Body image and quality of life in men with prostate cancer. Cancer Nursing. 2009;32:E1

[39] O’Shaughnessy PK, Laws T.

Australian men's long-term experiences following prostatectomy: A qualitative descriptive study. Contemporary Nurse. 2009;34:98
[40] Langelier DM, D'Silva A, Shank J, Grant C, Bridel W, Culos-Reed SN. Exercise interventions and their effect on masculinity, body image, and personal identity in prostate cancer-a systematic qualitative review. PsychoOncology. 2019;28:1184-1196. DOI: $10.1002 /$ pon.5060 


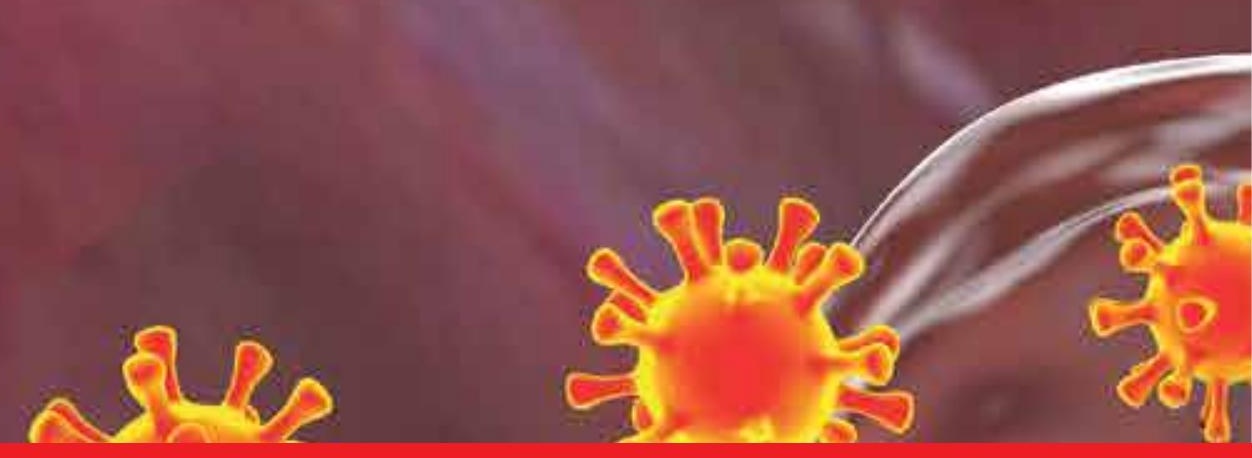

\section{Edited by Wei Wu, Francesco Ziglioli and Umberto Maestroni}

Male reproductive health is an important area affecting men's overall health and wellbeing. Infertility is a worldwide problem that affects approximately $15 \%$ of married couples. Half of these cases can be traced to male partners. Infertile men are at an elevated risk of cancer development later in life, primarily genitourinary malignancies such as testicular and prostate cancer. This book will focus on male reproductive health, from the aspects of semen quality, male infertility, testicular cancer, and prostate cancer, and their detection, diagnosis, treatment, and prevention.

\section{IntechOpen}
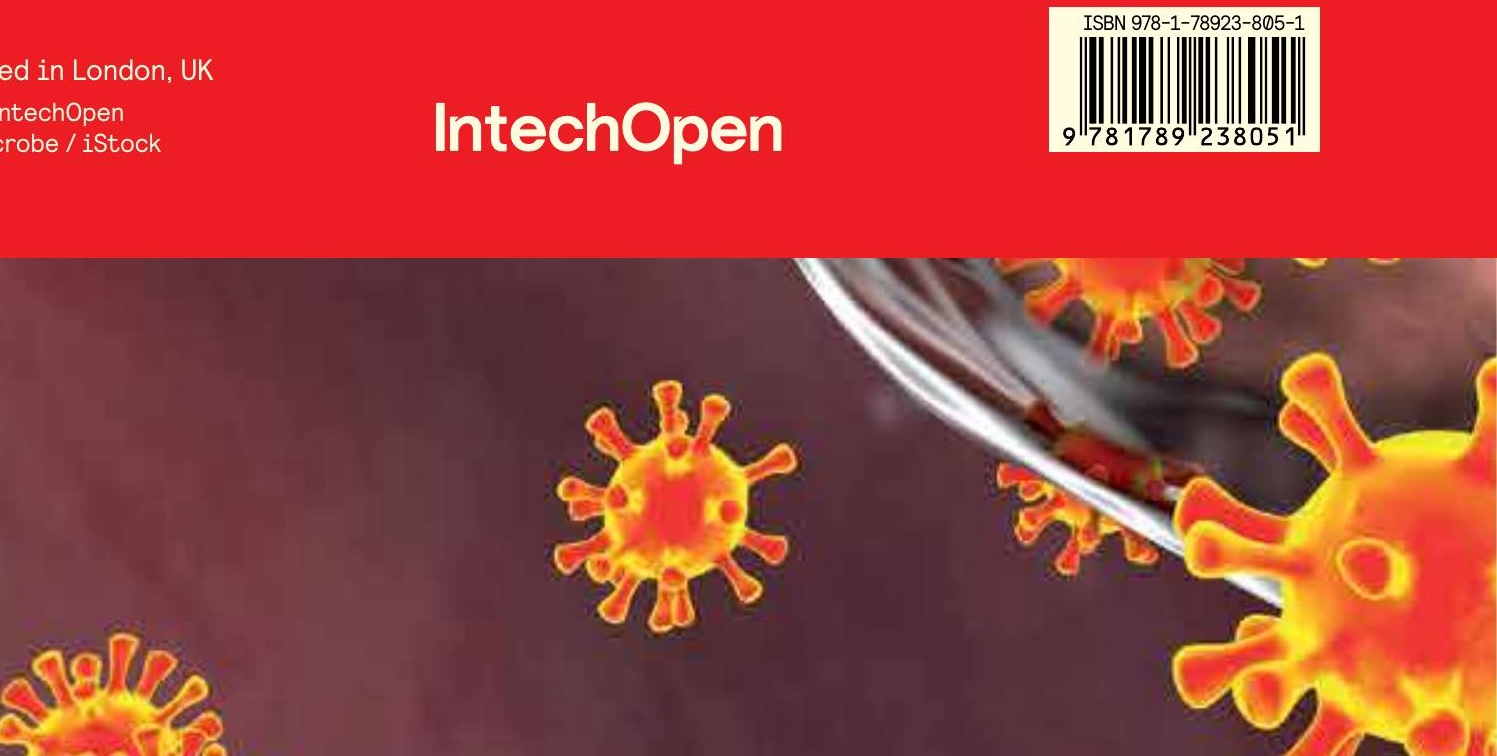